\title{
Modeling and Optimization of Natural \\ Gas Processing and Production \\ Networks
}

by

\author{
Saad Alsobhi
}

\author{
A thesis \\ presented to the University of Waterloo \\ in fulfillment of the \\ thesis requirement for the degree of \\ Doctor of Philosophy \\ in \\ Chemical Engineering
}

Waterloo, Ontario, Canada, 2015

C)Saad Alsobhi 2015 


\section{AUTHOR'S DECLARATION}

I hereby declare that I am the sole author of this thesis. This is a true copy of the thesis, including any required final revisions, as accepted by my examiners.

I understand that my thesis may be made electronically available to the public.

Saad Ali Saad Al-Sobhi 


\begin{abstract}
Natural gas is a nonrenewable energy source, so it is important to use it and utilize it in a sustainable manner. Globally, about $25 \%$ of energy consumption is supplied and fulfilled by natural gas and this percentage will stay true for the foreseeable future. Today, the fluctuations in commodities prices and demands all necessitate the proper planning and coordination in natural gas industries. Moreover, the strict environmental regulations, continuous advancement in technologies and different customer requirements and specifications, all mandate seeking many pathway options and continuous evaluation of the technologies. Thus, the overall objective of this research is to provide a framework for the design, synthesis, analysis, and planning of a natural gas processing and production networks. The overall framework helps the decision maker in the natural gas industry to evaluate and select optimally the production pathways and utilization options by using the mathematical modeling and optimization techniques in order to maximize the value of natural gas resource.
\end{abstract}

Toward this objective, a novel natural gas network has been synthesized for analysis and optimization. The developed network converts natural gas to LNG, condensate, LPG, gasoline, diesel, wax, and methanol as main products. The contributions of this dissertation fall mainly into three milestones; namely (1) simulation of natural gas network (2) mathematical formulation and optimization of the network and (3) sustainability assessment of the network.

The first milestone addresses the rigorous steady state simulation of natural gas network. The simulation of key processing units helped in calculating accurately material and energy balances. Furthermore, the sensitivity analysis or what-if analysis was performed to determine the effect of different operating-parameters on products yield. 
The second milestone is the comprehensive mathematical formulation and optimization represented by both linear programming (LP) and mixed integer linear programming (MILP) models. Firstly, a deterministic operational LP model has been formulated and implemented on natural gas processing and production networks. Based on the yields obtained from the simulation, LP model was able to tackle different scenarios, such as, variations and fluctuations in natural gas flow rate, natural gas price, products price, and so on. Secondly, a comprehensive MILP model for the optimal design and operation of natural gas processing network was proposed. The MILP model addresses the different technologies and configurations available for the selection of key processing units. Also, it considers the different operating modes practiced in industry in terms of low, moderate, and severe restrictions to the specifications level. Thirdly, another MILP model for the optimal design and operation of natural gas production network has been developed. We were able to address the different routes for natural gas utilization.

Finally, the third milestone is the sustainability assessment. The sustainability metrics or indicators were evaluated to investigate the sustainability dimensions and to address the economic, environmental, and societal aspects of the synthesized processing and production networks. The sustainability metrics proved to be useful in selecting pathways that are both economic and environmental friendly. 


\section{Acknowledgements}

All the praises go to Allah, the Most Beneficent and the Most Merciful for blessing me with the ability to seek knowledge and to pursue my $\mathrm{PhD}$ study.

There are many individuals who have sharpened my knowledge about chemical engineering in general and process system engineering (PSE) in particular. Among top of them is my advisor, Prof. Ali Elkamel. I am indebted to Prof. Elkamel for his continuous support, guidance, encouragement, and motivation throughout this research and for his sharing-knowledge attitude. I would like to extend my thanks and appreciation to my dissertation committee members, Prof.

Xianshe Feng, Dr. Hossam Gaber, Dr. Aiping Yu, and Dr. Fatih Safa for their constructive comments and valuable time.

As I am totally convinced that gaining the knowledge is an accumulation process, I need to express my thanks and appreciation to all my undergraduate and graduate studies professors and instructors. To name a few, I can't leave this page without expressing my gratitude and thanks to Prof. Mohmoud El-Halwagi, my master degree advisor for his positive impact on me and for his continuous care and support. I still remember and always recall his "Big Picture" philosophy in solving all my real life problems. Also, I am grateful to Dr. Hassan Alfadala, my undergraduate academic advisor for his continuous support, encouragements, and care.

Thanks are extended to all my colleagues, the PSE group at the University of Waterloo for the valuable discussions throughout this research.

I would like to express my gratitude and appreciation to my country, Qatar, and my academic sponsor, Qatar University, for the financial support.

Finally, I am grateful and thankful to my parents for their prayers, support, and encouragement. Thanks are extended for my brothers and sisters. My deepest thanks and love goes to my wife and my children for their support and encouragement. You have been the shining part and joy of my life. 


\section{Dedication}

To my parents, my wife, and my children, with love and gratitude 


\section{Table of contents}

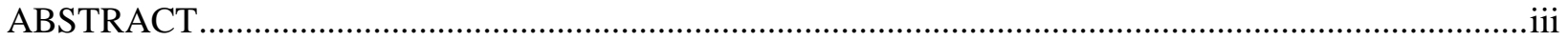

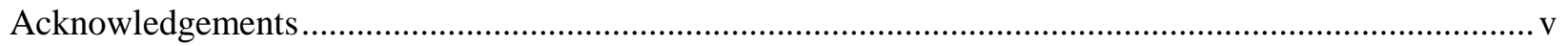

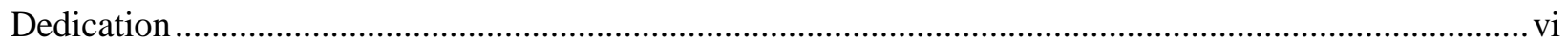

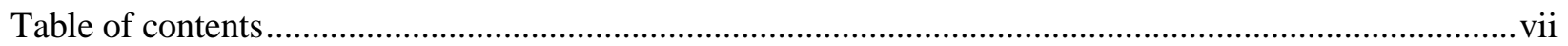

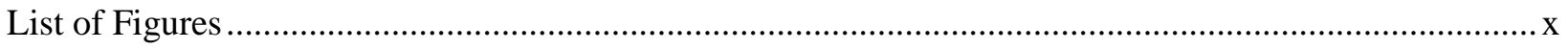

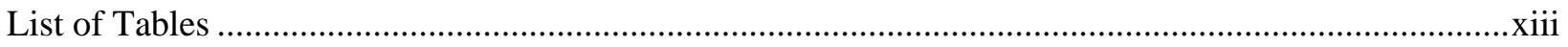

Nomenclature

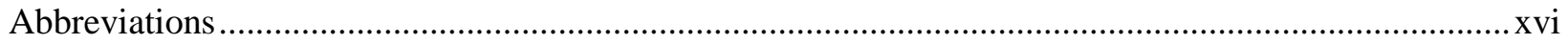

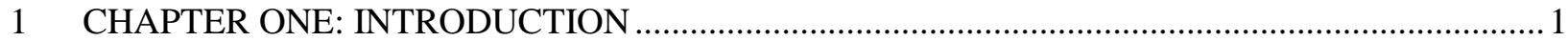

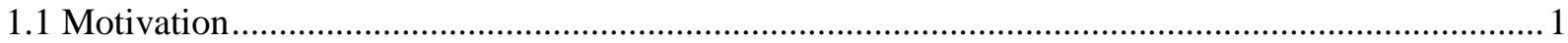

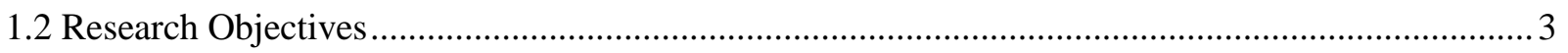

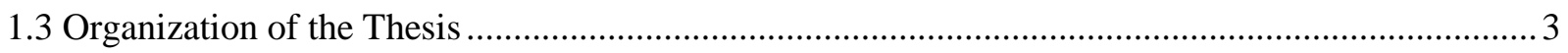

2. CHAPTER TWO: BACKGROUND AND PROCESS DESCRIPTION ...................................... 6

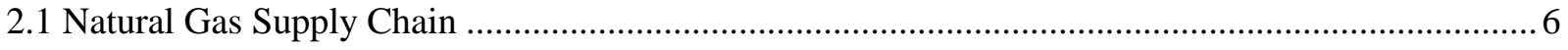

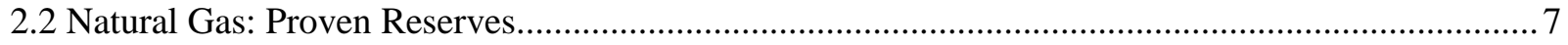

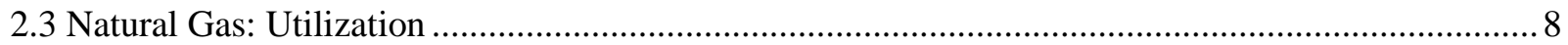

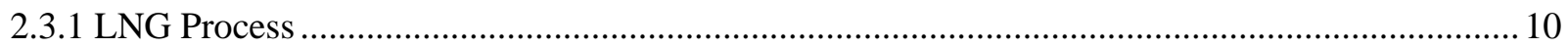

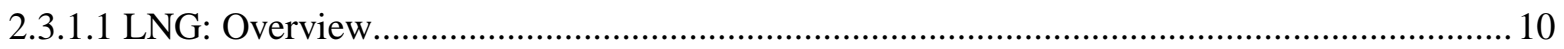

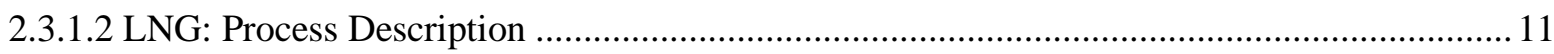

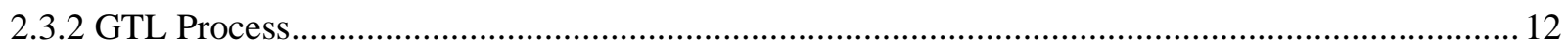

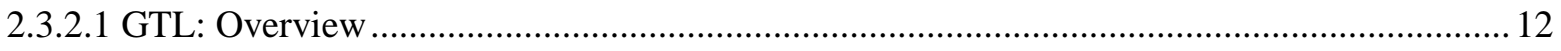

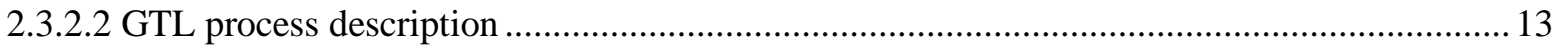

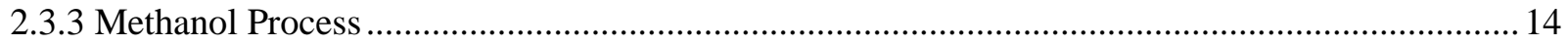

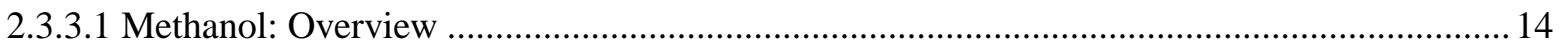

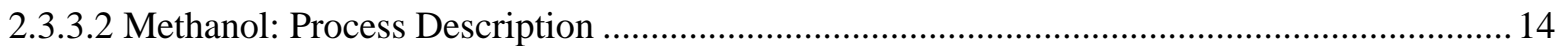

3. CHAPTER THREE: SIMULATION OF NATURAL GAS PROCESSING AND PRODUCTION

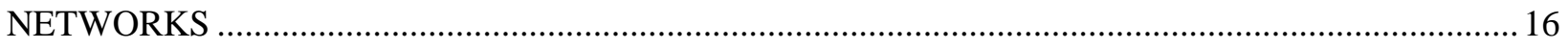

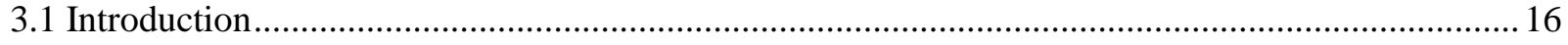

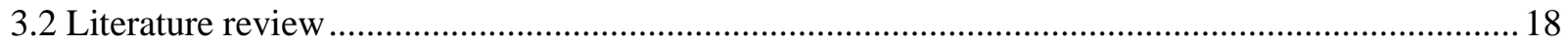

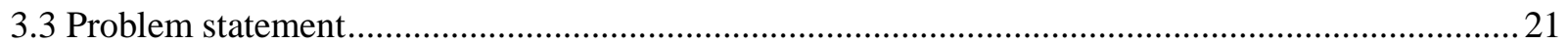


3.4 Steady state process simulation of natural gas processing and production network.

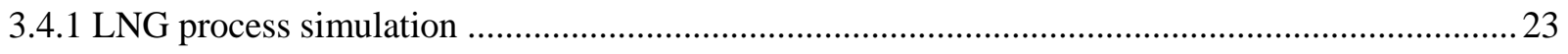

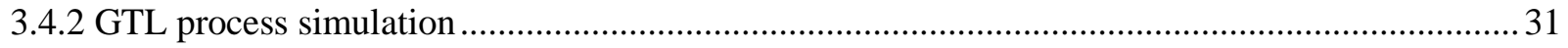

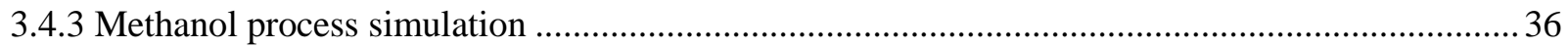

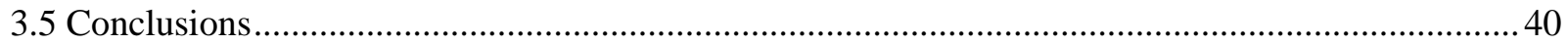

4. CHAPTER FOUR: LINEAR PROGRAMMING MODEL OF NATURAL GAS PROCESSING

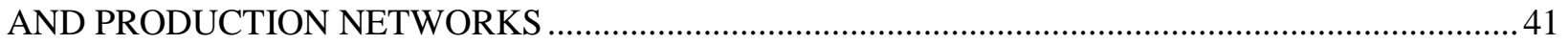

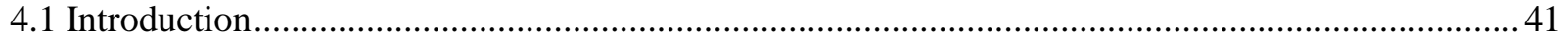

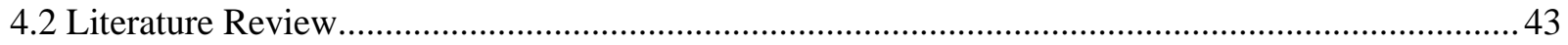

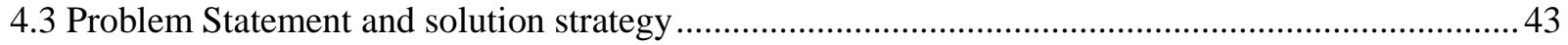

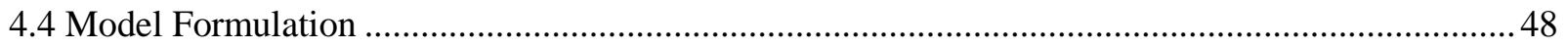

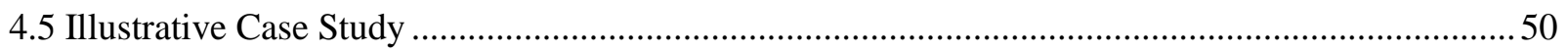

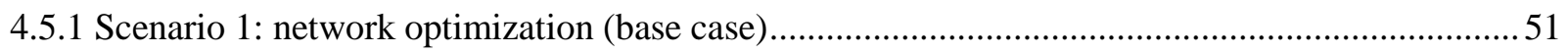

4.5.2 Scenario 2: natural gas feedstock flowrate incremental........................................................52

4.5.3 Scenario 3: natural gas feedstock and product prices incremental...........................................54

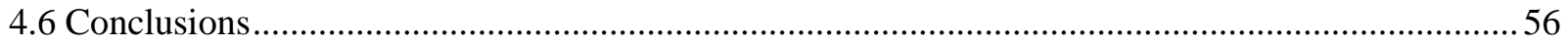

5. CHAPTER FIVE: MIXED INTEGER LINEAR PROGRAMMING MODEL FOR DESIGN AND OPERATION OF NATURAL GAS PROCESSING NETWORK …........................................................57

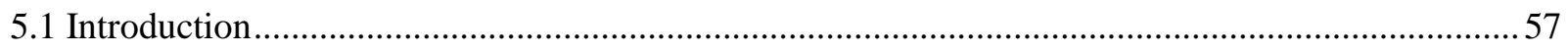

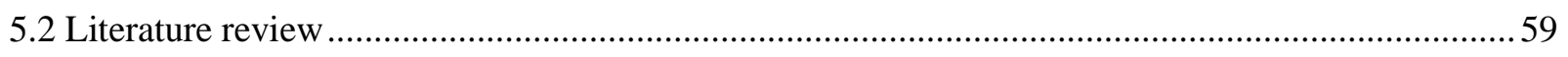

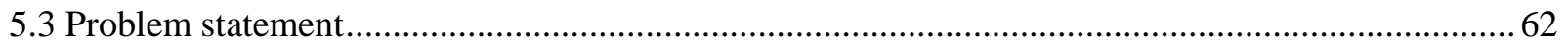

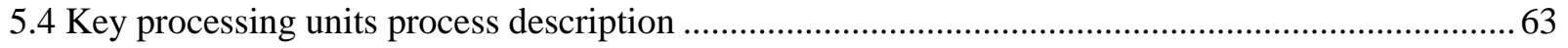

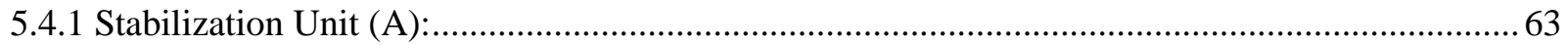

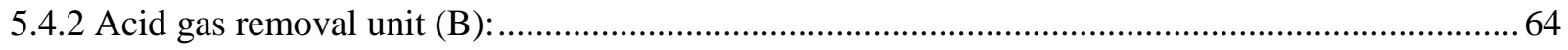

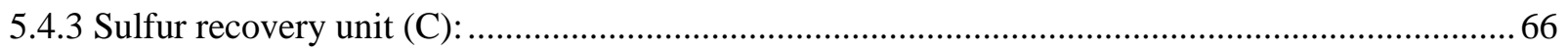

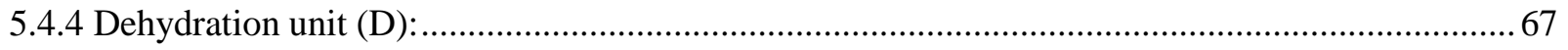

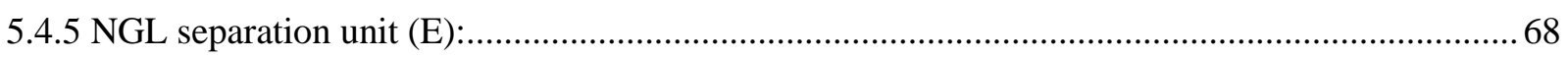

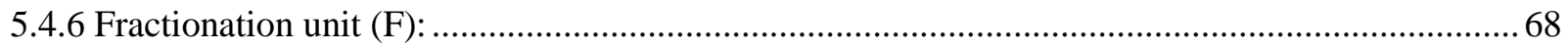

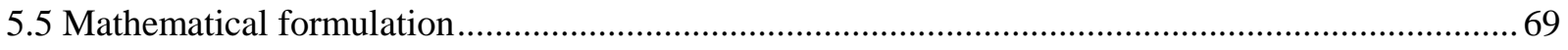

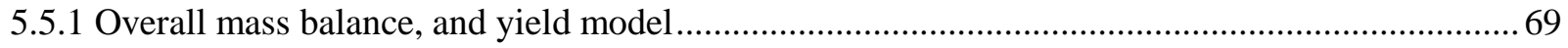

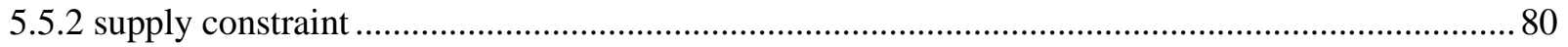

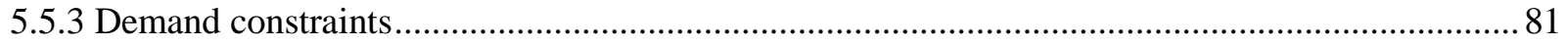

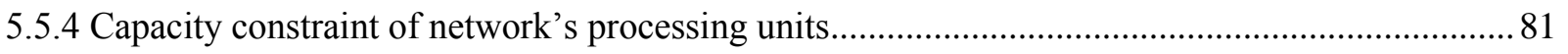

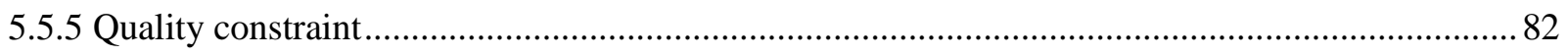




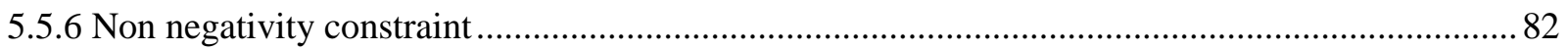

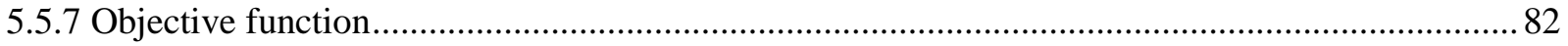

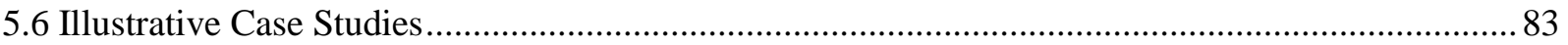

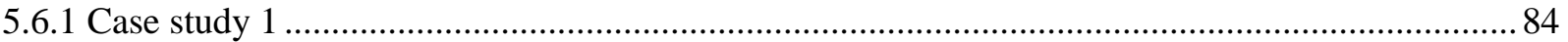

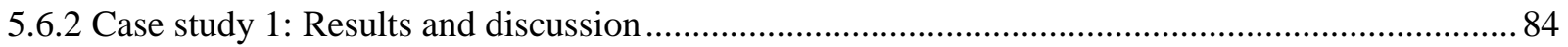

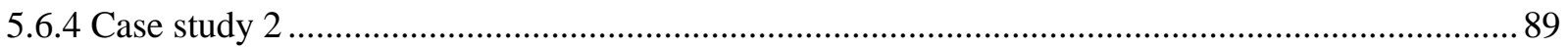

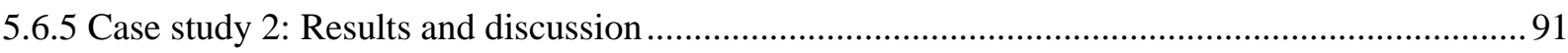

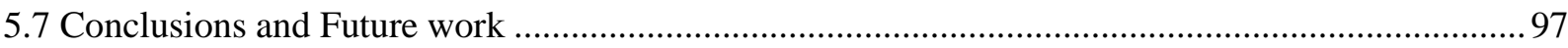

6. CHAPTER SIX: MIXED INTEGER LINEAR PROGRAMMING MODEL FOR DESIGN AND OPERATION OF NATURAL GAS PRODUCTION NETWORK …............................................... 98

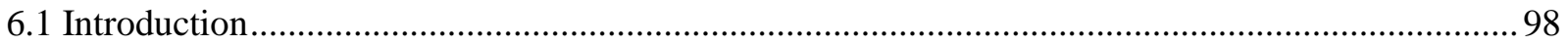

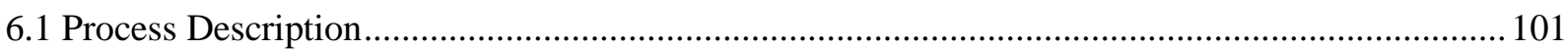

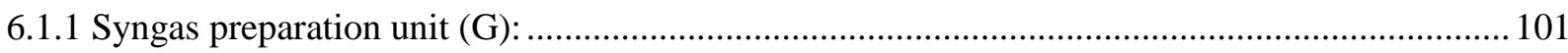

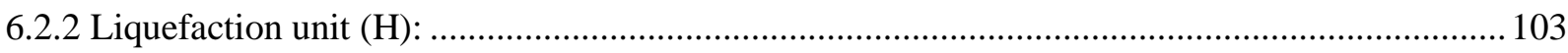

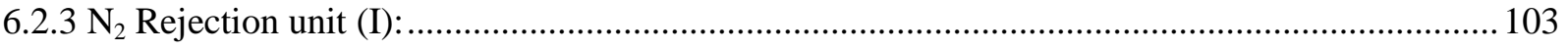

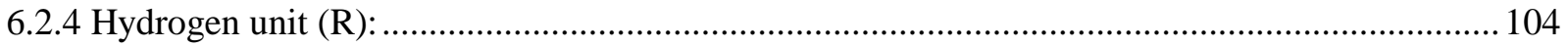

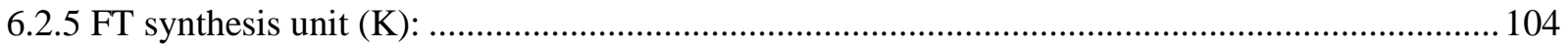

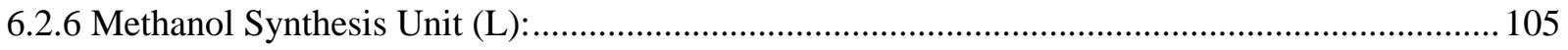

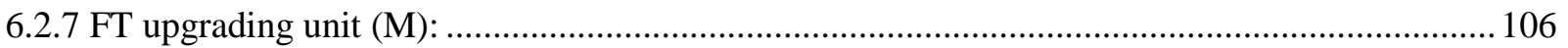

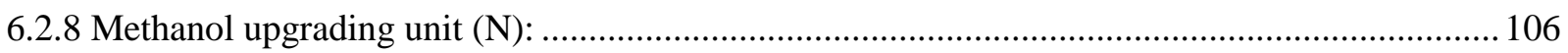

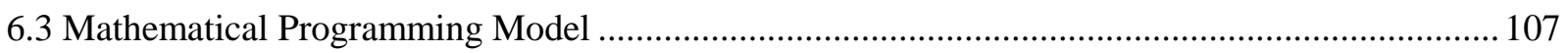

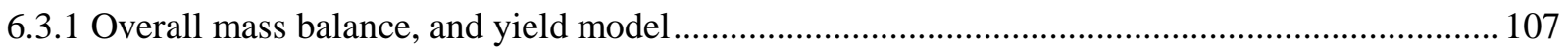

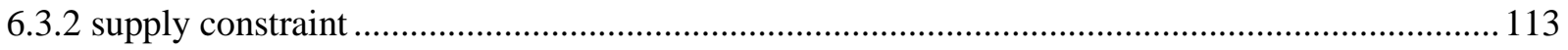

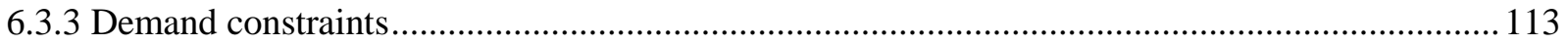

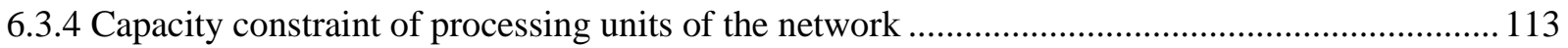

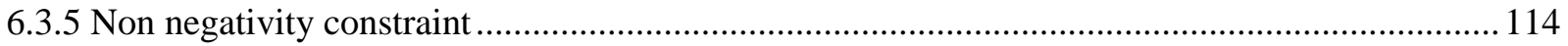

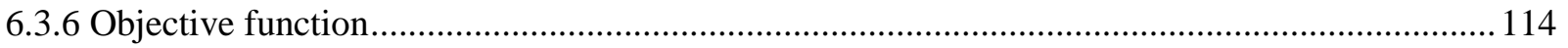

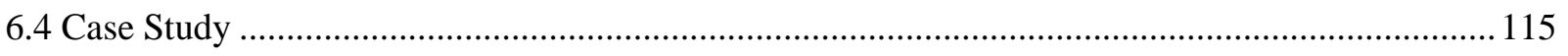

6.4.1 Planning using formulated MILP model (Economic) ........................................................... 120

6.4.2 Planning using formulated model (Sustainable) ......................................................................... 120

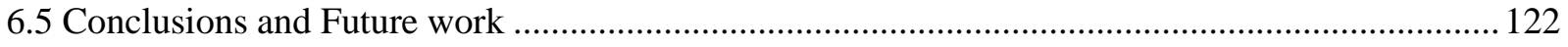

7. CHAPTER SEVEN: SUSTAINABILITY ASSESSMENT OF NATURAL GAS PROCESSING

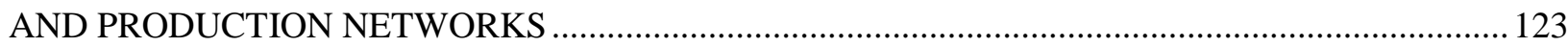

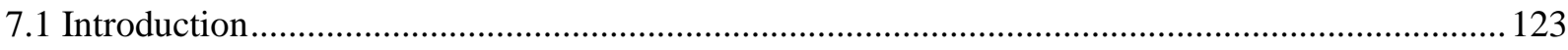




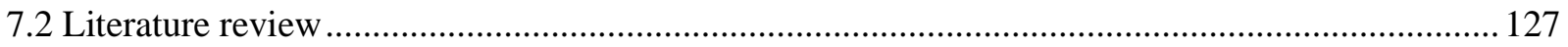

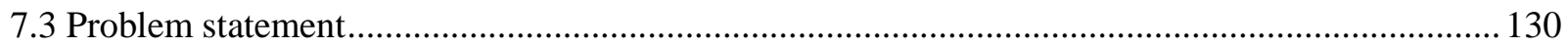

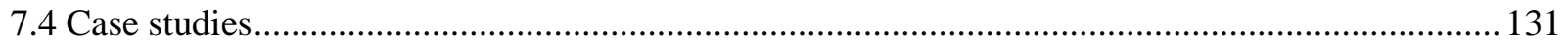

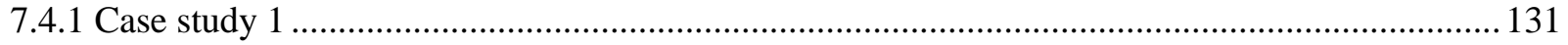

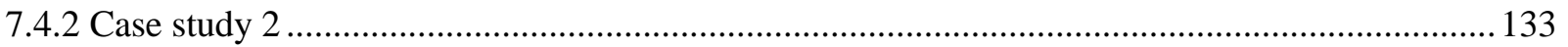

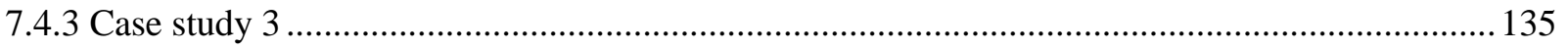

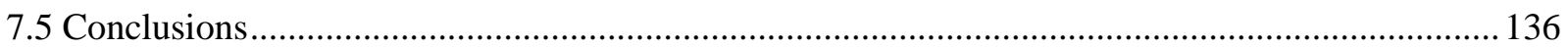

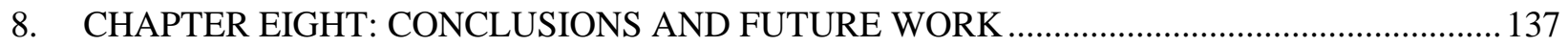

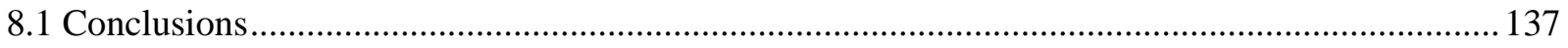

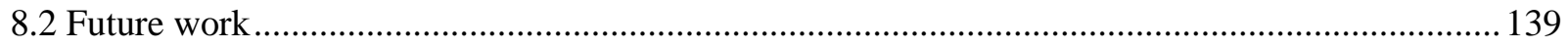

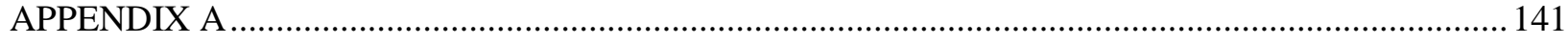

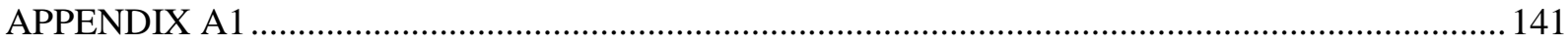

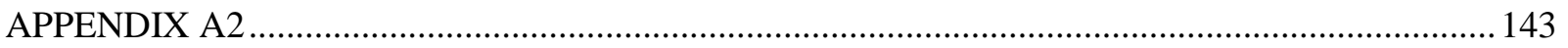

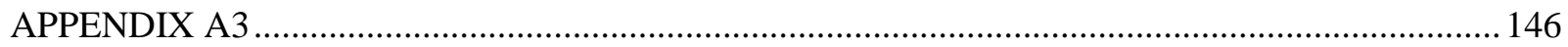

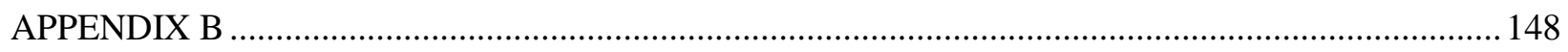

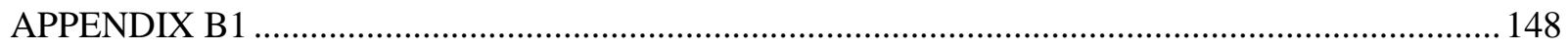

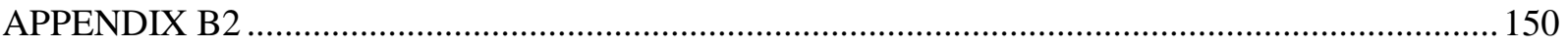

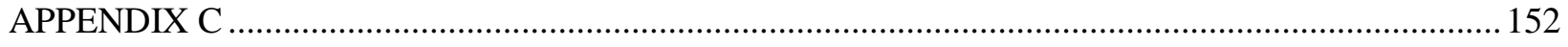

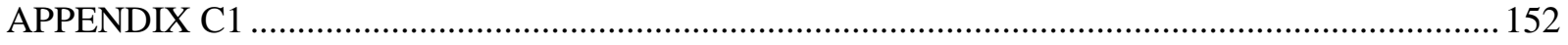

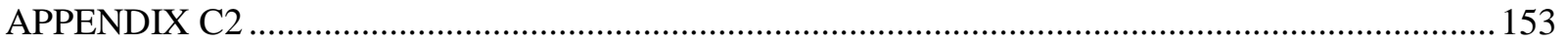

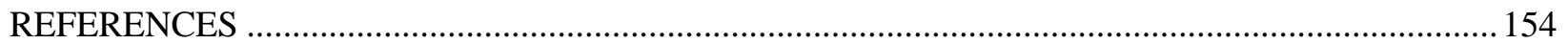




\section{List of Figures}

Figure 1.1 Consumption percentage of each fuel or energy source (BP, 2011) .................................... 1

Figure 1.2 Projection of world total energy consumption by fuel. (Data were taken from projections: EIA,

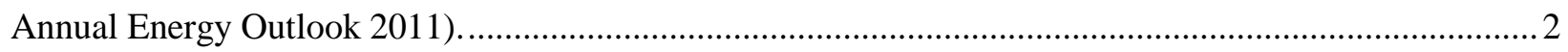

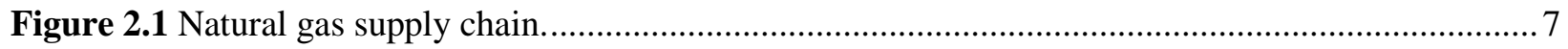

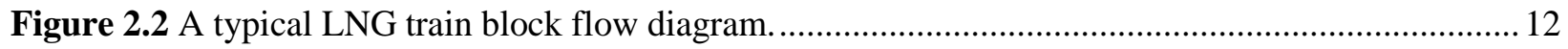

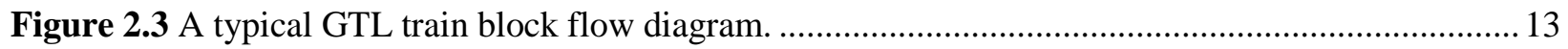

Figure 2.4 A typical methanol train block flow diagram. ...................................................................... 14

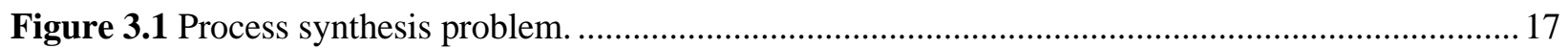

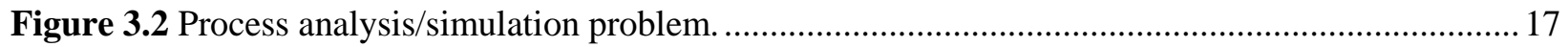

Figure 3.3 Key processing units of natural gas processing and production network..............................22

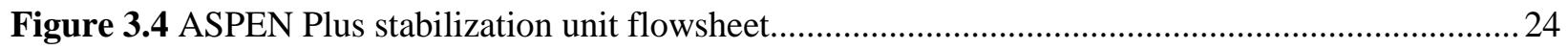

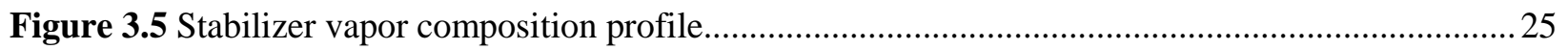

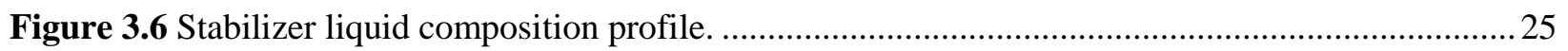

Figure 3.7 ASPEN Plus Acid Gas Removal Unit flowsheet................................................................26

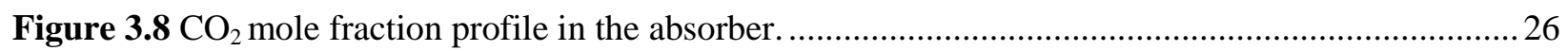

Figure 3.9 H2S mole fraction profile in the absorber. ....................................................................... 27

Figure 3.10 ASPEN Plus sulfur recovery unit (straight) flowsheet. ......................................................2

Figure 3.11 ASPEN Plus sulfur recovery unit (split) flowsheet. ...........................................................2 28

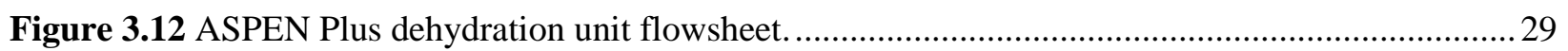

Figure 3.13 $\mathrm{H}_{2} \mathrm{O}$ composition profile in glycol dehydrator............................................................. 29

Figure 3.14 ASPEN Plus fractionation unit (conventional) flowsheet. ..................................................... 30

Figure 3.15 ASPEN Plus fractionation unit (nonconventional) flowsheet. ............................................. 30

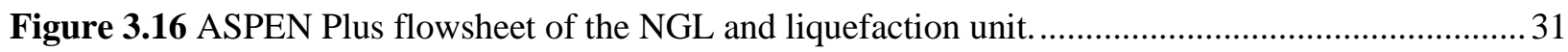

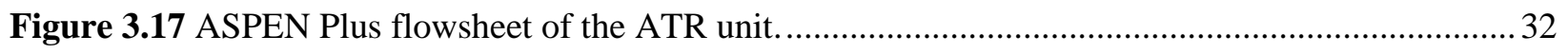

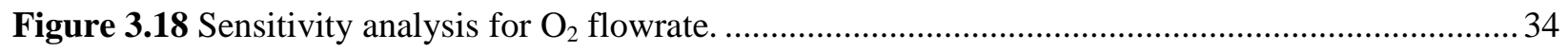

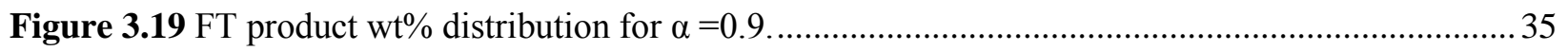

Figure 3.20 ASPEN Plus flowsheet of FT synthesis and upgrading unit............................................. 35

Figure 4.1 A schematic superstructure of natural gas network............................................................44

Figure 4.2 A schematic representations of steps in developing optimal structure of network..................46

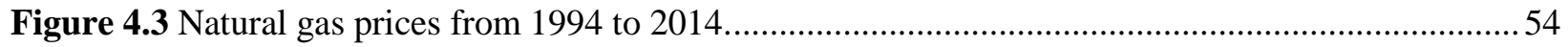

Figure 5.1 A representation of natural gas upstream processing network. ............................................ 60

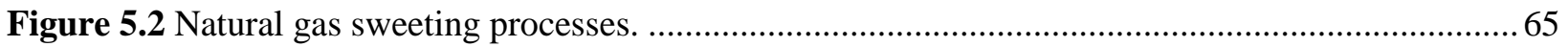




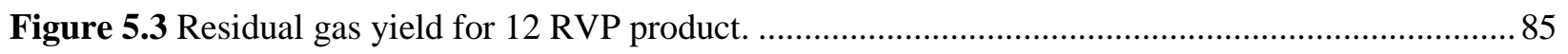

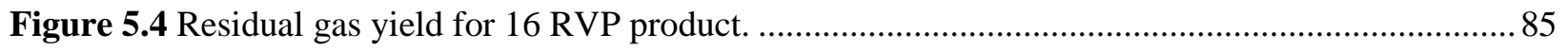

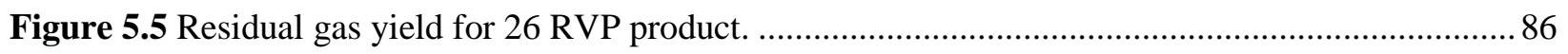

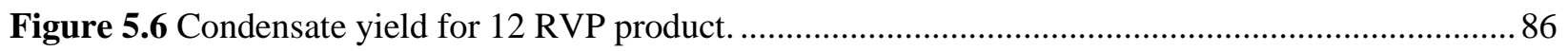

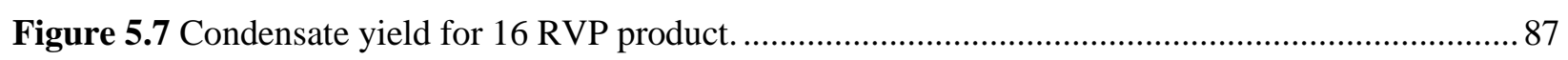

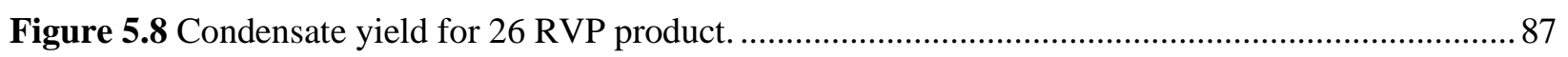

Figure 5.9 Natural gas processing pathway with selected design alternatives......................................91

Figure 6.1 A schematic representation of natural gas production network with alternatives for each

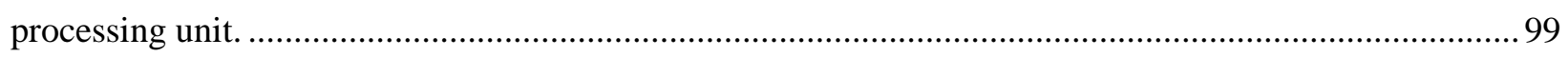

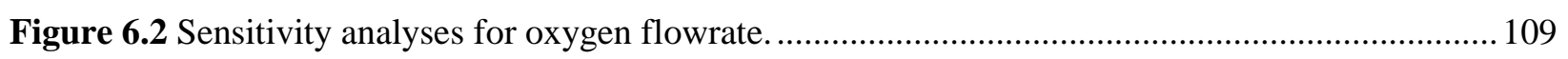

Figure 7.1 A schematic representation of the three dimensions of sustainability............................... 126

Figure 7.2 Trend in the number of publications addressing sustainability and chemical engineering from

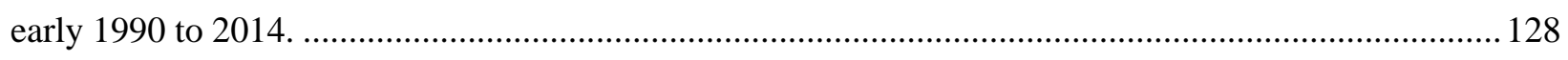

Figure 7.3 Three operating schemes for acid gas removal unit....................................................... 133 


\section{List of Tables}

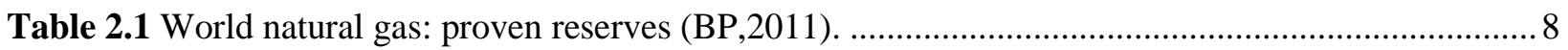

Table 3.1 Natural gas feed operating conditions and composition (Al-Sobhi, 2009)...........................21

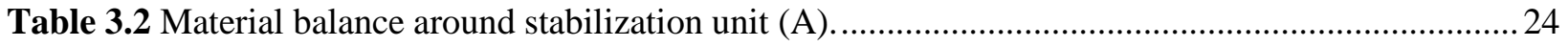

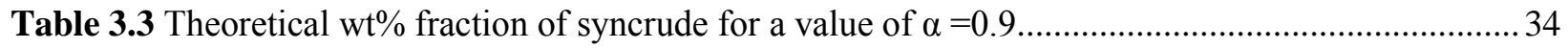

Table 3.4 Products yield and flowrate from LNG, GTL, and methanol processes. ................................ 38

Table 3.5 Capital cost, operating cost, and net $\mathrm{CO} 2$ emission of major processing units.........................39

Table 4.1 Possible technology of industrial processing units............................................................... 47

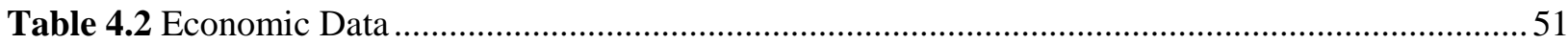

Table 4.3 Products yield from LNG, GTL, and methanol processes for base case...............................53

Table 4.4 Results comparison of three studied scenarios..................................................................55

Table 5.1 Total capital, annuity of capital, and total operating cost for 12, 16, 26 RVP products........88

Table 5.2 Different possible technologies available for selection.........................................................90

Table 5.3 Flowrate and operating conditions around unit A...............................................................92

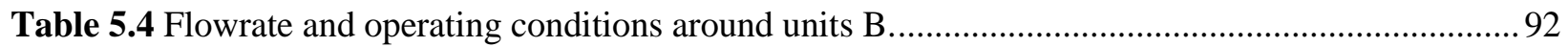

Table 5.5 Flowrate and operating conditions around units C..............................................................93

Table 5.6 Flowrate and operating conditions around units D. ............................................................ 93

Table 5.7 Flowrate and operating conditions around units E............................................................. 94

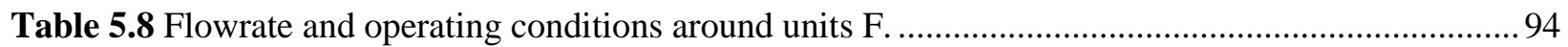

Table 5.9 Total capital, annuity of capital, and total operating cost of each processing unit...................95

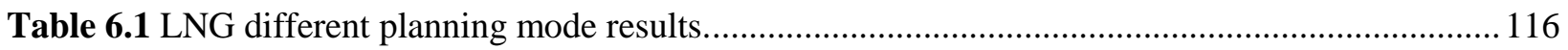

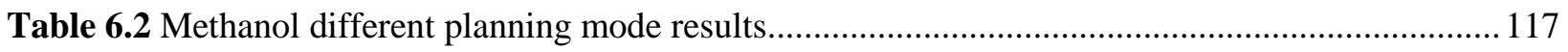

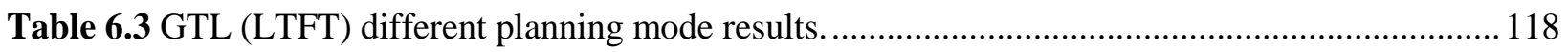

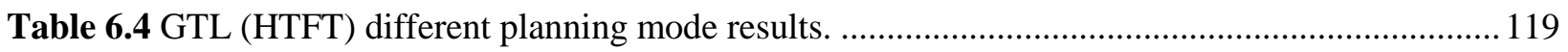

Table 6.5 CO2 equivalent values in tons/yr for different utilization options...................................... 121

Table 7.1 Metrics for comparing LNG, GTL, and methanol production processes............................... 132

Table 7.2 Metrics for comparing scheme B and $\mathrm{C}$ for acid gas removal unit...................................... 134

Table 7.3 Metrics for comparing LTFT and HTFT production processes ......................................... 135 


\section{Nomenclature}

\section{Nomenclature for Chapter5}

Sets

$i=$ processing unit

$J_{i}=$ technology/configuration of processing unit i, i $\in\{A, \ldots, F\}$

$m=$ operational mode

$K=$ product

\section{Variables}

\section{Binary variable}

$X_{j m}^{i}=1$ Denote the selection of technology $\mathrm{j}$ in processing unit $\mathrm{i}$ at operational mode $\mathrm{m}, 0$ otherwise

\section{Continuous variables}

$F_{\text {Natgas }}=$ mass flowrate of natural gas feedstock in $\mathrm{kg} / \mathrm{h}$

$F_{\text {resgas }}=$ mass flowrate of residual gas stream from unit $\mathrm{A}$ in $\mathrm{kg} / \mathrm{h}$

$F_{\text {field } 5+}=$ mass flowrate of field condensate stream in $\mathrm{kg} / \mathrm{h}$

$F_{\text {Sweetgas }}=$ mass flowrate of sweet gas stream in $\mathrm{kg} / \mathrm{h}$

$F_{\text {acidgas }}=$ mass flowrate of acidgas stream in $\mathrm{kg} / \mathrm{h}$

$F_{\text {Tailgas }}=$ mass flowrate of tailgas stream in $\mathrm{kg} / \mathrm{h}$

$F_{\text {sulfur }}=$ mass flowrate of sulfur stream in $\mathrm{kg} / \mathrm{h}$

$F_{\text {dehgas }}=$ mass flowrate of dehydrated gas stream in $\mathrm{kg} / \mathrm{h}$

$F_{\text {water-D }}=$ mass flowrate of water stream from unit D in $\mathrm{kg} / \mathrm{h}$

$F_{N G L}=$ mass flowrate of NGL stream in $\mathrm{kg} / \mathrm{h}$

$F_{C 2}=$ mass flowrate of ethane stream in $\mathrm{kg} / \mathrm{h}$

$F_{L P G}=$ mass flowrate of LPG stream in $\mathrm{kg} / \mathrm{h}$

$F_{\text {plantC5+ }}=$ mass flowrate of plant condensate stream in $\mathrm{kg} / \mathrm{h}$

$F_{C H 4}=$ mass flowrate of methane stream in $\mathrm{kg} / \mathrm{h}$

$F_{\text {acidgas }}^{H 2 S}=$ mass flowrate of $\mathrm{H} 2 \mathrm{~S}$ in acidgas stream in $\mathrm{kg} / \mathrm{h}$

$F_{\text {acidgas }}^{\mathrm{CO}}=$ mass flowrate of $\mathrm{CO} 2$ in acidgas stream in $\mathrm{kg} / \mathrm{h}$

$F_{\text {sweetgas }}^{H 2 S}=$ mass flowrate of H2S in sweetgas stream in $\mathrm{kg} / \mathrm{h}$

$F_{\text {Sweetgas }}^{\mathrm{CO} 2}=$ mass flowrate of $\mathrm{CO} 2$ in sweetgas stream in $\mathrm{kg} / \mathrm{h}$

parameters

$y_{A_{j, m}}^{\text {fieldC5+ }}=$ yield value for fieldC $5+$ stream

$y_{A_{j, m}}^{\text {resgas }}=$ yield value for residual gas stream

$y_{B_{j, m}}^{\text {tailgas }}=$ yield value for tail gas

$y_{B_{j, m}}^{\text {sweetgas }}=$ yield value for sweetgas stream

$y_{B_{j, m}}^{\text {acidgas }}=$ yield value for acidgas stream

$y_{B_{j, m}}^{H 2 S s w e e t g a s}=$ yield value for H2S in sweet gas stream

$y_{B_{j, m}}^{\text {CO2sweetgas }}=$ yield value for $\mathrm{CO} 2$ in sweet gas stream

$y_{B_{j, m}}^{H 2 \text { Sacidgas }}=$ yield value for $\mathrm{H} 2 \mathrm{~S}$ in acid gas stream

$y_{B_{j, m}}^{\text {CO2acidgas }}=$ yield value for $\mathrm{CO} 2$ in acid gas stream

$y_{c_{j, m}}^{\text {sulfur }}=$ yield value for sulfur stream 


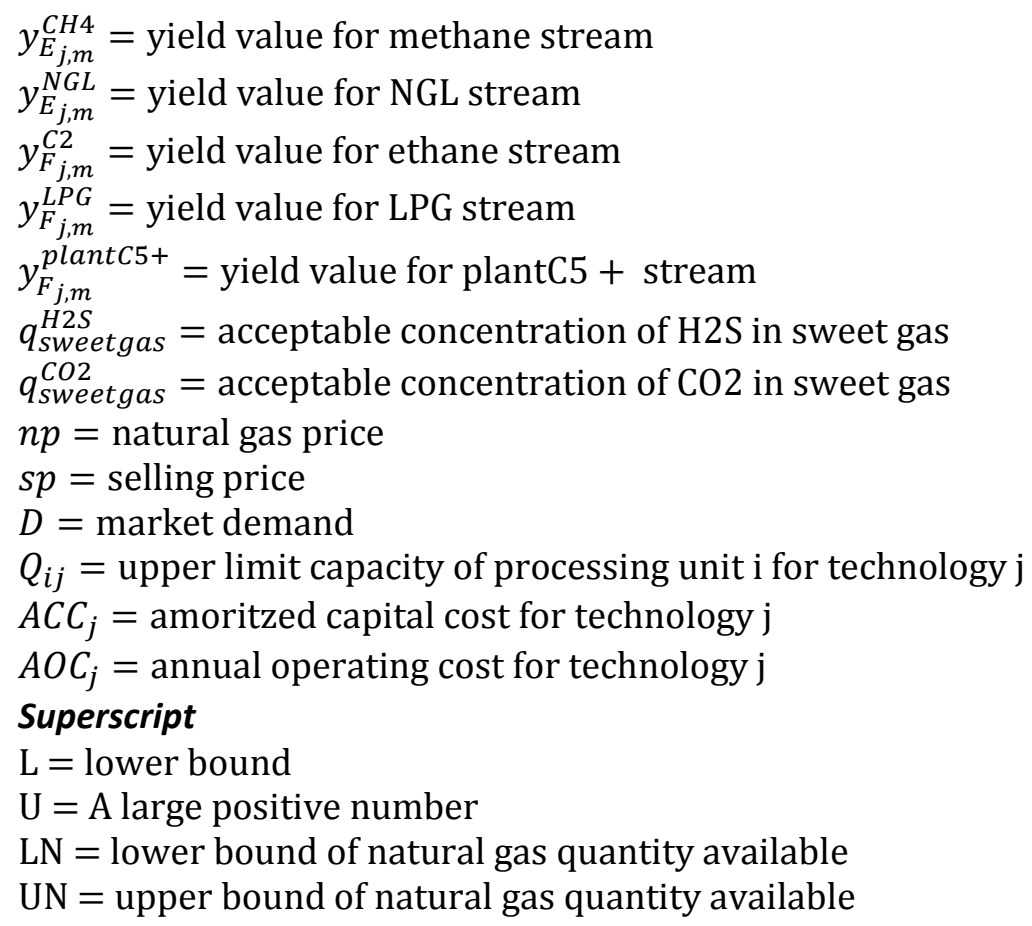




\section{Abbreviations}

$\begin{array}{ll}\text { RVP } & \text { Reid vapor pressure } \\ \text { MEA } & \text { Monoethanolamine } \\ \text { DGA } & \text { Diglycolamine } \\ \text { DEA } & \text { Diethanolamine } \\ \text { DIPA } & \text { Diisopropanolamine } \\ \text { MDEA } & \text { Methyldiethanolamine } \\ \text { EG } & \text { Ethylene glycol } \\ \text { DEG } & \text { Diethylene glycol } \\ \text { TEG } & \text { Triethylene glycol } \\ \text { TREG } & \text { Tetraethylene glycol } \\ \text { TGCU } & \text { Tail gas cleanup unit } \\ \text { C1 } & \text { Methane } \\ \text { C2 } & \text { Ethane } \\ \text { C3 } & \text { Propane } \\ \text { C4 } & \text { Butane } \\ \text { C5 } & \text { Pentane } \\ \text { C5+ } & \text { Pentane and heavier } \\ \text { C6 } & \text { Hexane } \\ \text { C6+ } & \text { Hexane and heavier } \\ \text { LNG } & \text { Liquefied natural gas } \\ \text { GTL } & \text { Gas to liquids } \\ \text { NGL } & \text { Natural gas liquids } \\ \mathrm{H}_{2} S & \text { Hydrogen sulfide } \\ \text { CO } & \text { Carbon dioxide } \\ \text { LP } & \text { Linear programming } \\ \text { MILP } & \text { Mixed integer linear programming } \\ \text { NLP } & \text { Nonlinear programming } \\ \text { MINLP } & \text { Mixed integer nonlinear programming } \\ \text { SGPS } & \text { Sarawak Gas Production System } \\ \text { GHG } & \text { Greenhouse gas } \\ \text { CNG } & \text { Compressed natural gas } \\ \text { GTS } & \text { Gas to solid } \\ \text { GTW } & \text { Gas to wire } \\ \text { CBM } & \text { Coal bed methane } \\ \text { FT } & \text { Fischer-Tropsch } \\ \text { DME } & \text { Dimethylether } \\ \text { RWGSR } & \text { Reserve water gas shift reaction } \\ & \end{array}$




\section{CHAPTER ONE: \\ INTRODUCTION}

\subsection{Motivation}

Natural gas is the cleanest primary fossil fuel. It produces less $\mathrm{CO}_{2}, \mathrm{NO}_{\mathrm{x}}, \mathrm{SO}_{\mathrm{x}}$, and particulates emissions when burned to produce energy compared to other fossil fuels, such as oil and coal (EIA, 1999). Specifically, less greenhouse gas (GHG) emissions responsible for global warming are generated. In 2010, natural gas was used and consumed globally to generate electricity by $24 \%$ relative to the other energy sources, namely, oil, coal, nuclear energy, hydroelectricity, and renewables. Figure 1 shows in percentage the total world consumption of each fuel or energy source of 12002.4 million tons oil equivalent in 2011 (BP, 2011).

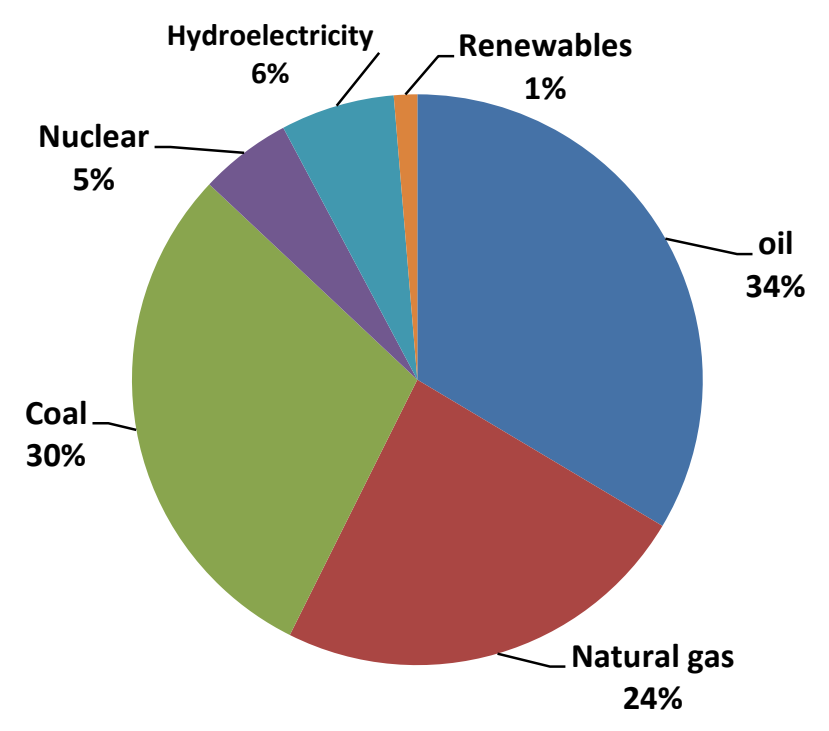

Figure 1.1 Consumption percentage of each fuel or energy source (BP, 2011). 


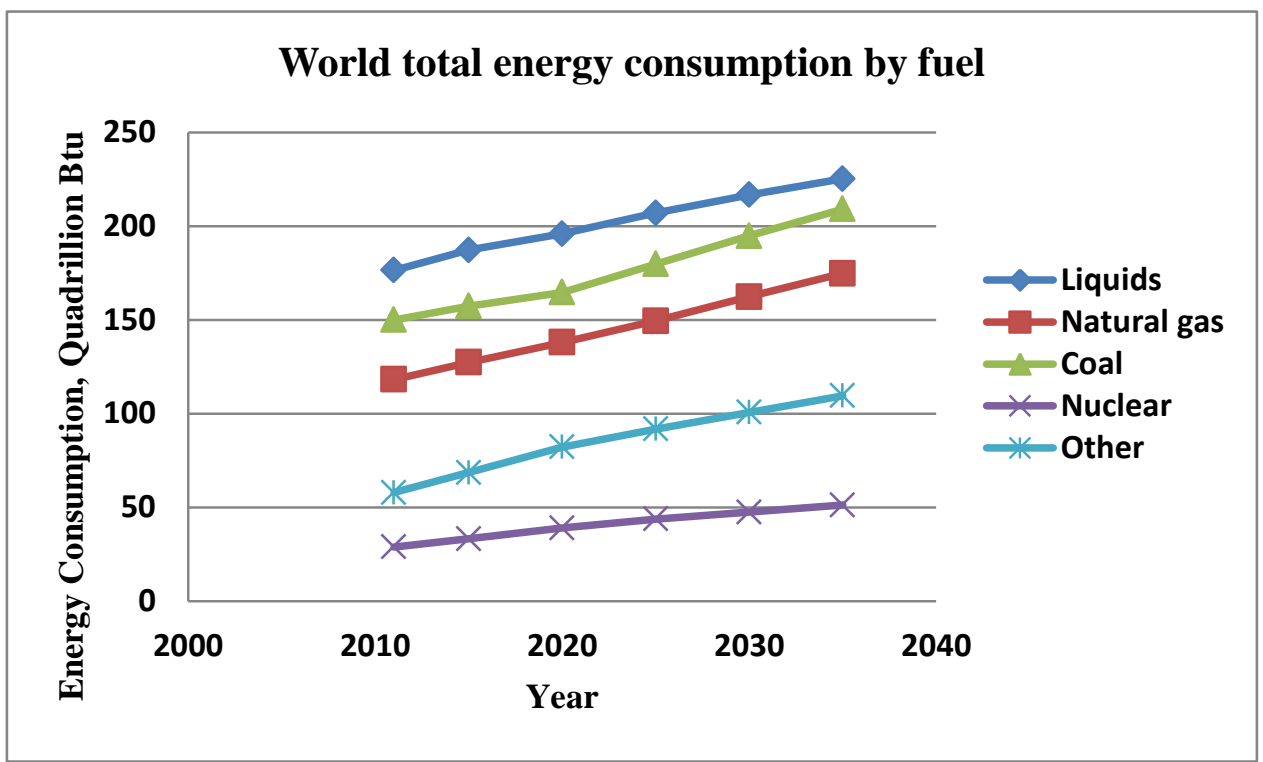

Figure 1.2 Projection of world total energy consumption by fuel. (Data were taken from projections: EIA, Annual Energy Outlook 2011).

Globally, about $85 \%$ of energy consumption is supplied and fulfilled by fossil fuels and this picture will remain true for the foreseeable future. The world total energy consumption will increase from 531.2 to 770 Quadrillion Btu by 2035. Although this represents a $45 \%$ increase in the total energy consumption, $80 \%$ of fuel consumption still will be provided by oil, natural gas, and coal. Furthermore, natural gas consumption will increase from 118 to 175 Quadrillion Btu in 2035. Thus, natural gas will maintain its contribution of $23 \%$. Figure 1.2 projects the total world energy consumption by fuel in Quadrillion Btu (EIA, 2011). 


\subsection{Research Objectives}

Here we mention and list the main objectives of this research,

- To develop a framework for natural gas utilization

- To synthesize a novel natural gas processing and production network that involves more than one utilization option

- To simulate and analyze the network in order to estimate accurately the mass and energy balances

- To present a mathematical model that addresses the operational strategy to utilize optimal usage of the natural gas recourse

- To design a natural gas processing and production network that has the following characteristics and attributes, such as involving and considering many technologies, different configurations, and different operating conditions

- To assess and benchmark the network's performance in the context of sustainability

\subsection{Organization of the Thesis}

The thesis is organized in eight chapters as follows:

\section{Chapter 1: INTRODUCTION}

This chapter discusses the importance of natural gas as a primary energy resource, and discusses the motivation behind this research. Also, it states the research objectives, and organization of the thesis. 


\section{Chapter 2: $\quad$ BACKGROUND AND PROCESS DESCRIPTION}

This chapter provides background about natural gas industry and describes the major production processes. In addition, it gives an overview of major production processes proposed in the novel synthesized network.

Chapter 3: SIMULATION OF NATURAL GAS PROCESSING AND PRODUCTION NETWORKS

This chapter presents the rigorous steady state simulation models for each key processing unit within the proposed processing and production network. The yields values are obtained from the simulation to be used in the developed mathematical models to further optimize and improve the network's performance.

Chapter 4: LINEAR PROGRAMMING MODEL OF NATURAL GAS PROCESSING AND PRODUCTION NETWORKS

This chapter presents the developed LP model that proved to be helpful to the decision maker in natural gas production processes to address the variation and changes in gas market prices, and yields. The model is tested on different scenarios and case studies.

Chapter 5: MIXED INTEGER LINEAR PROGRAMMING MODEL FOR DESIGN OF NATURAL GAS PROCESSING NETWORK

This chapter presents a MILP model for the optimal design and operation of natural gas processing network. Different technologies and configurations available for selection of key processing units are considered. Also, different operating modes practiced in industry 
in terms of low, moderate, and sever restrictions to the specifications level are investigated.

Chapter 6: MIXED INTEGER LINEAR PROGRAMMING MODEL FOR DESIGN AND OPERATION OF NATURAL GAS PRODUCTION NETWORK

This chapter addresses the production side of natural gas network. Different technologies and configurations of LNG, GTL, and methanol production systems are evaluated. A comprehensive MILP model for the optimal design and operation is presented for different utilization scenarios.

\section{Chapter 7: $\quad$ SUSTAINABILITY ASSESSMENT OF NATURAL GAS PROCESSING AND PRODUCTION NETWORKS}

This chapter evaluates the sustainability merits of processing and production network. The economic, environmental, and societal aspects can be incorporated in all models to improve the networks performance.

Chapter 8: CONCLUSIONS AND FUTURE WORK

This chapter gives the concluding remarks gained from this research and suggests recommendations for future work. 


\section{CHAPTER TWO}

\section{BACKGROUND AND PROCESS DESCRIPTION}

\subsection{Natural Gas Supply Chain}

Supply chain management is a discipline that integrates the manufacturing plants with their suppliers and customers in an efficient way. The supply chain problems may be divided into three categories: (1) supply chain network design (2) supply chain analysis and policy formulation and (3) supply chain planning and scheduling (Shah, 2005). The supply chain network design is a broad problem. Generally, it refers to a strategic activity which aims to increase its value by considering one or more of following decisions:

- $\quad$ Sourcing decisions-what supplies to use for each facility

- Allocation decisions- what products should be produced at each production facility

- Location decisions- where to locate new facilities

Supply chain or supply network can be distinguished and separated into production network and distribution network. The production network consists of all production plants and the storage facilities. However, the distribution network consists of all storage facilities and distribution facilities responsible to deliver the product to end user. A typical petroleum industry supply chain starts with an exploration phase, crude procurement and storage logistics, transportation to the refinery, refinery operations, and distribution of its products. In a similar fashion, natural gas supply chain starts with field exploration and drilling where the raw material is extracted and processed. Next, it is sent to the processing plant where a further processing takes place to make the desired products. Then, the loading and shipping occur to transfer the products to different 
destinations. Finally, the storage and distribution take place to distribute the product to final consumers. Figure 2.1 shows the natural gas supply chain diagram.

In the literature, both combined models for production/distribution and separate models for either production or distribution are presented. The decomposition strategy is preferred and justified in that when implemented, it eases the complexity involved in solving the combined model. Furthermore, the production cost is dominated in industrial processes (Camm et al., 1997). Thus, the focus of this research is on processing and production network design and the field exploration, transportation and distribution network design are out of the scope of this research.

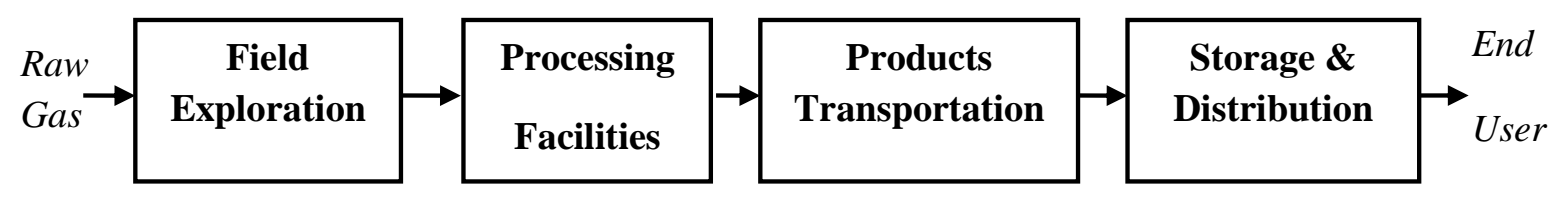

Figure 2.1 Natural gas supply chain.

\subsection{Natural Gas: Proven Reserves}

Natural gas reserves are located and distributed unequally. The top three countries in percentage share; Russian Federation, Iran, and Qatar account for 54\% of the total share. Furthermore, the top ten countries own approximately $80 \%$ of the total proven reserves (BP, 2011). Table 2.1 lists the top ten countries of total proven reserves. This geographical allocation makes the natural gas a stranded energy source in many cases. Stranded energy source as being either far from the markets or located in or near self-sufficient regions where the production exceeds the domestic demand. 
Table 2.1 World natural gas: proven reserves (BP,2011).

\begin{tabular}{lcc}
\hline Country & Reserves(tcf) & \% share of total \\
\hline Russian Federation & 1580.8 & 23.9 \\
Iran & 1045.7 & 15.8 \\
Qatar & 894.2 & 13.5 \\
Turkmenistan & 283.6 & 4.3 \\
Saudi Arabia & 283.1 & 4.3 \\
US & 272.5 & 4.1 \\
United Arab Emirates & 213.0 & 3.2 \\
Venezuela & 192.7 & 2.9 \\
Nigeria & 186.9 & 2.8 \\
Algeria & 159.1 & 2.4 \\
Others & 1497.3 & 22.8 \\
\hline Total & 6608.9 & 100 \\
\hline Data were extracted from BP statistical Review of world energy, June 2011 \\
*Trillion cubic feet at the end of 2010.
\end{tabular}

It is worth mentioning that this allocation promotes the advancement in natural gas industry. This advancement is clearly seen either in the way the natural gas is utilized or in the implementation of highly advanced technologies that make the utilization process of natural gas as efficient and cost effective as other fuels.

\subsection{Natural Gas: Utilization}

With high oil price and environmental considerations, natural gas will play significantly an important role in energy supply structure. There are a number of ways to monetize the natural gas resource. The utilization process depends on the resource location, quantity, quality and so on. Conventionally, pipelines are used to transfer the natural gas to the final consumers. In many cases, this option is not possible and even not practical when the resource is stranded and the transportation distance is long. Other options considered promising as reported by Thomas and Dawe, (2003), include: Liquefied natural gas (LNG), compressed natural gas (CNG), gas to solid (GTS), i.e. hydrates, gas to wire (GTW), i.e. electricity, gas to liquids (GTL), and gas to 
chemical. Moreover, there is a growing recognition of the unconventional gas sources, such as shale gas, coal bed methane (CBM) and deep tight gas, and it is expected that they will contribute significantly in the future (Economides \& Wood, 2009).

Many researchers have addressed these utilization options either individually or as a combination. They assessed the utilization option from design, operation, economic, and environment impact perspectives. For example, Khalilpour \& Karimi, (2012) considered LNG, CNG, and GTL as monetization options under the uncertainty of natural gas and oil prices. Wood, et al., (2012) presented a review study addressing the available opportunities for GTL industry. GTL economic viability depends strongly on oil prices because the GTL products such as low-sulfur gasoline and diesel are oil refinery products competitors. Oil prices of at least \$20-30 per barrel will justify the decision of considering GTL process as option of utilization according to studies done by Al-saadoon, (2007). The utilization way varies as being physical compression and mixing process like the case of LNG, CNG, and GTS or chemical conversion process like the case of GTL. These utilization options are described as mature, developing, and prospective options. Pipeline, and LNG are mature, GTL, CNG, GTW are developing. Additionally, another highly important factor of consideration in any industry is the capital investment; both fixed and operating costs. For energy intensive processes, such as refining, chemical, petrochemical, operating cost is considered to be significantly important. Many studies have ranged oil prices to be within $\$ 20-\$ 60 / b b l$ for other fuels derivatives to be competitive. In particular, GTL industry expansion is predicted if oil prices average above $\$ 20 / \mathrm{bbl}$ (Steynberg \& Dry, 2004). The economic viability analysis of GTL (Al-saadoon, 2007) showed that $\$ 36 / \mathrm{bbl}$ as the break-even crude oil price for $\$ 2.5 / \mathrm{MMBtu}$ natural gas feedstock cost. With oil price around $\$ 100$ per barrel (last quarter of 2013), simply the decision of considering GTL process is totally 
justified. For the abovementioned reasons, the three most attractive utilization processes, namely LNG, GTL, and methanol are considered in this research to represent the processing and production network.

\subsubsection{LNG Process}

\subsubsection{LNG: Overview}

The world's first LNG ship in 1959 carried cargoes from Louisiana to the United Kingdom, proving the feasibility of LNG transport. Five years later, the United Kingdom began importing LNG from Algeria, making Algeria the world's first major LNG exporter. The United Kingdom continued to import LNG until 1990, when British North Sea gas became a less expensive alternative. Japan first imported LNG from Alaska in 1969 and then moved to international LNG trade in the 1970s and 1980s with a heavy expansion of LNG imports. Japan currently imports more than 95 percent of its natural gas imports about half the LNG exported worldwide. LNG accounts for a growing share of world natural gas trade. LNG was accounted for $30.5 \%$ of global natural gas trade in 2010 (BP, 2011). World LNG trade is expected to double, from about 10 trillion cubic feet in 2010 to around 20 trillion cubic feet in 2040 (BP, 2011). Most of the increase in liquefaction capacity occurs in Australia and North America, where many of new liquefaction projects either are planned or under construction. On the other hand, LNG

production declines in North Africa and Southeast Asia at many of the older fields associated with the liquefaction facilities, because of high domestic natural gas consumption. 


\subsubsection{LNG: Process Description}

Natural gas is converted physically through compression and liquefaction to LNG. Natural gas is liquefied at $-160^{\circ} \mathrm{C}$ and 1 atm and this will reduce its volume by 600 times. Figure 2.2 shows a typical block flow diagram of an LNG train. Natural gas feedstock is received at inlet receiving unit where the initial gas-liquid separation and metering take place. The hydrocarbon condensate stream is stabilized in the condensate stabilization unit. Acid gas removal unit is designed to reduce the $\mathrm{CO}_{2}$ and $\mathrm{H}_{2} \mathrm{~S}$ concentration levels to specification limits. The specifications as reported by (Klinkenbijl, 2005) are set to be lower than $50 \mathrm{ppmv}$ for $\mathrm{CO}_{2}$ to prevent freezing in the main cryogenic heat exchanger and below $3.5 \mathrm{ppmv}$ for $\mathrm{H}_{2} \mathrm{~S}$ to meet sale gas and pipeline specifications. Sulfur is recovered as by-product. Gas leaving the acid gas removal unit is called sweet gas. This treated gas is passed to the dehydration, mercaptan, and mercury removal unit. The dehydration involves water vapor removal to a very low level for example below 0.5 ppmv. Mercury is removed to a very small level such as 0.01 microgram per normal cubic meter (Nm3). Heavier hydrocarbons are recovered in the pre-cooling NGL separation unit. They are sent to the fractionation unit where ethane, propane, butane, and plant condensate are recovered. The methane rich stream leaving the NGL separation unit is liquefied by one of approved large scale baseload natural gas liquefaction processes. These include, pure refrigerant cascade process, propane precooled mixed refrigerant process, propane precooled mixed refrigerant with back end nitrogen expander cycle, or other mixed refrigerant processes (Tusiani \& Shearer, 2007). 


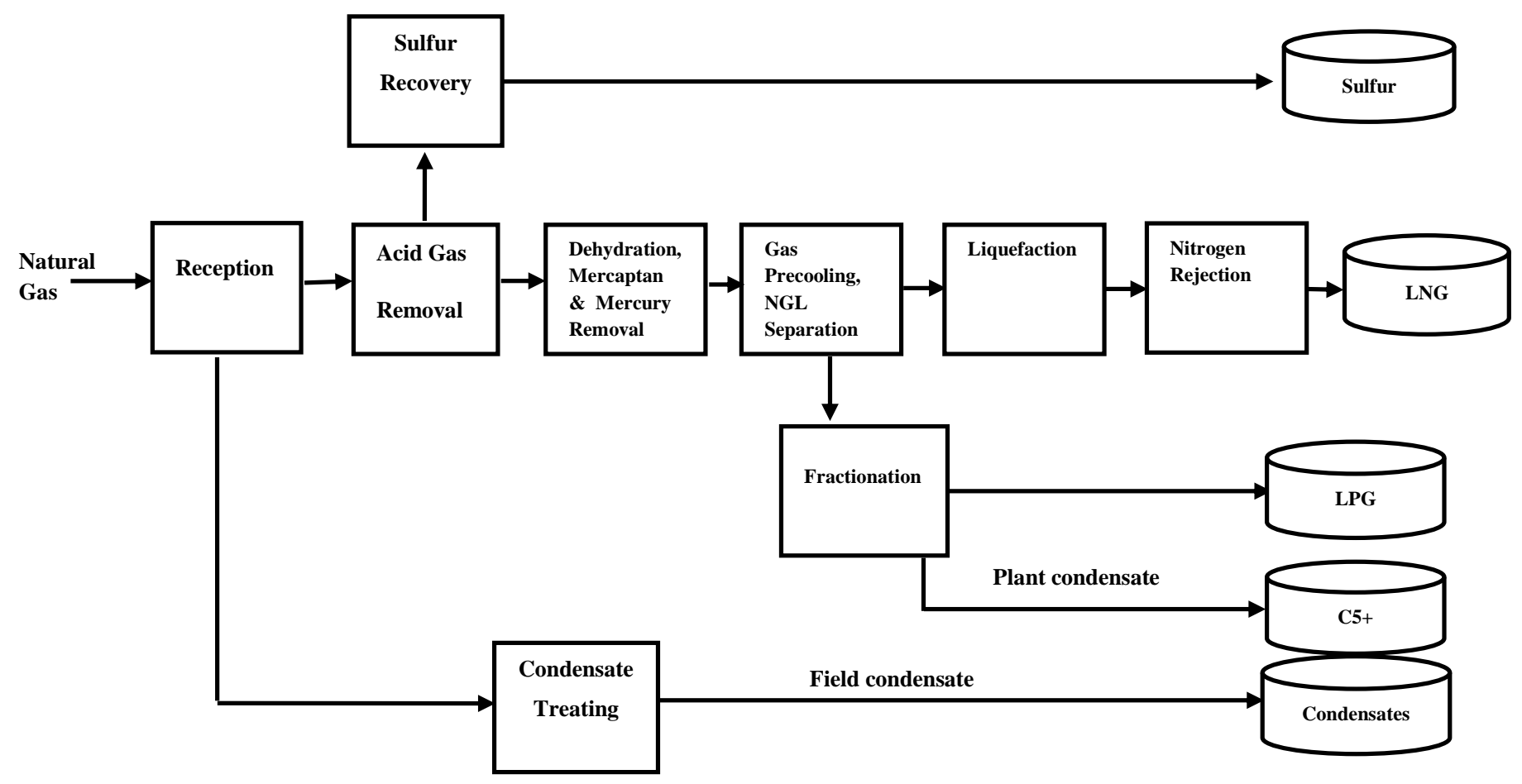

Figure 2.2 A typical LNG train block flow diagram.

\subsubsection{GTL Process}

\subsubsection{GTL: Overview}

Gas to liquid process is back dated to the early $20^{\text {th }}$ century when Franz Fischer and Hanz Tropsch developed an integrated synthesized hydrocarbon reaction named as Fischer-Tropsch (FT) reaction. Although coal was used initially in 1923 as the primary feedstock, the modern FT syntheses are still profoundly similar to the original process. For practicality and viability of GTL process from 1950 to 2000 the reader is referred to Dry, (2002). 


\subsubsection{GTL process description}

Natural gas is converted chemically through Fischer-Tropsch (FT) reaction into liquid fuels (A. Steynberg \& Dry, 2004). Figure 2.3 shows a typical block diagram of a GTL train. The upstream processing units such as stabilization, acid gas removal, sulfur recovery, dehydration, and natural gas liquids separation units are similar to those in LNG train. However, the downstream processing units consist mainly of three basic units. These are namely (1) Reforming or synthesis gas production unit where the proper syngas ratio $\left(\mathrm{H}_{2} / \mathrm{CO}\right)$ is produced. (2) FT synthesis unit where the synthesis fuels (synfuels) are produced (3) Product upgrading and separation unit where the hydro-treating/cracking takes place to obtain the final liquid fuels.

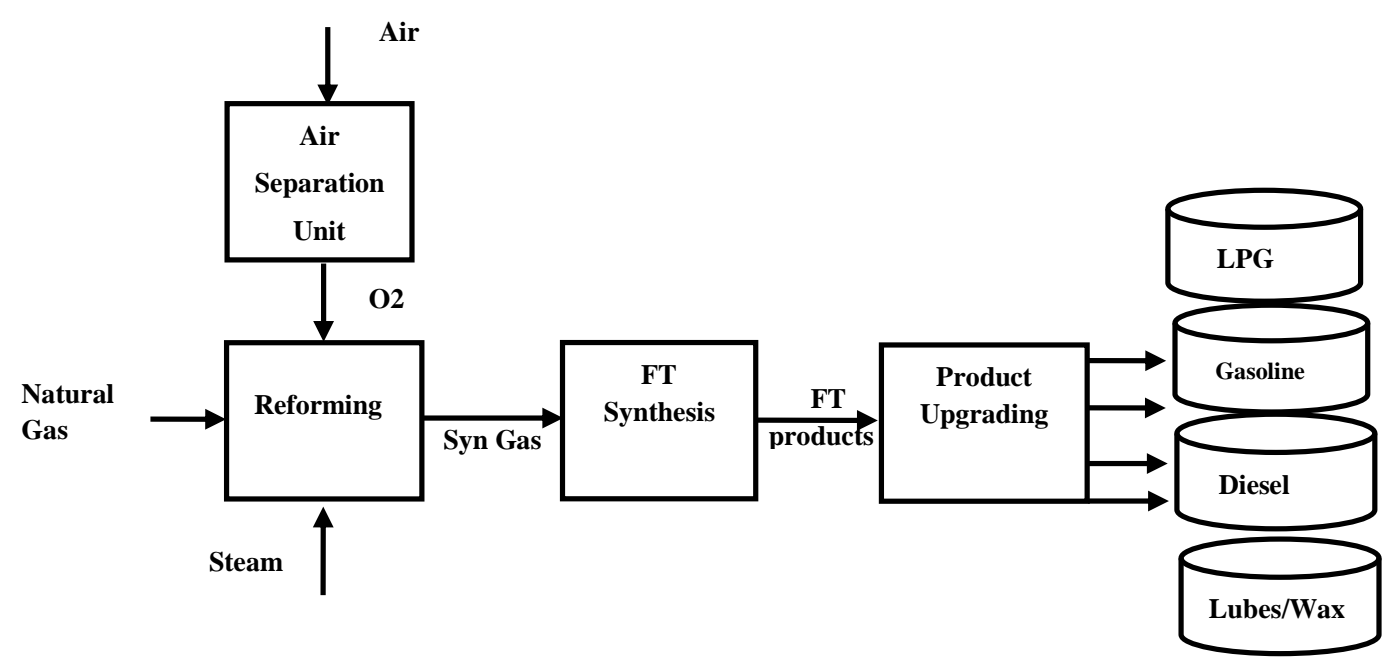

Figure 2.3 A typical GTL train block flow diagram. 


\subsubsection{Methanol Process}

\subsubsection{Methanol: Overview}

Methanol that is a primary feedstock for chemical industry is expected to contribute as fuel and energy carrier. Methanol when combined with dimethyl ether (DME) represents excellent fuels. Furthermore, methanol and DME can be blended with gasoline/diesel and used in internal combustions engines and in electricity generators (Olah, et al., 2006). For chemical sector, methanol to olefins and methanol to hydrogen are promising applications (Haid \& Koss, 2001).

\subsubsection{Methanol: Process Description}

Natural gas is converted chemically through reactions into methanol. Figure 2.4 shows a typical block flow diagram of a methanol train.

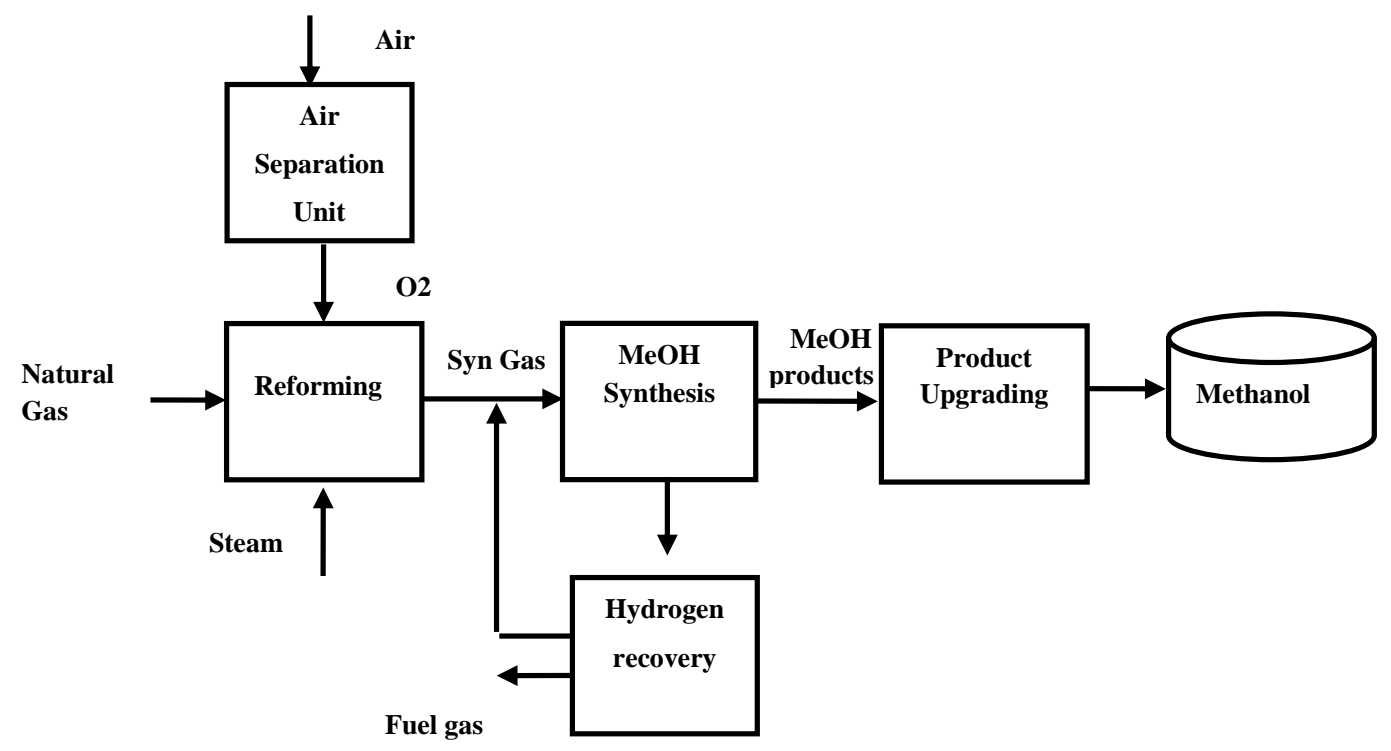

Figure 2.4 A typical methanol train block flow diagram. 
The upstream processing units such as stabilization, acid gas removal, sulfur recovery, dehydration, and natural gas liquids separation units are similar to those in LNG train. However, the downstream processing units consist mainly of three basic units (Olah et al., 2006). These are namely (1) Reforming or synthesis gas production unit where the proper molar syngas stoichiometric ratio $\mathrm{SR}=\left(\mathrm{H}_{2}-\mathrm{CO}_{2} / \mathrm{CO}+\mathrm{CO}_{2}\right)$ is produced. (2) Methanol synthesis unit where the crude methanol is produced (3) Product upgrading unit where the separation and distillation take place to obtain the final methanol product. 


\section{CHAPTER THREE:}

\section{SIMULATION OF NATURAL GAS PROCESSING AND PRODUCTION NETWORK}

\subsection{Introduction}

Process simulation plays an important role in the design and operation of any chemical, petrochemical, and refining process. It helps with the accurate estimation and calculation of mass and energy balances, transport and chemical kinetic equations, and physical properties. It also helps with equipment sizing and costing, profitability analysis, and optimization. Having generated candidate process flowsheets through process synthesis activity, comes the role of analysis and simulation to assess them. Clearly, this will facilitate the decision to be made by engineers and scientists to choose and select the most practical flowsheet.

Process synthesis requires that the input data and process output are provided, and process flowsheet (structure) is created. Whereas, in process analysis, both the input data and process flowsheet are provided, and process output will be obtained. Figure 3.1 and Figure 3.2 shows the activity of process synthesis and process analysis/simulation, respectively.

Different techniques are available to analyze the process and these include mathematical models, empirical correlations, and computer-aided process simulation tools. Many commercial process simulators (such as CHEMCAD, HYSYS, ASPEN Plus, and PRO/II) can be used to estimate the material and energy balances. 


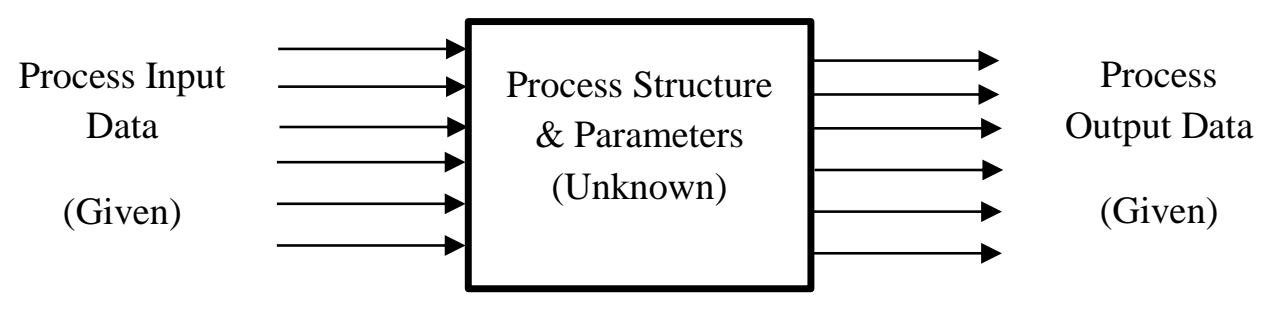

Figure 3.1 Process synthesis problem.

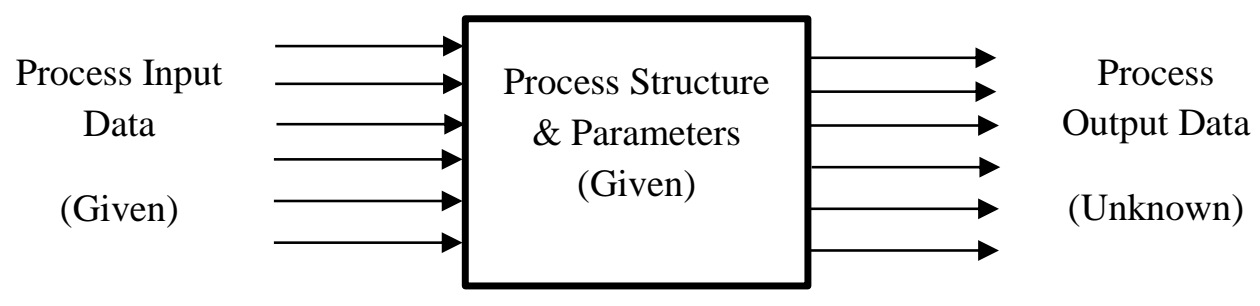

Figure 3.2 Process analysis/simulation problem.

The remainder of Chapter 3 is organized as follows. In the following Section, the literature review of a number of scientific publications addressing the importance and the implementation of simulation is given. Then the problem statement is mentioned and the steady state simulations of the key processing units of processing and production network are presented in Section 3.3 and 3.4 respectively. The chapter ends with some concluding remarks in Section 3.5. 


\subsection{Literature review}

A number of scientific publications addressed the importance and the implementation of simulation either in the design/operation of energy system or for economic assessment as will be seen. Different simulation package such as CHEMCAD, ASPEN Plus, HYSYS, and PRO/II have been showed to be beneficial in many applications and applicable in many industries. These include and span oil, gas, petrochemical, paper and pulp, and power industries. Here, some relevant work that utilized the simulation will be presented. Some were focused on a single natural gas conversion process such as GTL, LNG, gas to power, or gas to methanol. As mentioned earlier, the simulation package can be used to design a process, improve the design, or improve the operation through validation. For example, Zheng and Furimsky, (2003) developed a detailed flow sheet of the combined cycle cogeneration plant fuelled by natural gas. They used ASPEN Plus to simulate the cogeneration plant. The results generated using the simulation model were compared with the operating data of the commercial plant generating about 43.6 MW of electricity by gas turbine and $28.6 \mathrm{MW}$ of electricity by steam turbine. The key data generated using the ASPEN models were in good agreement with the operating data. Another simulation study carried out by Kim et al., (2009) on natural gas conversion to FT synthetic fuel. ASPEN HYSYS software simulation package was used to find optimum reaction conditions for maximum production of synthetic fuel. Optimum reaction temperature in FT synthesis unit was found to be $255^{\circ} \mathrm{C}$. They concluded that simulation results were reasonably well matched with experimental results and their simulation model for slurry phase FT synthesis reactor could be utilized to predict FT reactor performance under different reaction conditions.

Bao et al., (2010) developed a simulated case study of a GTL plant using natural gas to produce $118,000 \mathrm{bbl} / \mathrm{d}$ of products. ASPEN Plus software simulation package was used to simulate key 
processing units in GTL plant that will help in assess the economics of the process. Their study highlighted that depending on the price of natural gas, the return on investment ranges from $7.4 \%$ to $19.4 \%$ for the cost of natural gas being $\$ 8$ and 5/1000 SCF of natural gas, respectively. Also, a break-even point analysis considering current market conditions shows that the production capacity should be at least $57,000 \mathrm{bbl} / \mathrm{d}$ to make profit.

Ehlinger et al., (2014) presented a simulated work of shale gas-to-methanol production. Again, process simulation using ASPEN Plus along with published data were used to establish a basis for the techno-economic analysis of shale gas-to-methanol production. The results of the technoeconomic analysis demonstrate that production of methanol from shale gas would be profitable for a broad range of methanol selling prices and shale gas costs. For example, they found that a desirable $31 \%$ ROI is achieved for a methanol selling price of $\$ 2.00 / \mathrm{gal}$ and shale gas price of $\$ 3.50 / \mathrm{kSCF}$.

Fissore \& Sokeipirim, (2011) presented a study addressing the simulation and energy consumption of a cryogenic plant for the recovery of propane plus compounds from natural gas. ASPEN Plus has been used to simulate the process, and to investigate the effect of the main operating variables on the efficiency of propane plus recovery and on the energy required by the various pieces of equipment of the plant. With respect to the base case considered, the optimized plant allows for $25 \%$ heat reduction and up to $60 \%$ refrigeration reduction.

Al-Sobhi, et al., (2009) addressed the simulation and heat integration in an LNG plant. First, a typical LNG process was synthesized. ASPEN Plus simulation package was used to model the process and to determine flows, temperatures, and heat duties for various hot and cold streams. Then, thermal pinch analysis was carried out to target and reduce heating and cooling utilities. It 
was found that through heat integration, it is possible to reduce the heating utility by $15 \%$ and the cooling utility by $29 \%$.

Hao et al., (2008) used ASPEN plus to simulate an integrated GTL processes with iron and cobalt-based catalysts. The optimal flowsheet structures were selected for each catalyst based on the overall performance in terms of thermal and carbon efficiency and product distributions.

Sudiro \& Bertucco, (2009) developed a hybrid process producing synthetic gasoline and diesel from coal and natural gas. Three processes were modeled and simulated using ASPEN Plus namely, gas to liquids (GTL), coal to liquids (CTL) and the hybrid process that processes both natural gas and coal as feedstock. It was shown that he hybrid process produces $44.4 \%$ as fuel produced per unit of feedstock compared to $66.7 \%$ and $32.5 \%$ from GTL and CTL process, respectively. Also, environmental assessment in terms of $\mathrm{CO} 2$ emission was estimated for the three processes. It was shown that $2.45 \mathrm{~kg} \mathrm{CO} 2 / \mathrm{kg}$ liquid fuel from hybrid process, $0.63 \mathrm{~kg}$ $\mathrm{CO} 2 / \mathrm{kg}$ liquid fuel for GTL, and $4.66 \mathrm{~kg} \mathrm{CO} 2 / \mathrm{kg}$ liquid fuel for CTL were emitted.

Although the products yield values of selected processes can be obtained from previous works, the variations in operating conditions will results in different yield values. Thus, we need to simulate our own flowsheet to address the variation in operating conditions and their impact on the profitability of the processing and production network. Furthermore, in order to estimate the capital and operating cost using ICARUS, we need to converge the flowsheet first using the ASPEN Plus simulation package. 


\subsection{Problem statement}

Given natural gas feedstock with its composition, flow rate, operating conditions as shown in Table 3.1, it is desired to simulate the key processing units of the processing and production network using a simulation package. The main key processing units of LNG, GTL, and methanol will be considered for simulation and evaluation. The rigorous steady state simulation of the processing network will be carried out using ASPEN Plus V7.3 version. A novel natural gas processing and production network has been synthesized. The network starts with stabilization, unit (A) and ends with methanol upgrade, unit (M) as shown in Figure 3.3.

Table 3.1 Natural gas feed operating conditions and composition (Al-Sobhi, 2009).

\begin{tabular}{|c|c|}
\hline Flow rate & $\begin{array}{l}\text { 1,500 MMSCFD } \\
74,700 \mathrm{kmol} / \mathrm{hr} \\
1.5 \times 10^{6} \mathrm{~kg} / \mathrm{hr}\end{array}$ \\
\hline Temperature & $20{ }^{\circ} \mathrm{C}$ \\
\hline Pressure & 70 bar \\
\hline Component & $\mathrm{mol} \%$ \\
\hline$\stackrel{\mathrm{H}_{2 \mathrm{~S}}}{\mathrm{CO}_{2}}$ & $\begin{array}{l}1 \\
2\end{array}$ \\
\hline $\mathrm{N}_{2}$ & 4 \\
\hline $\mathrm{H}_{2} \mathrm{O}$ & 0.05 \\
\hline $\mathrm{CH}_{4}$ & 83 \\
\hline $\mathrm{C}_{2} \mathrm{H}_{6}$ & 5 \\
\hline $\mathrm{C}_{3} \mathrm{H} 8$ & 1.8 \\
\hline $\mathrm{i}-\mathrm{C}_{4} \mathrm{H}_{10}$ & 0.4 \\
\hline $\mathrm{n}-\mathrm{C}_{4} \mathrm{H}_{10}$ & 0.7 \\
\hline $\mathrm{i}-\mathrm{C}_{5} \mathrm{H}_{12}$ & 0.3 \\
\hline $\mathrm{n}-\mathrm{C}_{5} \mathrm{H}_{12}$ & 0.3 \\
\hline $\mathrm{n}-\mathrm{C}_{6} \mathrm{H}_{14}$ & 1.45 \\
\hline Total & 100 \\
\hline
\end{tabular}




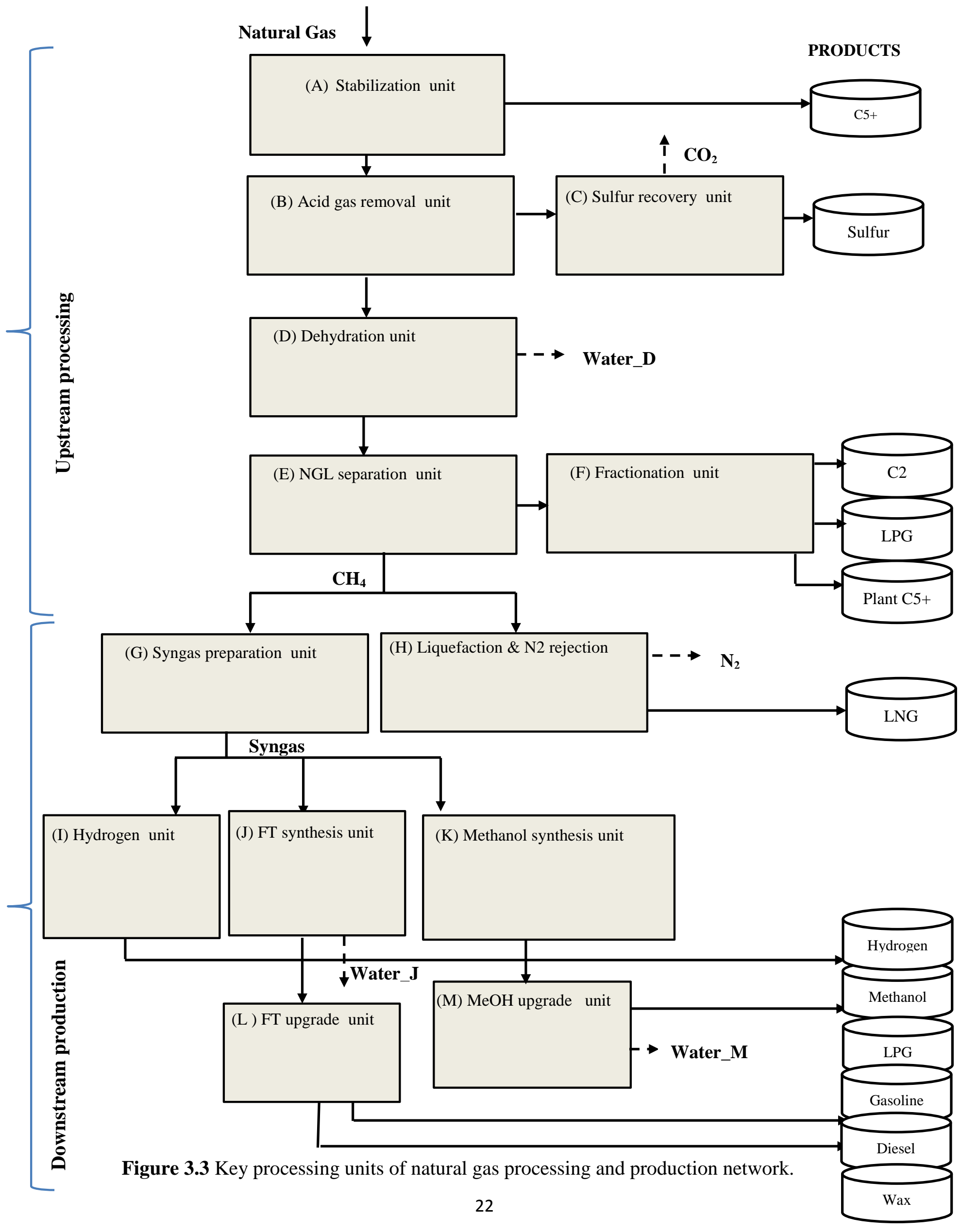




\subsection{Steady state process simulation of natural gas processing and production network}

\subsubsection{LNG process simulation}

The LNG process is represented by the processing units $(\mathrm{A}-\mathrm{F})$ and unit $(\mathrm{H})$ as shown in Figure 3.3. Natural gas feedstock with flow rate, operating conditions, and mole composition shown in Table 3.1, is received at inlet receiving unit. The steady state simulation of LNG process was carried out using ASPEN Plus. In general, cubic equation of state, for example, Peng Robinson or Soave-Redlich-Kwong equation (SRK) is appropriate and recommended for gas processing by ASPEN Plus. The Peng Robinson thermodynamic property method is considered and selected as global thermodynamic property method. However, NRTL was selected as thermodynamic property method for amine system. The primary gas/condensate separation takes place in stabilization unit, unit (A) and condensate $\mathrm{C}_{5+}$ product is stabilized. The primary purpose of stabilization unit is to recover the intermediate and heavy $\mathrm{C}_{5+}$ components to generate greater revenues. Figure 3.4 shows ASPEN Plus flowsheet representation of a typical stabilization unit. The feed and products flowrate in $\mathrm{kg} / \mathrm{h}$ are shown in Table 3.2. The recovery of $\mathrm{C}_{5+}$ components in both vapor and liquid phase are clearly seen in Figure 3.5 and Figure 3.6, respectively. The residual sour gas is then fed to Acid gas removal unit where $\mathrm{H}_{2} \mathrm{~S}$ and $\mathrm{CO}_{2}$ are removed using the mixed amine solution. Figure 3.7 shows ASPEN Plus flowsheet representation of a typical Acid gas removal unit. The composition of mixed amine solution is (15 wt\% DEA, $30 \mathrm{wt} \%$ MDEA, $45 \mathrm{wt} \%$ water). The $\mathrm{CO}_{2}$ and $\mathrm{H}_{2} \mathrm{~S}$ mole fraction in the sweet gas stream are 7.9 E-5, and 1.8 E25, as shown in Figure 3.8 and Figure 3.9 respectively. The elemental sulfur is recovered from the $\mathrm{H}_{2} \mathrm{~S}$ rich stream by the conventional straight or split flow Clause process shown in Figure 3.10 and Figure 3.11, respectively. The sweet gas is fed to dehydration unit. Figure 3.12 shows 
ASPEN Plus flowsheet representation of a typical dehydration unit. TEG glycol is used to remove the water content to $9.0 \mathrm{E}-05$ as water mole fraction as shown in Figure 3.13.

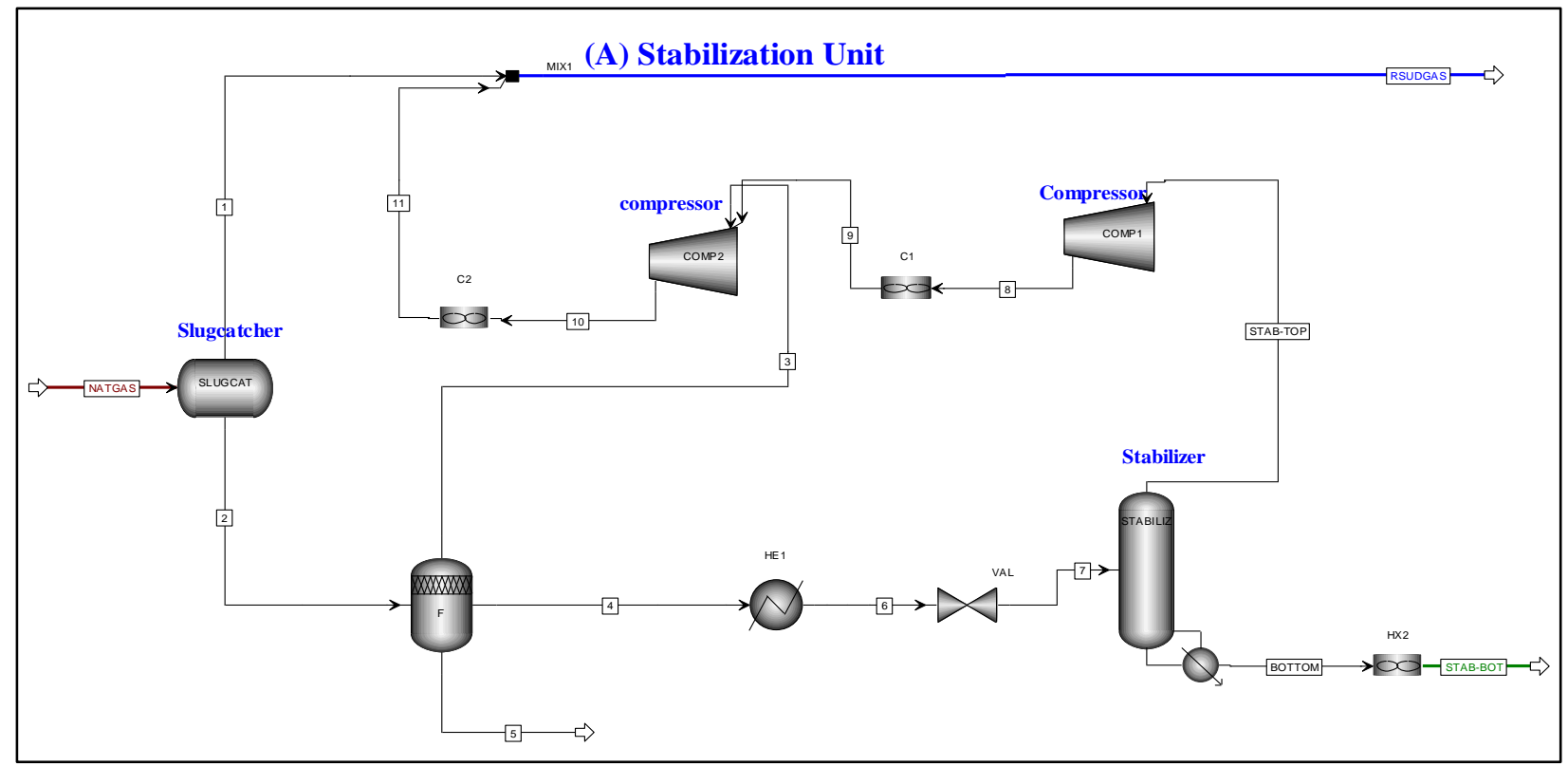

Figure 3.4 ASPEN Plus stabilization unit flowsheet.

Table 3.2 Material balance around stabilization unit (A).

$\begin{array}{lcl}\text { Stream name } & \text { Flow kg/h } & \mathrm{CO} 2 \mathrm{eqKg} / \mathrm{h} \\ \text { NATGAS } & 1515431.29 & 24934640.1 \\ \text { S5 } & 86.5218686 & 0.00551943 \\ \text { RSUDGAS } & 1449807.02 & 24934637.7 \\ \text { STAB-BOT } & 65538.1258 & 0 \\ \text { Net CO2eq.emission } & ---- & -2.43\end{array}$




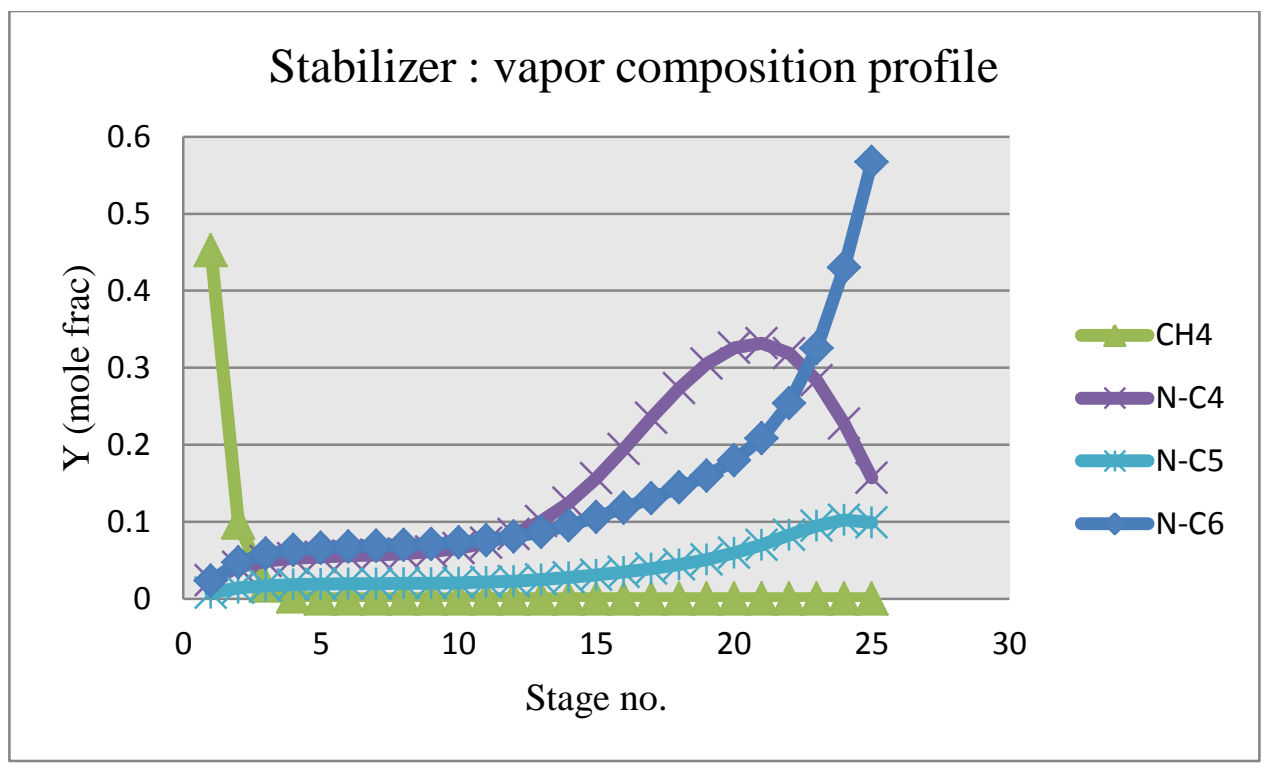

Figure 3.5 Stabilizer vapor composition profile.

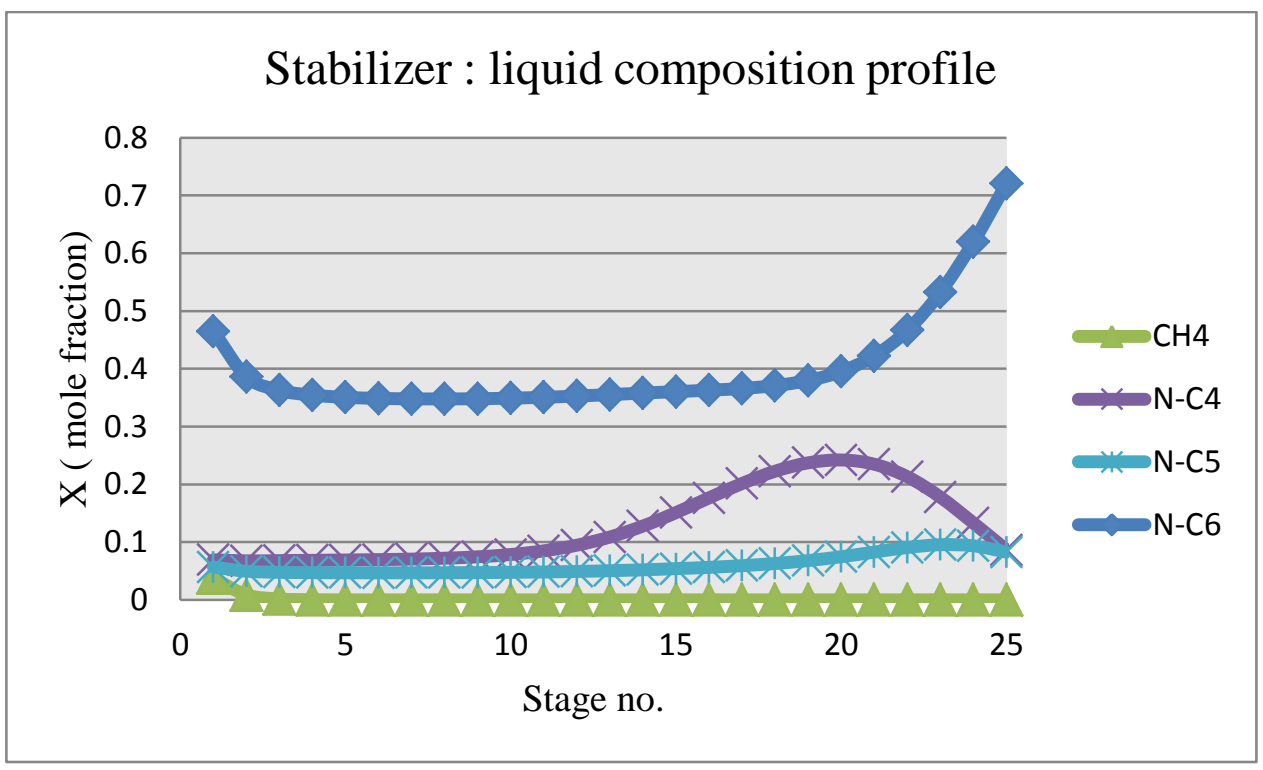

Figure 3.6 Stabilizer liquid composition profile. 
The main purpose of acid gas removal unit (AGRU) is the removal of $\mathrm{H}_{2} \mathrm{~S}, \mathrm{CO}_{2}$ and other impurities to low levels to meet gas specification and prevent plugging and corrosion problems.

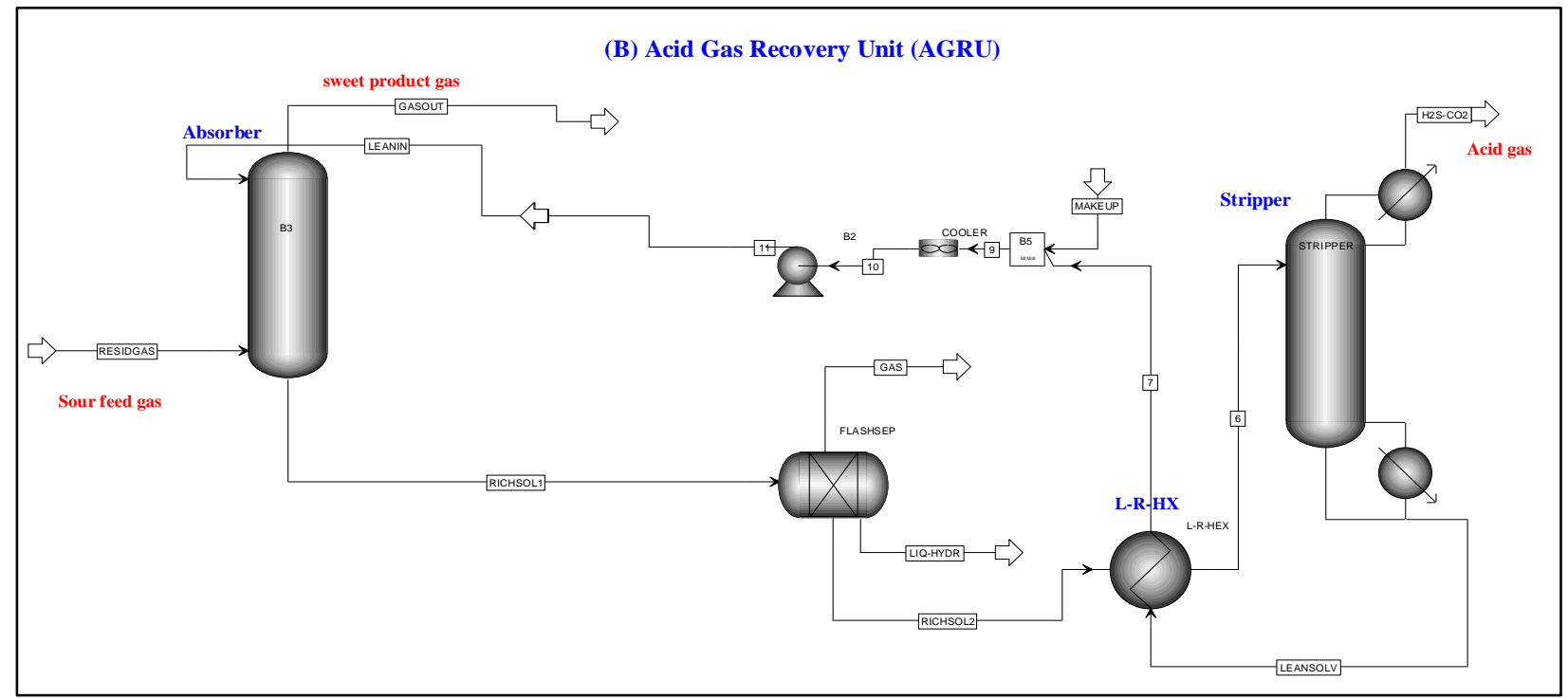

Figure 3.7 ASPEN Plus Acid Gas Removal Unit flowsheet.

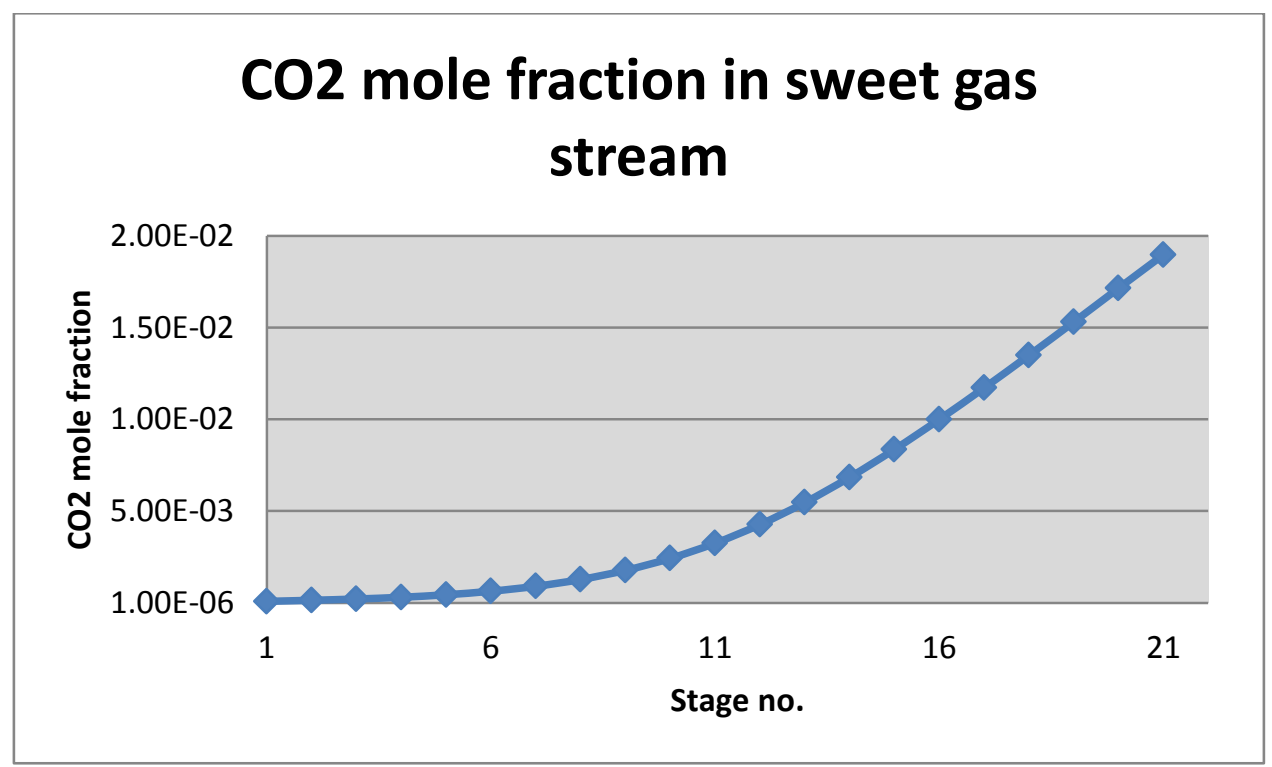

Figure 3.8 $\mathrm{CO}_{2}$ mole fraction profile in the absorber. 


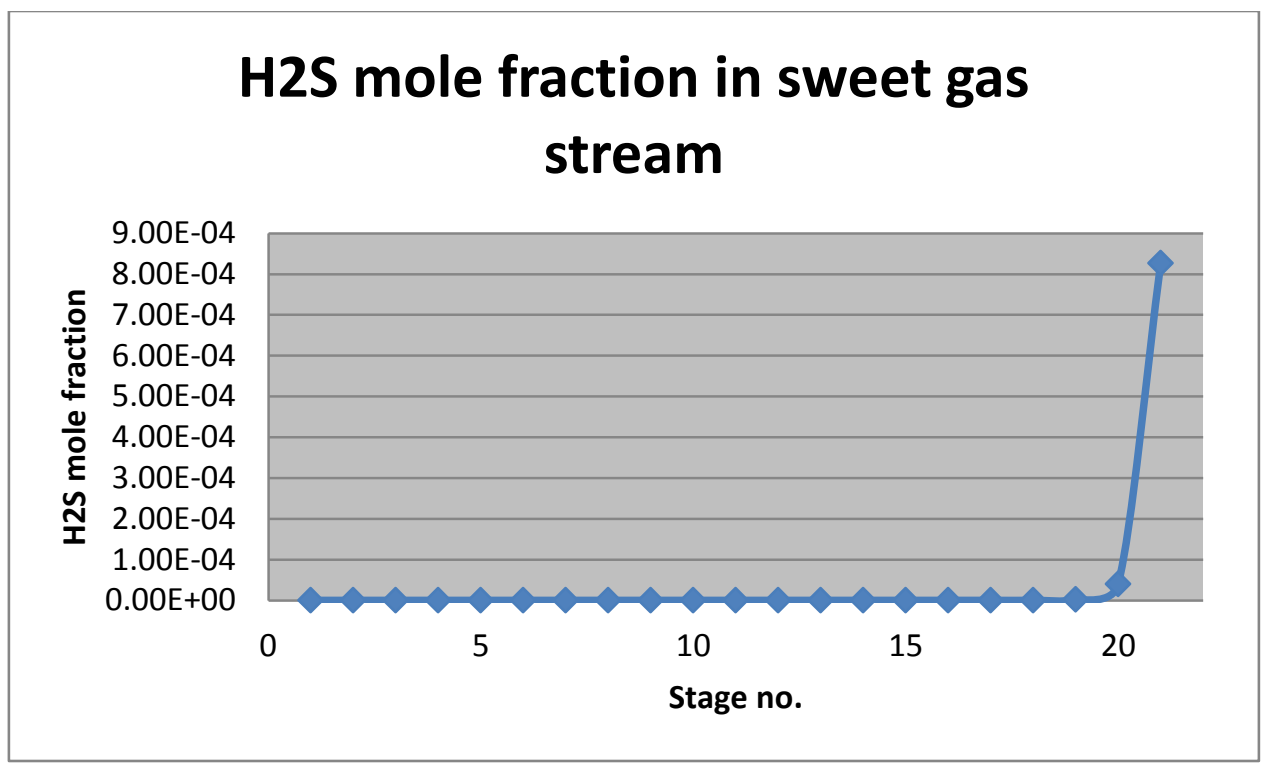

Figure 3.9 H2S mole fraction profile in the absorber. 


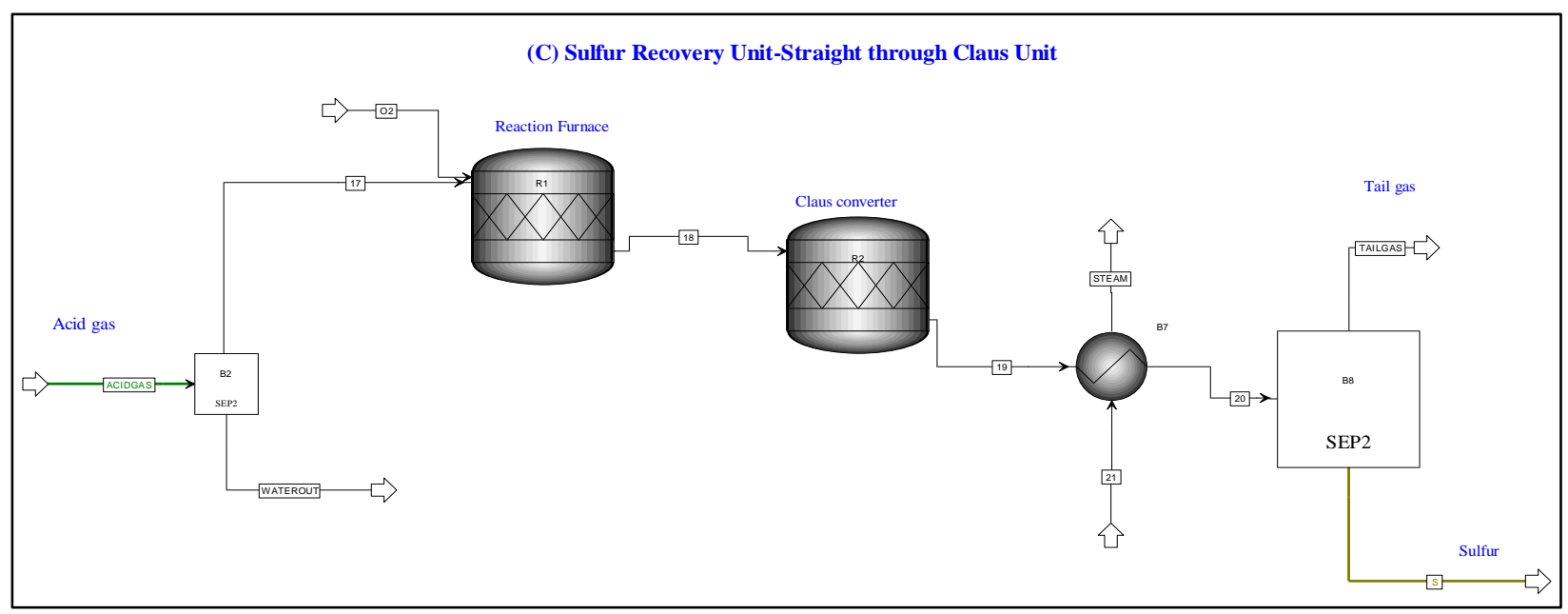

Figure 3.10 ASPEN Plus sulfur recovery unit (straight) flowsheet.

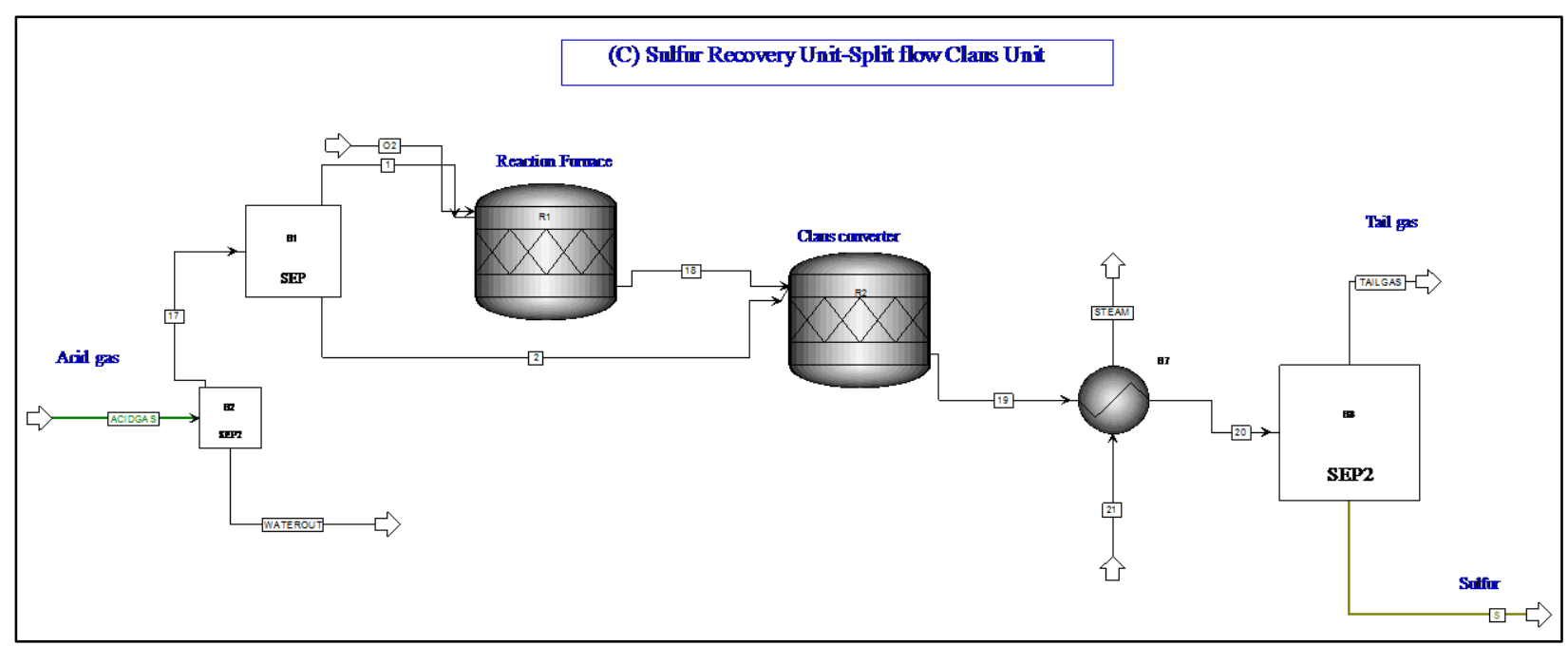

Figure 3.11 ASPEN Plus sulfur recovery unit (split) flowsheet. 


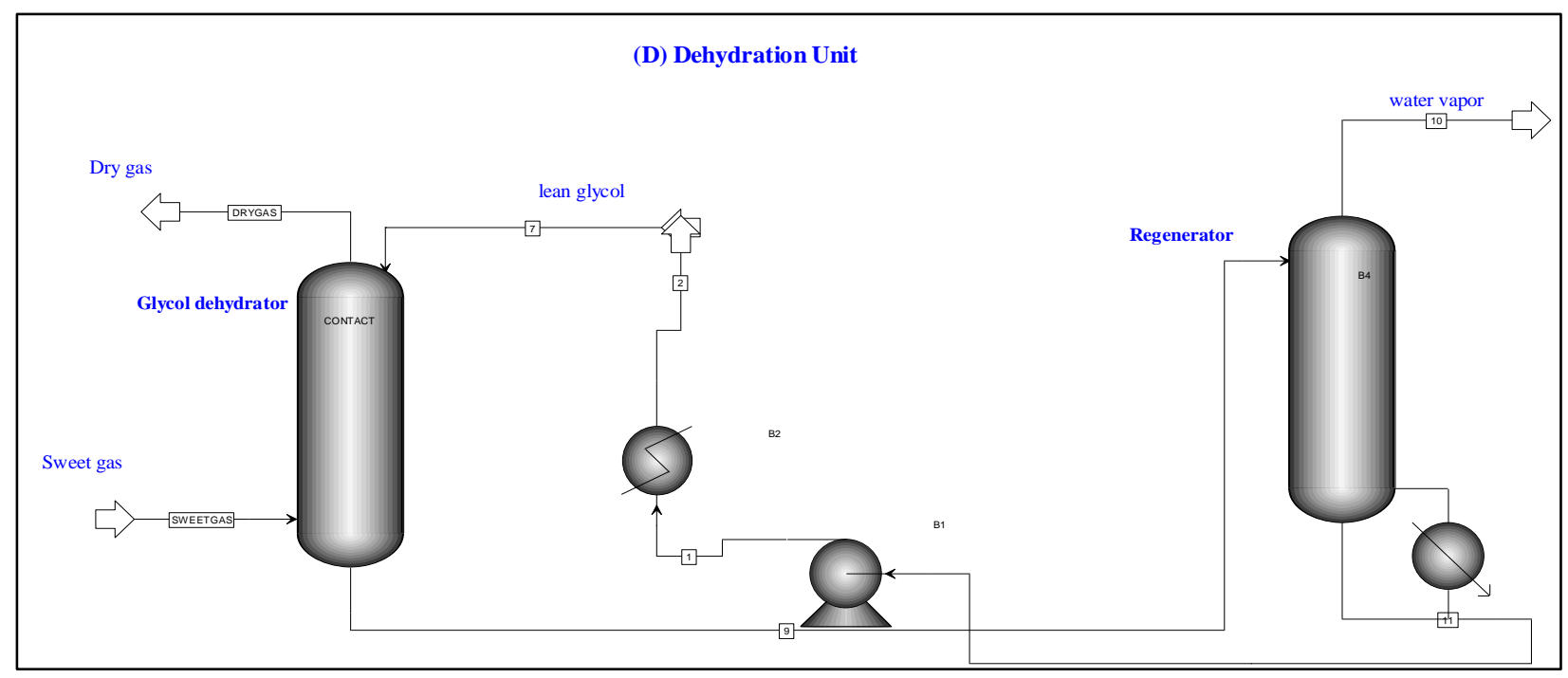

Figure 3.12 ASPEN Plus dehydration unit flowsheet.

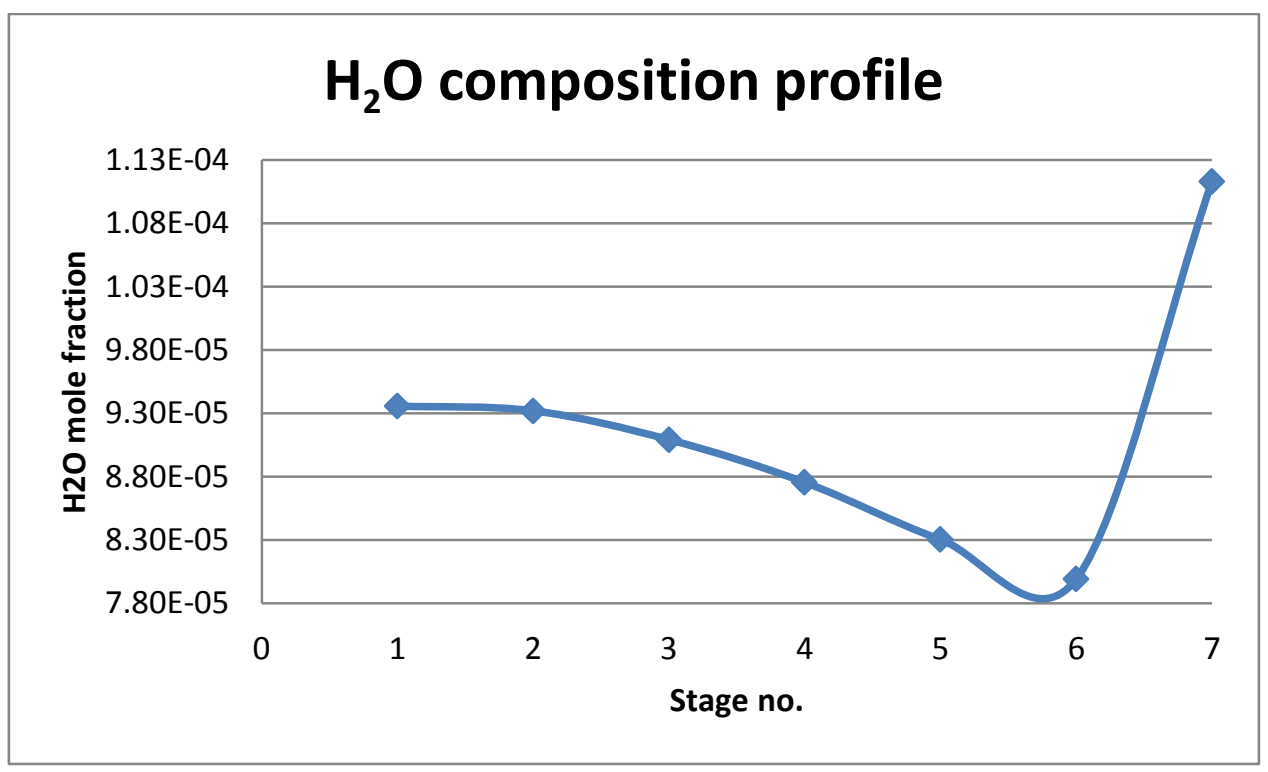

Figure 3.13 $\mathrm{H}_{2} \mathrm{O}$ composition profile in glycol dehydrator. 


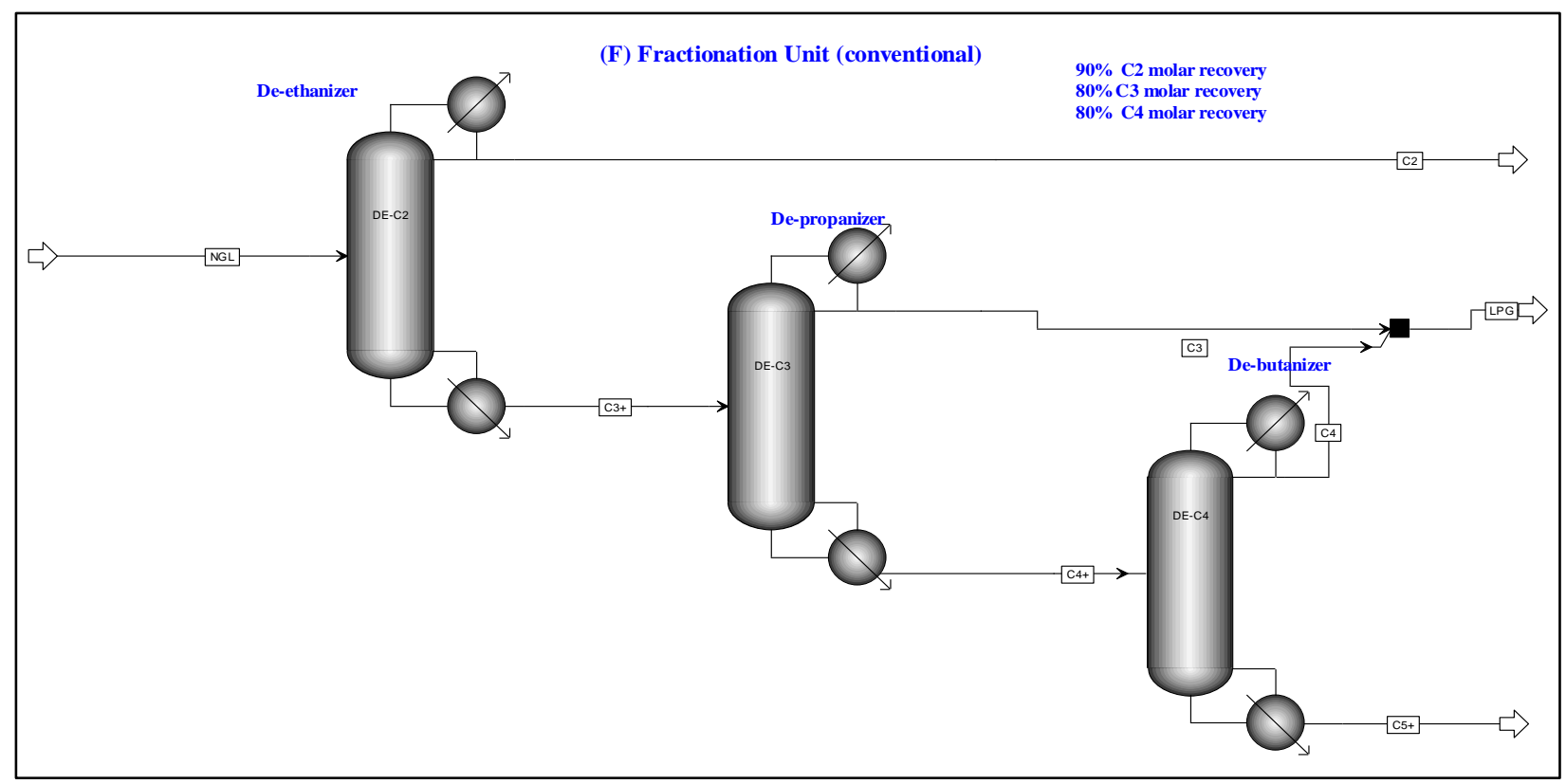

Figure 3.14 ASPEN Plus fractionation unit (conventional) flowsheet.

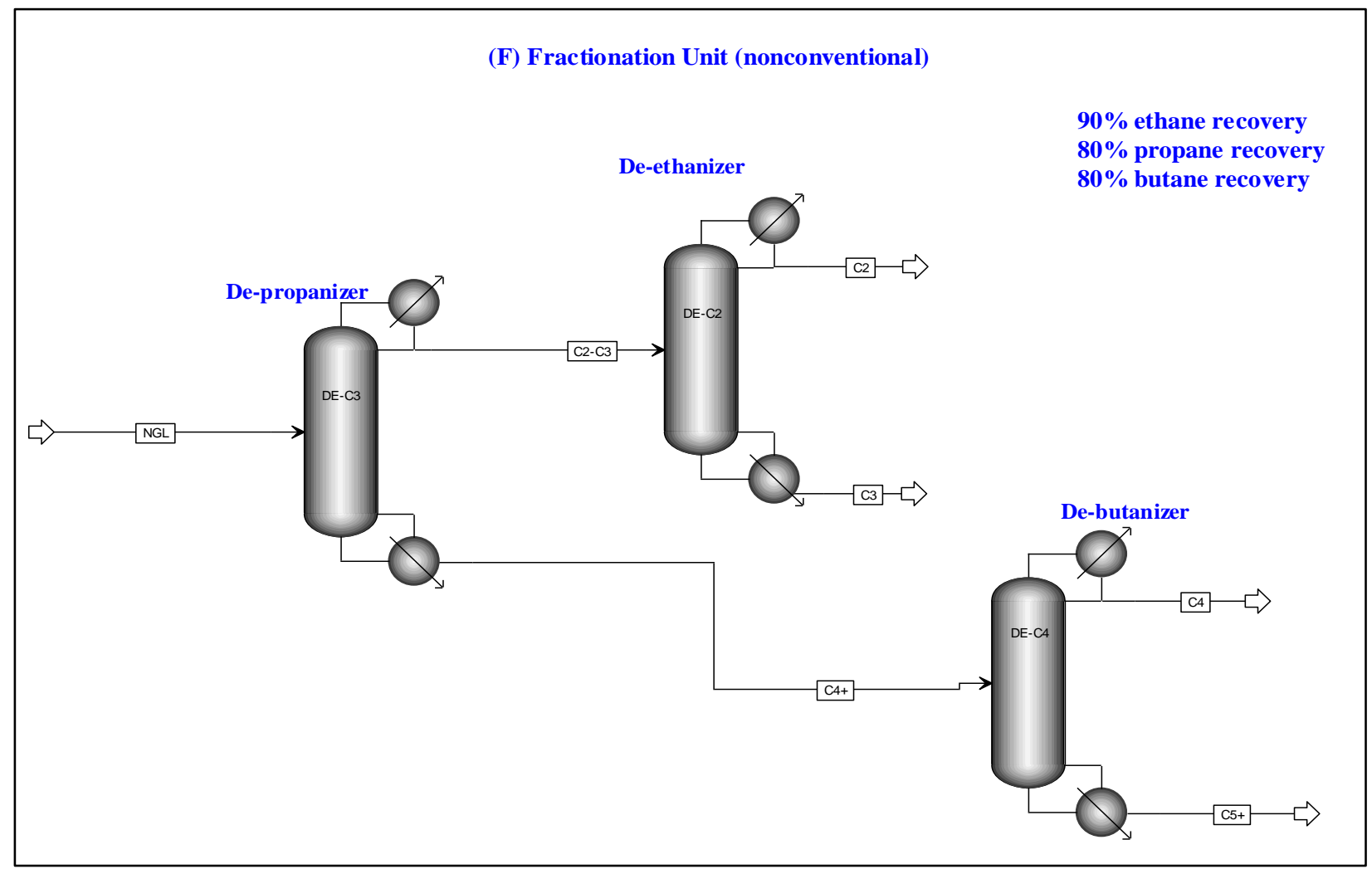

Figure 3.15 ASPEN Plus fractionation unit (nonconventional) flowsheet. 
he sweet dry gas stream is fed to NGL unit where the heavy hydrocarbons and LPG are separated from the gas that is mainly methane. The heavy hydrocarbons are sent to fractionation unit to be separated into ethane, propane, butane, and pentane products as shown in Figure 3.14 and Figure 3.15. The methane gas is liquefied to $-160^{\circ} \mathrm{C}$ using a mixed refrigerant (MR). The optimized MR composition is obtained from (Alabdulkarem, et. al., 2011). Figure 3.16 shows ASPEN Plus flowsheet representation of NGL recovery and liquefaction unit. A detailed discussion about cryogenic processes can be found in (Venkatarathnam, 2008). Then, the nitrogen is rejected to obtain the desired heating value of LNG product. The products mass flowrates and yields for all units are shown in Table 3.4.

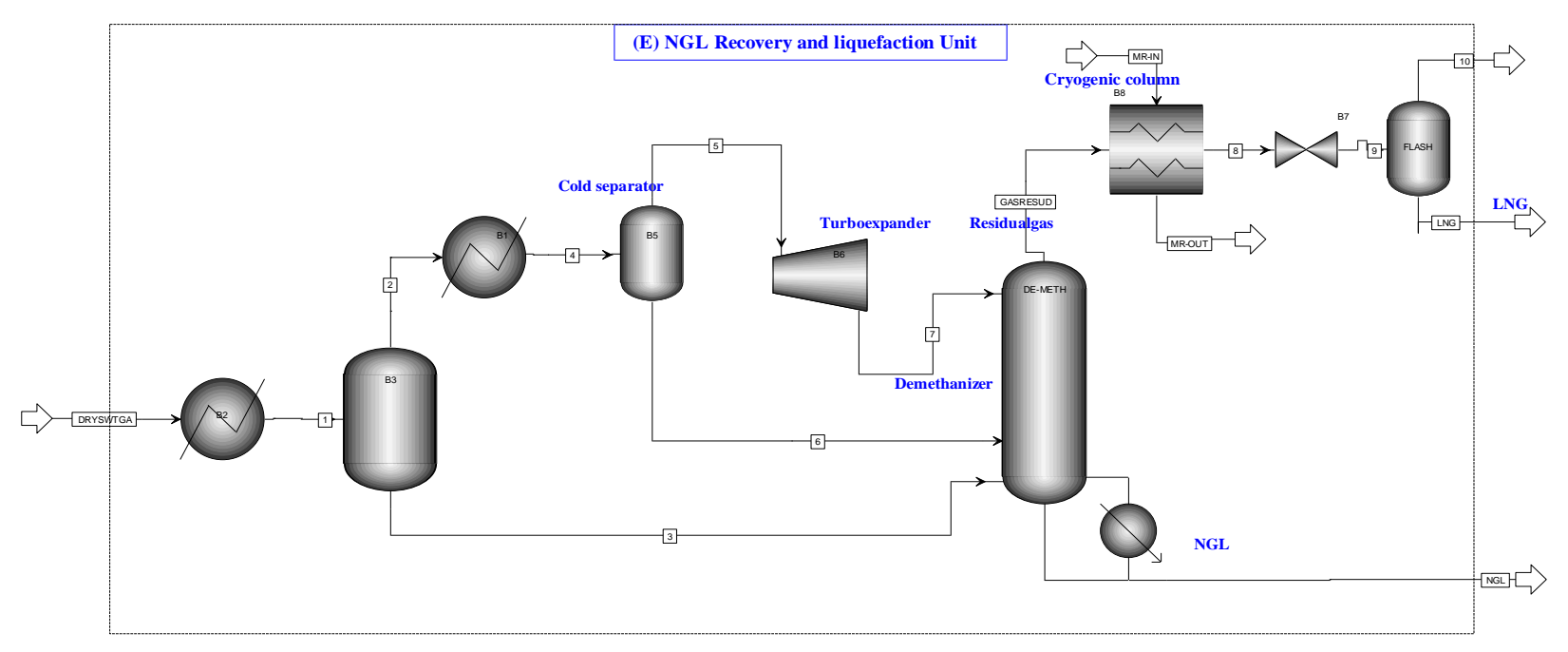

Figure 3.16 ASPEN Plus flowsheet of the NGL and liquefaction unit.

\subsubsection{GTL process simulation}

The GTL process is represented by units (A-F) and units $(\mathrm{G}, \mathrm{J}$ and $\mathrm{L})$ as shown in Figure 3.3. The treated methane gas from unit $(\mathrm{E})$ is preheated, mixed with steam and pure oxygen, and fed 
to Auto-thermal reactor (ATR). The ATR converts the natural gas that is mainly methane, steam, and pure oxygen into a syngas $\left(\mathrm{H}_{2} / \mathrm{CO}\right)$. The ATR reaction scheme is complex, but overall reaction is represented by (A. Steynberg \& Dry, 2004):

$\mathrm{CH}_{4}+3 / 2 \mathrm{O}_{2} \rightarrow \mathrm{CO}+2 \mathrm{H}_{2} \mathrm{O} \quad-\Delta \mathrm{H}_{298}^{\circ}=+519 \mathrm{KJ} / \mathrm{mole}$

$\mathrm{CH}_{4}+\mathrm{H}_{2} \mathrm{O} \leftrightarrow \mathrm{CO}+3 \mathrm{H}_{2} \quad-\Delta \mathrm{H}_{298}^{\circ}=-206 \mathrm{KJ} / \mathrm{mole}$

$\mathrm{CO}+\mathrm{H}_{2} \mathrm{O} \leftrightarrow \mathrm{CO}_{2}+\mathrm{H}_{2} \quad-\Delta \mathrm{H}_{298}^{\circ}=+41 \mathrm{KJ} /$ mole

The ATR is modeled as Equilibrium reactor in ASPEN Plus as shown in Fig. 3.17. For the given natural gas flowrate, the steam to $\mathrm{CH}_{4}$ is set to be 0.6 as the operating ratio. This very low ratio around 0.6, rather than the previously used high ratio of 1.5-2.0, becomes the state-of-the-art syngas ratio for FT application in modern plants in Europe and Middle East (A. Steynberg \& Dry, 2004).

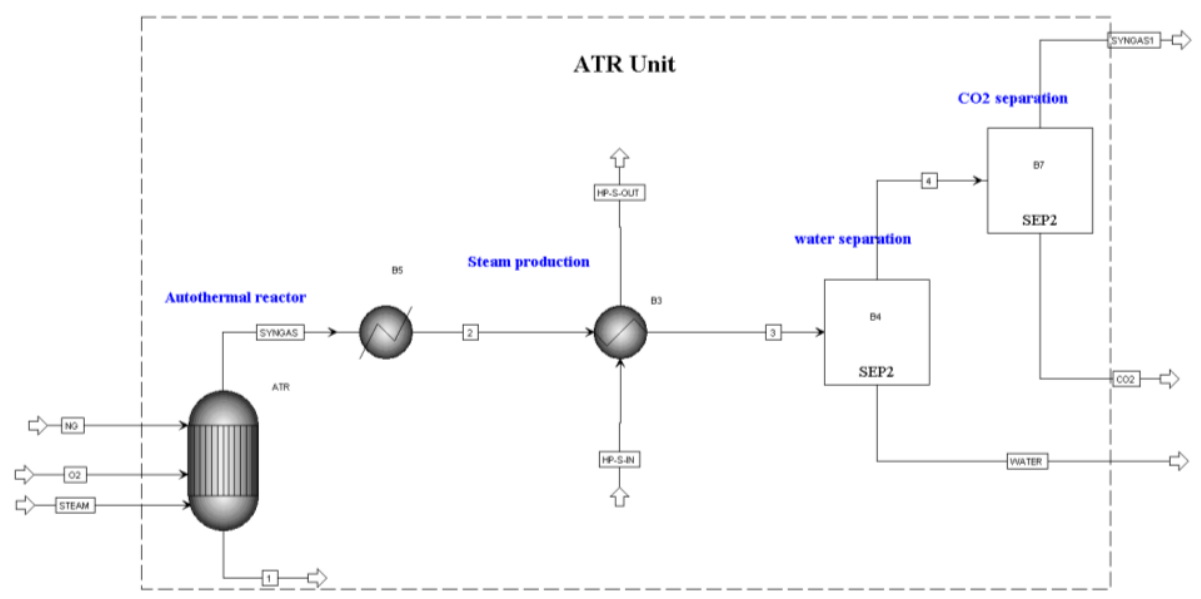

Figure 3.17 ASPEN Plus flowsheet of the ATR unit. 
Now, For the $\mathrm{O}_{2}$ flowrate sensitivity analysis was performed by varying the $\mathrm{O}_{2}$ flowrate to obtain the desired $\mathrm{H}_{2} / \mathrm{CO}$ ratio as seen in Figure 3.18. The syngas $\mathrm{H}_{2} / \mathrm{CO}$ ratio of 2 is achieved by using the ATR with 70,000-72,500 $\mathrm{kmol} / \mathrm{hr}$ as $\mathrm{O}_{2}$ flowrate.

The high syngas temperature is utilized by producing high pressure steam. The syngas is fed to slurry phase FT reactor which is modeled as Yield reactor. The FT reactor operating conditions are $240{ }^{\circ} \mathrm{C}$ and 20 bar. The FT synthesis

$\mathrm{nCO}+2 \mathrm{nH}_{2} \rightarrow\left\{-\mathrm{CH}_{2}-\right\} \mathrm{n}+\mathrm{nH}_{2} \mathrm{O}$

This study is considered as a low- temperature slurry-phase Fischer-Tropsch reactor with cobalt catalyst. The product distribution follows the chain growth probability function known as Anderson-Schulz-Flory (ASF) distribution (A. Steynberg \& Dry, 2004).

$W_{n} / n=(1-\alpha)^{2} \alpha^{n-1}$

Where $W_{n}$ is the mass fraction of the hydrocarbon molecular with carbon number $\mathrm{n}$ and $\alpha$ is the chain growth probability. An alpha value of 0.9 is selected to find the mass fraction of the hydrocarbons as shown in Figure 3.19. FT reactor is assumed to produce only paraffine (no olefin). The hydro-treating/ cracking of the waxes takes place to obtain the final desired products normally LPG, synthetic gasoline and diesel. Table 3.3 gives the theoretical wt\% fraction of syncrude produced from FT reactor for a value of $\alpha=0.9$. The products mass flowrates and yields for all units are shown in Table 3.4. Figure 3.20 shows ASPEN Plus flowsheet of FT synthesis and upgrading unit. 
Table 3.3 Theoretical weight percent of syncrude for a value of $\alpha=0.9$

$\begin{array}{ll}\text { Components } & \text { Weight (wt\%) } \\ \mathrm{C}_{1} & 1 \\ \mathrm{C}_{2} & 1.8 \\ \mathrm{C}_{3}-\mathrm{C}_{4} & 5.346 \\ \mathrm{C}_{5}-\mathrm{C}_{12} & 29.7195 \\ \mathrm{C}_{13}-\mathrm{C}_{18} & 20.108 \\ \mathrm{C}_{19+} & 42.026\end{array}$

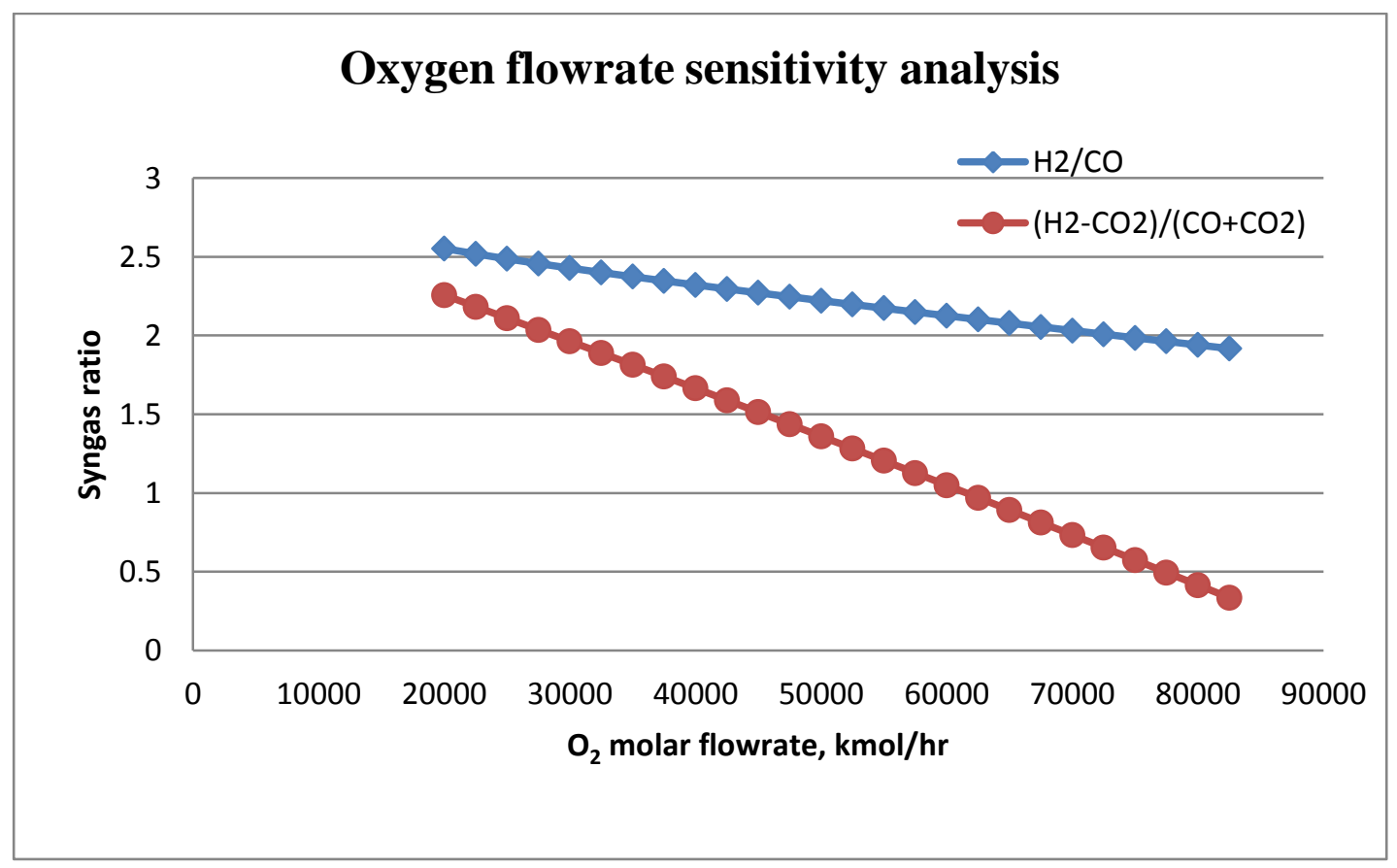

Figure 3.18 Sensitivity analysis for $\mathrm{O}_{2}$ flowrate. 


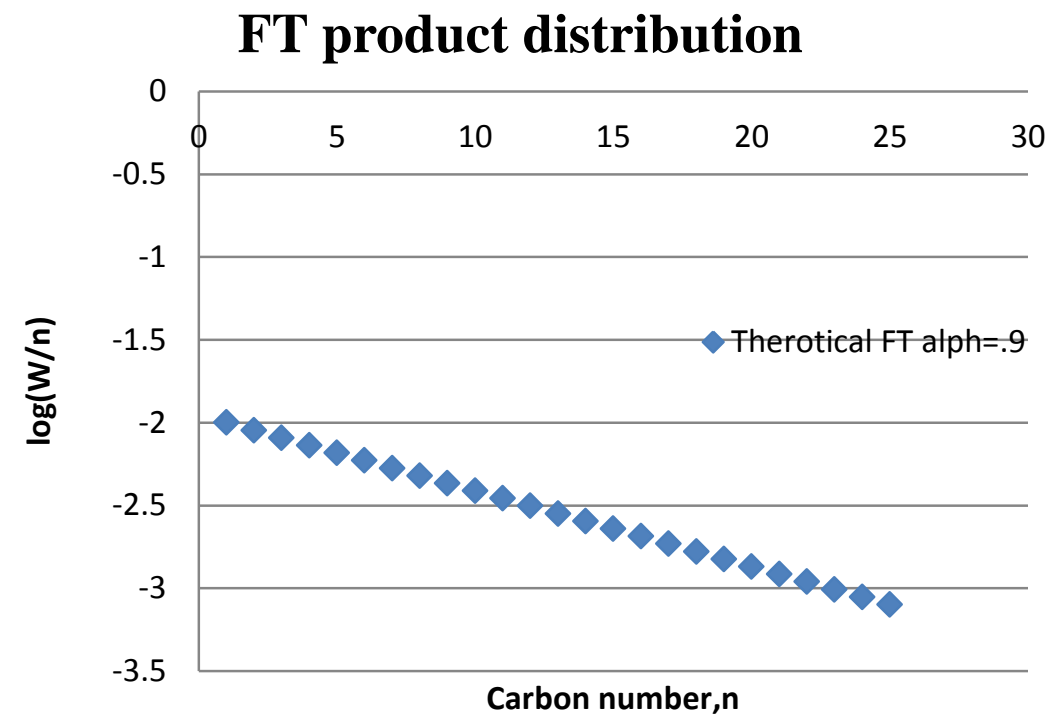

Figure 3.19 FT product wt $\%$ distribution for $\alpha=0.9$.

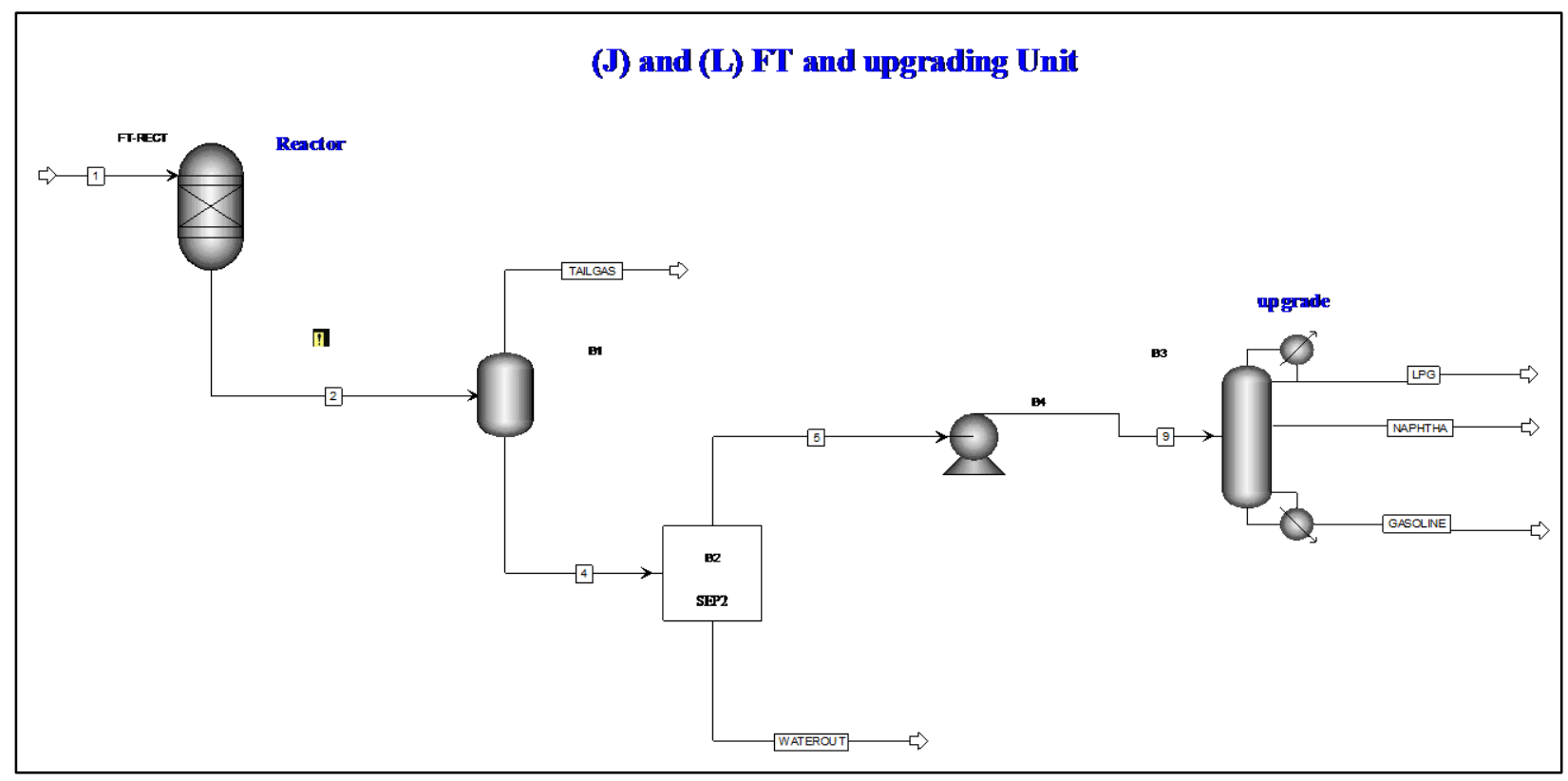

Figure 3.20 ASPEN Plus flowsheet of FT synthesis and upgrading unit. 


\subsubsection{Methanol process simulation}

The methanol process is represented by units (A-F) and units $(\mathrm{G}, \mathrm{K}$ and $\mathrm{M})$ as shown in Figure 3.3. The treated methane gas from unit $(\mathrm{E})$ is preheated, mixed with steam and pure oxygen, and fed to Auto-thermal reactor (ATR) similar to the one used in GTL process. The ATR converts the natural gas that is mainly methane, steam, and pure oxygen into proper syngas stoichiometric ratio $\mathrm{SR}=\left(\mathrm{H}_{2}-\mathrm{CO}_{2} / \mathrm{CO}+\mathrm{CO}_{2}\right)$. Now, one of the advantages of using the rigorous simulation is highlighted by using the sensitivity analysis modelling tool in ASPEN plus. For the $\mathrm{O}_{2}$ flowrate, sensitivity analysis was performed by varying the $\mathrm{O}_{2}$ flowrate to obtain the desired $\mathrm{H}_{2} / \mathrm{CO}$ and SR ratio of 2 for GTL and methanol applications. The syngas $\left(\mathrm{H}_{2} / \mathrm{CO}\right)$ and $\mathrm{SR}$ ratio of 2 is achieved by using the ATR with 72,500 and $27,500 \mathrm{kmol} / \mathrm{hr}$ as $\mathrm{O}_{2}$ flowrate for GTL and methanol applications, respectively as seen in Figure 3.18. The syngas with SR of 2 is fed to methanol synthesis reactor which is modeled as equilibrium reactor. The methanol synthesis typically consists of mainly three reactions, where the two reactions in equation (3.6) and (3.7) are exothermic, with heat of reaction equal to $-21.7 \mathrm{kcal} / \mathrm{mol}$ and $-9.8 \mathrm{kcal} / \mathrm{mol}$, respectively:

$$
\begin{array}{ll}
\mathrm{CO}+2 \mathrm{H}_{2} \leftrightarrow \mathrm{CH}_{3} \mathrm{OH} & -\Delta \mathrm{H}_{298}^{\circ}=-21.7 \mathrm{kcal} / \mathrm{mole} \\
\mathrm{CO}_{2}+3 \mathrm{H}_{2} \leftrightarrow \mathrm{CH}_{3} \mathrm{OH}+\mathrm{H}_{2} \mathrm{O} & -\Delta \mathrm{H}_{298}^{\circ}=-9.8 \mathrm{kcal} / \mathrm{mole} \\
\mathrm{CO}+\mathrm{H}_{2} \mathrm{O} \leftrightarrow \mathrm{CO}_{2}+\mathrm{H}_{2} & -\Delta \mathrm{H}_{298}^{\circ}=11.9 \mathrm{kcal} / \mathrm{mole}
\end{array}
$$

First of all, since the synthesis reactions are highly exothermic, heat released in the synthesis reaction should be either recovered for power generation or absorbed by cooling water to obtain an isothermal operation. Equation (3.8) describes the endothermic reverse water gas shift reaction (RWGSR) that also occurs during methanol synthesis, producing $\mathrm{CO}$ which can be further react with hydrogen to produce methanol. The methanol reactor operating pressures range 
from 50-100 atm and temperatures of $200-300{ }^{\circ} \mathrm{C}$. This low pressure route is the basis for most methanol production processes. Crude methanol leaving the reactor contains water and some impurities depending on feed gas composition, reaction conditions, and type and lifetime of the catalyst, such as dissolved gases (methane, $\mathrm{CO}, \mathrm{CO}_{2}$ ), higher alcohols (ethanol, propanol, butanol) and long-chain hydrocarbons. Methanol is available in three grades of purity: (1) fuel grade, (2) "A" grade, used as a solvent, (3) "AA" grade or chemical grade with highest purity with $99.85 \%$ methanol content (Olah, et. al., 2006). The distillation systems using one or more distillation columns will be used to purify the methanol product. The products mass flowrates and yields are shown in Table 3.4. Figure 3.21 shows ASPEN Plus flowsheet of methanol synthesis and upgrading unit.

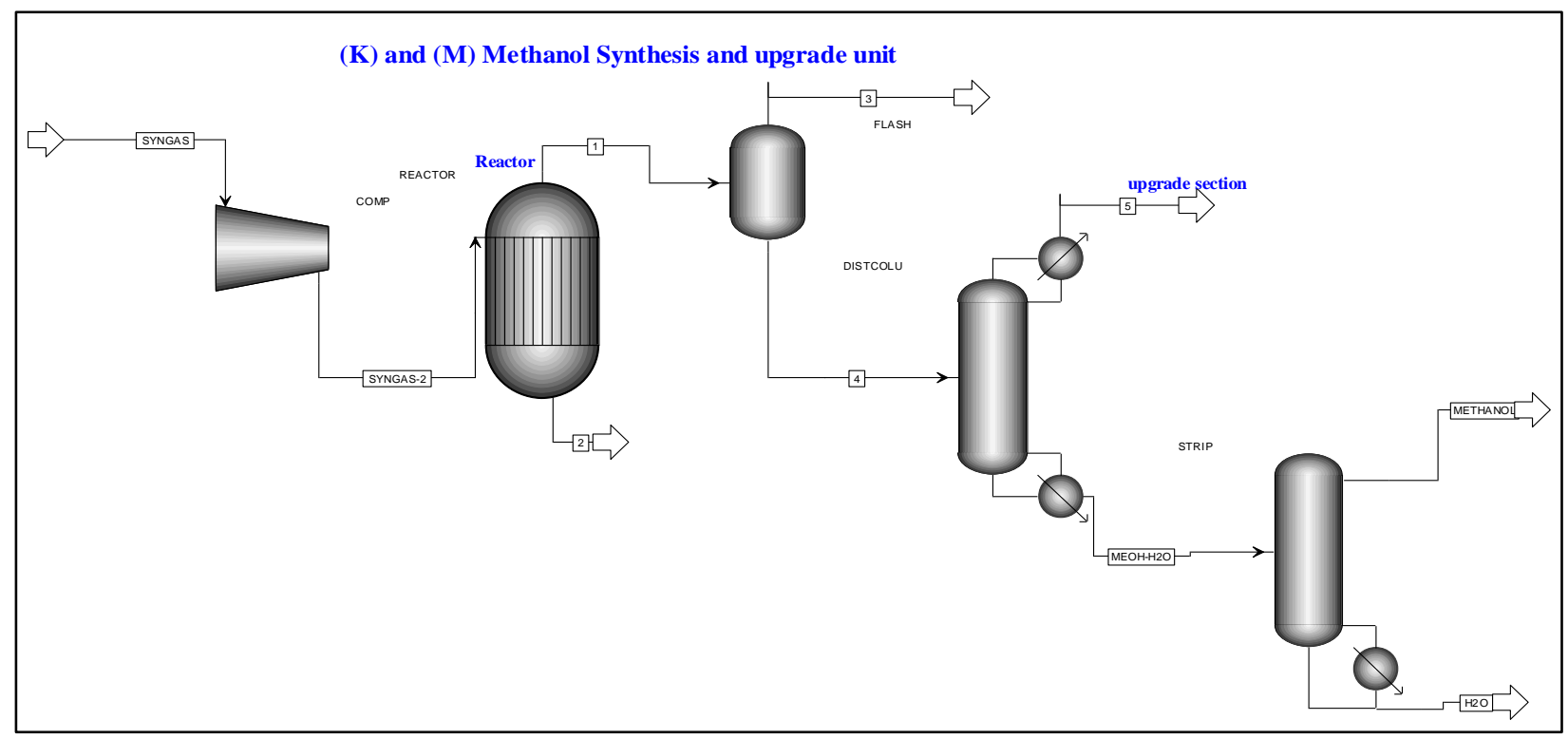

Figure 3.21 ASPEN Plus flowsheet of methanol synthesis and upgrading unit. 
Table 3.4 Products yield and flowrate from LNG, GTL, and methanol processes.

\begin{tabular}{|c|c|c|c|c|}
\hline & NG1 & NG2 & NG3 & Yield $^{*}$ \\
\hline \multicolumn{5}{|l|}{ Product $(\mathrm{kg} / \mathrm{h})$} \\
\hline Sulfur1 & 22,900 & $\begin{array}{ll}---- \\
\end{array}$ & ----- & 0.015 \\
\hline LNG1 & $1,044,157$ & ----- & ----- & 0.69 \\
\hline Ethane1 & 62,800 & ----- & ----- & 0.04 \\
\hline LPG1 & 75,200 & ----- & ----- & 0.05 \\
\hline Plant Condensate1 & 12,700 & $\begin{array}{ll}---- \\
\end{array}$ & $\begin{array}{ll}---- \\
\end{array}$ & 0.01 \\
\hline Field Condensate1 & 64,900 & ----- & ----- & 0.043 \\
\hline Losses**1 & 232,343 & $\begin{array}{ll}---- \\
\end{array}$ & $\begin{array}{ll}---- \\
\end{array}$ & 0.152 \\
\hline Sulfur2 & $\begin{array}{ll}---- \\
\end{array}$ & 22,900 & ----- & 0.015 \\
\hline Ethane2 & $\begin{array}{ll}---- \\
\end{array}$ & 62,800 & $\begin{array}{ll}---- \\
--1\end{array}$ & 0.04 \\
\hline LPG2 & ----- & 114,000 & ----- & 0.075 \\
\hline Gasoline2 & ----- & 227,911 & ----- & 0.15 \\
\hline Diesel2 & ----- & 174,730 & ---- & 0.11 \\
\hline Wax2 & ----- & 99,900 & ----- & 0.07 \\
\hline Plant Condensate2 & ----- & 12,700 & ----- & 0.01 \\
\hline Field Condensate 2 & $\begin{array}{ll}---- \\
---\end{array}$ & 64,900 & ----- & 0.043 \\
\hline Losses**2 & $\begin{array}{ll}---- \\
---\end{array}$ & 735,159 & ---- & 0.48 \\
\hline Sulfur3 & ----- & ----- & 22,900 & 0.015 \\
\hline Ethane3 & ---- & ---- & 62,800 & 0.04 \\
\hline LPG3 & ----- & ----- & 75,200 & 0.05 \\
\hline Methanol & ----- & ----- & 870,000 & 0.574 \\
\hline Field Condensate 3 & ----- & ---- & 64,900 & 0.043 \\
\hline Losses**3 & ----- & ----- & 419,200 & 0.27 \\
\hline $\begin{array}{l}\text { Available NG } \\
\text { supply }(\mathrm{kg} / \mathrm{hr})\end{array}$ & $1,515,000$ & $1,515,000$ & $1,515,000$ & ----- \\
\hline
\end{tabular}

*Yield defined as product flowrate divided by feedstock flowrate

**Losses represent other byproducts such as $\mathrm{CO}_{2}, \mathrm{~N}_{2}$, water, etc. 
Table 3.5 Capital cost, operating cost, and net $\mathrm{CO} 2$ emission of major processing units.

\begin{tabular}{|l|c|c|c|c|}
\hline Key unit & Capital cost & Operating cost & Utilities cost & Net CO2 \\
& $(\$)$ & $(\$ / y r)$ & $(\$ / y r)$ & equiv $^{*}$ \\
\hline Stabilization & $1.21 \mathrm{E}+07$ & $2.55 \mathrm{E}+09$ & $2.36 \mathrm{E}+09$ & $-2.43 \mathrm{E}+00$ \\
\hline Acid gas removal & $3.45 \mathrm{E}+07$ & $3.80 \mathrm{E}+08$ & $3.50 \mathrm{E}+08$ & $1.27 \mathrm{E}+04$ \\
\hline Sulfur recovery & $3.29 \mathrm{E}+06$ & $9.60 \mathrm{E}+05$ & $3.55 \mathrm{E}+04$ & 0 \\
\hline Dehydration & $2.76 \mathrm{E}+07$ & $1.21 \mathrm{E}+07$ & $9.87 \mathrm{E}+06$ & $-9.823 \mathrm{E}-09$ \\
\hline NGL recovery & $1.54 \mathrm{E}+07$ & $2.31 \mathrm{E}+09$ & $2.14 \mathrm{E}+09$ & $1.52 \mathrm{E}-03$ \\
\hline Fractionation & $8.05 \mathrm{E}+06$ & $1.77 \mathrm{E}+09$ & $1.64 \mathrm{E}+09$ & $-2.56 \mathrm{E}-11$ \\
\hline Liquefaction & $7.26 \mathrm{E}+06$ & $1.01 \mathrm{E}+06$ & $3.55 \mathrm{E}+04$ & $-1.31 \mathrm{E}-08$ \\
\hline Syngas production & $3.20 \mathrm{E}+07$ & $2.46 \mathrm{E}+07$ & $2.14 \mathrm{E}+07$ & $-2.33 \mathrm{E}+07$ \\
\hline FT syn. and upgrade & $1.51 \mathrm{E}+07$ & $1.25 \mathrm{E}+08$ & $1.15 \mathrm{E}+08$ & $2.31 \mathrm{E}+05$ \\
\hline Meth. syn. and upgrade & $4.39 \mathrm{E}+07$ & $2.59 \mathrm{E}+08$ & $2.37 \mathrm{E}+08$ & $8.32 \mathrm{E}+05$ \\
\hline Total cost LNG & $1.08 \mathrm{E}+08$ & $7.03 \mathrm{E}+09$ & $6.50 \mathrm{E}+09$ & $1.27 \mathrm{E}+04$ \\
\hline Total cost GTL & $1.48 \mathrm{E}+08$ & $7.17 \mathrm{E}+09$ & $6.63 \mathrm{E}+09$ & $-3.55 \mathrm{E}+07$ \\
\hline Total cost methanol & $1.77 \mathrm{E}+08$ & $7.31 \mathrm{E}+09$ & $6.75 \mathrm{E}+09$ & $-3.49 \mathrm{E}+07$ \\
\hline
\end{tabular}

* Net $\mathrm{CO}_{2}$ equiv value is obtained from Aspen plus and defined as output (products) equivalent minus input equivalent.

ICARUS, cost estimator and analyzer, has been used to evaluate and estimate the cost of the processes. Both the capital and operating cost of key processing units were estimated as shown in Table 3.5. 


\subsection{Conclusions}

A natural gas processing and production network has been designed. The network consists of a set of plants that are of main types LNG, GTL, and methanol. Each typical plant consists of a set of main processing units that are connected in a specified way and this gives the identity to the node in term of consumption of raw materials, production of final products, utility requirements, and environmental impact. Key components of the network include the stabilization, acid gas removal, sulfur recovery, dehydration, NGL recovery, fractionation, Liquefaction, nitrogen rejection, syngas production, FT synthesis, FT upgrade, methanol synthesis, and methanol upgrade units. ASPEN Plus, a simulation package was used to analyze the steady state performance of the network. Comprehensive mass and energy balance from process simulations were obtained. Furthermore, operating parameters were manipulated using different available tools and options such as sensitivity and design spec. $\mathrm{CO}_{2}$ equivalent values were obtained from ASPEN Plus simulation models for each key processing unit. ICARUS, cost estimator and analyzer, has been used to evaluate and estimate the cost of the processes. Both the capital and operating cost of key processing units were estimated for example, $\$ 6.50 \mathrm{E}+09, \$ 6.63 \mathrm{E}+09$, and \$ 6.75E+09 are the annual utilities cost for LNG, GTL, and methanol facilities, respectively. 


\section{CHAPTER FOUR}

\section{LINEAR PROGRAMMING MODEL OF NATURAL GAS PROCESSING AND PRODUCTION NETWORK}

\subsection{Introduction}

Optimization is concerned with selecting the best solution from the entire set of possible solutions. This best solution is either a global one or at least in a local neighborhood. The best solution is called an optimal solution. However, the every possible solution is called a feasible solution. Every optimization problem contains:

(i) At least one objective function to be optimized

(ii) Equality constraints ( equations)

(iii) Inequality constraints ( inequalities)

Or more broadly, mathematical model in optimization theory consists of four key components:

1. Objective function

2. Constraints (also called restrictions) and they are classified into equalities and inequalities

3. Data (also called the constants of a model)

4. Variables ( continuous, discrete)

Though the objective function is used to quantify the best solution described earlier, the constraints both the equality and inequality provide and set the limits and boundaries of possible solutions. The objective function is either maximized or minimized (profit function, cost 
function, etc). Examples of constraints include material and energy balances (equality), capacity limits (inequality), and so on.

According to the type of variables considered, mathematical models for optimization fall into different structure problems

- Linear programming (LP)

- Mixed integer linear programming (MILP)

- Nonlinear programming (NLP)

- Mixed integer nonlinear programming (MINLP)

The remainder of Chapter 4 is organized as follows. In the following section, we will provide a literature review on process modeling and planning in the chemical process industry using LP technique. Then we will mention the problem statement and solution strategy and the proposed model formulation in section 4.3 and 4.4, respectively. In section 4.5, we will illustrate the performance of the model through various industrial-scale natural gas processing and production examples and scenarios. The Chapter ends with some concluding remarks in section 4.6. 


\subsection{Literature Review}

LP is one of several mathematical programming techniques that attempt to solve problems by minimizing or maximizing a function of several independent variables. LP is widely used and efficient enough in analyzing complex industrial systems. LP was first introduced by Dantzig in 1947 to refer to the optimization problems in which both the objective function and the constraints are linear. The standard method to solve LP is the simplex method (Edgar, et al., 2001). LP is aimed to find a solution of a particular class of optimization problems. It is concerned with finding values for a set of variables which maximize or minimize a linear objective function of the variables, subject to a set of linear equality and inequality constraints. LP problems exhibit the special characteristic that the optimal solution lies on some constraints or at the intersection of several constraints. It was highlighted by Biegler \& Grossmann, (2004) that the design and synthesis of processes have been dominated by NLP and MINLP models due to the need for the explicit handling of performance equations, although simpler targeting models give rise to LP and MILP problems. Operations problems, however, tend to be dominated by linear models for example, LP and MILP, for planning, scheduling and supply chain problems.

\subsection{Problem Statement and solution strategy}

Modeling the natural gas supply chain is a challenging task. Therefore, researchers try to model the main two components; production and distribution networks separately. The production network includes both upstream and downstream processing. This technique simplifies the formulation, convergence, and increases the level of accuracy significantly (Zhang \& Zhu, 2000). 


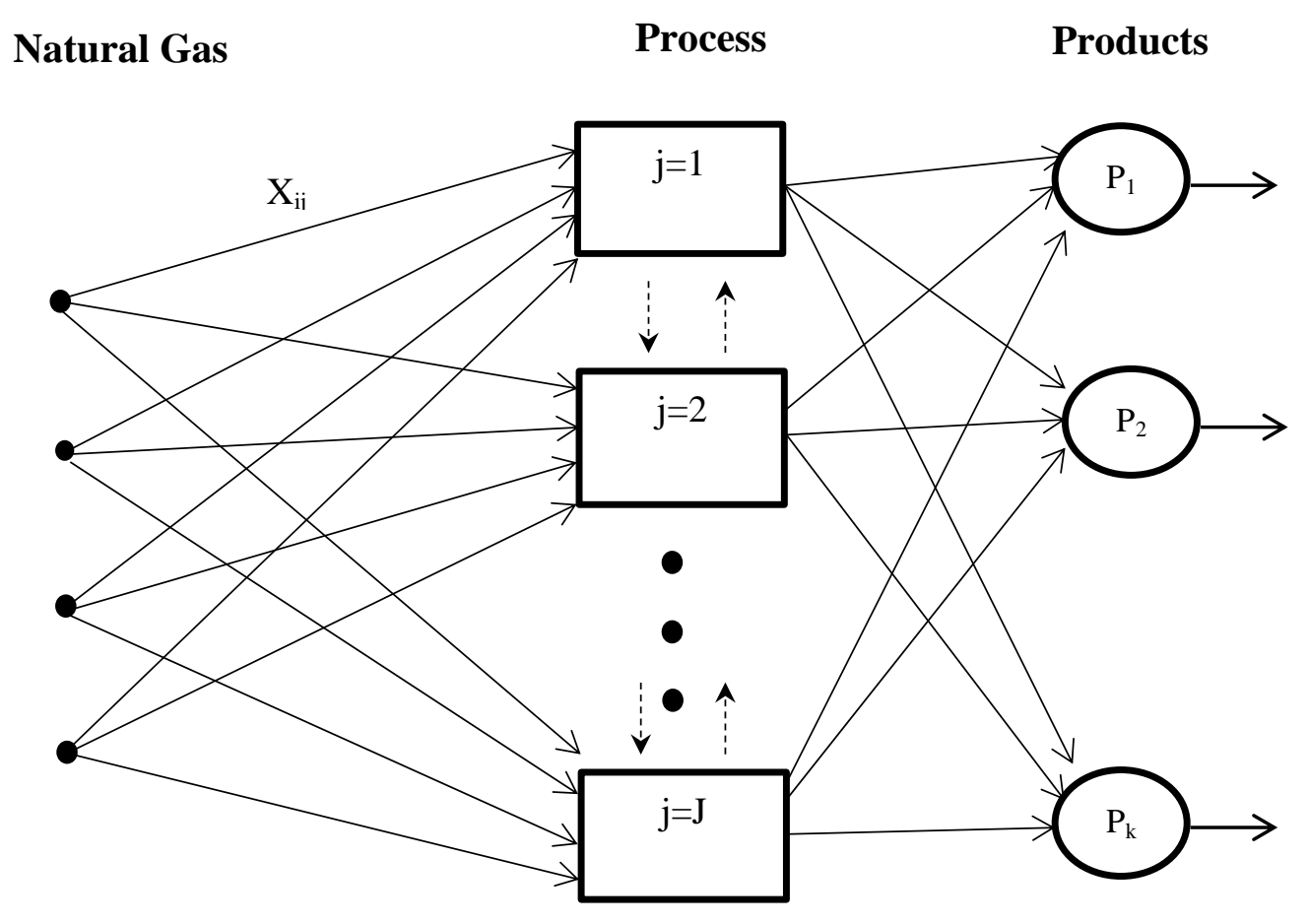

Figure 4.1 A schematic superstructure of natural gas network.

After modeling the processing and production network shown in Figure 4.1, we can simply answer the following questions:

- What is the optimal natural gas flow rate to each process?

- What is the optimal production level of each product? Which process can increase the economic portfolio of processing network? How to plan under the price fluctuations?

- Which process is more sustainable; for example, producing less $\mathrm{CO}_{2}$ emissions? How to make the processing network more sustainable?

- The effect of gas composition on the overall structure and optimal planning strategy? 
- The effect of demand on available capacity and expansion strategy in the processing network?

A natural gas processing and production network consisting of LNG, GTL, and methanol facilities is considered. The network involves the processing of natural gas feedstock to produce different set of main products such as LNG, gasoline, diesel, methanol, and by-products such as, sulfur, LPG, and condensate. The network is envisioned as a set of interconnected nodes representing the main processing units of three facilities. These nodes are connected by arcs that represent the material flows within each facility. The utilization options are specified and the problem boundaries are defined, for example, a specific flow rate, composition, and operating conditions. It is worth mentioning that considering a specific number of utilization processes will just represent the base case. Furthermore, any promising processes can be included in the future planning to address process flexibility. For example, hydrogen as a main product from natural gas, methanol to olefin (MTO) or methanol to gasoline (MTG) production process from methanol (Haid \& Koss, 2001; Wood, et al., 2012) or even hydrogen from methanol. The available technologies as shown in Table 1 are then screened. After consulting some published works and books (Saeid Mokhatab \& Poe, 2012; Olah et al., 2006; Robert \& John, 1998; A. Steynberg \& Dry, 2004; Tusiani \& Shearer, 2007) in natural gas processing industry, the most applicable one is selected for steady state simulation. In other words, we fix the topology of the superstructure for steady state simulation. The use of any process simulators (such as CHEMCAD, Aspen Plus, HYSYS, and PRO/II) will be beneficial at this step. The steady state simulation of the selected process flowsheet is carried out using ASPEN Plus V7.3 version (ASPEN Plus V7.3, 2011). Essentially, the material and energy balances are calculated at this step for each process. Products yield is obtained to be used in the mathematical programming 
step. After the steady state simulation is converged, equipment sizing is estimated. Then, Aspen process Economic Analyzer is used to estimate both the fixed capital and operating costs of each key unit of selected processes to be used in the mathematical model. A mathematical programming model is formulated as detailed in section 4 for optimal operation. The yields obtained from the simulation are used as parameters in the optimization step. The modeling software LINGO version 14.0 (LINGO, 2013) is used to run the model and obtain the optimal results. The solution strategy is depicted in Figure 4.2.

Natural gas feedstock flowrate, composition, etc.

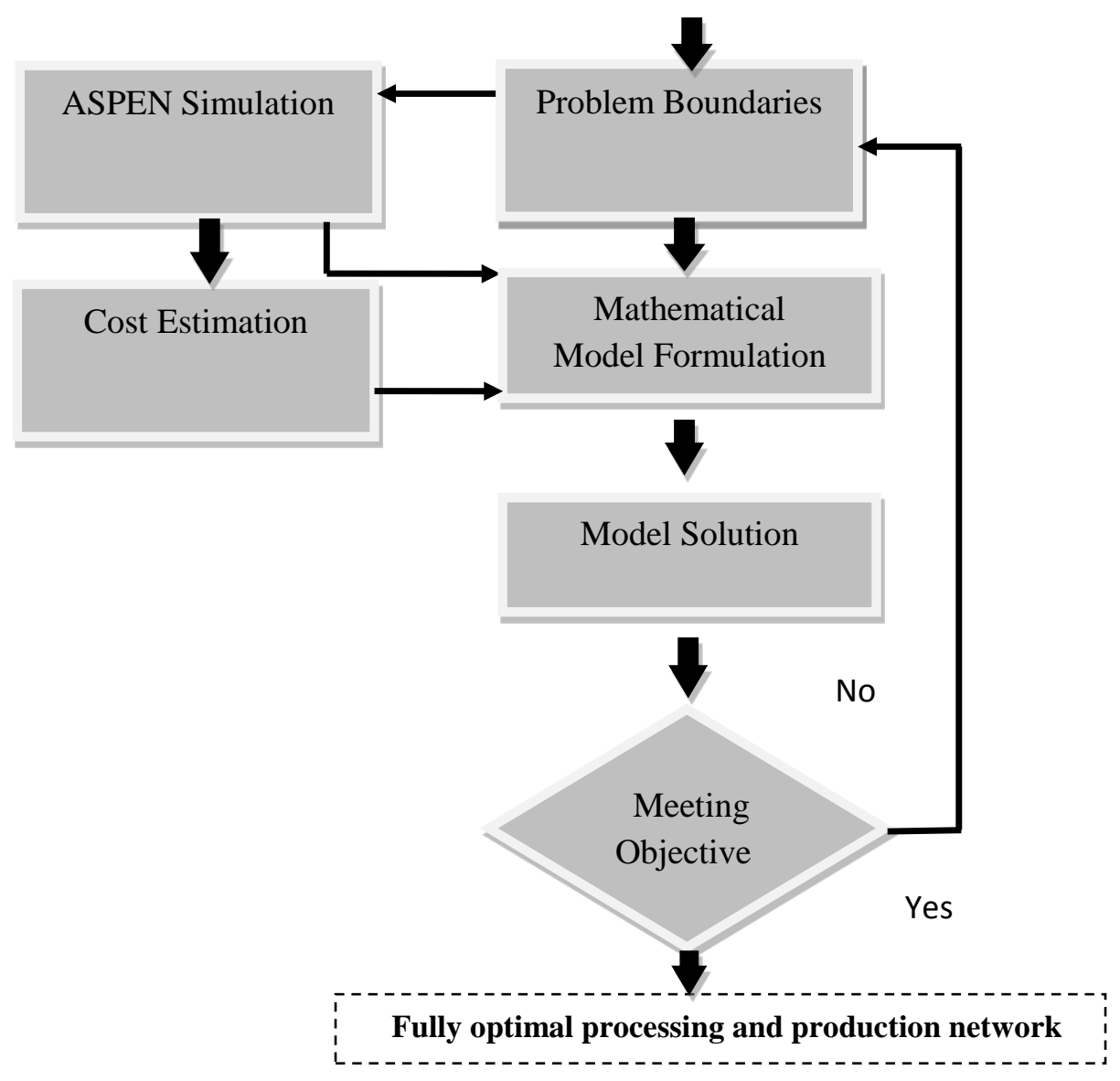

Figure 4.2 A schematic representations of steps in developing optimal structure of network. 
Table 4.1 Possible technology of industrial processing units.

\begin{tabular}{|c|c|c|}
\hline Major Processing Unit & Possible processes / technologies & Selected Process / technology \\
\hline Condensate Stabilization & $\begin{array}{l}\text { (a) Flash Vaporization } \\
\text { (b) Stabilization by Fractionation }\end{array}$ & Stabilization by Fractionation \\
\hline Acid Gas Removal & $\begin{array}{l}\text { (a) Indirect Conversion } \\
\text { (b) Direct Conversion, i,e.(Dry bed } \\
\text { or liquid phase) } \\
\text { (c) Separation Technologies, i,e } \\
\text { (membrane or cryogenic } \\
\text { fractionation) }\end{array}$ & Direct Conversion (liquid phase) \\
\hline Sulfur Recovery & $\begin{array}{l}\text { (a) Gas phase- Claus type } \\
\text { (b) Liquid-phase }\end{array}$ & Gas phase Claus type \\
\hline Dehydration & $\begin{array}{l}\text { (a) Liquid Desiccant (Glycol) } \\
\text { (b) Solid Desiccant } \\
\text { (c) Cooling the gas }\end{array}$ & Glycol \\
\hline NGL Recovery (Extraction) & $\begin{array}{l}\text { (a) Refrigeration Process } \\
\text { (b) Lean Oil Absorption } \\
\text { (c) Solid bed Adsorption } \\
\text { (d) Membrane Separation } \\
\text { (e) Twister Supersonic } \\
\end{array}$ & Refrigeration Process \\
\hline NGL Fractionation & $\begin{array}{ll}\text { (a) } & \text { Direct Sequence } \\
\text { (b) } & \text { Indirect Sequence }\end{array}$ & Direct Sequence \\
\hline Liquefaction & $\begin{array}{l}\text { (a) Pure-refrigerant cascade } \\
\text { (b) Propane-precooled mixed- } \\
\text { refrigerant } \\
\text { (c) Propane-precooled mixed- } \\
\text { refrigerant, with back-end } \\
\text { nitrogen expander-based } \\
\text { (d) Nitrogen expander-based }\end{array}$ & Propane-precooled mixed-refrigerant \\
\hline Reforming (Syngas production) & $\begin{array}{l}\text { (a) Steam Reforming } \\
\text { (b) Adiabatic oxidative reforming } \\
\text { (c) Auto-thermal reforming }\end{array}$ & Auto-thermal reforming \\
\hline FT synthesis & $\begin{array}{ll}\text { (a) Low temperature FT } \\
\text { (b) } \text { High temperature FT } \\
\end{array}$ & Low temperature FT \\
\hline Methanol synthesis & $\begin{array}{l}\text { (a) Quench } \\
\text { (b) Steam raising } \\
\text { (c) Gas cooled (tubular) }\end{array}$ & Quench \\
\hline Product Upgrading & $\begin{array}{l}\text { (a) Direct Sequence distillation } \\
\text { (b) Indirect Sequence distillation }\end{array}$ & Direct Sequence distillation \\
\hline
\end{tabular}




\subsection{Model Formulation}

The gas processing and production network consists of a set of plants or nodes $j \in J$ that are of main types LNG, GTL, and methanol. Each node consists of a set of main processing units that are connected in a specified way and this gives the identity to the node in term of consumption of raw materials, production of final products, utility requirements, and environmental impact as shown in Figure 4.1. In order to propose an appropriate mathematical model we first define the following sets, indices, parameters, and variables:

\section{Sets}

$\mathrm{I}=\{1,2,3, \ldots, \mathrm{I}\}$ which are fed to processing network consisting of different set of processes (nodes)

$\mathrm{J}=\{\mathrm{J} 1, \mathrm{~J} 2, \mathrm{~J} 3, \ldots\}$ where $\mathrm{J} 1=\{\mathrm{LNG}\}, \mathrm{J} 2=\{\mathrm{GTL}\}, \mathrm{J} 3=\{$ Methanol $\}$ producing different set of products

$\mathrm{K}=\{1,2,3, \ldots, \mathrm{K}\}$ by using different utilities $\mathrm{U}=\{1,2,3, \ldots, \mathrm{U}\}$

\section{Variables:}

$\mathrm{X}_{\mathrm{ij}}=$ mass flowrate of natural gas $\mathrm{i}$ feeding process $\mathrm{j}$

$\mathrm{Y}_{\mathrm{jk}}=$ mass flowrate of product $\mathrm{k}$ from process $\mathrm{j}$

$\mathrm{X}_{\mathrm{i}}=\sum_{j=1}^{J} \mathrm{X}_{\mathrm{ij}}=$ total mass flowrate of natural gas fed to processing network

$\mathrm{X}_{\mathrm{j}}=\sum_{i=1}^{I} \mathrm{X}_{\mathrm{ij}}=$ total mass flowrate entering process/node $\mathrm{j}$

Euj= utility requirement per unit feed of unit $\mathrm{j}$ for utility $\mathrm{u}$

Objective function is set to maximize profit, 
Maximize

$\sum_{\mathrm{j}=1}^{\mathrm{J}} \sum_{k=1}^{K} \mathrm{C}_{\mathrm{jk}} \mathrm{Y}_{\mathrm{jk}}-\sum_{\mathrm{i}=1}^{\mathrm{I}} \sum_{j=1}^{J} \mathrm{C}_{\mathrm{ij}} \mathrm{X}_{\mathrm{ij}}-\sum_{\mathrm{j}=1}^{\mathrm{J}} f(X j) \cdot X j-\sum_{\mathrm{j}=1}^{\mathrm{J}} \sum_{u=1}^{U} \mathrm{C}_{\mathrm{u}} \mathrm{g}\left(\mathrm{E}_{u j}\right)$

The objective function is calculated as the sum of product values minus the cost of raw material, the operating cost, and the cost of utility consumption. The function $f\left(X_{j}\right)$ and $g\left(E_{u j}\right)$ are in general nonlinear function with $\mathrm{f}\left(\mathrm{X}_{\mathrm{j}}\right)$ indicating the variable of operating cost with amount produced by unit $\mathrm{j}$ and $\mathrm{g}\left(\mathrm{E}_{\mathrm{uj}}\right)$ indicates the utility consumption function as a function of utility requirement per unit $\mathrm{j}$.

\section{System Constraints:}

The main constraint covering the processing network is the material balance constraint and will be represented by the yield obtained from the steady state simulation.

\section{(1) Supply constraint}

Total natural gas allowable usage from the field per day

$\sum_{i=1}^{I} X_{i j} \leq X_{i}^{U}$

\section{(2) Process capacity constraint}

Lower and upper capacity for each process

$X_{j}^{L} \leq X_{j} \leq X_{j}^{U}$

\section{(3) Demand constraint}

$Y_{k}^{L} \leq Y_{k} \leq Y_{k}^{U}$ 
(4) Material balance: Fixed plant yield

$Y_{k}=\sum_{j=1}^{J} Y_{j k}$

$Y_{j k}=\sum_{j=1}^{J} \sum_{i=1}^{I} Y_{i j} X_{i j}$

(5) Utility consumption constraint

$E_{u j} \leq E_{u}^{U}$

(6) Non negativity constraint

All the variables are positive

\subsection{Illustrative Case Study}

An illustrative case study is presented to show the applicability of the framework proposed earlier. The steady state simulation of the processing and production network was carried out using Aspen Plus as discussed in chapter three. A typical natural gas composition (mol\%) as shown in Table 3.1 with a specific flowrate and operating conditions is used in our analysis. Also, the product yields and flowrate shown in Table 3.3 are used for the implementation of LP model. The model has been solved for different scenarios. 


\subsubsection{Scenario 1: network optimization (base case)}

After carrying out the steady state simulation of LNG, GTL, and methanol processes, the products mass flowrate in $\mathrm{kg} / \mathrm{hr}$, yield, and demand range of LNG, GTL, and methanol processes products are tabulated for the base case conditions in Table 3.3. The economic data are shown in Table 4.2. The LP model has 25 variables and 81 constraints. It has been solved in LINGO 14.0 version. The input file for LINGO can be found in Appendix A1. The optimal values of products flowrate are tabulated in the last column of Table 4.3. It was found that $\$ 219,038$ is the optimal hourly profit as defined by the objective function. Furthermore, 1,550,000, 1,550,000 and $1,550,000 \mathrm{~kg} / \mathrm{hr}$ were the optimal natural gas feedstock flowrate to LNG, GTL, and methanol facilities, respectively. If we decrease the availability of natural gas from 4,650,000 to 4,600,000 per day we found the following results,

Table 4.2 Economic Data

\begin{tabular}{|l|l|}
\hline Natural gas & $\$ 4.4$ per MMBtu \\
\hline Sulfur & $\$ 200$ per ton \\
\hline Ethane & $\$ 10$ per MMBtu \\
\hline LNG & $\$ 7$ per thousand cubic feet \\
\hline LPG & $\$ 2.5$ per gallon \\
\hline Plant Condensate & $\$ 15$ per MMBtu \\
\hline Field Condensate & $\$ 12$ per MMBtu \\
\hline Gasoline & $\$ 2.8$ per gallon \\
\hline Diesel & $\$ 3$ per gallon \\
\hline Wax & $\$ 2$ per gallon \\
\hline Methanol & $\$ 500$ per ton \\
\hline
\end{tabular}




\subsubsection{Scenario 2: natural gas feedstock flowrate incremental}

In this scenario, we consider the increase in natural gas feedstock flowrate by running the simulation for higher flowrate from 1500 to 1800 MMSCFD fed to the stabilization unit. After 1800 MMSCFD, we started to get some converge issues. So, 1800 MMSCFD is the maximum flowrate to be fed to each processing facility. With the new higher flow rate and updated operating and utility cost, it was found that $\$ 155,946.0$ is the optimal hourly profit as defined by the objective function. The lower value of the profit is justified by the higher operating and utilities cost and the fixed demand of the products similar to base case scenario. The input file for LINGO can be found in Appendix A2. If we lower the availability of natural gas feedstock from $5,400,000 \mathrm{~kg}$ per day to $5,200,000$ and $5,100,000$ we find that the hourly net profit is $\$ 41,000$ and $\$-41,500$ respectively. 
Table 4.3 Products yield from LNG, GTL, and methanol processes for base case.

\begin{tabular}{|c|c|c|c|c|c|c|c|}
\hline & NG1 & NG2 & NG3 & Yield" & $\begin{array}{c}\text { Min. } \\
\text { demand }\end{array}$ & $\begin{array}{c}\text { Max. } \\
\text { demand }\end{array}$ & $\begin{array}{c}\text { LINGO } \\
\text { Model's } \\
\text { output }\end{array}$ \\
\hline \multicolumn{8}{|l|}{$\begin{array}{l}\text { Product } \\
(\mathrm{kg} / \mathrm{hr})\end{array}$} \\
\hline Sulfur1 & 22,900 & ----- & ---- & 0.015 & 20,000 & 30,000 & 30000 \\
\hline LNG1 & $1,044,157$ & ----- & ---- & 0.690 & $1,000,000$ & $1,200,000$ & 1009000 \\
\hline Ethane1 & 62,800 & $\begin{array}{l}---- \\
--\end{array}$ & ----- & 0.040 & 60,000 & 70,000 & 60000 \\
\hline LPG1 & 75,200 & ----- & ----- & 0.050 & 70,000 & 80,000 & 80000 \\
\hline Plant Condesate1 & 12,700 & ---- & ---- & 0.010 & 10,000 & 15,000 & 10000 \\
\hline Field Condensate1 & 64,900 & ----- & ----- & 0.043 & 60,000 & 70,000 & 60000 \\
\hline Losses**1 & 232,343 & $\begin{array}{l}---- \\
--1\end{array}$ & ----- & 0.152 & 230,000 & 235,000 & 230000 \\
\hline Sulfur2 & ---- & 22,900 & ----- & 0.015 & 20,000 & 30,000 & 21150 \\
\hline Eathane2 & ---- & 62,800 & ---- & 0.040 & 60,000 & 70,000 & 70000 \\
\hline LPG2 & ----- & 114,000 & ----- & 0.075 & 110,000 & 120,000 & 120000 \\
\hline Gasoline2 & ----- & 227,911 & ----- & 0.150 & 220,000 & 230,000 & 230000 \\
\hline Diesel2 & ---- & 174,730 & ----- & 0.110 & 170,000 & 180,000 & 180000 \\
\hline Wax2 & $\begin{array}{l}---- \\
--\end{array}$ & 99,900 & $\begin{array}{l}---- \\
--\end{array}$ & 0.070 & 95,000 & 100,000 & 100000 \\
\hline Plant Condesate 2 & ----- & 12,700 & ----- & 0.010 & 10,000 & 15,000 & 15000 \\
\hline Field Condensate2 & ----- & 64,900 & ---- & 0.043 & 60,000 & 70,000 & 70000 \\
\hline Losses**2 & ---- & 735,159 & ----- & 0.480 & 733,000 & 735,200 & 733000 \\
\hline Sulfur3 & ---- & ----- & 22,900 & 0.015 & 20,000 & 30,000 & 30000 \\
\hline Eathane3 & $-\overline{----}$ & ----- & 62,800 & 0.040 & 60,000 & 70,000 & 70000 \\
\hline LPG3 & ---- & ----- & 75,200 & 0.050 & 70,000 & 80,000 & 80000 \\
\hline Methanol & $\begin{array}{l}---- \\
--\end{array}$ & $\begin{array}{l}---- \\
--\end{array}$ & 870,000 & 0.574 & 850,000 & 900,000 & 900000 \\
\hline Field Condensate3 & ----- & ----- & 64,900 & 0.043 & 60,000 & 70,000 & 70000 \\
\hline Losses $* * 3$ & ----- & $\begin{array}{l}---- \\
\end{array}$ & 419,200 & 0.270 & 400,000 & 410,000 & 400000 \\
\hline $\begin{array}{l}\text { Available NG } \\
\text { supply(kg/hr) }\end{array}$ & $1,515,000$ & $1,515,000$ & $1,515,000$ & ----- & ---- & $-\cdots-\cdot$ & ---- \\
\hline
\end{tabular}

*Yield defined as product flowrate divided by feedstock flowrate

**Losses represent other byproducts such as $\mathrm{CO}_{2}, \mathrm{~N}_{2}$, water, etc. 


\subsubsection{Scenario 3: natural gas feedstock and product prices incremental}

In this scenario, we consider the increase in both the natural gas feedstock and products prices. As can be seen from Figure 4.7 natural gas price fluctuate a lot from $\$ 2$ to 9 per MMBtu for the period 1994 to 2014 . Thus, we need to consider this by solving the model for $50 \%$ and $100 \%$ incremental from base case prices. The optimal values of products flowrate are tabulated in the last column in Table 3. It was found that $\$ 1,339,721$ and $\$ 2,479,711$ are the optimal hourly profit as defined by the objective function for $50 \%$ and $100 \%$ incremental, respectively. Furthermore, $1,550,000 \mathrm{~kg} / \mathrm{h}, 1,523,666 \mathrm{~kg} / \mathrm{h}$ and 1,526,334 kg/h were the optimal natural gas feedstock flowrate to LNG, GTL, and methanol facilities, receptively for both $50 \%$ and $100 \%$.

The input file for LINGO can be found in Appendix A3.

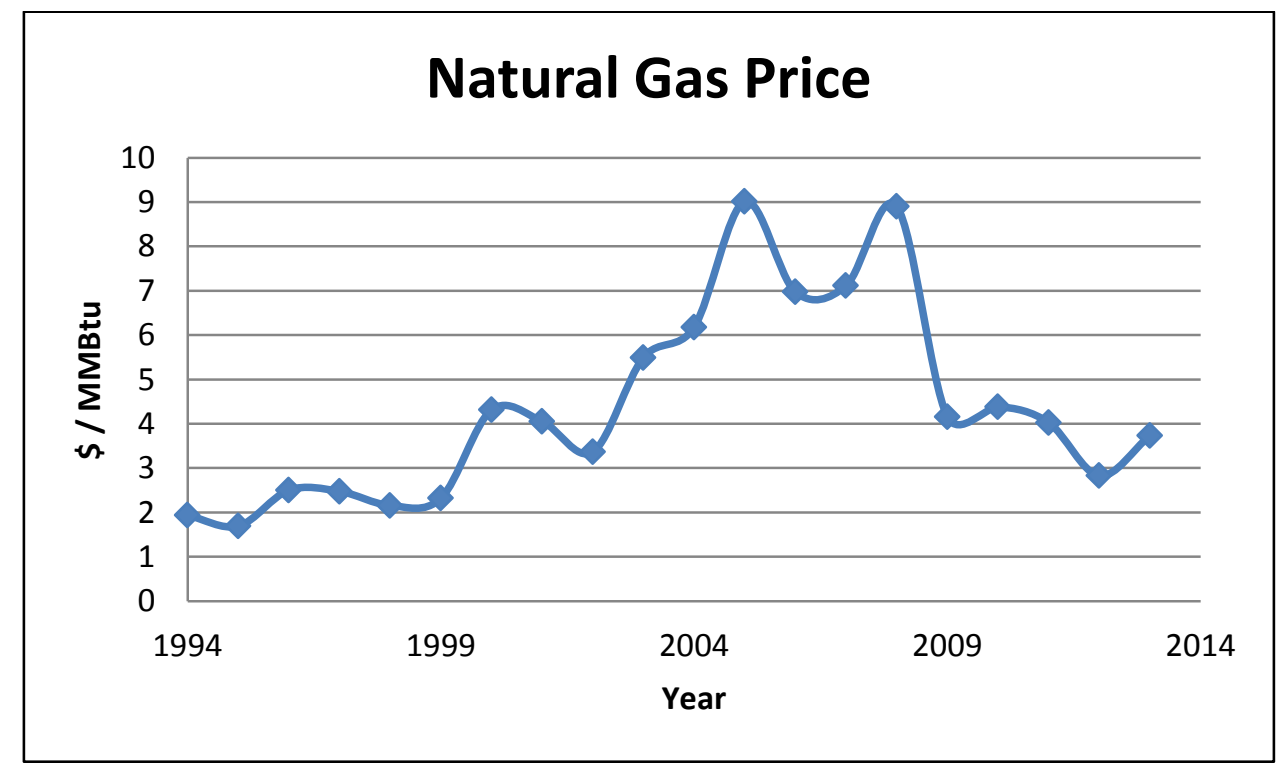

Figure 4.3 Natural gas prices from 1994 to 2014. 
Table 4.4 Results comparison of three studied scenarios.

\begin{tabular}{|lcccc|}
\hline & Scenario 1 & Scenario 2 & \multicolumn{2}{c|}{ Scenario 3 } \\
\hline & & & $50 \%$ & $100 \%$ \\
\hline Sulfur & 71,150 & 60,000 & 60,000 & 60,000 \\
\hline LNG & $1,090,000$ & $1,245,000$ & $1,090,000$ & $1,090,000$ \\
\hline Ethane & 200,000 & 180,000 & 180,000 & 180,000 \\
\hline LPG & 280,000 & 420,000 & 280,000 & 280,000 \\
\hline Plant Condensate & 25,000 & 22,000 & 25,000 & 25,000 \\
\hline Field Condensate & 181,334 & 175,000 & 181,334 & 181,334 \\
\hline Losses**1 & 230,000 & 300,000 & 230,000 & 230,000 \\
\hline Gasoline2 & 230,000 & 220,000 & 230,000 & 230,000 \\
\hline Diesel2 & 180,000 & 222,900 & 180,900 & 180,900 \\
\hline Wax2 & 100,000 & 90,000 & 100,000 & 100,000 \\
\hline Losses**2 & 733,000 & 950,000 & 733,000 & 733,000 \\
\hline Methanol & 900,000 & $1,002,500$ & 900,000 & 900,000 \\
\hline Losses**3 & 400,000 & 500,000 & 400,000 & 400,000 \\
\hline Profit (\$/hr) & 219,037 & 155,946 & $1,339,721$ & $2,479,711$ \\
\hline
\end{tabular}

We observe from Table 4.3 that we can maximize the network's profit by processing more natural gas feedstock and when the products selling price increases by $50 \%$ or $100 \%$ from base case prices. Also, the model solves for lower values for all losses streams because they do not contribute to the processing network's profit. The losses stream from the GTL process is the highest where $\mathrm{CO}_{2}$, and water are produced in large amounts as wasted products. Thus, further consideration of capturing the $\mathrm{CO}_{2}$ and utilizing it within the network and incorporating waste water management will improve the performance significantly. 


\subsection{Conclusions}

Natural gas processing and production network is an important component of natural gas supply chain. So, a general planning model of the network is a legitimate goal. A strategic planning LP model for maximizing the profit of the natural gas processing and production network was presented. In this chapter, the capability and applicability of the proposed model has been shown through the consideration of different planning scenarios to show and help the decision maker in natural gas industry. In our study, all parameters were assumed to be deterministic, for example, availability of natural gas as the raw material; prices of natural gas feedstock, prices of final products and chemicals; production costs; and market demand for finished products. However, the current situation of fluctuating natural gas and crude oil prices and demands requires us to consider the impact of uncertainties. For example, source and availability of natural gas as the raw material; prices of feedstock, chemicals, and commodities; production costs; and future market demand for finished products will have a direct impact on final decisions. Thus, acknowledging the shortcomings of deterministic models, the next phase of investigation should be towards addressing uncertainties in the design problem. 


\section{CHAPTER FIVE}

\section{MIXED INTEGER LINEAR MODEL FOR THE DESIGN AND OPERATION OF NATURAL GAS PROCESSING NETWORK}

\subsection{Introduction}

The main role of gas facility is to process both associated and non-associated gas to produce high-quality natural gas and hydrocarbon liquids products. The gas facility typically consists of many major processing units. For the processing unit, there is no single technology or process configuration that is superior in all aspects. Many process configurations are available for selection and the choice of technologies can be vast. The proper selection of processing units and how they are integrated significantly impact the overall project economics and success. Therefore, for optimal design of the natural gas processing network, process selection of the individual units must be made on the basis of an integrated approach considering the interactions between these units. The main objective of this work is to provide a systematic framework that enables the consideration of many flowsheet alternatives for the superstructure development, and then evaluate them. This is done with the aid of optimization. According to Kallrath's survey of real world problems (Kallrath, 2000), it was highlighted that mixed integer optimization plays an important role in the applications of process industries, such as: production planning (production, logistics, and marketing), process design (chemical process industry, food industry, refineries) and network design (planning, strategic planning). 
Towards this objective, a comprehensive formulated mathematical model is presented. The model helps the decision maker in gas industry to examine and optimally select the most costeffective and environmentally sustainable pathways in processing networks. In general, natural gas processing networks are designed to maximize the profit. Different metrics can also be considered such as, plant capex, plant efficiency, operating cost, $\mathrm{CO}_{2}$ emission, power consumption, products through put, etc.

The novelty of this work comes in two parts; the first part is the consideration of many different alternatives and technologies for the flowsheet representation to develop the superstructure. The second is the consideration of different operating modes, such as variations in operating temperature, pressure for each alternative that impacts the product yields significantly.

The remainder of Chapter 5 is organized as follows. In the following Section the literature review on natural gas offshore and onshore processing is given. Then the problem statement is mentioned and key processing units are descried in Sections 5.3 and 5.4. The model formulation is presented in Section 5.5. In Section 5.6, two examples are presented to illustrate the applicability of the proposed strategy and optimization model. The chapter ends with some concluding remarks in Section 5.7. 


\subsection{Literature review}

The Natural gas supply chain starts with exploration, offshore/onshore processing, storage, and finally distribution to end users/consumers. Depending on the location and quantity being processed, usually offshore processing is preferred for small quantities. Numerous works have been published addressing the offshore processing (Johansen, 2011). For example, Iyer et al., (1998) presented a multi-period mixed-integer linear programming (MILP) model for the planning and scheduling of offshore oil field facilities investment and operation. Their model objective function is to maximize total NPV for long-term planning horizon, and the decision variables in their model are the choice of reservoirs to develop, selection of well sites, the schedule of well drilling and platform installation, capacities of well and production platforms, and the fluid production rates from wells for each time period. Ajay et al,. (2008) developed a nonconvex mixed-integer nonlinear programming model for production allocation in the upstream natural gas supply chain. The model includes realistic pressure flowrate relationships and represents multiple qualities of gas in the network. The model features are inspired by the Sarawak Gas Production System (SGPS) in East Malaysia. Later, Gupta \& Grossmann, (2012) proposed an improved multi-period nonconvex mixed integer nonlinear programming (MINLP) model for a multi-field site with six major extensions and differences. Such as, it includes three components (oil, water, and gas) explicitly in the formulation; nonlinear reservoir behavior in the model is approximated using higher order polynomials, avoiding bilinear and other nonlinear terms, with the objective of maximizing total NPV for long-term planning horizon. This work focuses on onshore processing network. It is important to highlight that this work differs from our previous work with respect to the network representation where the network topology was fixed Al-Sobhi \& Elkamel, (2015). In other words, a specific technology or configuration for the 
processing units was selected for simulation and optimization and no design alternatives were allowed and considered in the analysis. Figure 5.1 shows the natural gas processing network with alternatives. The natural gas enters the processing network at stabilization, unit (A), where different C5+ product qualities can be obtained depending on the operating mode of selected technology. Then, the residual gas enters the acid gas removal, unit (B) for $\mathrm{H}_{2} \mathrm{~S}$ and $\mathrm{CO}_{2}$ capturing. The acid-gas stream enters the sulfur recovery, unit (C) for sulfur recovery and production.

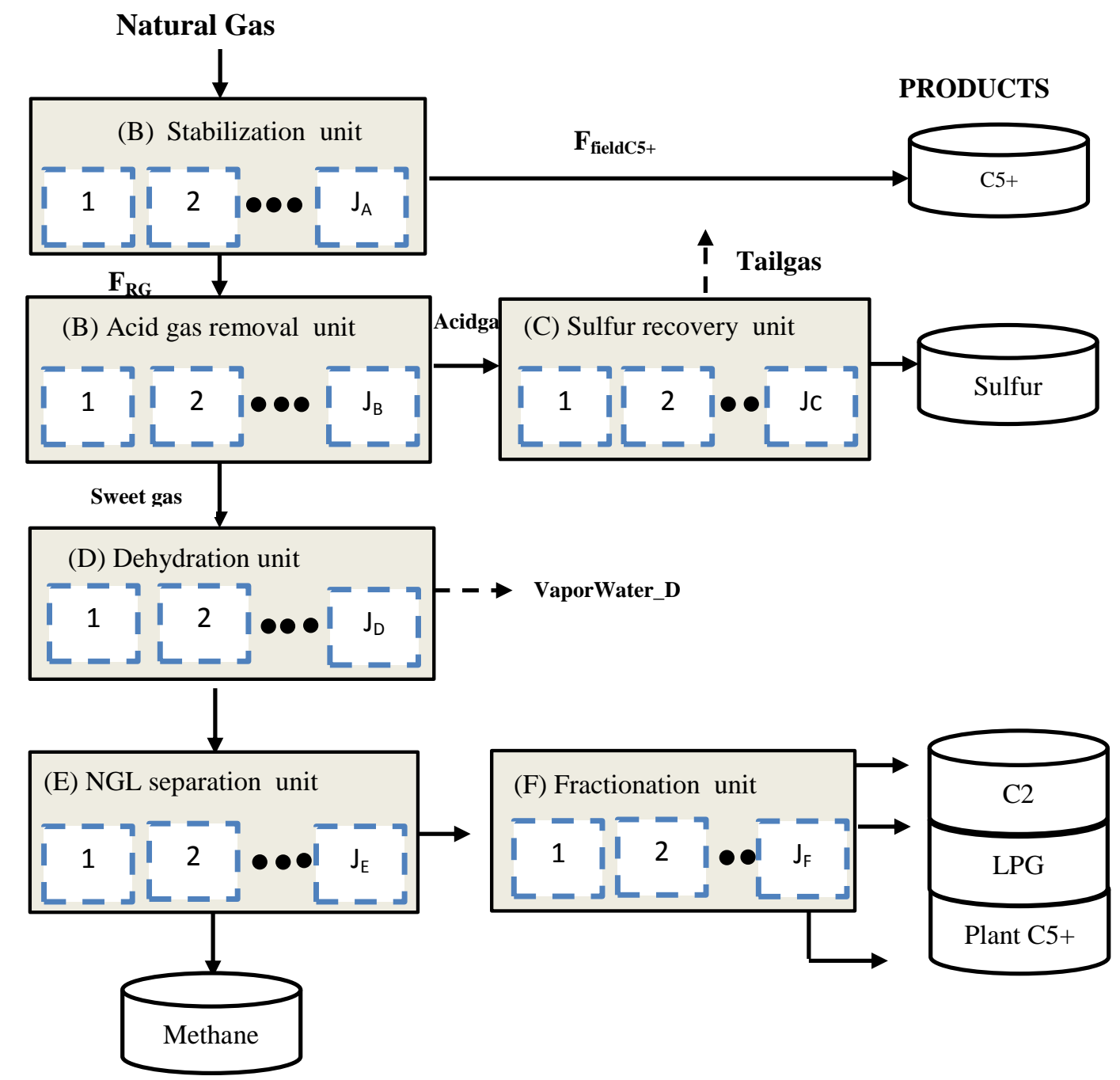

Figure 5.1 A representation of natural gas upstream processing network. 
The sweet-gas stream with required $\mathrm{H}_{2} \mathrm{~S}$ and $\mathrm{CO}_{2}$ concentration level enters the dehydration, unit (D) to remove water to reduce pipeline corrosion and eliminate line blockage caused by hydrate formation. The dehydrated stream enters the NGL recovery, unit (E) to recover NGL products stream which is finally fractionated in unit $(\mathrm{F})$ into ethane, $\mathrm{LPG}$, and plant $\mathrm{C} 5+$ products.

Although the modeling, simulation and optimization of a single natural gas process have been addressed previously, the design and operation of enterprise-wide natural gas processing network, to the best of our knowledge, has not been addressed in the literature to this extent. Also, similar endeavors for the design of processing network have been reported in the literature. Liu et al., (2009) for example, presented a MINLP model for the optimal design of polygeneration energy systems. It is a coal-based polygeneration plant producing electricity and methanol. A suitable superstructure was introduced, based on partitioning a general polygeneration energy system into four major blocks, for each of which alternative available technologies and types of equipment were considered. Schulz et al., (2005) addressed the supply chain optimization of a petrochemical complex. The complex was set to comprise of two natural gas liquid processing (NGL) plants, two ethylene plants, a chlorine plant, a VCM plant, a PVC plant, two polyethylene plants, ammonia and urea plant. They presented and formulated two multi-period mixed integer nonlinear programming (MINLP) models with different levels of rigorousness. Both models were formulated to include production, product delivery, and inventory management. The more rigorous model provides a higher objective function value. The objective function was the maximization of total profit, defined as the difference between sales revenue and the total operating cost plus any penalty for not meeting demands and inventory targets during the given time horizon. Quaglia et al., (2012) presented an integrated business and engineering framework for the synthesis and design of processing networks. The 
framework formulated as MINLP employs a systematic approach to solve simultaneously both the business and the engineering aspects of soybean resources allocation problems, allowing at the same time, comparison of a large number of alternatives at their optimal points. The main unique feature of this work is that it presents a comprehensive mixed integer optimization model to help in selecting the optimal superstructure among the available options for natural gas processing network. It addresses different design alternatives for the main processing units (e.g. different acid gas removal technologies, different sulfur recovery configurations, etc.) in an integrated manner with the variation in the operating conditions and their impact. Another feature is that it focuses on processing network, an important component of natural gas supply chain.

\subsection{Problem statement}

Different factors should be considered prior to the selection of optimal technology, and they can be summarized as follows:

- $\quad$ Feedstock flow rate, composition, pressure, and temperature

- $\quad$ Specification level for product purity and quality

- $\quad$ Process flexibility with regard to feedstock changes

- Capital and operation cost for the process

Given different technological options/alternatives for each processing unit of gas facility as was shown in Figure 5.1, it is desired to design, simulate and optimize the natural gas processing network in order to find the optimal configuration that: 
- $\quad$ Maximizes the products production i,e yield

- $\quad$ Meets the product specification and limits

- $\quad$ Minimizes the capital investment

- $\quad$ Minimizes the operating cost

- $\quad$ Minimizes $\mathrm{CO}_{2 \text { (equivalent) }}$ or $\mathrm{CO}_{2}$ emission

The best practice to establish the optimum design of processing network should be critically examined by taking all the process and environmental limitations into account within a flexible, operable and economically justified window.

\subsection{Key processing units process description}

In this section, the key processing units of the network are described. Although the key processing units were mentioned briefly in Chapter 3, they are described in more details here for their importance in the mathematical formulation. As shown in Figure 5.1, the processing network starts with the stabilization, unit (A) and ends with fractionation, unit (F).

\subsubsection{Stabilization Unit (A):}

The primary purpose of the stabilization unit is to recover the intermediate and heavy $\mathrm{C}_{5+}$ components early from the feedstock to generate revenues. Sale of optimal liquids products maximizes profits by adjusting the fraction of liquids recovered while meeting the specifications for the natural gas. The stabilized liquid has two important characteristics; its vapor pressure and hydrogen sulfide content, for safe and environmental handling, processing, and exportation. The stabilization process can be performed in industry through either flash vaporization or fractionation. The flash vaporization is a simple operation where the feed is flashed through two or three flash tanks. The separation between the vapor and condensate phases occurs due to 
equilibrium principles. Flash vaporization is an old technology and is not used in a modern gas plant (Saeid Mokhatab \& Poe, 2012). However, stabilization by fractionation is a modern and widely accepted in industry. The stabilization is typically carried out in a absorber with a reboiler and internal trays. Moreover, a refluxed distillation tower is used for better separation. The condensate product is sold based on a specified Reid Vapor Pressure (RVP) defined by the customer. The RVP is controlled by manipulating the bottom rebolier temperature. A detailed discussion can be found in Campbell, (2000); GPSA (2004).

\subsubsection{Acid gas removal unit (B):}

The primary purpose of the acid gas removal unit is to reduce the concentration of the acid gases, carbon dioxide $\left(\mathrm{CO}_{2}\right)$ and hydrogen sulfide $\left(\mathrm{H}_{2} \mathrm{~S}\right)$ to very low levels. Natural gas with $\mathrm{H}_{2} \mathrm{~S}$ or other sulfur compounds are called sour gas, whereas gas with only $\mathrm{CO}_{2}$ is called sweet gas. Furthermore, $\mathrm{H}_{2} \mathrm{~S}$ and $\mathrm{CO}_{2}$ are referred to as acid gas components because they form a weak acid when dissolved in water. This is achieved to meet the specification and prevent corrosion and plugging problems. Now, there are four possibilities for natural gas purification processes (Kidnay \& Parrish, 2006):

1. $\mathrm{CO}_{2}$ removal from a gas that contains no $\mathrm{H}_{2} \mathrm{~S}$

2. $\mathrm{H}_{2} \mathrm{~S}$ removal from a gas that contains no $\mathrm{CO}_{2}$

3. Simultaneous removal of both $\mathrm{CO}_{2}$ and $\mathrm{H}_{2} \mathrm{~S}$

4. Selective removal of $\mathrm{H}_{2} \mathrm{~S}$ from a gas that contains both $\mathrm{CO}_{2}$ and $\mathrm{H}_{2} \mathrm{~S}$

Since the acid gases concentration varies from region to region, and the final product specification defined by consumers is different, many purification processes are available for selection as shown in Figure 5.2. Generally, they can be categorized as liquid-phase absorption, solid adsorption, membrane, direct conversion, and cryogenic fractionation. 


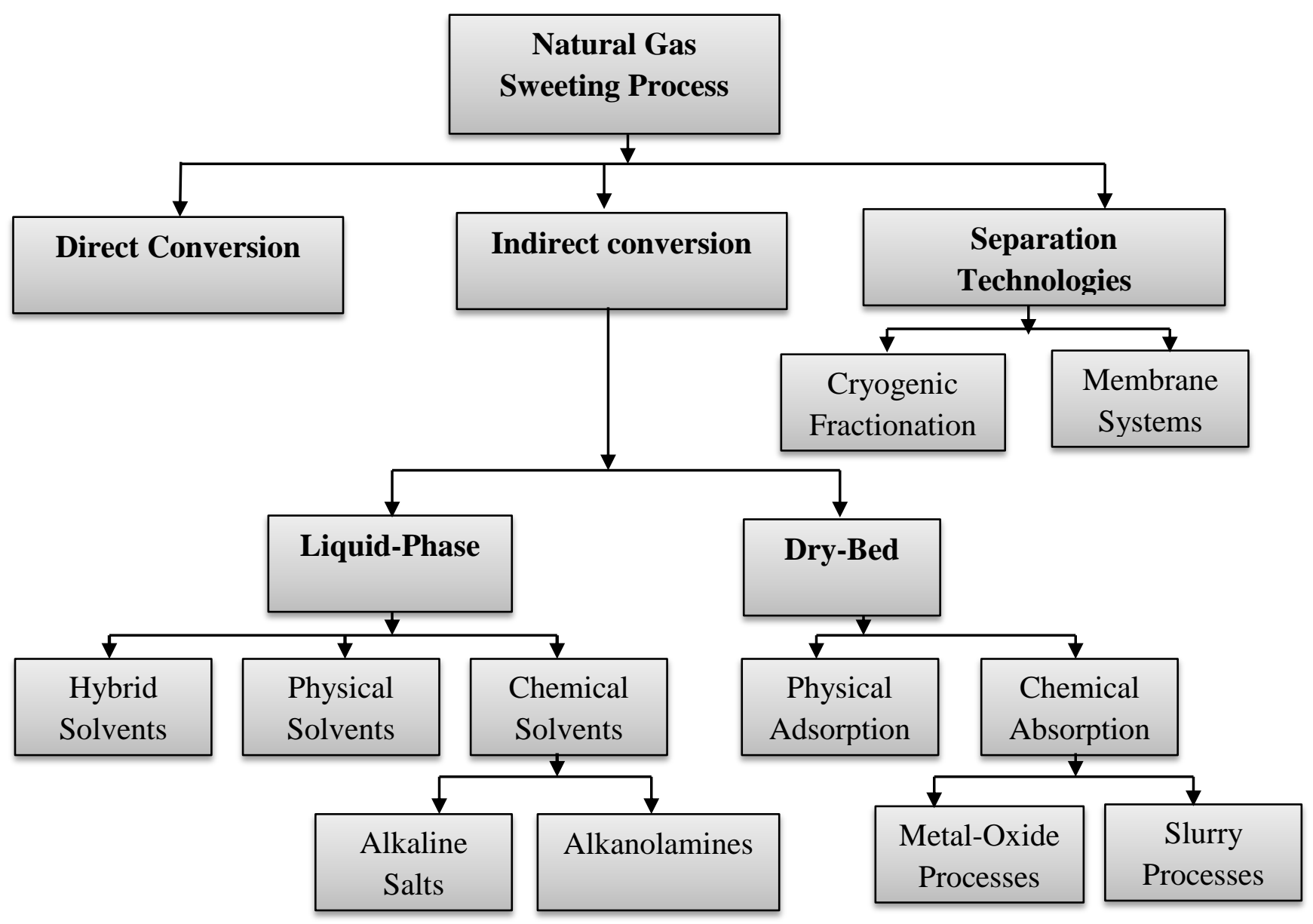

Figure 5.2 Natural gas sweeting processes.

Liquid-phase absorption processes are dominated industrially and classified into three categories: chemical solvent, physical solvent, and hybrid solvent. In the chemical solvent process, absorption of acid gases is achieved mainly by the use of alkanolamines or alkaline salt of various weak acid such as sodium and potassium salts of carbonate. In physical solvent processes, which use an organic solvent, no chemical reaction occurs and acid gas removal depends on physical absorption. Hybrid solvent processes use a mixture of a chemical and physical solvent. In all liquid absorption processes, the two major cost factors are the solvent 
circulation rate, which affects both equipment size and operating costs, and the energy requirement for solvent regeneration. Amines are compounds formed from ammonia $\left(\mathrm{NH}_{3}\right)$ by replacing one or more of the hydrogen atoms with another hydrocarbon group. Amines are categorized as being primary, secondary, and tertiary. Replacement of a single hydrogen produces a primary amine such as monoethanolamine (MEA), and diglycolamine (DGA), replacement of two hydrogen atoms produces a secondary amine such as diethanolamine (DEA), and diisopropanolamine (DIPA), and finally, replacement of all three of the hydrogen atoms produces a tertiary amine such as methyldiethanolamine (MDEA). Primary amines are the most reactive, followed by the secondary and tertiary amines. The amines are used in water solutions in concentrations ranging from approximately 10 to $65 \mathrm{wt} \%$ amines. A detailed discussion may be found in (Campbell, 2000; GPSA, 2004; Kohl \& Nielsen, 1997).

\subsubsection{Sulfur recovery unit $(C)$ :}

The main purpose of the sulfur recovery unit is to convert the $\mathrm{H}_{2} \mathrm{~S}$ component to elemental sulfur. Currently, two options are available for dealing with large quantities of $\mathrm{H}_{2} \mathrm{~S}$ : (1) Disposal of the gas by injection into underground formations (2) Conversion of the $\mathrm{H}_{2} \mathrm{~S}$ into a usable product, elemental sulfur. However, $\mathrm{H}_{2} \mathrm{~S}$ is more commonly converted into elemental sulfur, much of which goes into sulfuric acid production. The conversion of $\mathrm{H}_{2} \mathrm{~S}$ into elemental sulfur is done industrially by the use of the Claus process or one of its modifications. The two modified Claus configurations are: straight through and split flow. The straight-through process is preferred when the feedstock has a high $\mathrm{H}_{2} \mathrm{~S}$ concentration, for instance, up to $55 \mathrm{~mol} \% \mathrm{H}_{2} \mathrm{~S}$; with air or acid gas preheat, it can process 30 to $55 \mathrm{~mol} \% \mathrm{H}_{2} \mathrm{~S}$ in the feed. The split-flow configuration can process feedstock that contains lower concentrations, for example, 5 to 30 mol $\% \mathrm{H}_{2} \mathrm{~S}$. The straight-through process provides the highest sulfur-recovery efficiency (GPSA 
Engineering Data Book, 2004). All Claus units involve two step processes, an initial combustion in a furnace, and then the combustion products pass through a series of catalytic converters, each of which produces elemental sulfur. The overall reaction involves the vapor-phase oxidation of hydrogen sulfide to form water and elemental sulfur, according to the following reaction:

$3 \mathrm{H}_{2} \mathrm{~S}+3 / 2 \mathrm{O}_{2} \rightarrow 3 \mathrm{H} 2 \mathrm{O}+(3 / \mathrm{x}) \mathrm{S}_{\mathrm{x}}$

In practice, the above reaction is carried out in two steps:

$\mathrm{H}_{2} \mathrm{~S}+3 / 2 \mathrm{O}_{2} \leftrightarrow \mathrm{H}_{2} \mathrm{O}+\mathrm{SO}_{2}$

$2 \mathrm{H}_{2} \mathrm{~S}+\mathrm{SO}_{2} \leftrightarrow 2 \mathrm{H}_{2} \mathrm{O}+(3 / \mathrm{x}) \mathrm{S}_{\mathrm{x}}$

The first reaction is a highly exothermic combustion reaction, whereas the second is a more weakly exothermic reaction. A tail gas cleanup unit (TGCU) is often designed and employed to eliminate the last of the sulfur compounds to meet environmental limits. The most commonly used processes are Shell Claus Offgas Treating (SCOT), SUPERCLAUS, and cold-bed adsorption (CBA) (GPSA, 2004).

\subsubsection{Dehydration unit (D):}

The primary purpose of the dehydration unit is to remove the water to reduce pipeline corrosion and eliminate line blockage caused by hydrate formation. The main two processes applied industrially are: absorption and adsorption. Water levels in natural gas can be reduced to the 10 ppmv range in a physical absorption process in which the gas is contacted with a liquid that absorbs the water vapor. In practice, the glycols, ethylene glycol (EG), diethylene glycol (DEG), triethylene glycol (TEG), tetraethylene glycol (TREG) and propylene glycol are the most 
commonly used absorbents; TEG is the glycol of choice in most cases (GPSA Engineering Data Book, 2004).

\subsubsection{NGL separation unit (E):}

The primary purpose of NGL unit is to separate the gas from liquids to reach a specific heating value. Pipeline quality natural gas specifications include limits on sulfur and water content, along with higher heating value, which must be about 950 to $1,150 \mathrm{Btu} / \mathrm{scf}(35,400$ to $42,800 \mathrm{~kJ} / \mathrm{Sm} 3)$ (GPSA, 2004).The process elements involved in hydrocarbon recovery vary, depending upon the desired products and gas volume being processed as well as inlet gas composition and pressure. Broadly, the commercially available technology options for NGL extraction are (1) refrigeration processes, (2) lean oil absorption (3) solid bed adsorption (4) membrane separation (5) Twister supersonic separation. A detailed discussion can be found in (Campbell, 2000; GPSA, 2004).

\subsubsection{Fractionation unit (F):}

The primary purpose of the fractionation unit is to fractionate the liquid into its various components (ethane, propane, isobutene, normal butane, and gasoline) which have a higher market value as purity products. The bottom liquid from the NGL recovery unit is fractionated by heating and passing it through a series of distillation columns. There are many options in designing the order, or the sequence of columns for products recovery. The number of possible sequence or configuration $(\mathrm{S})$ is related to components number $(\mathrm{C})$ by the relation:

S = [2(C-1)!/ C!(C-1)! (Peters, et al., 2004; Seider, et al.,2004). 


\subsection{Mathematical formulation}

The mathematical formulation includes an objective function that maximizes the profit and several model constraints to satisfy products demand, $\mathrm{CO}_{2}$ emission limits, operational restrictions and limitations. The mathematical model consists of set of equalities and inequalities that briefly describe mathematically each block in the superstructure in terms of overall mass balance, yield, quality, different technologies, demand, capacity constraints, and so on.

\subsubsection{Overall mass balance, and yield model}

The overall mass balance, yield, and operating mode of each processing unit are presented starting with the stabilization unit. As mentioned earlier the purpose of stabilization is to maximize the recovery of $\mathrm{C} 5+$ from natural gas feedstock. The product is called field condensate, $F_{\text {fieldc5+ }}$, since it is recovered early from field feedstock.

Overall mass balance around unit (A) is given in equation (5.4),

$F_{\text {Natgas }}=F_{\text {resgas }}+F_{\text {fieldc } 5+}$

Because we need to select just one stabilization technology from available technologies, we have the following constraint equation (5.5),

$\sum_{m \in M_{A}} \sum_{j \in J_{A}} X_{j m}^{A}=1 \quad A=$ stabilization unit

Where, $J_{A}=\{$ set of stabilization technologies $\}$ and

$M_{A}=\{$ set of operating mode for stabilization technologies $\}$

$X_{j m}^{A}=1$ if technology $j$ is selected, at a specific operating mode, $m$, for $A$

$$
=0 \text { otherwise }
$$




$$
F_{\text {Natgas }_{j, m}}=F_{\text {resgas }_{j, m}}+F_{\text {fieldC }_{j, m}+m} \quad \forall j \in J_{A}, m \in M_{A}
$$

Where $j$ indicates technology and $m$ is a set of operating mode for example different pressure and temperature as operating conditions.

The switching constraints are given by equations (5.7) and (5.8), for example,

$F_{\text {resgas }_{j, m}} \leq X_{j m}^{A} * F_{\text {resgas }}^{U} \quad \forall j \in J_{A}, m \in M_{A}$

$F_{\text {fieldC }{ }_{j, m}} \leq X_{j m}^{A} * F_{\text {fieldC5+ }}^{U} \quad \forall j \in J_{A}, m \in M_{A}$

$F_{\text {resgas }}, m=0$ if technology $j$ was not selected, then

$\mathrm{F}_{\text {resgas }_{j, \mathrm{~m}}} \leq \mathrm{F}_{\text {fieldc5+ }}^{\mathrm{U}}$ which is true when $j$ is selected at operating mode, $\mathrm{m}$.

The yield value $y_{A_{j, m}}^{\text {fieldC5+ }}$ in equation (5.9) is obtained from Aspen Plus steady state simulator for selected technology $j$ and at specific operating mode, $m$, and are used as a better approximate to estimate the field condensate flowrate for different natural gas flowrates.

$$
F_{\text {fieldC }{ }_{j, m}}=y_{A_{j, m}}^{\text {fieldC5+ }} * X_{j m}^{A} * F_{\text {Natgas }} \quad \forall j \in J_{A}, m \in M_{A}
$$

The total $F_{\text {fieldc5 }}$ flowrate from the network is given in equation (5.10),

$F_{\text {fieldC } 5+}=\sum_{m \in M_{A}} \sum_{j \in J_{A}} F_{\text {field } 5+{ }_{j, m}}$

The yield value $y_{A_{j, m}}^{\text {resgas }}$ in equation (5.11) is also obtained from Aspen Plus steady state simulator for selected technology $j$ at a specific operating mode $\mathrm{m}$ and is used as better approximates to estimate the field condensate flowrate for different natural gas flowrate.

$F_{\text {resgas }_{j, m}}=y_{A_{j, m}}^{\text {resgas }} * F_{\text {Natgas }} \quad \forall j, m$ 
The total $F_{\text {resgas }}$ flowrate from the network is given in equation (5.12),

$F_{\text {resgas }}=\sum_{m \in M_{A}} \sum_{j \in J_{A}} F_{\text {resgas }_{j, m}}$

The acid gas stream, $F_{\text {acidgas }}$, that is mainly $\mathrm{H}_{2} \mathrm{~S}$ and $\mathrm{CO}_{2}$ is separated from residual gas and overall mass balance around unit (B) is given in equation (5.13),

$F_{\text {resgas }}=F_{\text {sweetgas }}+F_{\text {acidgas }}$

Because we need to select just one acid gas removal technology from available technologies, we have the following constraint equation (5.14),

$\sum_{m \in M_{B}} \sum_{j \in J_{B}} X_{j m}^{B}=1 \quad B=$ acidgas removal unit

Where, $J_{B}=\{$ set of acid gas removal technologies $\}$ and

$M_{B}=\{$ set of operating mode for acid gas removal technologies $\}$

$X_{j m}^{B}=1$ if technology $j$ is selected at a specific operating mode, $m$ for $B$.

$$
=0 \text { otherwise }
$$

$F_{\text {resgas }_{j, m}}=F_{\text {sweetgas }_{j, m}}+F_{\text {acidgas }_{j, m}} \quad \forall j \in J_{B}, m \in M_{B}$

The switching constraints are shown by equations (5.16) and (5.17), such as,

$F_{\text {Sweetgas }_{j, m}} \leq X_{j m}^{B} * F_{\text {Sweetgas }}^{U} \quad \forall j \in J_{B}, m \in M_{B}$

$F_{\text {acidgas }_{j, m}} \leq X_{j m}^{B} * F_{\text {acidgas }}^{U} \quad \forall j \in J_{B}, m \in M_{B}$

The yield values $y_{B_{j, m}}^{\text {sweetgas }}$ and $y_{B_{j, m}}^{\text {acidgas }}$ given in equations (5.18) and (5.19) are obtained respectively, by dividing the sweet gas and acid gas flowrate for selected technology $j$ obtained from Aspen Plus steady state simulator by the total natural gas feedstock flowrate and can be used as an approximate value to estimate the sweet gas and acid gas flowrates for different natural gas flowrates. 


$$
\begin{array}{ll}
F_{\text {sweetgas }_{j, m}}=y_{B_{j, m}}^{\text {sweetgas }} * F_{\text {Natgas }} & \forall j \in J_{B}, m \in M_{B} \\
F_{\text {acidgas }_{j, m}}=y_{B_{j, m}}^{\text {acidgas }} * F_{\text {Natgas }} & \forall j \in J_{B}, m \in M_{B}
\end{array}
$$

The total $F_{\text {sweetgas }}$ and $F_{\text {acidgas }}$ flowrate from the network are given in equations (5.20) and (5.21),

$$
\begin{array}{ll}
F_{\text {Sweetgas }}=\sum_{m} \sum_{j} F_{\text {sweetgas }_{j, m}} & \forall j, m \\
F_{\text {acidgas }}=\sum_{m} \sum_{j} F_{\text {acidgas }_{j, m}} & \forall j, m
\end{array}
$$

Since the $\mathrm{H}_{2} \mathrm{~S}$ and $\mathrm{CO}_{2}$ have a certain specification for LNG and GTL process, $\mathrm{H}_{2} \mathrm{~S}$ removal to $<4$ ppmv for GTL application and $\mathrm{CO}_{2}$ to either 50 ppmv for LNG and possibly up to 1 or $2 \% \mathrm{v}$ for GTL application (Klinkenbijl, 2005), we need to apply the same constraints and equations on them. $\mathrm{H}_{2} \mathrm{~S}$ mass balance around unit (A) is given in equation (5.22),

$F_{\text {Natgas }}^{H 2 S, m}=F_{\text {resgas }_{j, m}}^{H 2 S}+F_{\text {fieldC }^{2}{ }_{j, m}}^{H 2 S}$

The switching constraint are given in equations (5.23-5.24),

$F_{\text {resgas }_{j, m}}^{H 2 S} \leq X_{j m}^{A} * F_{\text {resgas }}^{H 2 S^{U}} \quad \forall j \in J_{A}, m \in M_{A}$

$F_{\text {fieldC5+ }_{j, m}}^{H 2 S} \leq X_{j m}^{A} * F_{\text {fieldC5+ }}^{H 2 S^{U}} \quad \forall j \in J_{A}, m \in M_{A}$

The yield values $y_{A_{j, m}}^{H 2 S r e s g a s}$ and $y_{A_{j, m}}^{H 2 \text { SfieldC5+ }}$ given in equation (5.25-5.26) are obtained from Aspen Plus steady state simulator and can be used as an approximate value to estimate $\mathrm{H}_{2} \mathrm{~S}$ flowrate for different natural gas flowrates.

$$
\begin{array}{ll}
F_{\text {resgas }_{j, m}}^{H 2 S}=y_{A_{j, m}}^{H 2 \text { Sacidgas }} * F_{\text {Natgas }} & \forall j \in J_{A}, m \in M_{A} \\
F_{\text {fieldC }_{+}{ }_{j, m}}^{H 2 S}=y_{A_{j, m}}^{\text {HSsweetgas }} * F_{\text {Natgas }} & \forall j \in J_{A}, m \in M_{A}
\end{array}
$$

The total $F_{\text {resgas }}^{H 2 S}$ and $F_{\text {fieldC5+ }}^{H 2 S}$ flowrate from unit (A) are given in equations (5.27) and (5.28), 


$$
\begin{aligned}
& F_{\text {resgas }}^{H 2 S}=\sum_{m} \sum_{j} F_{\text {resgas }_{j, m}}^{H 2 S} \\
& F_{\text {fieldC }^{H}+}^{H 2 S}=\sum_{m} \sum_{j} F_{\text {fieldC }^{H}+_{j, m}}^{\mathrm{H} S}
\end{aligned}
$$

$\mathrm{CO}_{2}$ mass balance around unit (A) is given in equation (5.29),

$$
F_{\text {Natgas }_{j, m}}^{\text {CO2 }}=F_{\text {resgas }_{j, m}}^{\text {CO2 }}+F_{\text {fieldC5 }_{j, m}}^{\text {CO2 }}
$$

The switching constraint are given in equations (5.30-5.31),

$$
\begin{array}{ll}
F_{\text {resgas }_{j, m}}^{\text {CO2 }} \leq X_{j m}^{A} * F_{\text {resgas }}^{\text {CO2 }}{ }^{U} & \forall j \in J_{A}, m \in M_{A} \\
F_{\text {fieldC }^{C O}{ }_{j, m}}^{\text {CO2 }} \leq X_{j m}^{A} * F_{\text {fieldC }^{C O}+}^{\mathrm{CO}^{U}} & \forall j \in J_{A}, m \in M_{A}
\end{array}
$$

The yield values $y_{A_{j, m}}^{\text {CO2resgas }}$ and $y_{A_{j, m}}^{\text {CO2fieldC5+ }}$ given in equation (5.32-5.33) are obtained from Aspen Plus steady state simulator and are used as better approximate values to estimate CO2 flowrates in residual gas and field condensate streams for different natural gas flowrates.

$$
\begin{array}{ll}
F_{\text {resgas }_{j, m}}^{\text {CO2 }}=y_{A_{j, m}}^{\text {CO2acidgas }} * F_{\text {Natgas }} & \forall j \in J_{A}, m \in M_{A} \\
F_{\text {fieldC }^{\text {CO }}{ }_{j, m}}^{\text {CO2 }}=y_{A_{j, m}}^{\text {CO2sweetgas }} * F_{\text {Natgas }} & \forall j \in J_{A}, m \in M_{A}
\end{array}
$$

The total $F_{\text {resgas }}^{\mathrm{CO} 2}$ and $F_{\text {fieldC5+ }}^{\mathrm{CO} 2}$ flowrate from unit (A) are given in equations (5.34) and (5.35),

$$
\begin{aligned}
& F_{\text {resgas }}^{\mathrm{CO2}}=\sum_{m} \sum_{j} F_{\text {resgas }_{j, m}}^{\mathrm{CO2}} \\
& F_{\text {fieldC } 5+^{\mathrm{CO} 2}}=\sum_{m} \sum_{j} F_{\text {fieldC }{ }_{j}, m}^{\mathrm{CO} 2}
\end{aligned}
$$

$\mathrm{H}_{2} \mathrm{~S}$ mass balance around unit (B) is given in equation (5.36), 
$F_{\text {resgas }_{j, m}}^{H 2 S}=F_{\text {acidgas }_{j, m}}^{\mathrm{H2S}}+F_{\text {sweetgas }_{j, m}}^{\mathrm{H} 2 S}$

The switching constraint are given in equations (5.37-5.38),

$F_{\text {acidgas } j, m}^{H 2 S} \leq X_{i j m} * F_{\text {acidgas }}^{H 2 S^{U}} \quad \forall j \in J_{B}, m \in M_{B}$

$F_{\text {sweetgas }_{j, m}}^{H 2 S} \leq X_{\text {ijm }} * F_{\text {sweetgas }}^{H 2 S^{U}} \quad \forall j \in J_{B}, m \in M_{B}$

The yield values $y_{B_{j, m}}^{H 2 \text { Sacidgas }}$ and $y_{B_{j, m}}^{H 2 \text { Ssweetgas }}$ given in equation (5.39-5.40) are obtained from Aspen Plus steady state simulator and can be used as an approximate value to estimate $\mathrm{H}_{2} \mathrm{~S}$ flowrate for different natural gas flowrates.

$$
\begin{array}{ll}
F_{\text {acidgas }_{j, m}}^{\text {H2S }}=y_{B_{j, m}}^{\text {H2Sacidgas }} * F_{\text {Natgas }} & \forall j \in J_{B}, m \in M_{B} \\
F_{\text {sweetgas }_{j, m}}^{H 2 S}=y_{B_{j, m}}^{H 2 \text { Ssweetgas }} * F_{\text {Natgas }} & \forall j \in J_{B}, m \in M_{B}
\end{array}
$$

The total $F_{\text {acidgas }}^{H 2 S}$ and $F_{\text {Sweetgas }}^{H 2 S}$ flowrate from unit (B) are given in equations (5.41) and (5.42),

$$
\begin{array}{ll}
F_{\text {acidgas }}^{H 2 S}=\sum_{m} \sum_{j} F_{\text {acidgas }_{j, m}}^{H 2 S} & \forall j \in J_{B}, m \in M_{B} \\
F_{\text {Sweetgas }}^{H 2 S}=\sum_{m} \sum_{j} F_{\text {Sweetgas }_{j, m}}^{H 2 S} & \forall j \in J_{B}, m \in M_{B}
\end{array}
$$

$\mathrm{CO}_{2}$ mass balance around unit (B) is given in equation (5.43),

$F_{\text {resgas }_{j, m}}^{\mathrm{CO} 2}=F_{\text {acidgas }_{j, m}}^{\mathrm{CO2}}+F_{\text {Sweetgas }_{j, m}}^{\mathrm{CO} 2}$

The switching constraints are given in equations (5.44-5.45), such as,

$$
\begin{aligned}
& F_{\text {acidgas }_{j, m}}^{C O 2} \leq X_{j m}^{B} * F_{\text {acidgas }}^{\mathrm{CO}^{U}} \quad \forall j \in J_{B}, m \in M_{B} \\
& F_{\text {Sweetgas }_{j, m}}^{\mathrm{CO}} \leq X_{j m}^{B} * F_{\text {Sweetgas }}^{\mathrm{CO}^{U}} \quad \forall j \in J_{B}, m \in M_{B}
\end{aligned}
$$


The yield values $y_{B_{j m}}^{\text {CO2acidgas }}$ and $y_{B_{j m}}^{\text {Co2sweetgas }}$ given in equations (5.46-5.47) are obtained from Aspen Plus steady state simulator and can be used as approximate values to better estimate $\mathrm{CO}_{2}$ flowrates for different natural gas flowrates.

$F_{\text {acidgas }_{j, m}}^{\text {CO2 }}=y_{B_{j, m}}^{\text {CO2acidgas }} * F_{\text {Natgas }}$
$F_{\text {Sweetgas }_{j, m}}^{\text {CO2 }}=y_{B_{j, m}}^{\text {CO2sweetgas }} * F_{\text {Natgas }}$

The $F_{\text {acidgas }}^{\mathrm{CO} 2}$ and $F_{\text {sweet gas }}^{\mathrm{CO}}$ flowrate from acid gas removal unit are given in equations (5.48-5.49),

$$
\begin{array}{lr}
F_{\text {acidgas }}^{\text {CO2 }}=\sum_{m} \sum_{j} F_{\text {acidgas }_{j, m}}^{\text {CO2 }} & \forall j \in J_{B}, m \in M_{B} \\
F_{\text {Sweetgas }}^{\text {CO2 }}=\sum_{m} \sum_{j} F_{\text {Sweetgas }_{j, m}}^{\text {CO2 }} & \forall j \in J_{B}, m \in M_{B}
\end{array}
$$

Since the $\mathrm{CO}_{2}$ and $\mathrm{H}_{2} \mathrm{~S}$ concentration levels will be in ppm level after acid gas removal unit, then material balance, and yield equations would be sufficient up to unit (B).

The acid gases stream, $F_{\text {acidgas, }}$ mainly $\mathrm{H}_{2} \mathrm{~S}$ is fed to sulfur recovery unit to recover sulfur, $F_{\text {sulfur. }}$ So, mass balance around unit $(\mathrm{C})$ is given in equation (5.50),

$F_{\text {acidgas }}=F_{\text {tailgas }}+F_{\text {sulfur }}$

Because we need to select just one sulfur recovery technology from available technologies, we have the following constraint equation (5.51),

$$
\sum_{m \in M_{C}} \sum_{j \in J_{C}} X_{j m}^{C}=1 \quad C=\text { sulfur recovery unit }
$$

Where, $J_{C}=\{$ set of sulfur recovery technologies $\}$ and

$$
M_{C}=\{\text { set of operating mode for sulfur recovery technologies }\}
$$

$X_{j m}^{C}=1$ if technology $j$ is selected at a specific operating mode, $m$ for $C$.

$$
=0 \text { otherwise }
$$


Mass balance around unit (C) for every selected sulfur recovery technology is given in equation (5.52),

$F_{\text {acidgas }_{j, m}}=F_{\text {tailgas }_{j, m}}+F_{\text {sulfur }_{j, m}} \quad \forall j \in J_{C}, m \in M_{C}$

The switching constraint around sulfur recovery unit (i=C) are given in equations (5.53-5.54), such as,

$F_{\text {tailgas }_{j, m}} \leq X_{j m}^{C} * F_{\text {tailgas }}^{U} \quad \forall j \in J_{B}, m \in M_{B}$

$F_{\text {sulfur }_{j, m}} \leq X_{j m}^{C} * F_{\text {sulfur }}^{U} \quad \forall j \in J_{B}, m \in M_{B}$

The yield values $y_{C_{j, m}}^{\text {tailgas }}$, and $y_{C_{j, m}}^{\text {sulfur }}$, in equations (5.55-5.56) are obtained respectively, by dividing the tail gas, and sulfur flowrate for selected technology $j$ obtained from Aspen Plus steady state simulator by the total natural gas feedstock flowrate and are used as better approximate values to estimate tail gas, and sulfur flowrates for different natural gas flowrate.

$$
\begin{array}{ll}
F_{\text {tailgas }_{j, m}}=y_{C_{j, m}}^{\text {tailgas }} * F_{\text {Natgas }} & \forall j \in J_{C}, m \in M_{C} \\
F_{\text {sulfur }_{j, m}}=y_{C_{j, m}}^{\text {sulfur }} * F_{\text {Natgas }} & \forall j \in J_{C}, m \in M_{C}
\end{array}
$$

The total $F_{\text {tailgas }}$, and $F_{\text {sulfur }}$ from the unit $(\mathrm{C})$ are given in equations (5.57-5.58),

$$
\begin{aligned}
& F_{\text {tailgas }}=\sum_{m} \sum_{j} F_{\text {tailgas }_{j, m}} \\
& F_{\text {sulfur }}=\sum_{m} \sum_{j} F_{\text {sulfur }_{j, m}}
\end{aligned}
$$

The sweet gas stream $F_{\text {sweetgas }}$ is sent to the dehydration unit to remove water. Water balance around unit (D) is given in equation (5.59),

$$
F_{\text {Sweetgas }}=F_{\text {water-D }}+F_{\text {Dehgas }}
$$


Because we need to select just one dehydration technology from available technologies, we have the following constraint as shown in equation (5.60),

$$
\sum_{m \in M_{D}} \sum_{j \in J_{D}} X_{j m}^{D}=1 \quad D=\text { dehydration unit }
$$

Where, $J_{D}=\{$ set of dehydration technologies $\}$ and

$$
M_{D}=\{\text { set of operating mode for dehydration technologies }\}
$$

$X_{j m}^{D}=1$ if technology $j$ is selected at a specific operating mode, $m$ for $D$.

$$
=0 \text { otherwise }
$$

$$
F_{\text {sweetgas }_{j, m}}=F_{\text {water } D_{j, m}}+F_{\text {Dehgas }_{j, m}} \quad \forall j \in J_{D}, m \in M_{D}
$$

The yield values $y_{D_{j, m}}^{\text {water }}$ and $y_{D_{j, m}}^{\text {dehgas }}$ in equations (5.62) and (5.63) respectively, are obtained by dividing the water, and dehydrated gas flowrate for selected technology $j$ obtained from Aspen Plus steady state simulator by the total natural gas feedstock flowrate and can be used as an approximate value to estimate the water and dehydrated gas flowrates for different natural gas flowrates.

$$
\begin{array}{ll}
F_{{\text {water }-D_{j, m}}}=y_{D_{j, m}}^{\text {water }} * F_{\text {Natgas }} & \forall j \in J_{D}, m \in M_{D} \\
F_{\text {dehgas }_{j, m}}=y_{D_{j, m}}^{\text {dehgas }} * F_{\text {Natgas }} & \forall j \in J_{D}, m \in M_{D}
\end{array}
$$

The switching constraints in equations (5.64-5.65), will ensure just one technology being selected such as,

$$
\begin{array}{ll}
F_{{\text {water }-D_{j, m}}} \leq X_{j m}^{D} * F_{\text {water }}^{D^{U}} & \forall j \in J_{D}, m \in M_{D} \\
F_{\text {Dehgas }_{j, m}} \leq X_{j m}^{D} * F_{\text {Dehgas }}^{U} & \forall j \in J_{D}, m \in M_{D}
\end{array}
$$

The total $F_{\text {water-D }}$ and $F_{\text {Dehgas }}$ flowrate are given in equations (5.66) and (5.67) 


$$
\begin{aligned}
& F_{\text {water }-D}=\sum_{m \in M_{D}} \sum_{j \in J_{D}} F_{\text {water }-D_{j, m}} \\
& F_{\text {Dehgas }}=\sum_{m \in M_{D}} \sum_{j \in J_{D}} F_{\text {Dehgas }_{j, m}}
\end{aligned}
$$

The rich methane stream, $F_{\mathrm{CH} 4}$ is recovered from NGL unit and the overall mass balance around unit $(\mathrm{E})$ is given in equation (5.68),

$$
F_{\text {Dehgas }}=F_{C H 4}+F_{N G L}
$$

Because we need to select just one NGL technology from available technologies, we have the following constraint (5.69),

$$
\sum_{m \in M_{E}} \sum_{j \in J_{E}} X_{j m}^{E}=1 \quad E=\text { dehydration unit }
$$

Where, $J_{E}=\{$ set of $N G L$ recovery technologies $\}$ and

$$
M_{E}=\{\text { set of operating mode for NGL recovery technologies }\}
$$

$X_{j m}^{E}=1$ if technology $j$ is selected at a specific operating mode, $m$ for $E$.

$$
=0 \text { otherwise }
$$

So, the mass flow for each technology $\mathrm{j}$ at operating mode, $\mathrm{m}$ is given in (5.70)

$$
F_{\text {Dehgas }_{j, m}}=F_{C H 4_{j, m}}+F_{N G L_{j, m}}
$$

The yield values $y_{E_{j, m}}^{C H 4}$ and $y_{E_{j, m}}^{N G L}$ in equations (5.71-5.72) are obtained respectively, by dividing the methane rich stream, and NGL stream flowrate for selected technology $j$ obtained from Aspen Plus steady state simulator by the total natural gas feedstock flowrate and can be used as approximate values to estimate their respective flowrates for different natural gas flowrate.

$$
\begin{array}{ll}
F_{C H 4_{j, m}}=y_{E_{j, m}^{C H 4}}^{C H} * F_{\text {Natgas }} & \forall j \in J_{E}, m \in M_{E} \\
F_{N G L_{j, m}}=y_{E_{j, m}}^{N G L} * F_{\text {Natgas }} & \forall j \in J_{E}, m \in M_{E}
\end{array}
$$


The switching constraint of unit (E) shown in equations (5.73-5.74) will ensure that the flowrates for non-existing units are zero. Such as,

$$
\begin{array}{ll}
F_{N G L_{j, m}} \leq X_{j m}^{E} * F_{N G L}^{U} & \forall j \in J_{E}, m \in M_{E} \\
F_{C H 4_{j, m}} \leq X_{j m}^{E} * F_{C H 4}^{U} & \forall j \in J_{E}, m \in M_{E}
\end{array}
$$

And, the total flowrate of methane rich stream and NGL are given in equations $(5.75-5.76)$

$$
\begin{aligned}
F_{C H 4} & =\sum_{m \in M_{E}} \sum_{j \in J_{E}} F_{C H 4_{j, m}} \\
F_{N G L} & =\sum_{m \in M_{E}} \sum_{j \in J_{E}} F_{N G L_{j, m}}
\end{aligned}
$$

The recovered $F_{N G L}$ stream is sent to fractionation unit and the overall mass balance around unit $(\mathrm{F})$ is given in equation (5.77)

$F_{N G L}=F_{C 2}+F_{L P G}+F_{p l a n t C 5+}$

Where,

$$
\begin{aligned}
& F_{C 2}=\sum_{m \in M_{F}} \sum_{j \in J_{F}} F_{C 2_{j, m}} \\
& F_{L P G}=\sum_{m \in M_{F}} \sum_{j \in J_{F}} F_{L P G_{j, m}} \\
& F_{\text {plantC5+ }}=\sum_{m \in M_{F}} \sum_{j \in J_{F}} F_{\text {plant } C 5+_{j, m}}
\end{aligned}
$$

Because we need to select just one technology from available technologies, we have the following constraint (5.81),

$$
\sum_{m \in M_{F}} \sum_{j \in J_{F}} X_{j m}^{E}=1 \quad F=\text { fractionation unit }
$$

Where, $J_{F}=\{$ set of fractionation technologies $\}$ and

$$
M_{F}=\{\text { set of operating mode for fractionation technologies }\}
$$


$X_{j m}^{F}=1$ if technology $j$ is selected at a specific operating mode, $m$.

$$
=0 \text { otherwise }
$$

The yield values $y_{F_{j, m}}^{C 2}, y_{F_{j, m}}^{L P G}$ and $y_{F_{j, m}}^{\text {plantC5+ }}$ in equations (5.82-5.84) are obtained respectively, by dividing the flowrate of selected technology $j$ obtained from Aspen Plus steady state simulator by the total natural gas feedstock flowrate and can be used as approximate values to estimate their perspective flowrates for different natural gas flowrates. Although the field $\mathrm{C}_{5+}$ and plant $\mathrm{C}_{5+}$ streams have a quite similar composition, it is assumed that plant $\mathrm{C}_{5_{+}}$has a higher selling value.

$F_{C 2_{j, m}}=y_{F_{j, m}}^{C 2} * F_{\text {Natgas }} \quad \forall j \in J_{F}, m \in M_{F}$

$F_{L P G_{j, m}}=y_{F_{j, m}}^{L P G} * F_{N a t g a s} \quad \forall j \in J_{F}, m \in M_{F}$

$F_{\text {plant } C 5+{ }_{j}, m}=y_{F_{j, m}}^{\text {plantC5+ }} * F_{\text {Natgas }} \quad \forall j \in J_{F}, m \in M_{F}$

The switching constraint of unit (E) shown in equations (5.85-5.87) will ensure that the flowrates for non-existing units are zero. Such as,

$$
\begin{array}{ll}
F_{C 2_{j, m}} \leq X_{j m}^{F} * F_{C 2}^{U} & \forall j \in J_{F}, m \in M_{F} \\
F_{L P G_{j, m}} \leq X_{j m}^{F} * F_{L P G}^{U} & \forall j \in J_{F}, m \in M_{F} \\
F_{\text {plantC5+ }{ }_{j, m}} \leq X_{j m}^{F} * F_{\text {plantC5+ }}^{U} & \forall j \in J_{F}, m \in M_{F}
\end{array}
$$

\subsection{2 supply constraint}

Consumption of natural gas feedstock through the network should not exceed the upper natural gas availability limit, $F_{\text {Natgas }}^{U N}$ as shown in equation (5.88), and should be higher than the minimum quantity fed to the network, $F_{\text {Natgas }}^{L N}$.

$$
F_{\text {Natgas }}^{L N} \leq F_{\text {Natgas }} \leq F_{\text {Natgas }}^{U N}
$$




\subsubsection{Demand constraints}

The annual demand constraints of network's main products are given in equations (5.89-5.94)

$$
\begin{aligned}
& D_{\text {fieldC5+ }} \leq F_{\text {fieldC5+ }} \\
& D_{\text {plantC5+ }} \leq F_{\text {plantC5+ }} \\
& D_{\text {sulfur }} \leq F_{\text {sulfur }} \\
& D_{C 2} \leq F_{C 2} \\
& D_{L P G} \leq F_{L P G} \\
& D_{C H 4} \leq F_{C H 4}
\end{aligned}
$$

\subsubsection{Capacity constraint of network's processing units}

Capacity constraint of main processing units of the network are given in equations (5.95-5.100)

$$
\begin{array}{ll}
F_{\text {Natgas }} \leq Q_{j}^{A} * X_{i j m} & \forall j \in J_{A}, m \in M_{A} \\
F_{\text {resgas }} \leq Q_{j}^{B} * X_{i j m} & \forall j \in J_{B}, m \in M_{B} \\
F_{\text {acidgas }} \leq Q_{j}^{C} * X_{i j m} & \forall j \in J_{C}, m \in M_{C} \\
F_{\text {sweetgas }} \leq Q_{j}^{D} * X_{i j m} & \forall j \in J_{D}, m \in M_{D} \\
F_{\text {dehgas }} \leq Q_{j}^{E} * X_{i j m} & \forall j \in J_{E}, m \in M_{E} \\
F_{N G L} \leq Q_{j}^{F} * X_{i j m} & \forall j \in J_{F}, m \in M_{F}
\end{array}
$$

where $Q_{j}^{i},(\mathrm{i}=\mathrm{A}, \ldots, \mathrm{F})$ denotes the upper capacity limit for unit processing $\mathrm{i}$ for technology $\mathrm{j}$. 


\subsubsection{Quality constraint}

There are some quality specifications that needed to be met such as, $\mathrm{CO}_{2}$ composition in sweet gas stream shown in equation (5.101)

$F_{\text {Sweetgas }}^{\text {CO2 }} / F_{\text {Sweetgas }} \leq q_{\text {sweetgas }}^{\text {CO2 }}$

$\mathrm{H}_{2} \mathrm{~S}$ composition in sweet gas stream shown in equation (5.102)

$F_{\text {sweetgas }}^{\text {H2S }} / F_{\text {sweetgas }} \leq q_{\text {sweetgas }}^{H 2 S}$

Where $q_{\text {sweetgas }}^{\mathrm{CO}}$ and $q_{\text {sweetgas }}^{\mathrm{H2S}}$ are the acceptable concentration level of $\mathrm{CO}_{2}$ and $\mathrm{H}_{2} \mathrm{~S}$ in sweet gas stream, respectively.

\subsubsection{Non negativity constraint}

All the variables are positive

\subsubsection{Objective function}

As discussed earlier in the problem statement several objective functions can be used to optimize the network. We design the network to maximize the annual profit. Capital investment plays an important role in choosing among design alternatives. The total cost is represented by an annualized capital cost, variable annual operating costs, and fixed annual operating cost of major units for example units (A-F) plus the annual cost of natural gas usage. It is assumed that capital costs are amortized over the lifetime of the project life of 20 years with $10 \%$ as a compound interest rate. The total annual profit is calculated as the sum of all product sales minus cost, as shown in equation (5.103), 
maximize annual profit

$$
\begin{array}{ll}
=\sum_{k} s p_{k} * F_{k}-n p * F_{\text {natgas }}-\sum_{i} \sum_{m} \sum_{j} A C C_{j} * X_{j m}^{i} \\
-\sum_{i} \sum_{m} \sum_{j} A O C_{j} \\
* X_{j m}^{i} \quad \forall i, j, m, k
\end{array}
$$

Where,

$s p_{k}$ is the selling price of each network products

$n p$ is natural gas feedstock price

$F_{k}$ is products mass flowrate

$F_{\text {natgas }}$ is natural gas mass flowrate

$A C C_{j}=$ amoritzed capital cost for technology $\mathrm{j}$

$A O C_{j}=$ annual operating cost for technology $\mathrm{j}$

\subsection{Illustrative Case Studies}

Two illustrative case studies are presented to show the applicability of the overall framework and formulated model presented in the previous sections. The steady state simulation of the processing network was carried out using Aspen Plus. The main key processing units such as stabilization, acid gas removal, dehydration, sulfur recovery, NGL recovery, and NGL fractionation were considered. A typical natural gas composition (mol\%) shown in Table 3.1 with a specific flowrate and operating conditions is used in our analysis. The cost data represented in the case study are based on ICARUS software output and open-source data. 


\subsubsection{Case study 1}

Given the natural gas as a feedstock with its properties such as composition, flowrate, and pressure and temperature, it is desired to optimally design a stabilization unit, unit (A) as was shown in Figure 3.4. Different product quality with different reid vapor pressure (RVP) can be produced by changing the stabilization column operating conditions and in particular the column pressure as can be found in Campbell, 2000.

\subsubsection{Case study 1: Results and discussion}

A typical stabilization unit was considered for steady state simulation in Aspen Plus. Three condensate qualities with 12, 16, 26 RVP quality were selected for comparison by manipulating column pressure. As can be seen from Figures (5.4), (5.5), and (5.6) that the yield values for all residual gas stream are not constant. Also, they change with different operating conditions such as stabilizer's pressure. In a similar way, the yield values of condensate $\mathrm{C} 5+$ streams as shown in Figures (5.7), (5.8), and (5.9), respectively. 


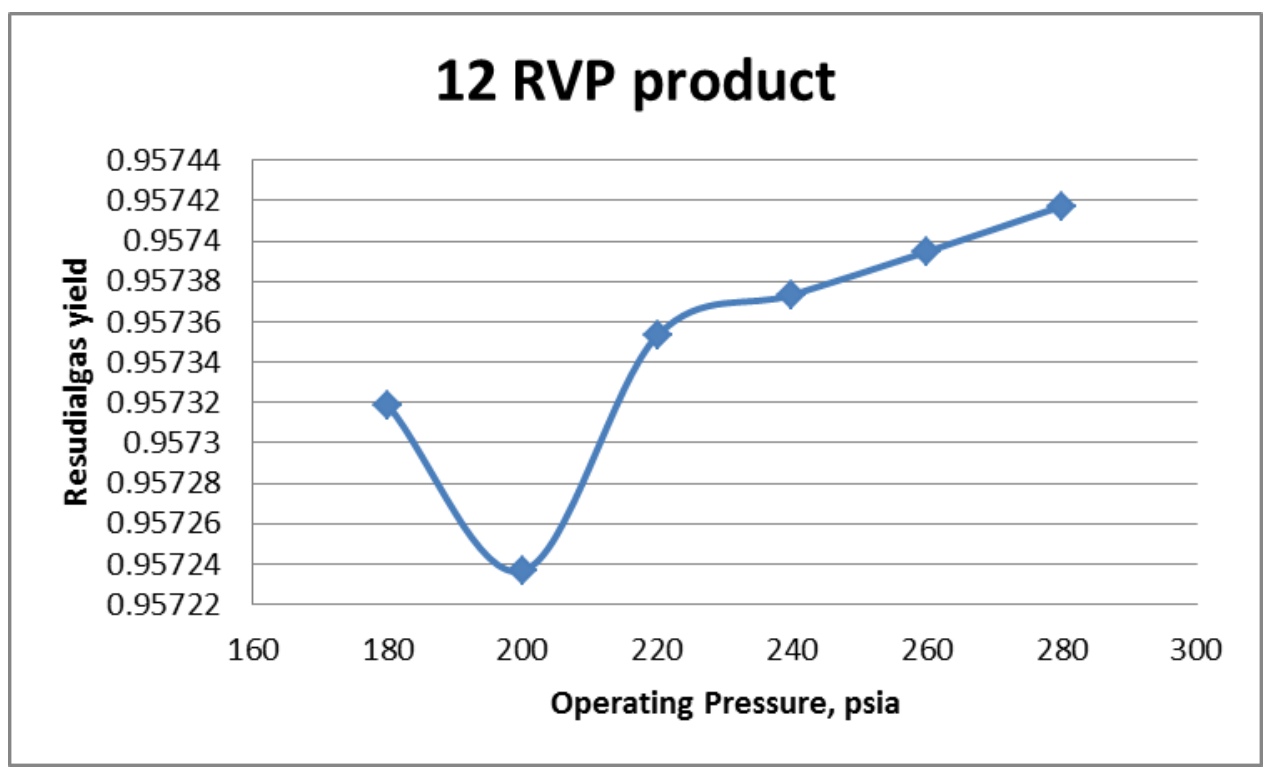

Figure 5.3 Residual gas yield for 12 RVP product.

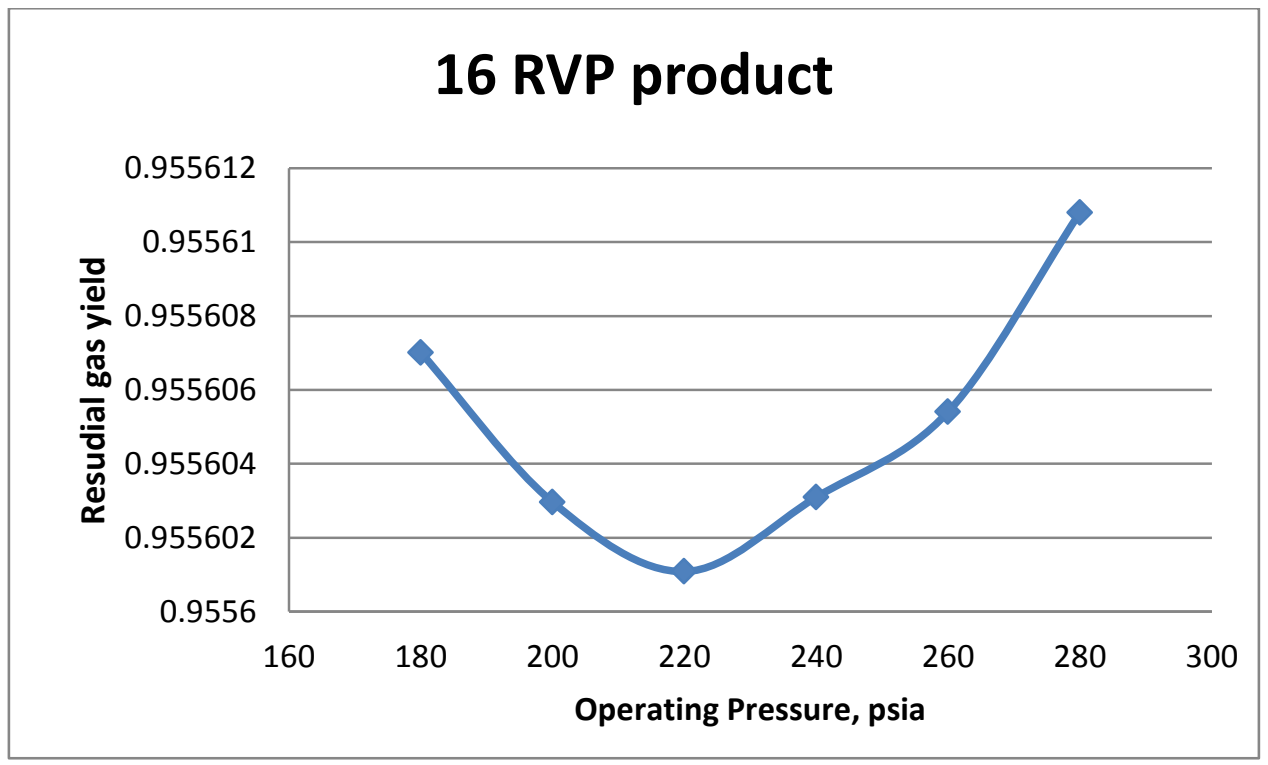

Figure 5.4 Residual gas yield for 16 RVP product. 


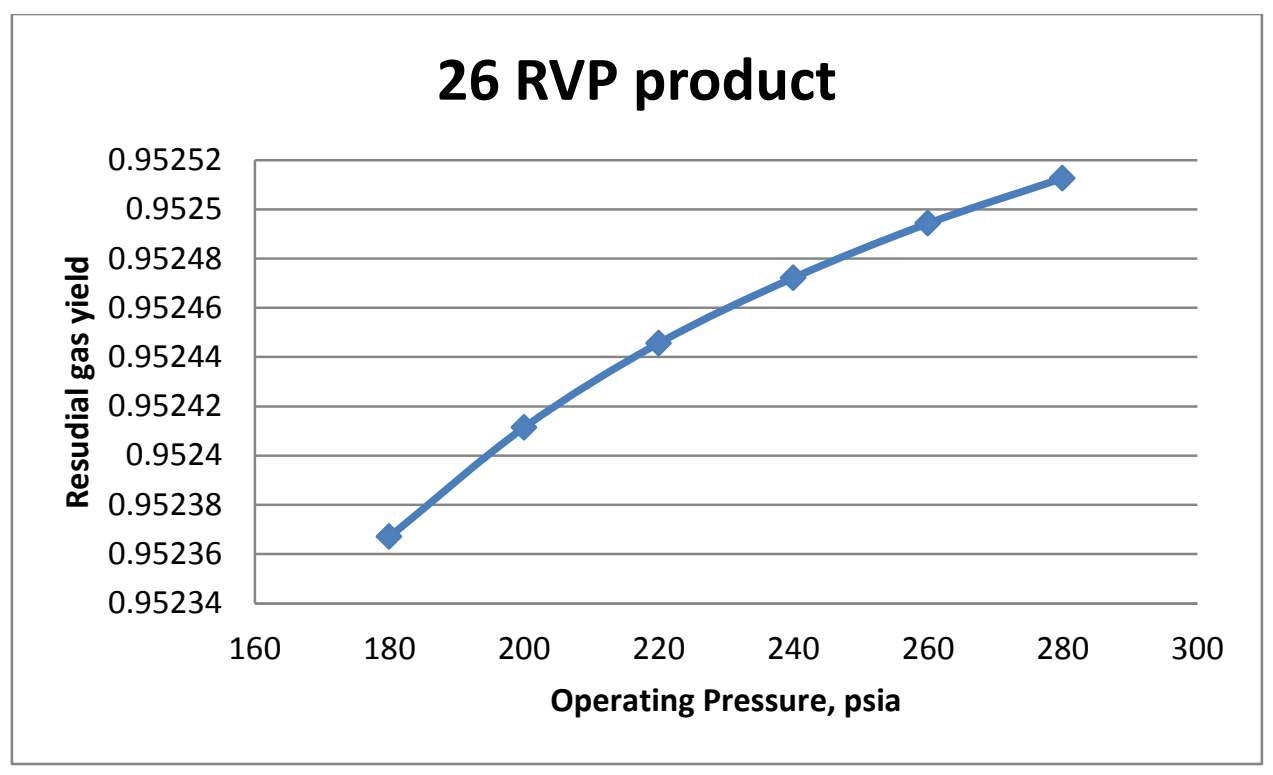

Figure 5.5 Residual gas yield for 26 RVP product.

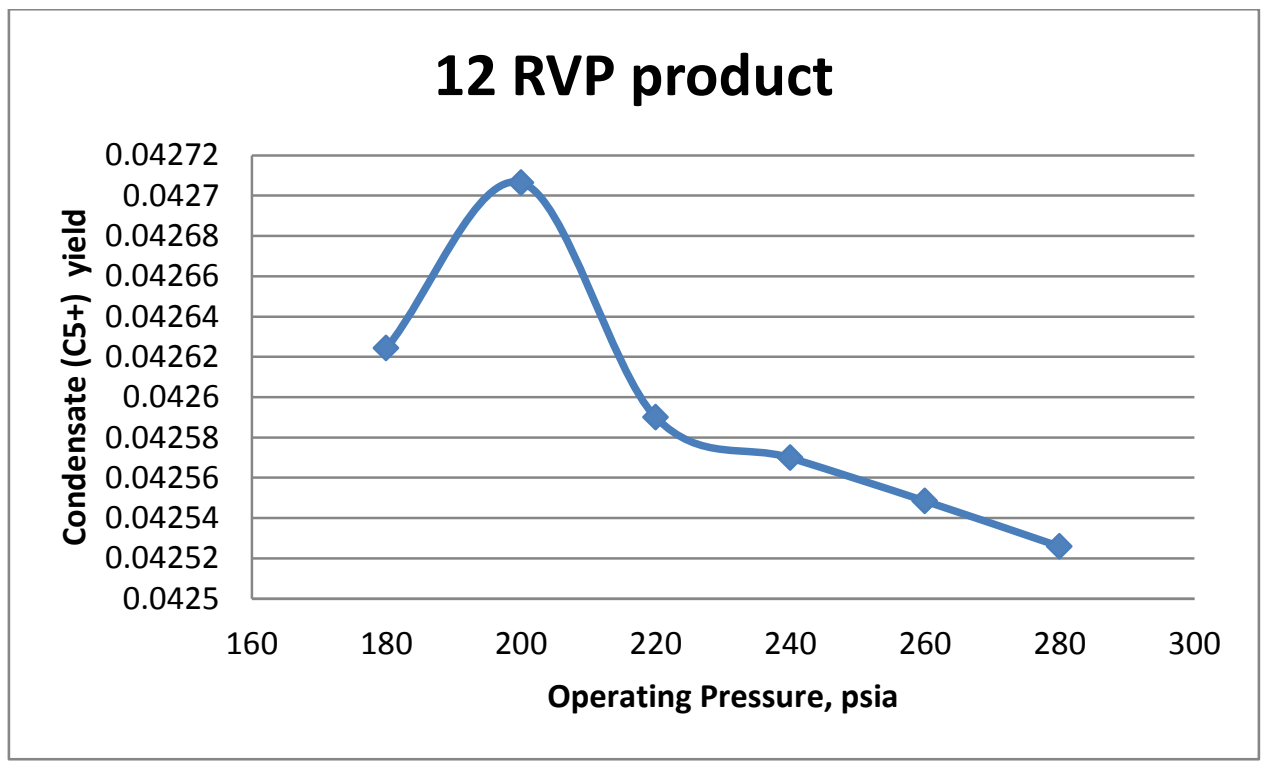

Figure 5.6 Condensate yield for 12 RVP product. 


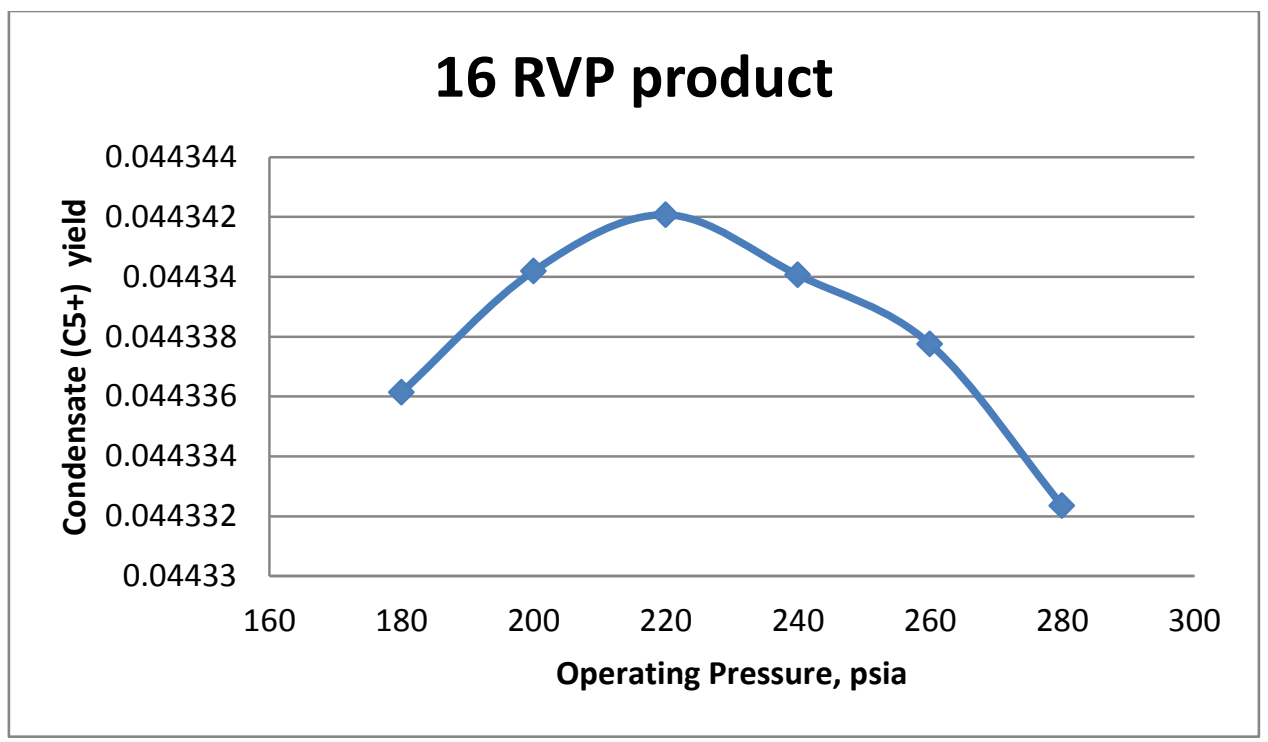

Figure 5.7 Condensate yield for 16 RVP product.

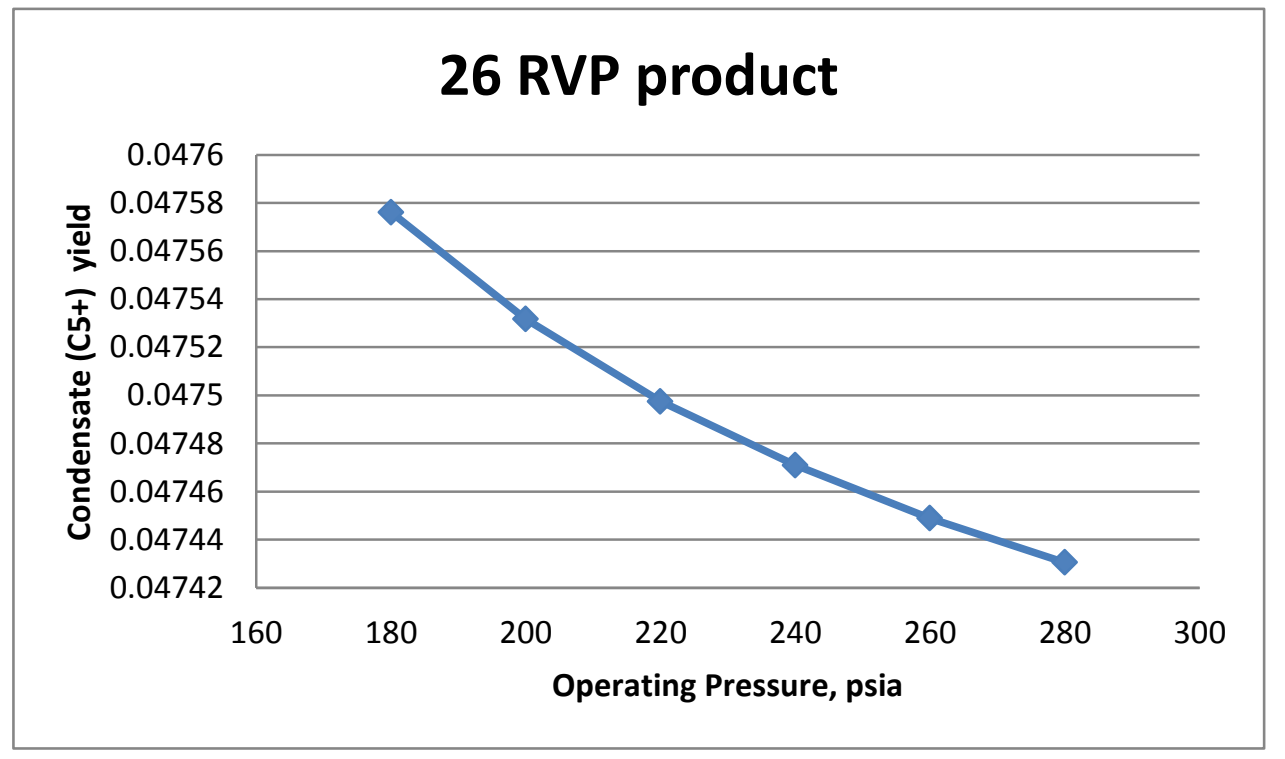

Figure 5.8 Condensate yield for 26 RVP product. 
Table 5.1 Total capital, annuity of capital, and total operating cost for 12, 16, 26 RVP products.

\begin{tabular}{|c|c|c|c|c|c|c|c|c|c|}
\hline \multirow{2}{*}{$\begin{array}{l}\text { Processing } \\
\text { unit } \\
\text { conditions } \\
\end{array}$} & \multicolumn{3}{|c|}{ Total capital cost $(\$)$} & \multicolumn{3}{|c|}{ Annuity of capital } & \multicolumn{3}{|c|}{ Total operating $\operatorname{cost}(\$ / y r)$} \\
\hline & 12 RVP & $16 \mathrm{RVP}$ & $26 \mathrm{RVP}$ & $12 \mathrm{RVP}$ & 16 RVP & $26 \mathrm{RVP}$ & 12 RVP & 16 RVP & $26 \mathrm{RVP}$ \\
\hline $\begin{array}{l}\text { Stabilization at } \\
180 \text { psia }\end{array}$ & $1.28 \mathrm{E}+07$ & $1.22 \mathrm{E}+07$ & $1.10 \mathrm{E}+07$ & $1.56 \mathrm{E}+06$ & $1.48 \mathrm{E}+06$ & $1.34 \mathrm{E}+06$ & $3.90 \mathrm{E}+09$ & $2.81 \mathrm{E}+09$ & $5.84 \mathrm{E}+09$ \\
\hline $\begin{array}{l}\text { Stabilization at } \\
200 \text { psia }\end{array}$ & $1.18 \mathrm{E}+07$ & $1.14 \mathrm{E}+07$ & $1.10 \mathrm{E}+07$ & $1.44 \mathrm{E}+06$ & $1.39 \mathrm{E}+06$ & $1.34 \mathrm{E}+06$ & $6.40 \mathrm{E}+06$ & $5.32 \mathrm{E}+06$ & $5.61 \mathrm{E}+09$ \\
\hline $\begin{array}{l}\text { Stabilization at } \\
220 \text { psia }\end{array}$ & $1.20 \mathrm{E}+07$ & $1.19 \mathrm{E}+07$ & $1.09 \mathrm{E}+07$ & $1.460 \mathrm{E}+06$ & $1.45 \mathrm{E}+06$ & $1.33 \mathrm{E}+06$ & $6.58 \mathrm{E}+06$ & $5.44 \mathrm{E}+06$ & $5.40 \mathrm{E}+09$ \\
\hline $\begin{array}{l}\text { Stabilization at } \\
240 \text { psia }\end{array}$ & $1.20 \mathrm{E}+07$ & $1.14 \mathrm{E}+07$ & $1.10 \mathrm{E}+07$ & $1.460 \mathrm{E}+06$ & $1.39 \mathrm{E}+06$ & $1.34 \mathrm{E}+06$ & $6.70 \mathrm{E}+06$ & $6.13 \mathrm{E}+06$ & $5.23 \mathrm{E}+09$ \\
\hline $\begin{array}{l}\text { Stabilization at } \\
260 \text { psia }\end{array}$ & $1.25 \mathrm{E}+07$ & $1.15 \mathrm{E}+07$ & $1.10 \mathrm{E}+07$ & $1.520 \mathrm{E}+06$ & $1.40 \mathrm{E}+06$ & $1.34 \mathrm{E}+06$ & $6.84 \mathrm{E}+06$ & $6.25 \mathrm{E}+06$ & $5.07 \mathrm{E}+09$ \\
\hline $\begin{array}{l}\text { Stabilization at } \\
280 \text { psia }\end{array}$ & $1.17 \mathrm{E}+07$ & $1.19 \mathrm{E}+07$ & $1.10 \mathrm{E}+07$ & $1.42 \mathrm{E}+06$ & $1.45 \mathrm{E}+06$ & $1.34 \mathrm{E}+06$ & $8.08 \mathrm{E}+06$ & $6.40 \mathrm{E}+06$ & $4.93 \mathrm{E}+09$ \\
\hline
\end{tabular}

The total capital cost, annuity of capital, and total operating cost for all condensate qualities under different operating conditions such as stabilizer pressure are given in Table 5.1. Based on the different yields obtained for condensate abd resudialgas, the formulated model was applied on stabilzation unit. The linearity was maintained by discretizing product yield function over the operating conditions range by running many simulation cases and various yield values were obtained. The different RVP products processed by stabilization unit ( $\mathrm{i}=\mathrm{A})$ are reprented by the second index, for example, $\mathrm{j}=1$ for $12 \mathrm{RVP}, \mathrm{j}=2$ for $16 \mathrm{RVP}$, and $\mathrm{j}=3$ for $26 \mathrm{RVP}$. The third index represents the operating pressure and $m=1, \ldots, 6$, where $m=1$ for 180 psia $m=2$ for 200 psia and so on. The MILP has 78 variables with 18 integer variables and 80 constraints. It has been solved in LINGO 14.0 version. The input file and its solution for LINGO can be found in Appendix B1.The optimal results such as flowrate values of field condensate and resudial gas products are 68,727 and 1,481,185 $\mathrm{kg} / \mathrm{h}$ respectively. Also, the condesate $\mathrm{C}_{5+}$ product with 16 RVP at 200 psia, represented by the binary variable as the optimal seleced quality product among 
other qualities. It was found that $\$ 5.83 \mathrm{E}+08$ is the optimal annual profit as defined by the objective function.

\subsubsection{Case study 2}

Natural gas processing network starts with stabilization unit and the consequence other units with design options is considered for analysis and optimization. Many process configurations are available for selection and the choice of technologies can be vast as shown in Table 5.1. As mentioned earlier, there is no single technology or process configuration that is superior in all aspects. Figure 5.10, shows the selected configurations and options of some processing units for analysis and optimization. For example, three Different configurations are available for acid gas removal unit, unit (B). In first configuration, MDEA is used only to absorb $\mathrm{CO}_{2}$ and $\mathrm{H}_{2} \mathrm{~S}$ to the desired level, in the second configuration uses a mixed amine solution of MDEA and DEA is used and in the third configuration, two absorbers are used, MDEA is used in the first absorber column and DEA in the second absorber. Also, two different process configurations for sulfur recovery, unit (C) are considered with different operating conditions. Moreover, two process schemes are available for fractionation unit, unit $(\mathrm{F})$; the direct or conventional configuration and indirect or non-conventional configuration. In the direct configuration, de-ethanizer, deproponizer, and de-butanizer are place in sequence to separate NGL into different products. However, in the non-conventional configuration the de-propanizer, de-ethanizer, and debutanizer are place in sequence with at least $90 \%$ ethane mole recovery, $80 \%$ propane mole recovery, and $80 \%$ butane mole recovery fixed in both cases. So, it is desired to design optimally the natural gas processing network by considering the different configurations available for key processing units with different operating modes. 
Table 5.2 Different possible technologies available for selection.

\begin{tabular}{|c|c|c|c|}
\hline $\begin{array}{l}\text { Major } \\
\text { Processing Unit }\end{array}$ & Possible processes / technologies & $\begin{array}{l}\text { Selected Process } \\
\text { / technology }\end{array}$ & Operating mode \\
\hline $\begin{array}{l}\text { (A) Condensate } \\
\text { Stabilization }\end{array}$ & $\begin{array}{l}\text { 1. Flash Vaporization } \\
\text { 2. Stabilization by Fractionation }\end{array}$ & $\begin{array}{l}\text { Stabilization by } \\
\text { Fractionation }\end{array}$ & Operating pressure \\
\hline $\begin{array}{l}\text { (B) Acid Gas } \\
\text { Removal }\end{array}$ & $\begin{array}{l}\text { 1. Indirect Conversion } \\
\text { 2. Direct Conversion, i,e.(Dry } \\
\text { bed or liquid phase) } \\
\text { 3. Separation Technologies, i,e } \\
\text { (membrane or cryogenic } \\
\text { fractionation) }\end{array}$ & $\begin{array}{l}\text { Direct } \\
\text { Conversion } \\
\text { (liquid phase) }\end{array}$ & $\begin{array}{l}\text { Solvent type, solvent } \\
\text { concentration, absorbers } \\
\text { arrangement, etc. }\end{array}$ \\
\hline $\begin{array}{l}\text { (C) Sulfur } \\
\text { Recovery }\end{array}$ & $\begin{array}{l}\text { 1. Gas phase- Claus type } \\
\text { 2. Liquid-phase }\end{array}$ & $\begin{array}{l}\text { Gas phase Claus } \\
\text { type }\end{array}$ & Straight vs split \\
\hline (D) Dehydration & $\begin{array}{l}\text { 1. Liquid Desiccant (Glycol) } \\
\text { 2. Solid Desiccant } \\
\text { 3. Cooling the gas }\end{array}$ & Glycol & $\begin{array}{l}\text { Glycol concentration and } \\
\text { circulation rate }\end{array}$ \\
\hline $\begin{array}{l}\text { (E) NGL } \\
\text { Recovery }\end{array}$ & $\begin{array}{ll}\text { 1. } & \text { Refrigeration Process } \\
\text { 2. } & \text { Lean Oil Absorption } \\
\text { 3. } & \text { Solid bed Adsorption } \\
\text { 4. } & \text { Membrane Separation } \\
\text { 5. } & \text { Twister Supersonic } \\
\end{array}$ & $\begin{array}{l}\text { Refrigeration } \\
\text { Process }\end{array}$ & $\begin{array}{l}\text { Demethanizer pressure in } \\
\text { expander plant }\end{array}$ \\
\hline $\begin{array}{l}\text { (F) NGL } \\
\text { Fractionation }\end{array}$ & $\begin{array}{ll}\text { 1. } & \text { Direct Sequence } \\
\text { 2. } & \text { Indirect Sequence }\end{array}$ & $\begin{array}{l}\text { Direct Sequence } \\
\text { Indirect } \\
\text { Sequence }\end{array}$ & Recovery achieved \\
\hline
\end{tabular}




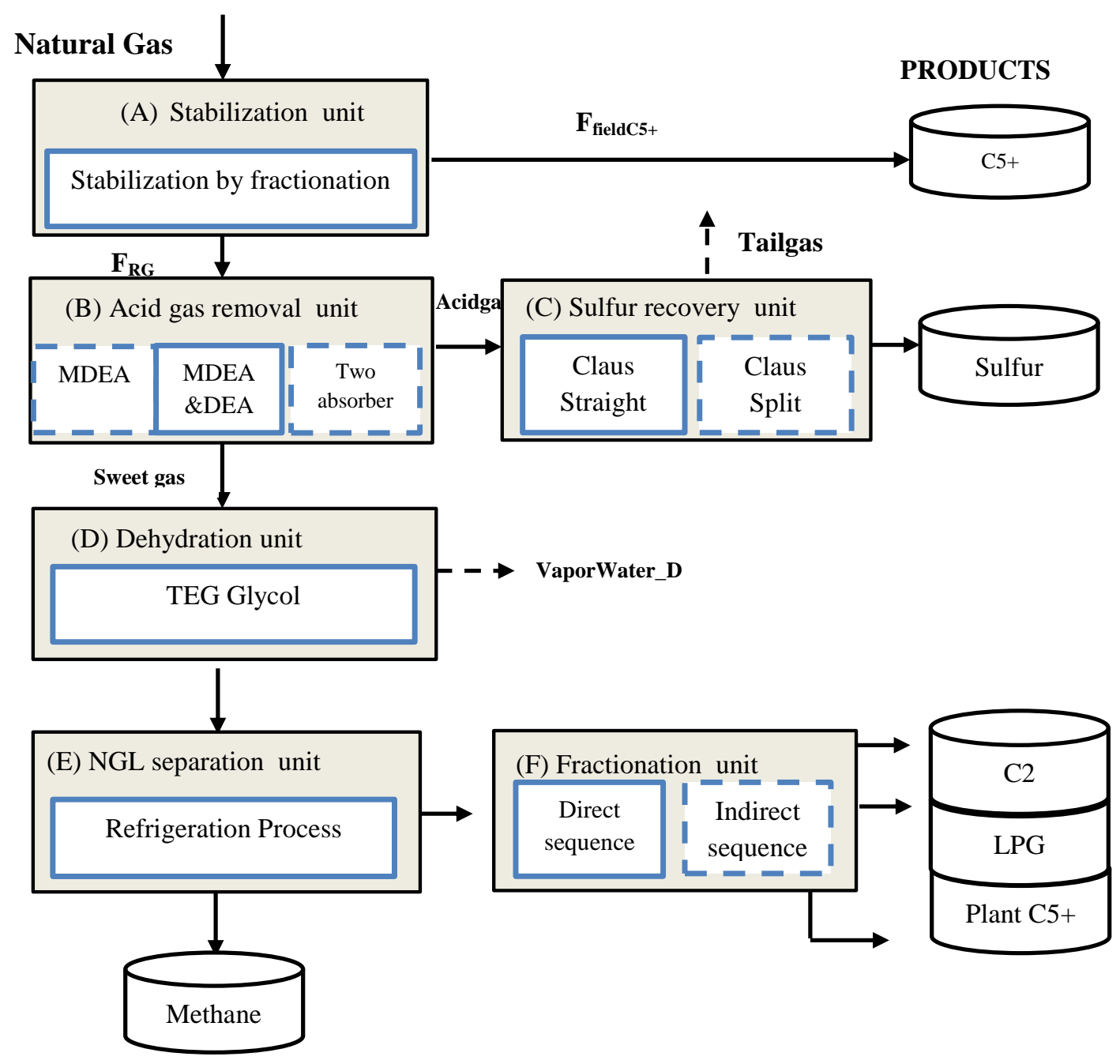

Figure 5.9 Natural gas processing pathway with selected design alternatives.

\subsubsection{Case study 2: Results and discussion}

After running the steady state simulation using ASPEN Plus V7.1 for each key processing unit with different configurations and operating mode, the material and energy balances are obtained. The mass and molar flowrate and operating conditions around each unit are tabulated in Tables 5.3-5.8 and presented below. Table 5.3 shows the mass and molar flow, and operating conditions results of three different modes for stabilizer pressure 180, 200, and 220 psia. 
Table 5.3 Flowrate and operating conditions around stabilization, unit A.

\begin{tabular}{|c|c|c|c|c|c|c|c|c|c|}
\hline \multicolumn{10}{|c|}{ Stabilization, unit (A) } \\
\hline $\begin{array}{l}\text { Operating mode } \\
\text { Stabilizer pressure }\end{array}$ & \multicolumn{3}{|c|}{$\begin{array}{l}\text { Mode } 1 \\
\text { (180 psia) }\end{array}$} & \multicolumn{3}{|c|}{$\begin{array}{c}\text { Mode } 2 \\
\text { (200 psia) }\end{array}$} & \multicolumn{3}{|c|}{$\begin{array}{c}\text { Mode } 3 \\
\text { (220 psia) }\end{array}$} \\
\hline Stream name & Natgas & Resgas & $\begin{array}{l}\text { Field- } \\
\text { C5+ }\end{array}$ & Natgas & Resgas & $\begin{array}{l}\text { Field- } \\
\text { C5+ }\end{array}$ & Natgas & Resgas & $\begin{array}{l}\text { Field- } \\
\text { C5+ }\end{array}$ \\
\hline $\begin{array}{l}\text { Total molar } \\
\text { Flow, } \\
\text { kmol/hr }\end{array}$ & 74707 & 73897 & 847 & 74707 & 73854 & 847 & 74707 & 73854 & 800 \\
\hline $\begin{array}{l}\text { Total mass } \\
\text { Flow, } \mathrm{kg} / \mathrm{hr}\end{array}$ & 1515431 & 1450481 & 67188 & 1515431 & 1448150 & 67194 & 1515431 & 1448148 & 64542 \\
\hline $\begin{array}{l}\text { Temperature, } \\
{ }^{\circ} \mathrm{C}\end{array}$ & 60 & 294 & 150 & 60 & 20 & 157 & 60 & 20 & 170 \\
\hline Pressure, bar & 70 & 54 & 13 & 70 & 55 & 15 & 70 & 55 & 16 \\
\hline Vapor Frac & 1.000 & 0.999 & 0.000 & 1.000 & 0.999 & 0.000 & 1.000 & 0.999 & 0.000 \\
\hline Liquid Frac & 0.000 & $6.6 \mathrm{E}-05$ & 1.000 & 0.000 & $1.8 \mathrm{E}-05$ & 1.000 & 0.000 & $1.8 \mathrm{E}-05$ & 1.000 \\
\hline $\mathrm{H}_{2} \mathrm{Smol} \%$ & 0.01 & 0.01 & $\begin{array}{c}8.2 \mathrm{E}- \\
09\end{array}$ & 0.01 & 0.01 & $\begin{array}{c}8.2 \mathrm{E}- \\
09\end{array}$ & 0.01 & 0.01 & $\begin{array}{c}8.2 \mathrm{E}- \\
09\end{array}$ \\
\hline $\mathrm{CO}_{2} \mathrm{~mol} \%$ & 0.02 & 0.02 & $\begin{array}{c}3.3 \mathrm{E}- \\
17\end{array}$ & 0.02 & 0.02 & $\begin{array}{c}3.3 \mathrm{E}- \\
17\end{array}$ & 0.02 & 0.02 & $\begin{array}{c}3.3 \mathrm{E}- \\
17\end{array}$ \\
\hline RVP, psia & --- & --- & 16 & --- & --- & 16 & --- & --- & 16 \\
\hline
\end{tabular}

Table 5.4 Flowrate and operating conditions around units B.

\begin{tabular}{|l|c|c|c|c|c|c|}
\hline Acid gas removal, unit (B) & \multicolumn{9}{|c|}{$\begin{array}{c}\text { Mode 2 } \\
\text { Mode 1 } \\
\text { Operating mode }\end{array}$} & \multicolumn{2}{c|}{$\begin{array}{c}\text { Mode 3 } \\
\text { (MDEA 35wt\%) }\end{array}$} & $\begin{array}{c}\text { MDEA30wt\%+DEA15wt\%) } \\
\text { (MDEAfirst+DEAsecond) }\end{array}$ \\
\hline Stream name & Sweetgas1 & Acidgas1 & Sweetgas2 & Acidgas2 & Sweetgas3 & Acidgas3 \\
\hline $\begin{array}{l}\text { Total molar Flow, } \\
\text { kmol/hr }\end{array}$ & 66325 & 1704 & 71596 & 4766 & 71521 & 18112 \\
\hline $\begin{array}{l}\text { Total mass Flow, } \\
\text { kg/hr }\end{array}$ & 1138779 & 43517 & 1309177 & 144079 & 1307758 & 398257 \\
\hline Temperature, ${ }^{\circ} \mathbf{C}$ & 25 & 102 & 20 & 97 & 35 & 114 \\
\hline Pressure, bar & 55 & 2 & 55 & 2 & 55 & 2 \\
\hline Vapor Frac & 1.000 & 1.000 & 1.000 & 1.000 & 1.000 & 1.000 \\
\hline Liquid Frac $^{\mathbf{H}_{2} \text { Smol\% }}$ & 0.000 & 0.000 & 0.000 & 0.000 & 0.000 & 0.000 \\
\hline $\mathbf{C O}_{2} \mathbf{m o l \%}^{1.36 e-29}$ & 0.40 & $1.83 \mathrm{e}-25$ & 0.47 & 0 & 0.04 \\
\hline
\end{tabular}


Table 5.5 Flowrate and operating conditions around units C.

\begin{tabular}{|c|c|c|c|c|}
\hline \multicolumn{5}{|c|}{ Sulfur recovery, unit $\mathrm{C}$} \\
\hline $\begin{array}{l}\text { Operating } \\
\text { mode }\end{array}$ & \multicolumn{2}{|c|}{$\begin{array}{c}\text { Mode 1 } \\
\text { (Claus straight) }\end{array}$} & \multicolumn{2}{|c|}{$\begin{array}{c}\text { Mode 2 } \\
\text { (Claus split) }\end{array}$} \\
\hline $\begin{array}{l}\text { Stream } \\
\text { name }\end{array}$ & Sulfur1 & Tailgas1 & Sulfur2 & Tailgas2 \\
\hline $\begin{array}{l}\text { Total Flow } \\
\text { kmol/hr }\end{array}$ & 717 & 2551 & 670 & 2789 \\
\hline $\begin{array}{l}\text { Total Flow } \\
\text { kg/hr }\end{array}$ & 22993 & 93489 & 21492 & 101391 \\
\hline $\begin{array}{l}\text { Temperature } \\
{ }^{\circ} \mathrm{C}\end{array}$ & 100 & 100 & 100 & 100 \\
\hline Pressure bar & 5 & 5 & 5 & 5 \\
\hline Vapor Frac & 0.000 & 0.895 & 0.000 & 0.960 \\
\hline Liquid Frac & 1.000 & 0.104 & 1.000 & 0.039 \\
\hline
\end{tabular}

Table 5.6 Flowrate and operating conditions around units D.

\begin{tabular}{|l|c|c|}
\hline \multicolumn{2}{|l|}{ Dehydration, unit (D) } \\
\hline & \multicolumn{2}{|c|}{ Mode 1 } \\
\hline $\begin{array}{l}\text { Stream } \\
\text { name }\end{array}$ & DryGas1 & $\begin{array}{c}\text { Vapor } \\
\text { water-D1 }\end{array}$ \\
\hline $\begin{array}{l}\text { Total Flow } \\
\text { kmol/hr }\end{array}$ & 69899 & 1738 \\
\hline $\begin{array}{l}\text { Total Flow } \\
\text { kg/hr }\end{array}$ & 1248403 & 61415 \\
\hline $\begin{array}{l}\text { Temperature } \\
\text { 'C }\end{array}$ & 27 & 58 \\
\hline Pressure bar & 50 & 5 \\
\hline Vapor Frac & 1.000 & 1.000 \\
\hline Liquid Frac & 0.000 & 0.000 \\
\hline
\end{tabular}


Table 5.7 Flowrate and operating conditions around units E.

\begin{tabular}{|l|c|c|}
\hline \multicolumn{2}{|l|}{ NGL recovery, unit (E) } \\
\hline & \multicolumn{2}{|c|}{ Mode 1 } \\
\hline $\begin{array}{l}\text { Stream } \\
\text { name }\end{array}$ & Methane & NGL1 \\
\hline $\begin{array}{l}\text { Total Flow } \\
\text { kmol/hr }\end{array}$ & 66617 & 3935 \\
\hline $\begin{array}{l}\text { Total Flow } \\
\text { kg/hr }\end{array}$ & 1128351 & 150684 \\
\hline $\begin{array}{l}\text { Temperature } \\
\text { oC }\end{array}$ & -93 & 35 \\
\hline Pressure bar & 20 & 20 \\
\hline Vapor Frac & 1.000 & 0.684 \\
\hline Liquid Frac & 0.000 & 0.316 \\
\hline
\end{tabular}

Table 5.8 Flowrate and operating conditions around units F.

\begin{tabular}{|l|c|c|c|c|c|c|}
\hline NGL fractionation, unit (F) & \multicolumn{3}{c|}{$\begin{array}{c}\text { Mode 2 } \\
\text { (Indirect sequence) }\end{array}$} \\
\hline & \multicolumn{3}{|c|}{$\begin{array}{c}\text { Mode 1 } \\
\text { (Direct sequence) }\end{array}$} & \multicolumn{2}{|c|}{ LPG2 } & p.cond2 \\
\hline $\begin{array}{l}\text { Stream } \\
\text { name }\end{array}$ & Ethane1 & LPG1 & p.cond1 & Ethane2 & LPG \\
\hline $\begin{array}{l}\text { Total Flow } \\
\text { kmol/hr }\end{array}$ & 2107 & 1607 & 222 & 2100 & 1651 & 184 \\
\hline $\begin{array}{l}\text { Total Flow } \\
\text { kg/hr }\end{array}$ & 62344 & 73150 & 15190 & 62164 & 75725 & 12791 \\
\hline $\begin{array}{l}\text { Temperature } \\
\text { 'C }\end{array}$ & -29 & 49 & 135 & -29 & 50 & 139 \\
\hline Pressure bar & 19 & 18 & 18 & 19 & 18 & 18 \\
\hline Vapor Frac & 0.000 & 0.054 & 0.000 & 0.000 & 0.074 & 0.000 \\
\hline Liquid Frac & 1.000 & 0.946 & 1.000 & 1.000 & 0.926 & 1.000 \\
\hline
\end{tabular}


Table 5.9 Total capital, annuity of capital, and total operating cost of each processing unit.

\begin{tabular}{|c|c|c|c|c|}
\hline Processing unit & $\begin{array}{l}\text { Operating } \\
\text { conditions }\end{array}$ & $\begin{array}{l}\text { Total } \\
\text { capital cost } \\
(\$)\end{array}$ & $\begin{array}{l}\text { Annuity of } \\
\text { capital }\end{array}$ & $\begin{array}{l}\text { Total } \\
\text { Operating } \\
\operatorname{cost}(\$ / y r)\end{array}$ \\
\hline \multicolumn{5}{|l|}{ (A) Stabilization } \\
\hline & 12.4 bar, $151{ }^{\circ} \mathrm{C}$ & $1.22 \mathrm{E}+07$ & $1.48 \mathrm{E}+06$ & $2.81 \mathrm{E}+09$ \\
\hline & 13.8 bar, $157^{\circ} \mathrm{C}$ & $1.14 \mathrm{E}+07$ & $1.39 \mathrm{E}+06$ & $5.32 \mathrm{E}+06$ \\
\hline & 15.2 bar, $163{ }^{\circ} \mathrm{C}$ & $1.19 \mathrm{E}+07$ & $1.45 \mathrm{E}+06$ & $5.44 \mathrm{E}+06$ \\
\hline \multicolumn{5}{|l|}{ (B) Acid gas removal } \\
\hline (1)MDEA 35wt $\%$ & $55.2 \mathrm{bar}, 35^{\circ} \mathrm{C}$ & $3.42 \mathrm{E}+07$ & $4.17 \mathrm{E}+06$ & $4.55 \mathrm{E}+07$ \\
\hline (2)MDEA30wt $\%+D E A 15 w t \%$ & 55.2 bar, $35^{\circ} \mathrm{C}$ & $3.45 \mathrm{E}+07$ & $4.20 \mathrm{E}+06$ & $3.80 \mathrm{E}+08$ \\
\hline (3) MDEAfirst+DEAsecond & 55.2 bar, $21.1^{\circ} \mathrm{C}$ & $8.04 \mathrm{E}+07$ & $9.78 \mathrm{E}+06$ & $1.38 \mathrm{E}+09$ \\
\hline \multicolumn{5}{|l|}{ (C) Sulfur recovery } \\
\hline \multirow[t]{3}{*}{ Clause straight } & 5 bar, $200{ }^{\circ} \mathrm{C}$ & $3.06 \mathrm{E}+06$ & $3.72 \mathrm{E}+05$ & $9.59 \mathrm{E}+05$ \\
\hline & 5 bar, $300^{\circ} \mathrm{C}$ & $3.07 \mathrm{E}+06$ & $3.73 \mathrm{E}+05$ & $9.59 \mathrm{E}+05$ \\
\hline & 5 bar, $400^{\circ} \mathrm{C}$ & $3.29 \mathrm{E}+06$ & $4.01 \mathrm{E}+05$ & $9.60 \mathrm{E}+05$ \\
\hline \multirow[t]{3}{*}{ Clause split } & 5 bar, $200{ }^{\circ} \mathrm{C}$ & $3.27 \mathrm{E}+06$ & $3.06 \mathrm{E}+06$ & $9.59 \mathrm{E}+05$ \\
\hline & 5 bar, $300^{\circ} \mathrm{C}$ & $3.29 \mathrm{E}+06$ & $3.07 \mathrm{E}+05$ & $9.59 \mathrm{E}+05$ \\
\hline & 5 bar, $400^{\circ} \mathrm{C}$ & $3.46 \mathrm{E}+06$ & $4.21 \mathrm{E}+05$ & $9.60 \mathrm{E}+05$ \\
\hline (D) Dehydration & 50 bar, $21.1^{\circ} \mathrm{C}$ & $2.76 \mathrm{E}+07$ & $3.36 \mathrm{E}+06$ & $1.21 \mathrm{E}+07$ \\
\hline (E) NGL separation & 14 bar, $-62.2^{\circ} \mathrm{C}$ & $1.68 \mathrm{E}+07$ & $2.04 \mathrm{E}+06$ & $2.48 \mathrm{E}+09$ \\
\hline $\begin{array}{l}\text { (F) Fractionation } \\
\text { (1)Conventional }\end{array}$ & 20 bar, $143{ }^{\circ} \mathrm{C}$ & $8.05 \mathrm{E}+06$ & $9.79 \mathrm{E}+05$ & $1.77 \mathrm{E}+09$ \\
\hline (2) nonconventional & 20 bar, $-9.4^{\circ} \mathrm{C}$ & $1.28 \mathrm{E}+07$ & $1.55 \mathrm{E}+06$ & $2.46 \mathrm{E}+11$ \\
\hline
\end{tabular}

The total capital, annuity of capital, and total operating cost of each processing unit are shown in Table 5.9. Based on the different yields obtained for different products, and different capital and operating cost for each option. The formulated model was applied on processing network.The formulated MILP has 66 variables with 14 integer variables and 89 constraints. It has been solved in LINGO 14.0 version with branch and bound solver type. The input file and its solution for LINGO can be found in Appendix B2. The solid line units are the ones selected shown in Figure 5.9 by the formulated model. It was found that $\$ 3.94 \mathrm{E}+09$ is the optimal annual profit as defined by the objective function. The optimal results such as flowrate values are 68727 , 
$30587,1102851,48547,56962$, and $11828 \mathrm{~kg} / \mathrm{h}$ for field condensate, sulfur, methane, ethane, LPG, and plant condensate products, respectively. Also, X122, X212, X311, X411, X511, and X611 are the optimal seleced binary variables. X122 means operating the stabilization at 13.8 bar, $157{ }^{\circ} \mathrm{C}$ to produce $16 \mathrm{RVP}$ product. Although, the first configuration of acid gas removal unit has the lowest total annual operating cost, with significant $\mathrm{H}_{2} \mathrm{~S}$ removal, $\mathrm{CO}_{2}$ was not removed. X212 represents operating acid gas removal unit with (MDEA 30wt\%+DEA15wt\%) at 55 bar and $35{ }^{\circ} \mathrm{C} . \mathrm{X} 311$ represents operating the sulfur recovery unit at $5 \mathrm{bar}, 200{ }^{\circ} \mathrm{C}$ with Clause straight configuration. X411 represents operating the dehydration unit at $50 \mathrm{bar}, 21.1^{\circ} \mathrm{C}$ with TEG. X511 represents operating the NGL recovery unit at 14 bar, $-62.2{ }^{\circ} \mathrm{C}$. Finally, X611 represents operating the fractionation unit at $20 \mathrm{bar},-9.4{ }^{\circ} \mathrm{C}$ with direct sequence configuration. 


\subsection{Conclusions and Future work}

A comprehensive mixed-integer linear programming (MILP) model was developed for the design and optimization of natural gas processing network. The natural gas processing network consisting of six major blocks, namely, stabilization, acid gas removal, sulfur recovery, dehydration, NGL recovery, and NGL fractionation was simulated using ASPEN Plus simulation package. For each processing unit, various relevant technologies and types of equipment were considered. The simulation-optimization framework was implemented on two detailed case studies to demonstrate the key features and applicability of the proposed approach. The yield data for the MILP model as parameters were obtained from the simulation. In order to keep the linearity of the model the product yield function was discretized over the operating conditions range by running many simulation cases and various yield values were obtained. Furthermore, the demand constraint of MILP model was set as demand range from the simulated products flowrate. Next, we need to address the design and optimization of the downstream of the natural gas network. 


\section{CHAPTER SIX}

\section{MIXED INTEGER MODEL FOR DESIGN AND OPERATIONAL OF NATURAL GAS PRODUCTION NETWORK}

\subsection{Introduction}

Many potential applications are available for diversification and utilization of natural gas resources. These include pipelines, liquefied natural gas (LNG), compressed natural gas (CNG), gas to solids (GTS), i.e. hydrates, gas to wire (GTW), i.e. electricity, gas to liquids (GTL). Furthermore, a wide range of products and these include clean fuels, plastic precursors or methanol and gas to commodity (GtC), such as aluminium, glass, cement or iron (Thomas, 2003). British Columbia ranked second to Alberta in natural gas production in Canada, considered the following options as promising utilization options; LNG, GTL, methanol, and fertilizers such as ammonia (BC Ministry of Energy, 2013; British Columbia's natural gas strategy, 2012). For each key processing unit of production process, there is no single technology or process configuration that is superior in all aspects. Thus, many process configurations are available for selection and the choice of technologies can be vast. Therefore, for optimal design of the natural gas production network, process selection of the individual units must be made on the basis of an integrated approach that considers interactions between units and integration among them. The main objective of this work is to provide a systematic framework and formulate a comprehensive mixed integer optimization model to select the optimal superstructure among the available options for natural gas production network. 


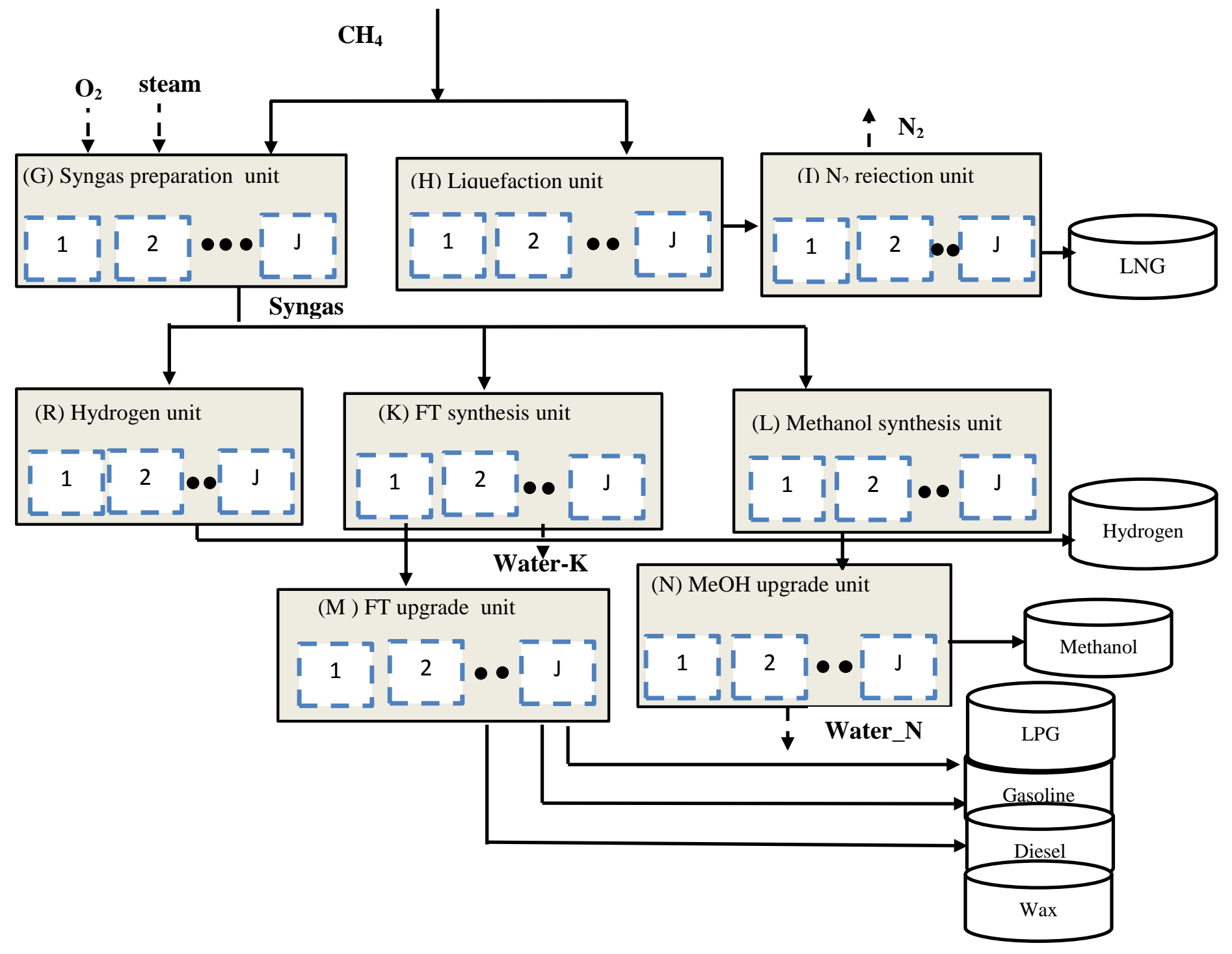

Figure 6.1 A schematic representation of natural gas production network with alternatives for each processing unit.

We focus in this Chapter on production network. The production network is represented by three major facilities, namely, LNG, GTL and Methanol. LNG volume is expected to triple over the 2014-2040 period to meet approximately 15 percent of global gas demand (ExxonMobil, 2014) with the center of the trade shifting from northeast Asia toward an even Atlantic/Pacific basin split. GTL technology offers an alternative way to convert chemically methane into longer-chain hydrocarbons such as liquid fuels and other valuable liquid hydrocarbons (e.g. lubricants and 
base oils), which can be transported much more compactly and easily (Wood, et al., 2012). GTL fuel products (i.e., gasoline and diesel) can be used either directly or blended with conventional diesel and burned in conventional diesel-powered vehicles. Methanol is currently mainly used in petrochemical industry and considered as one of the highest volume commodity petrochemicals, with a consumption of more than 40 million tons per year (Olah, et al., 2006). Because of many attributes such as convenience and safety in terms of transportation, storage, and usage, it is expected to substitute to some extent oil derivate fuel for automobile and power generation (Olah, et al., 2006). It is important to highlight that this work differs from our previous work (S.A. Al-Sobhi \& Elkamel, 2015) in regard the network representation where the network topology was fixed; in other words, a specific technology or configuration of processing unit was selected for simulation and optimization. However, in this work we allow the considerations of many options and alternatives of flowsheet. Also, this network is a continuation of processing network developed earlier in Chapter five.

A novel production network that considers various alternatives has been developed. Figure 6.1 shows the superstructure of natural gas production with alternatives for each production block. A comprehensive mixed integer optimization model is proposed to address natural gas production network. The main unique feature of this work is that it addresses different production processes namely LNG, GTL, and methanol along with different design alternatives for each main processing units namely syngas preparation, Liquefaction, N2 rejection, Hydrogen, FT synthesis, Methanol synthesis, FT upgrade, and Methanol upgrade units. For example, different LNG liquefaction cycles, competing syngas manufacturing technologies, different types of FischerTropsch catalysts and reactors, etc. with wide range of operational conditions. Another feature is 
that it focuses on production network, an important component of natural gas supply chain, through rigorous simulation, modeling, and optimization.

The remainder of Chapter 6 is organized as follows. The key processing units are described in section 6.2. Then the mathematical model is formulated and presented in section 6.3. In section 6.4, we will illustrate the performance of the model through an industrial-scale natural gas production system and discuss the main findings. The Chapter ends with some concluding remarks in section 6.5 .

\subsection{Process Description}

Since the focus of this chapter is on production network, for example units (G-M) shown previously, the key units of the network are described below.

\subsubsection{Syngas preparation unit (G):}

The primary purpose of syngas unit is to produce the synthesis gas (syngas), a mixture of CO and $\mathrm{H}_{2}$, from the methane rich stream. Syngas preparation is an important part for GTL, methanol, and hydrogen production. Also, it plays an important role in the conversion of natural gas into transportation fuels, such as methanol, DME, synthetic gasoline, and diesel. For GTL plant in particular, it is responsible for $60 \%$ of the investments (Rostrup-Nielsen, 2002). Different technologies are available to produce syngas from natural gas (Aasberg-Petersen et al., 2001; Luyben, 2014; Rostrup-Nielsen, 2000; Wilhelm et al, 2001). Namely, these include: catalytic steam methane reforming (SMR), two-step reforming, partial oxidation (POX), autothermal reforming (ATR), combined Reforming (CR), ceramic membrane reforming (CMR), and dry reforming (DR). The combined reforming consists of a combination of steam methane reforming and autothermal reforming. The choice of reforming technology is determined by balancing 
between the characteristics of each one, economic, and environmental impact. In POX process the methane rich stream reacts with steam and oxygen to produce hydrogen, carbon monoxide and carbon dioxide. POX could allow the absence of catalyst and thus lower $\mathrm{CO}_{2}$ content, but it requires oxygen and a high operating temperature causing soot formation that is hard to handle. However, in SMR process, oxygen is not required but it produces much higher hydrogen than needed. The ATR has the most favorable $\mathrm{H}_{2} / \mathrm{CO}$ ratio for cobalt-based catalyst; however, it needs oxygen to proceed. In general, ATR shows up in many commercial processes due to its ability to handle large-scale scenarios. ATR was shown to be the cheapest solution fulfilling the optimum requirements of the FT and methanol syntheses unit (Rostrup-Nielsen, 2002). Future improvements for example, in air separation unit may lead to cost reduction. The most expensive part of the plant is the oxygen plant, typically represents $30-40 \%$ of the investments of the syngas unit (Rostrup-Nielsen, 2002) and a tight integration of the oxygen plant with the syngas unit would reduce syngas generation cost for the application of ATR (Aasberg-petersen et al., 2003; Wilhelm et al., 2001). Although that CMR shows promising results, substantial issues still need to be solved. So, CMR is not considered as a real competitor to ATR or combinations of ATR/HTER within the next 10 years (Bakkerud, 2005). Julia et al,. (2014) assessed syngas technologies for methanol production from shale gas. Four reforming technologies were considered in their work, namely, partial oxidation (POX), steam methane reforming (SMR), autothermal reforming (ATR), and combined reforming (CR). The results showed that the use of POX or ATR provides the best alternative with the high profitability potential for methanol production. However, from an environmental aspect, CR turned out to be the option with the lowest carbon footprint. Noureldin et al., (2014) addressed the optimization and selection of natural or shale gas reforming. The considered four major reforming options namely, steam 
reforming, partial oxidation, dry reforming, and combined reforming. They found that combined reforming (including trireforming) improved the process aspects such as energy usage, safety, and flexibility.

\subsubsection{Liquefaction unit (H):}

The main purpose of the liquefaction unit is to liquefy the methane rich stream. Many liquefaction technologies exist and their difference arise mainly in the types of refrigeration cycles they employ. The most commonly utilized LNG technologies (Tusiani \& Shearer, 2007) are: APCI Propane Pre-cooled Mixed Refrigerant (PPMR) process, Phillips Optimized Cascade LNG Process (OCLP), and Shell Dual Mixed Refrigerant (DMR) process. While the PPMR process dominates the industry, there has been considerable diversification of liquefaction processes recently. Mokhatab and Economides, (2006) presented a critical overview of LNG processes and provided a comprehensive analysis of the main methods available for the liquefaction of natural gas in an onshore LNG plant. They also discussed selection issues relating to the main technologies that affect LNG plant configuration. The selected PPMR process as the basis for the liquefaction design, covers nearly $90 \%$ of the total baseload LNG capacity installed worldwide since 1972. Also, it is generally accepted to be the most cost effective and reliable baseload LNG process available.

\subsection{3 $\mathrm{N}_{2}$ Rejection unit (I):}

The main purpose of nitrogen rejection unit is to reject the nitrogen to meet another pipeline gas specification. Three scenarios require nitrogen separation or rejection: (1) processing a gas high in nitrogen to produce a pipeline quality gas, (2) Removing nitrogen from a natural gas so that the nitrogen can be used in an enhanced oil recovery (EOR) operation, and (3) Separating helium 
from nitrogen in a helium recovery operation (Kidnay \& Parrish, 2006). Three basic methods are used for removal of nitrogen from natural gas: (A) cryogenic distillation, (B) adsorption, and (C) membrane separation. The most common method of removing nitrogen from natural gas is cryogenic distillation. For feed concentrations below $20 \% \mathrm{~N}_{2}$, a single-column design can be used. For higher concentrations, a dual-column is preferred (GPSA Engineering Data Book, 2004).

\subsubsection{Hydrogen unit (R):}

The primary purpose of the hydrogen unit is to produce hydrogen to the specifications needed for utilization and distribution. Typically, hydrogen is produced mainly by three main steps, (1) Syngas Preparation: the steam reforming of natural gas is the principal industrial process for the production of hydrogen; it accounts for more than half of the world hydrogen production (Mueller-Langer et al., 2007), (2) Water Shift Reaction; in the exothermic water gas shift reaction, $\mathrm{CO}$ reacts with more steam producing additional hydrogen and $\mathrm{CO}_{2}$. The product gas consists mainly of $\mathrm{H}_{2}$ and $\mathrm{CO}_{2}$, and some impurities such as unconverted $\mathrm{CH}_{4}$ and $\mathrm{CO}$, (3) separation step: the $\mathrm{CO}_{2}$ is removed by an alkaline-based solution such as alkanolamines via chemical absorption and a hydrogen-rich gas is produced which is further purified via pressure swing adsorption (PSA).

\subsubsection{FT synthesis unit (K):}

The purpose of Fischer-Tropsch (FT) synthesis unit is to produce long-chain hydrocarbon molecules (syncrude) from syngas feedstock. The primary focus of most large-scale FT technologies in current market conditions is to produce high-quality low-emissions GTL gasoline, diesel, jet fuel and naphtha for petrochemical feedstock or gasoline blending. There are 
two major categories of natural gas-based FT processes (Dry, 2002): (A) the high-temperature Fischer Tropsch (HTFT) (Steynberg, et al., 1999) and (B) the low-temperature Fischer Tropsch (LTFT) (Espinoza, et al., 1999; Jager \& Espinoza, 1995). In HTFT, the typical operating conditions of high temperatures range from $300-350{ }^{\circ} \mathrm{C}$ and pressures of approximately $2.5 \mathrm{MPa}$. Though the high-temperature, iron catalyst-based FT GTL process produces fuels such as gasoline and diesel that are closer to those produced from conventional oil refining, the resultant GTL fuels are sulphur-free, but contain some aromatics. Conversion in HTFT can be greater than $85 \%$ (de Klerk, 2011), but not all the products are readily usable or capable of producing high quality transport fuels. HTFT processes tend to be conducted in either circulating fluidized bed reactors or fluidised bed reactors (Velasco et al., 2010). LTFT involves the use of lowtemperature, cobalt-catalyst-based processes, either in slurry-phase bubble-column reactors (e.g. Sasol) or in multi-tubular fixed-bed reactors (e.g. Shell). LTFT produces a synthetic fraction of diesel (GTL diesel) that is virtually free of sulphur and aromatics. Typical process operating conditions for LTFT are temperatures of $200-240{ }^{\circ} \mathrm{C}$ and pressures of approximately 2.0-2.5 MPa. Conversion in LTFT is typically only about $60 \%$ with recycle or reactors operating in series to limit catalyst deactivation (de Klerk, 2011).

\subsubsection{Methanol Synthesis Unit (L):}

The purpose of methanol synthesis unit is to produce raw methanol from syngas feedstock. Raw methanol is a mixture of methanol, a small amount of water, dissolved gases, and traces of byproducts. The methanol synthesis catalyst and process are highly selective with a selectivity of 99.9\%. The conversion of hydrogen and carbon oxides to methanol is described by the following reactions (6.1), (6.2), and (6.3):

$$
\mathrm{CO}_{2}+3 \mathrm{H}_{2} \leftrightarrow \mathrm{CH}_{3} \mathrm{OH}+\mathrm{H}_{2} \mathrm{O} \quad-\Delta \mathrm{H}_{298 \mathrm{~K}, 50 \mathrm{Bar}}=40.9 \mathrm{~kJ} / \mathrm{mol}
$$


$\mathrm{CO}+2 \mathrm{H}_{2} \leftrightarrow \mathrm{CH}_{3} \mathrm{OH}$

$\mathrm{CO} 2+\mathrm{H}_{2} \leftrightarrow \mathrm{CO}+\mathrm{H}_{2} \mathrm{O}$
$-\Delta \mathrm{H}_{298 \mathrm{~K}, 50 \mathrm{Bar}}=90.7 \mathrm{~kJ} / \mathrm{mol}$

$-\Delta \mathrm{H}_{298 \mathrm{~K},}, 50 \mathrm{Bar}=49.8 \mathrm{~kJ} / \mathrm{mol}$

There are three major categories of synthesis reactor or converter: (A) Quench reactor

(B) Adiabatic reactors in series (C) Boiling water reactors (BWR)

A quench reactor consists of a number of adiabatic catalyst beds. In practice up to five catalyst beds have been installed in series in one pressure shell. The reactor feed is split and distributed to the synthesis reactor between the individual catalyst beds. The quench reactor design is not considered today for large capacity plants. The adiabatic reactors system normally comprises of 2-4 fixed bed reactors placed in series with cooling between the reactors. The design can be scaled up to single-line capacities of 10,000 MTPD or more. The BWR is in principle a shell and tube heat exchanger with catalyst on the tube side. The reactor is cooled by circulating boiling water on the shell side. The steam produced may be used as process steam. The reaction temperature is controlled and optimized by controlling the pressure of the circulating boiling water. The reactor will operate at intermediate temperatures between $240-260{ }^{\circ} \mathrm{C}$.

\subsubsection{FT upgrading unit (M):}

The purpose of FT upgrading unit is purification and separation of synthesis crude into desired products. The hydro-treating/ cracking of the waxes takes place to obtain the final desired products normally LPG, synthetic gasoline and diesel.

\subsubsection{Methanol upgrading unit $(\mathrm{N})$ :}

The purpose of methanol distillation unit is purification of the raw methanol to produce methanol product with a specific purity. The crude methanol from synthesis unit contains water and other 
byproducts. Typical byproducts include DME, higher alcohols, other oxygenates and minor amounts of acids and aldehydes. Different designs of distillation column system are available to be implemented. The design of this unit depends on the desired end product. Grade AA methanol requires removal of essentially all water and byproducts while the requirements for fuel grade methanol are more relaxed. Two or three distillation columns usually are used to achieve the AA grade specification which is the most commonly accepted specification in world methanol trade, where the first is a stabilizer for removal of dissolved gases.

\subsection{Mathematical Programming Model}

The mathematical formulation includes an objective function that maximizes the profit, and several model constraints to satisfy energy demand, $\mathrm{CO}_{2}$ emission limits, operational restrictions and limitations. The mathematical model consists of a set of equations and constraints that holistically describe mathematically each block in the superstructure in terms of overall mass balance, yield, quality, different technologies, demand, and capacity constraints, and so on.

\subsubsection{Overall mass balance, and yield model}

The overall mass balance and yield representation of each key processing unit in the production network is presented starting with the syngas unit. The rich methane stream, $F_{C H 4}$ recoverd from NGL unit (unit E in upstream processing network) is sent to both syngas preparation unit and liquefaction unit. The exact percentage of methane fed to each unit to be determined by optimization yet lower bound values are set for both units to ensure that both units receive methane. So, the overall mass balance of methane rich stream can be written as:

$F_{C H 4}=F_{C H 4}^{G}+F_{C H 4}^{H}$ 
Because we need to select just one reforming technology from available technologies, we have the following constraint shown in equation (6.5),

$$
\sum_{m \in M_{G}} \sum_{j \in J_{G}} X_{j m}^{G}=1 \quad G=\text { syngas reforming unit }
$$

Where, $J_{G}=\{$ set of reforming technologies $\}$ and

$$
M_{G}=\{\text { set of operating mode for reforming technologies }\}
$$

$X_{j m}^{G}=1$ if technology $j$ is selected at a specific operating mode, $m$.

$$
=0 \text { otherwise }
$$

Although different technologies are available to produce syngas from natural gas, we will consider only ATR and SMR as competing technologies of reforming unit for their applicability in large scale applications. The rich methane stream directed to syngas unit, $F_{C H 4}^{G}$ is fed along with steam flowrate, $F_{\text {steam }}^{G}$, for the case of SMR and oxygen flow rate, $F_{O 2}^{G}$, for the case of ATR to produce the required syngas ratio as shown in equation (6.6). We will write 2 different types of balances for each technology such as $j=\mathrm{ATR}, \mathrm{SMR}$. Output of each option is $\mathrm{H}_{2}, \mathrm{CO}$ and $\mathrm{CO}_{2}$ as shown in equation (6.6) with different flowrate and accordingly we get different syngas $\left(\mathrm{H}_{2} / \mathrm{CO}\right)$ ratios. The desirable composition of the syngas for the low-temperature FT corresponds to a ratio $\mathrm{H}_{2} / \mathrm{CO}$ of 2 .

$F_{C H 4_{j}}^{G}+F_{\text {steam }_{j}}^{G}+F_{O 2_{j}}^{G}=F_{H 2_{j}}^{G}+F_{C O_{j}}^{G}+F_{C O 2_{j}}^{G}+F_{\text {water }_{j}}^{G}$

Whereas, the syngas flowrate is defined in equation (6.7),

$F_{\text {syngas } j}^{G}=F_{H 2 j}^{G}+F_{C O_{j}}^{G}+F_{C O 2_{j}}^{G}$

For $\mathrm{j}=\mathrm{ATR}$, the steam to $\mathrm{CH}_{4}$ is set to be 0.6 as the operating ratio as shown in equation (6.8). This very low ratio around 0.6 , rather than the previously used high ratio of $1.3-2.0$, becomes the 
state-of-the-art syngas ratio for FT application in modern plants in Europe and Middle East (A. Steynberg \& Dry, 2004).

$F_{\text {steam }_{j}}^{G}=0.6 * F_{C H 4_{j}}^{G}$

$F_{O 2_{j}}^{G}=f\left(F_{C H 4_{j}}^{G}\right)$

Equation 6.9 stated that the required oxygen flowrate is a function of methane flowrate. In order to produce the required syngas ratio, we need to generate $\mathrm{O}_{2}$ and $\mathrm{CH}_{4}$ flowrate data from the simulation and get different syngas ratio values by changing oxygen flowrate for a given methane flowrate. Then, by plotting syngas ratio vs $\mathrm{O} 2$ flowrate, we can find the right value of $\mathrm{O}_{2}$ that corresponds to a syngas ratio of 2 . Also, the simulator sensitivity analysis modeling option can be used for this purpose as shown in Figure 6.2.

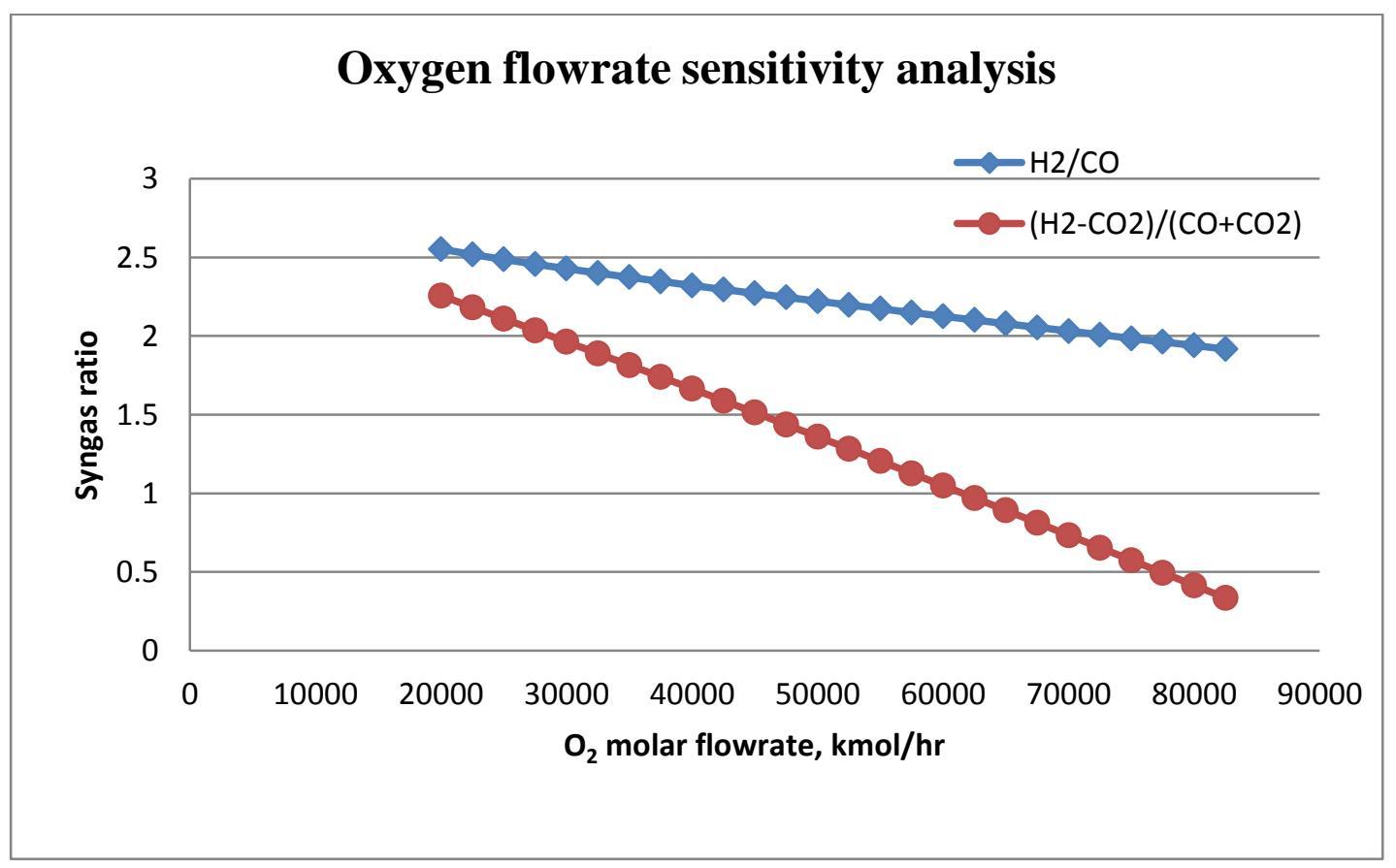

Figure 6.2 Sensitivity analyses for oxygen flowrate. 
For $\mathrm{j}=\mathrm{SMR}$, the overall material balance is given in equation (6.10)

$$
\begin{aligned}
& F_{C H 4_{j}}^{G}+F_{\text {steam }_{j}}^{G}=F_{H 2_{j}}^{G}+F_{C O_{j}}^{G}+F_{C O 2_{j}}^{G} \\
& F_{\text {steam }_{j}}^{G}=f\left(F_{\mathrm{CH}_{j}}^{G}\right)
\end{aligned}
$$

$$
F_{\text {syngas }}^{G}=\sum_{m \in M_{D}} \sum_{j \in J_{D}} F_{\text {syngas }}^{G}
$$

Furthermore, the produced syngas is distributed among the candidate receiving units namely, hydrogen unit (R), FT synthesis unit (K), and methanol synthesis unit (L) as shown in equation (6.13). Again the exact $F_{\text {syngas }}^{G}$ fed to three units namely, hydrogen production unit (R), FT synthesis unit $(\mathrm{K})$, and methanol synthesis unit (L) is an optimization variable. Yet the lower bound value is set for the three units to ensure that all units receive syngas flowrate.

$$
\begin{aligned}
& F_{\text {syngas }_{j}}^{G}=F_{\text {syngas }_{j}}^{R}+F_{\text {syngas }_{j}}^{K}+F_{\text {syngas }_{j}}^{L} \\
& F_{\text {syngas }_{j}}^{R}=F_{H 2}^{R}+F_{C O}^{R}+F_{C O 2}^{R}
\end{aligned}
$$

Because we need to select just one hydrogen production from the different available technologies, we have the following constraints shown in equations (6.15) and (6.16),

$$
\sum_{m \in M_{R}} \sum_{j \in J_{R}} X_{j m}^{R}=1 \quad R=\text { hydrogen production block }
$$

Where, $J_{R}=\{$ set of hydrogen production technologies $\}$ and

$$
M_{R}=\{\text { set of operating mode for hydrogen production technologies }\}
$$

$X_{j m}^{R}=1$ if technology $j$ is selected at a specific operating mode, $m$.

$$
=0 \text { otherwise }
$$

$$
F_{\text {syngas }_{j}}^{R} \leq X_{j m}^{R} * F_{\text {syngas }^{J, U}} \quad \forall j \in J_{R}, m \in M_{R}
$$


In a similar fashion for FT and methanol syntheses, we have the following constraints shown in equations (6.17) and (6.18) for FT synthesis and equations (6.19) and (6.20) for methanol synthesis,

$$
\sum_{m \in M_{K}} \sum_{j \in J_{K}} X_{j m}^{K}=1 \quad K=\text { FT production unit }
$$

Where, $J_{K}=\{$ set of FT production technologies $\}$ and

$$
M_{K}=\{\text { set of operating mode for FT production technologies }\}
$$

$X_{j m}^{K}=1$ if technology $j$ is selected at a specific operating mode, $m$.

$$
=0 \text { otherwise }
$$

$F_{\text {syngas }_{j}}^{K} \leq X_{j m}^{K} * F_{\text {syngas }}^{J, U} \quad \forall j \in J_{K}, m \in M_{K}$

$\sum_{m \in M_{L}} \sum_{j \in J_{L}} X_{j m}^{L}=1 \quad L=$ methanol synthesis unit

Where, $J_{L}=\{$ set of methanol synthesis technologies $\}$ and

$$
M_{L}=\{\text { set of operating mode for methanol synthesis technologies }\}
$$

$X_{j m}^{L}=1$ if technology $j$ is selected at a specific operating mode, $m$.

$$
=0 \text { otherwise }
$$

$F_{\text {syngas }_{j}}^{L} \leq X_{j m}^{L} * F_{\text {syngas }}^{J, U} \quad \forall j \in J_{L}, m \in M_{L}$

Hydrogen from unit R, as shown in (6.21)

$F_{H 2}=f\left(F_{\text {syngas }_{j}}^{J}\right)$

Equation 6.21 stated that the produced hydrogen flowrate is a function of syngas flowrate and selected syngas technology. The rich methane stream fed to liquefaction unit, $F_{C H 4}^{H}$ is compressed and cooled down to $-160 \mathrm{C}$. Now, this stream is in a liquid form but with nitrogen content, $F_{C H 4(l) \_N 2}^{I}$, and is sent to $\mathrm{N}_{2}$ rejection unit to reject $\mathrm{N} 2$ stream and get LNG stream, $F_{L N G}$ as shown in equation (6.22) 
$F_{C H 4}^{H}=F_{N 2}+F_{L N G}$

$\sum_{m \in M_{H}} \sum_{j \in J_{H}} X_{j m}^{H}=1 \quad H=$ liquefaction unit

Where, $J_{H}=\{$ set of liquefaction technologies $\}$ and

$M_{H}=\{$ set of operating mode for liquefaction unit technologies $\}$

$X_{j m}^{H}=1$ if technology $j$ is selected at a specific operating mode, $m$.

$$
=0 \text { otherwise }
$$

$F_{L N G_{j}} \leq X_{j m}^{H} * F_{L N G}^{U} \quad \forall j \in J_{H}, m \in M_{H}$

Equations (6.25) to (6.31), give the overall material balances around unit (M) and unit $(\mathrm{N})$,

$$
\begin{aligned}
& F_{H 2}^{K}+F_{C O}^{K}+F_{C O 2}^{K}=F_{\text {syncrude }}^{K}+F_{\text {water }}^{K} \\
& F_{H 2}^{L}+F_{C O}^{L}+F_{C O 2}^{L}=F_{\text {methanolcrude }}^{L}+F_{\text {water }}^{L} \\
& F_{\text {methanol }}^{N}=F_{\text {methanol_crude }}^{L}-F_{\text {water }}^{L} \\
& F_{L P G}^{M}=s f_{1} * F_{\text {syncrude }}^{K} \\
& F_{\text {Gasoline }}^{M}=s f_{2} * F_{\text {syncrude }}^{K} \\
& F_{\text {Diesel }}^{M}=s f_{3} * F_{\text {syncrude }}^{K} \\
& F_{\text {Wax }}^{M}=s f_{4} * F_{\text {syncrude }}^{K}
\end{aligned}
$$

Where $s f_{1}, s f_{2}, s f_{3}$ and $s f_{4}$ are pre-specified selectivity factors for LPG, gasoline, diesel, and wax, respectively. 


\subsection{2 supply constraint}

Consumption of methane stream through the network should not exceed the upper methane availability limit, $F_{C H 4}^{U}$ as shown in equation (6.32), and should be higher than the minimum quantity fed to the network, $F_{C H 4}^{L}$.

$F_{C H 4}^{L} \leq F_{C H 4} \leq F_{C H 4}^{U}$

\subsubsection{Demand constraints}

The annual demand constraints of network's main products are given in equations (6.33-6.40)

$D_{L N G} \leq F_{L N G}$

$D_{\text {Hydogen }} \leq F_{\text {Hydrogen }}$

$D_{\text {Methanol }} \leq F_{\text {methanol }}^{N}$

$D_{L P G}^{M} \leq F_{L P G}^{M}$

$D_{\text {Gasoline }} \leq F_{\text {Gasoline }}^{M}$

$D_{\text {Desiel }} \leq F_{\text {Diesel }}^{M}$

$D_{\text {Wax }} \leq F_{W a x}^{M}$

\subsubsection{Capacity constraint of processing units of the network}

Capacity constraint of main processing units of the production network are given in equations $(6.40-6.39)$ 


$$
\begin{array}{lr}
F_{C H 4}^{G}+F_{\text {steam }}^{G}+F_{O 2}^{G} \leq F_{\text {Natgas }} \leq Q_{G j} * X_{j m}^{G} & \forall j \in J_{G}, m \in M_{G} \\
F_{C H 4}^{H}+F_{N 2} \leq Q_{H j} * X_{j m}^{H} & \forall j \in J_{H}, m \in M_{H} \\
F_{H 2}^{R}+F_{C O}^{R} \leq Q_{R j} * X_{j m}^{R} & \forall j \in J_{R}, m \in M_{R} \\
F_{H 2}^{K}+F_{C O}^{K} \leq Q_{K j} * X_{j m}^{K} & \forall i \in J_{K}, m \in M_{K} \\
F_{H 2}^{L}+F_{C O}^{L} \leq Q_{L j} * X_{j m}^{L} & \forall i \in J_{L}, m \in M_{L} \\
F_{\text {syncrude }}^{M}+F_{\text {water }}^{M} \leq Q_{G j} * X_{j m}^{M} & \forall i \in J_{M}, m \in M_{M} \\
F_{\text {methanolcrude }}^{N}+F_{\text {water }}^{N} \leq Q_{G j} * X_{j m}^{N} & \forall i \in J_{N}, m \in M_{N}
\end{array}
$$

where $Q_{i j}$, denotes the upper capacity limit for unit processing i (i=G,H,I,R,K,L,M, and N) for technology j.

\subsubsection{Non negativity constraint}

All variables are positive

\subsubsection{Objective function}

The objective of the proposed optimization model is to maximize the annual profit of production network. The total production cost is represented by an annualized capital cost, variable annual operating costs, and fixed annual operating cost of major units for example units $(\mathrm{G}-\mathrm{N})$ plus the annual cost of methane stream usage. It is assumed that capital costs are amortized over the lifetime of the project life of 20 years with $10 \%$ as a compound interest rate.

Annual revenue is calculated as the sum of all product sales minus processing cost 
maximize annual profit

$$
\begin{array}{ll}
=\sum_{p} s p_{p} \cdot F_{p}-\sum_{C H 4} n p \cdot F_{C H 4}-\sum_{i} \sum_{m} \sum_{j} A C C_{j} * X_{j m}^{i} \\
-\sum_{i} \sum_{m} \sum_{j} A O C_{j} * X_{j m}^{i}, & \forall i, m, k, C H 4, j
\end{array}
$$

Where,

$s p_{k}$ is the selling price of each network products

$n p$ is natural gas feedstock price

$A C C_{j}=$ amoritzed capital cost for technology $\mathrm{j}$

$A O C_{j}=$ annual operating cost for technology $\mathrm{j}$

\subsection{Case Study}

An illustrative case study is presented to show the applicability of the overall framework and formulated model presented in the previous sections. Different rigorous simulations of the production network pathway were carried out using Aspen Plus to obtain surrogate models or appropriate yield equations for the production flowrate. The main key processing units such as syngas preparing unit $(\mathrm{G})$, liquefaction unit $(\mathrm{H}), \mathrm{N} 2$ rejection unit (I), hydrogen unit (R), FT

synthesis unit (K), methanol synthesis unit (L), FT upgrade unit (M), and $\mathrm{MeOH}$ upgrade unit (N) are considered. The methane stream comes from NGL recovery unit (E) with a specific flowrate and operating conditions is used in our analysis. The cost data represented in the case study are based on ICARUS software output and open-source data. 
We present below the results of some of the simulation scenarios. Different percentage values for methane utilization considering different utilization production processes such as LNG, GTL, and methanol are considered. For example, $100 \%, 70 \%, 50 \%$, and $30 \%$ of methane stream is utilized. First, we assume that LNG is the most promising option and 100\%, $70 \%, 50 \%$, and $30 \%$ of methane stream is utilized to produce just LNG. Table 6.1 shows the total capital cost, total operating cost, total utilities cost, yield values, and objective function values for each planning mode considering LNG production.

Table 6.1 LNG different planning mode results.

\begin{tabular}{|l|c|c|c|c|}
\hline LNG & $100 \%$ & $70 \%$ & $50 \%$ & $30 \%$ \\
\hline Total Capital Cost, \$ & $1.845 \mathrm{E}+07$ & $1.43 \mathrm{E}+07$ & $1.16 \mathrm{E}+07$ & $8.90 \mathrm{E}+06$ \\
\hline Amortized capital cost, \$/yr & $2.24 \mathrm{E}+06$ & $1.74 \mathrm{E}+06$ & $1.42 \mathrm{E}+06$ & $1.08 \mathrm{E}+06$ \\
\hline Total Operating Cost, \$/yr & $2.481 \mathrm{E}+09$ & $1.74 \mathrm{E}+09$ & $1.24 \mathrm{E}+09$ & $7.45 \mathrm{E}+08$ \\
\hline Total Utilities Cost, \$/yr & $2.296 \mathrm{E}+09$ & $1.61 \mathrm{E}+09$ & $1.15 \mathrm{E}+09$ & $6.89 \mathrm{E}+08$ \\
\hline Desired Rate of Return, \%/yr & 10 & 10 & 10 & 10 \\
\hline lifetime of the project, yr & 20 & 20 & 20 & 20 \\
\hline LNG mass flow rate, kg/h & 1128350.68 & 789845.48 & 564175.3 & 338505.2 \\
\hline LNG yield & 0.882273667 & 0.6175916 & 0.441137 & 0.2646821 \\
\hline objective function, \$ & $1.96 \mathrm{E}+09$ & $1.34 \mathrm{E}+09$ & $9.26 \mathrm{E}+08$ & $5.11 \mathrm{E}+08$ \\
\hline
\end{tabular}


Second, we assume that methanol is the most promising option and $100 \%, 70 \%, 50 \%$, and $30 \%$ of methane stream is utilized to produce just methanol. Table 6.2 shows the total capital cost, total operating cost, yield values, and objective function values for each planning mode considering methanol production.

Table 6.2 Methanol different planning mode results.

\begin{tabular}{|l|c|c|c|c|}
\hline Methanol & $100 \%$ & $70 \%$ & $50 \%$ & $30 \%$ \\
\hline Total Capital Cost, \$ & $4.48 \mathrm{E}+07$ & $3.37 \mathrm{E}+07$ & $2.50 \mathrm{E}+07$ & $1.93 \mathrm{E}+07$ \\
\hline Amortized capital cost, \$/yr & $5.45 \mathrm{E}+06$ & $4.10 \mathrm{E}+06$ & $3.04 \mathrm{E}+06$ & $2.35 \mathrm{E}+06$ \\
\hline Total Operating Cost, \$/yr & $7.15 \mathrm{E}+07$ & $5.85 \mathrm{E}+07$ & $5.04 \mathrm{E}+07$ & $4.23 \mathrm{E}+07$ \\
\hline Total Utilities Cost, \$/yr & $6.20 \mathrm{E}+07$ & $5.06 \mathrm{E}+07$ & $4.34 \mathrm{E}+07$ & $3.62 \mathrm{E}+07$ \\
\hline Desired Rate of Return, \%/yr & 10 & 10 & 10 & 10 \\
\hline lifetime of the project, yr & 20 & 20 & 20 & 20 \\
\hline Methanol mass flowrate, $\mathrm{kg} / \mathrm{h}$ & 688052.861 & 481614.89 & 344010.6 & 206406.38 \\
\hline Water mass flowrate,kg/h & 479.91334 & 335.93837 & 239.956 & 143.97359 \\
\hline Methanol Yield & 0.667163311 & 0.4669929 & 0.333566 & 0.2001398 \\
\hline objective function, \$ & $1.10 \mathrm{E}+09$ & $8.45 \mathrm{E}+08$ & $5.68 \mathrm{E}+08$ & $2.91 \mathrm{E}+08$ \\
\hline
\end{tabular}


Third, we assume that GTL is the most promising option and $100 \%, 70 \%, 50 \%$, and $30 \%$ of methane stream is utilized to produce just FT products. Now, for FT process we have two distinct operating options such as LTFT and HTFT. Table 6.3 and Table 6.4 show the total capital cost, total operating cost, total utilities cost, yield values, and objective function values for each planning mode considering LTFT and HTFT production, respectively.

Table 6.3 GTL (LTFT) different planning mode results.

\begin{tabular}{|l|c|c|c|c|}
\hline GTL LTFT & $100 \%$ & $70 \%$ & $50 \%$ & $30 \%$ \\
\hline Total Capital Cost, $\$$ & $8.64 \mathrm{E}+07$ & $6.41 \mathrm{E}+07$ & $4.40 \mathrm{E}+07$ & $3.04 \mathrm{E}+07$ \\
\hline Amortized capital cost, \$/yr & $1.05 \mathrm{E}+07$ & $7.80 \mathrm{E}+06$ & $5.35 \mathrm{E}+06$ & $3.70 \mathrm{E}+06$ \\
\hline Total Operating Cost, \$/yr & $3.16 \mathrm{E}+07$ & $2.29 \mathrm{E}+07$ & $1.62 \mathrm{E}+07$ & $1.06 \mathrm{E}+07$ \\
\hline Total Utilities Cost, \$/yr & $2.43 \mathrm{E}+07$ & $1.70 \mathrm{E}+07$ & $1.17 \mathrm{E}+07$ & $6.96 \mathrm{E}+06$ \\
\hline Desired Rate of Return, \%/yr & 10 & 10 & 10 & 10 \\
\hline lifetime of the project, yr & 20 & 20 & 20 & 20 \\
\hline LPG mass flowrate, $\mathrm{kg} / \mathrm{h}$ & 12850.0323 & 4471.2343 & 2724.718 & 2395.3593 \\
\hline Gasoline mass flowrate, $\mathrm{kg} / \mathrm{h}$ & 83664.4917 & 57695.939 & 41179.17 & 27772.542 \\
\hline Diesel mass flowrate, $\mathrm{kg} / \mathrm{h}$ & 162909.448 & 114611.64 & 76506.51 & 40225.929 \\
\hline Wax mass flowrate, $\mathrm{kg} / \mathrm{h}$ & 610755.817 & 443272.05 & 310537.7 & 188175.01 \\
\hline Water mass flowrate, $\mathrm{kg} / \mathrm{h}$ & 65799.166 & 34693.161 & 32462.11 & 19477.269 \\
\hline LPG Yield & 0.0124599 & 0.0043355 & 0.002642 & 0.0023226 \\
\hline Gasoline Yield & 0.081124405 & 0.0559443 & 0.039929 & 0.0269294 \\
\hline Diesel Yield & 0.157963454 & 0.111132 & 0.074184 & 0.0390047 \\
\hline Wax Yield & 0.592213035 & 0.4298141 & 0.30111 & 0.1824619 \\
\hline objective function, \$ & $1.78 \mathrm{E}+09$ & $1.40 \mathrm{E}+09$ & $9.35 \mathrm{E}+08$ & $5.13 \mathrm{E}+08$ \\
\hline
\end{tabular}


As can be observed from above tabulated results, that 1.96E+09, 1.10E+09, 1.78E+09, 1.86E+09 are the objective function values (profit) for $100 \%$ utilization mode of LNG, methanol, LTFT, and HTFT, respectively. However, by inspection many other combination will results in a higher profit such as (70\%LNG, 30\% HTFT) results in \$ $2.82 \mathrm{E}+09,(70 \%$ HTFT, 30\% LNG ) mode results in \$ 2.47E+09 and (50\% LNG, 50\%HTFT) combination results in \$ $2.33 \mathrm{E}+09$ and so on. So, there is a combination of utilization modes resulting in a higher objective function value and we will use the formulated MILP model for this purpose to find the optimal combination.

Table 6.4 GTL (HTFT) different planning mode results.

\begin{tabular}{|l|c|c|c|c|}
\hline GTL HTFT & $100 \%$ & $70 \%$ & $50 \%$ & $30 \%$ \\
\hline Total Capital Cost, \$ & $9.05 \mathrm{E}+07$ & $5.77 \mathrm{E}+07$ & $4.72 \mathrm{E}+07$ & $3.44 \mathrm{E}+07$ \\
\hline Amortized capital cost, \$/yr & $1.10 \mathrm{E}+07$ & $7.02 \mathrm{E}+06$ & $5.74 \mathrm{E}+06$ & $4.18 \mathrm{E}+06$ \\
\hline Total Operating Cost, \$/yr & $4.56 \mathrm{E}+09$ & $1.51 \mathrm{E}+09$ & $1.15 \mathrm{E}+09$ & $9.23 \mathrm{E}+08$ \\
\hline Total Utilities Cost, \$/yr & $4.17 \mathrm{E}+09$ & $1.40 \mathrm{E}+09$ & $1.06 \mathrm{E}+09$ & $8.52 \mathrm{E}+08$ \\
\hline Desired Rate of Return, \%/yr & 10 & 10 & 10 & 10 \\
\hline lifetime of the project, yr & 20 & 20 & 20 & 20 \\
\hline LPG mass flowrate, kg/h & 67897.6575 & 308035.15 & 202597.2 & 205456.65 \\
\hline Gasoline mass flowrate, kg/h & 308035.145 & 223772.38 & 136950.1 & 137400.18 \\
\hline Diesel mass flowrate, kg/h & 202597.181 & 158931.39 & 103560 & 94116.642 \\
\hline Wax mass flowrate, kg/h & 205456.651 & 77533.101 & 50212.7 & 47775.874 \\
\hline Water mass flowrate, kg/h & 124744.604 & 87321.223 & 62504.02 & 61502.146 \\
\hline LPG Yield & 0.065836258 & 0.2986831 & 0.196446 & 0.1992189 \\
\hline Gasoline Yield & 0.298683079 & 0.2169786 & 0.132792 & 0.1332287 \\
\hline Diesel Yield & 0.196446252 & 0.1541062 & 0.100416 & 0.0912592 \\
\hline Wax Yield & 0.199218908 & 0.0751792 & 0.048688 & 0.0463254 \\
\hline objective function, \$ & $2.82 \mathrm{E}+08$ & $1.96 \mathrm{E}+09$ & $1.41 \mathrm{E}+09$ & $1.48 \mathrm{E}+09$ \\
\hline
\end{tabular}




\subsubsection{Planning using formulated MILP model (Economic)}

In this section, we show the benefits of the developed model in helping us select and find the optimal production pathway. Based on the different yields obtained for different products, and different capital and operating costs for each utilization option. The formulated model was applied on the production network.The formulated MILP has 24 variables with 4 integer variables and 39 constraints. It has been solved in LINGO 14.0 version with branch and bound solver type. The ouput of LINGO programming code can be found in Appendix C1. It was found that $\$ 4.20 \mathrm{E}+09$ is the optimal annual profit as defined by the objective function. The optimal solution selects methanol and HTFT combination with $196079 \mathrm{~kg} / \mathrm{h}$ and $1003921 \mathrm{~kg} / \mathrm{h}$ as a utilized methane stream. This is (16\% methanol, $84 \%$ HTFT) as a combination mode. The optimal results such as product flowrate values are 130817, 66094, 299854, 200000, 200784 $\mathrm{kg} / \mathrm{h}$ for methanol, LPG, gasoline, desiel, and wax, respectively.

\subsubsection{Planning using formulated model (Sustainable)}

In this section, we consider the environmental impact as another equally important aspect besides the economic objective while designing the production network. The environmental impact represented by $\mathrm{CO}_{2}$ or $\mathrm{CO}_{2 \mathrm{eq}}$ are incorporated in the analysis. The $\mathrm{CO}_{2 \mathrm{eq}}$ values for each utilization mode is obtained for the ASPEN Plus simulator. ASPEN Plus reports greenhouse gas (GHG) emissions in terms of $\mathrm{CO} 2$ equivalents of global warming potential (GWP) for the streams based on data from three popular standards, the IPCC's $2^{\text {nd }}(\mathrm{SAR})$, the $4^{\text {th }}(\mathrm{AR} 4)$ Assessment reports, and the U.S. EPA's proposed rules from 2009. The greenhouse gases are namely Carbon dioxide, Methane, Nitrous oxide, Hydrofluorocarbons, Perfluorocarbons, Sulfur hexafluoride, and Nitrogen triflouride. We consider in our analysis the standard carbon cost as \$ 
40 per tonne of $\mathrm{CO} 2$ equivalent emitted for the base case (British Petroleum, 2014). Then, different carbon prices such as $\$ 20$ (low), and \$80 (high) are considered to address possible foreseeable scenarios. Table 6.5 shows the $\mathrm{CO} 2$ equivalent values in tons/yr for different utilization options considering SAR standard.

Table 6.5 CO2 equivalent values in tons/yr for different utilization options.

\begin{tabular}{|c|c|c|c|c|}
\hline & $100 \%$ & $70 \%$ & $50 \%$ & $30 \%$ \\
\hline LNG & 0.01471095 & $-7.23 \mathrm{E}+07$ & $-1.21 \mathrm{E}+08$ & $-1.69 \mathrm{E}+08$ \\
\hline Methanol & $-1.14 \mathrm{E}+04$ & $-7.95 \mathrm{E}+03$ & $-5.68 \mathrm{E}+03$ & $-3.41 \mathrm{E}+03$ \\
\hline LTFT & $3.94 \mathrm{E}+05$ & $1.57 \mathrm{E}+05$ & $1.96 \mathrm{E}+05$ & $1.17 \mathrm{E}+05$ \\
\hline HTFT & $1.94 \mathrm{E}+06$ & $1.36 \mathrm{E}+06$ & $9.72 \mathrm{E}+05$ & $9.95 \mathrm{E}+05$ \\
\hline
\end{tabular}

Now, the process with positive values will be discredited for carbon equivalent cost and a negative cost will be shown in their profit equation as they are emitting GHG according to their corresponding ASPEN Plus flowsheet. Whereas, the process with negative values will be credited for carbon equivalent cost and a positive cost will be shown in their profit equation as their output product streams are emitting less $\mathrm{CO} 2$ equivalent than their inputs streams according to their corresponding ASPEN Plus flowsheet. After incorporating carbon equivalent cost value of $\$ 40$ per ton emitted, it was found that $\$ 4.165 \mathrm{E}+09$ is the optimal annual profit as defined by the objective function. The optimal solution still selects methanol and HTFT combination with $196079 \mathrm{~kg} / \mathrm{h}$ and $1003921 \mathrm{~kg} / \mathrm{h}$ as a utilized methane stream. This is (16\% methanol, 84\%HTFT) as a combination mode. Furthermore, we found that $\$ 4.183 E+09$ and 4.127E+09 are the optimal 
annual profit for $\$ 20$ and $\$ 80$ per ton emitted, respectively. The output of LINGO programming code can be found in Appendix C2.

\subsection{Conclusions and Future work}

A novel natural gas production unit has been synthesized and analyzed. ASPEN Plus simulation package showed to be beneficial in calculating mass and energy balances accurately and finding the different yield equations. Then, the developed comprehensive mixed-integer linear programming (MILP) model has been implemented for the design and optimization of natural gas production network. By inspection, there was a combination of utilization modes resulting in a higher objective function value and the formulated MILP model was used for this purpose to find the optimal combination. We addressed the problem from two aspects, first the pure economic model resulted in $\$ 4.20 \mathrm{E}+09$ as the optimal annual profit defined by the objective function and (16\% methanol, $84 \%$ HTFT) as a combination mode. Then, we incorporated carbon equivalent cost values in the objective function. For $\$ 40$ per ton emitted, and we found that $\$ 4.165 \mathrm{E}+09$ as the optimal annual profit. The optimal solution still selects methanol and HTFT combination with $196079 \mathrm{~kg} / \mathrm{h}$ and $1003921 \mathrm{~kg} / \mathrm{h}$ as a utilized methane stream. This is (16\% methanol, $84 \%$ HTFT) as a combination mode. Furthermore, we found that \$4.183E+09 and 4.127E+09 are the optimal annual profit for $\$ 20$ and $\$ 80$ per ton emitted, respectively. 


\section{CHAPTER SEVEN}

\section{SUSTAINABILITY ASSESSMENT OF NATURAL GAS NETWORK}

\subsection{Introduction}

Recently, sustainability has emerged in process system engineering (PSE) as a key issue. Many definitions are available to define sustainability. However, the most widely known definition of sustainable development, which has been used as the basis for many definitions, is that given in the Brundtland Report (Brundtland, 1987): 'Sustainable development is development which meets the needs of the present population without compromising the ability of future generations to meet their own needs'.

Many researchers emphasized the importance of chemical engineers to contribute in sustainability development. The contributions that the chemical engineers have made in the last 20 years or so, are recognizable by the diversity of activities that engages chemical engineering profession (Batterham, 2003).

Sustainability requires a new generation of engineers who are trained to adopt a holistic view of processes by considering interactions among industrial processes, human and ecological systems. Therefore, the quest for sustainability requires research and educational innovation and advances in engineering, economics, and sociology in a coherent manner (Bakshi \& Fiksel, 2003).

Traditionally, chemical engineers are known for designing and operating processes with the focus on material utilization, cost and safety. For over a couple of decades, chemical engineers have been incorporating environment concerns into process design and operation in terms of sustainability (Batterham, 2003, 2006). 
Sustainability can be seen from different hierarchies or levels. For example, Batterham (Batterham, 2006) highlighted that five levels are required to create a connecting path between global and individual activities:

- Level 1: Global objectives.

- Level 2: Industry strategy.

- Level 3: Enterprise targets.

- Level 4: Specific projects.

- Level 5: Individual actions/measured outcomes.

And the new sustainable chemical engineering needs to engage in issues such as greenhouse gas (GHG) reduction (level 1) rather than just modelling system (level 4) and process measures and analysis (level 5).

Moving next to the aspects or dimensions of sustainability, researchers have attempted to measure improvements in terms of three groups of metrics corresponding to the three main aspects of sustainability: ecological metrics, economic metrics, and sociological metrics. Two classes of metrics or indicators are used to indicate the state and performance of the system. State metrics of a system are known as content indicators and those that measure the behavior of a system, are known as performance indicators (Sikdar, 2003). The metrics measure only one aspect of the system, are refereed to one-dimensional (1-D). The metrics attempts to measure 2D aspects are refereed to 2-D metrics as shown in Figure 7.1 and belonging to the interactions of any two aspects of sustainability. Thus, we can identify eco-efficiency metrics, socio-ecological metrics, and socio-economic metrics. The 3-D metrics obtained from the intersection of all three aspects, are called true sustainability metrics.

These seven types can be summarized below (Sikdar, 2003): 
Group 1 (1-D): economic, ecological, and sociological indicators

Group 2 (2-D): socio-economic, eco-efficiency, and socio-ecological indicators

Group 3 (3-D): sustainability indicators

Five basic indicators of sustainability are:

- Material intensity: Material intensity is expressed as pounds of material wasted (not converted to desirable product) per unit output. This metric is calculated by subtracting the mass of product and saleable co-products from the mass of raw materials input to the process.

- Energy intensity: Energy intensity is expressed as Btus per unit output. It is a measure of the net fuel-energy consumed to provide the heat and power requirements for the process.

- Water consumption: Water consumption is expressed as gallons of fresh water, excluding rainwater, consumed per unit output.

- Toxic emissions: Toxic emissions are expressed as pounds of toxic material emitted by the process per unit output.

- Pollutant emissions: are expressed as pounds of pollutants emitted by the process per unit output.

- Greenhouse gas emissions: are expressed as pounds of carbon dioxide equivalents emitted per unit output. 


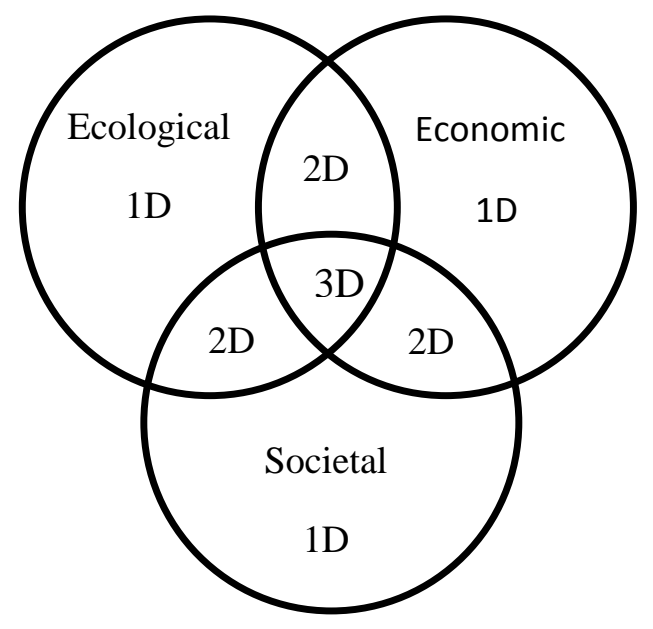

Figure 7.1 A schematic representation of the three dimensions of sustainability.

The metrics or indicators are beneficial to assess the system or process sustainability aspects. For example, the framework proposed by Azapagic \& Perdan, (2000) contributed towards standardization of the indicators of sustainable development for industry.

The applications of sustainability metrics (Azapagic \& Perdan, 2000; Schwarz, et al., 2002) include:

- comparison of similar products made by different companies

- evaluating of different processes

- benchmarking performance

- Tracking progress towards sustainable development

- Stacking along the supply chain

- Calculation metrics for facilities

- Calculating metrics with other tool 


\subsection{Literature review}

In this section, we will present the published works addressing sustainability metrics in industrial processes, and in particular in chemical processes. As mentioned earlier, sustainability has been gaining popularity in chemical engineering education and practice (El-Halwagi, 2012). Figure 7.1 shows the trend in the number of publications from early 1990 to 2014 when we use key words "sustainability chemical engineering" in the search engine Scopus with 425 as a total number of documents.

Al-Sharrah, et al., (2001) developed a planning model for petrochemical Industry with an environmental objective. They formulated and presented a mixed-integer programming model of a petrochemical network. The objective was to quantify the sustainability by incorporating added value and the health index. The two objective functions representing sustainability were the added value and the health index. Also, the multi-objective optimization technique provides the design engineer and industrial planner a powerful mathematical tool for designing and operating large scale chemical processing systems subject to economic and environmental constraints.

Martins, et al., (2007) presented the application of a new framework for sustainability metrics to industrial processes, in particular, to chemical processes. The four 3D metrics proposed in their works namely, material intensity, energy intensity, potential chemical risk, and potential environmental impacts are applicable to a wide range of process systems. The implementation of the framework on two example; chlorine production process using three different alternatives (membrane, diaphragm, and mercury cells), and the separation of an acetone/chloroform mixture by two different solvents (benzene and methyln-pentyl-ether) showed that this framework can be effective in selecting the more-sustainable process by comparing process alternatives. Also, they 
highlighted that a decision can be made by considering only the $3 \mathrm{D}$ metrics first, and if needed, extend the consideration to 2D and, eventually, $1 \mathrm{D}$ metrics.

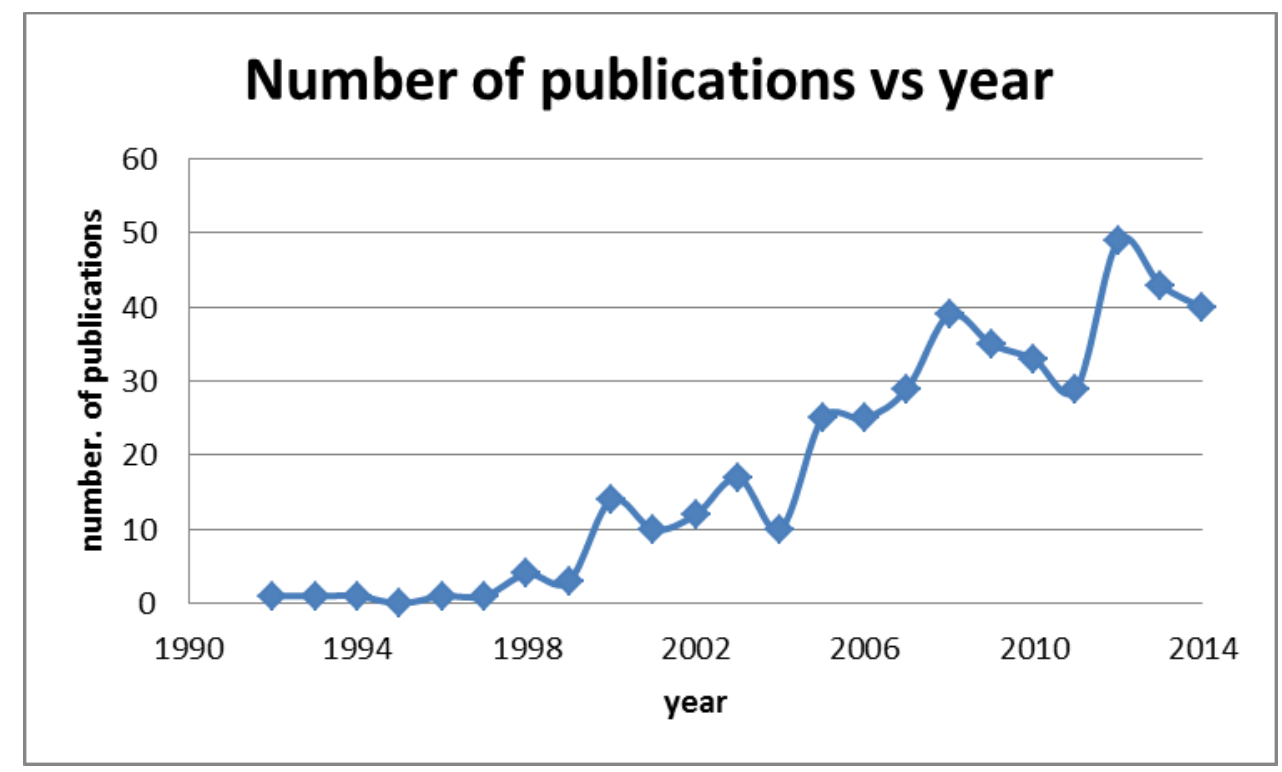

Figure 7.2 Trend in the number of publications addressing sustainability and chemical engineering from early 1990 to 2014 .

Carvalho, et al., (2008) presented a generic and systematic methodology for identifying the feasible retrofit design alternatives of any chemical process. The methodology helps in determining a set of mass and energy indicators from steady-state process data. Also, it helps establishing the operational and design targets, and identifying the design alternatives that can match a set of design targets through a sensitivity-based analysis. The importance of this indicator based method is that it is able to identify alternatives, where one or more performance criteria (factors) move in the same direction thereby eliminating the need to identify tradeoffbased solutions. 
Tugnoli, et al., (2008) developed a procedure consisting of four main operative steps for the quantitative assessment of key performance indicators suitable for the sustainability analysis of alternative processes, mainly addressing the early stages of process design. The overall (aggregated) index calculated by the weight factors is mainly influenced by the differences in the inherent safety and environmental impact of the different processes, such as, the less sustainable process, having an overall impact more than three times higher with respect to the other processes. They concluded that the application of the developed methodology provides useful insights to address sustainability issues in a decision making process during the early process design stage, addressing both the selection of process technology and the early identification of expected critical impacts.

Tugnoli, et al., (2011) developed a procedure based on the systematic development of a "tree of impacts" for the sustainability analysis of design options in the early stages of process development (conceptual and basic design). It provided a comprehensive set of key performance indicators, dynamically defined according to the impact issues of concern for the process. The procedure was applied to industrial production of cyclohexanone, with the sustainability assessment of three alternative design options.

Zheng, et al., (2012) presented a methodology to assist reaction pathway selection at the conceptual design stage from sustainability context. The sustainability of each reaction pathway is assessed in terms of profit potential, driving force of the pathway (Gibbs free energy), inherent safety index, potential environmental index, and atom economy. The sustainability performance of different potential reaction pathways is evaluated, which help systematically the designers improve the screening efficiency by eliminating inferior reaction alternatives, and identify the 
key areas for further improvement in future design, thus reducing the complexity and labor in the following basic engineering design stage.

\subsection{Problem statement}

Although natural gas is considered as the cleanest primary fossil fuel and accordingly its processing and production system as the cleanest system among the other systems like oil and coal, it is not zero-emission system. The aim of this chapter is to address the sustainability dimensions of natural gas processing and production network. The natural gas network that consists of LNG, GTL, and methanol facilities shown previously, is considered for analysis. Given the synthesized and simulated natural gas processing and production network, it is desired to assess the sustainability metrics for different manufacturing processes. The use of process simulators (such as CHEMCAD, Aspen Plus, HYSYS, and PRO/II) is useful at this platform. The performance indicators, mostly concerned with the means of improving the sustainability characteristics of a system are considered. There is no a specific number of metrics that could be judged as sufficient, but the following four metrics prove to be enough.

The metrics will provide means for comparing

- Resource consumption

- Energy consumption

- Water consumption

- Pollution emissions 


\subsection{Case studies}

\subsubsection{Case study 1}

After analyzing each production alternative performance by calculating mass and energy balances to determine the impacts from the alternative of the natural gas processing and production network, it is desired to assess the sustainability metrics. ASPEN Plus simulation package is used to calculate accurately mass and energy balances. Evaluating and comparing the process performance is done through metrics that measure the economic worth, environmental impact, societal value, and so on need to be calculated for comparing the alternatives. The uses of the metrics as indicators of sustainability will help to evaluate the relative performance of production processes in terms of impact per unit output. We will use the simple rule that indicates that the lower the metric the more effective the process. A lower metric indicates that either the impact of the process is less (the numerator is smaller) or the output of the process is more (the denominator is larger). Material intensity index, energy intensity index, water consumption, and pollution emissions metrics are used to assess the network's performance. Table 7.1 gives the metrics values for LNG, GTL, and methanol production processes. For material intensity metrics, the simulated values for products and losses for the base case shown in Table 4.3 are considered. LNG process shows to be better in terms of material consumption with $0.228856 \mathrm{lb}$ per pound of product index. In other words, less wasted materials are produced from LNG process. GTL and methanol processes have 1.163492 and 0.814444 as material intensity index, respectively. Clearly, the GTL and methanol processes have higher indexes. Both, the wasted produced water and $\mathrm{CO}_{2}$ emission are responsible for this high values. For energy intensity metrics, the input energy for key processing units obtained from the ASPEN 
Plus simulation are considered. It was found 0.05783, 0.0933, 0.11053 MMBtu per pound of product for LNG, GTL, and methanol processes, respectively. All the processes have zero water consumption indexes, because the fresh water is not used as input feed to produce products. However, water is produced as wasted stream and used in other utility applications. The reader is referred to (Gabriel et al., 2014) for targeting of the Water-Energy Nexus in Gas-to-Liquid Processes.

Finally, the $\mathrm{CO}_{2 \mathrm{eq}}$ is evaluated for all processes. $\mathrm{CO}_{2 \mathrm{eq}}$ values are obtained from the Aspen Plus simulation package in terms of $\mathrm{lb}$ produced. Then, the $\mathrm{CO}_{2 \mathrm{eq}}$ is calculated and found to be 0.0000, 36.7978, $25.524 \mathrm{lb}$ per pound of product for LNG, GTL, and methanol processes, respectively.

Table 7.1 Metrics for comparing LNG, GTL, and methanol production processes.

\begin{tabular}{|lcccc|}
$\begin{array}{l}\text { Product } \\
\text { (Production } \\
\text { Process) }\end{array}$ & Unit & $\begin{array}{c}\text { LNG } \\
\text { Per pound of } \\
\text { product }\end{array}$ & $\begin{array}{c}\text { GTL } \\
\text { Per pound of } \\
\text { product }\end{array}$ & $\begin{array}{c}\text { Methanol } \\
\text { Per pound of } \\
\text { product }\end{array}$ \\
\hline Material & $\mathrm{lb}$ & 0.228 & 0.909 & 0.814 \\
\hline Energy & MMBtu & 0.058 & 0.0933 & 0.111 \\
\hline Water & gal & 0.0000 & 0.0000 & 0.0000 \\
\hline $\mathbf{C O}_{\mathbf{2} \text { eq }}$ & $\mathrm{lb}$ & 0.0000 & 36.798 & 25.524 \\
\hline
\end{tabular}




\subsubsection{Case study 2}

The Acid Gas Removal Unit, unit (B) is revisited. The three operating modes of amine system are considered for analysis. Since the metrics calculations helps in benchmarking process performance and evaluating of different processes, we will consider acid gas removal for sustainability assessment. For example, three different operating modes are available for unit (B). In the first configuration, MDEA is used only to absorb $\mathrm{CO}_{2}$ and $\mathrm{H}_{2} \mathrm{~S}$ to the desired level, in the second configuration, a mixed amine solution of MDEA and DEA is used and in the third configuration, two absorbers are used, MDEA is used in the first absorber column and DEA in the second absorber.

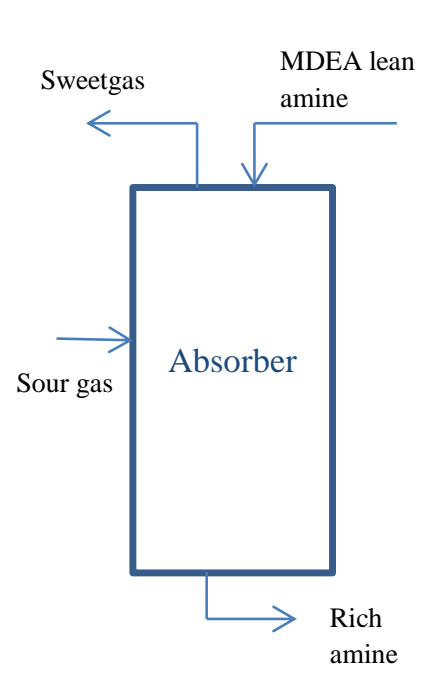

Scheme (A)

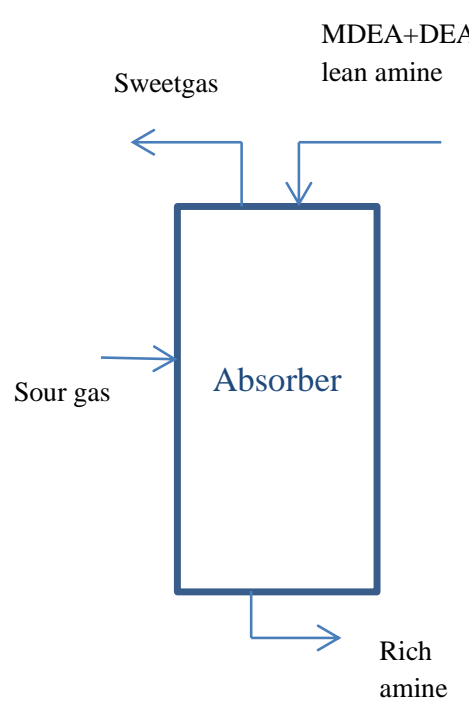

Scheme (B)

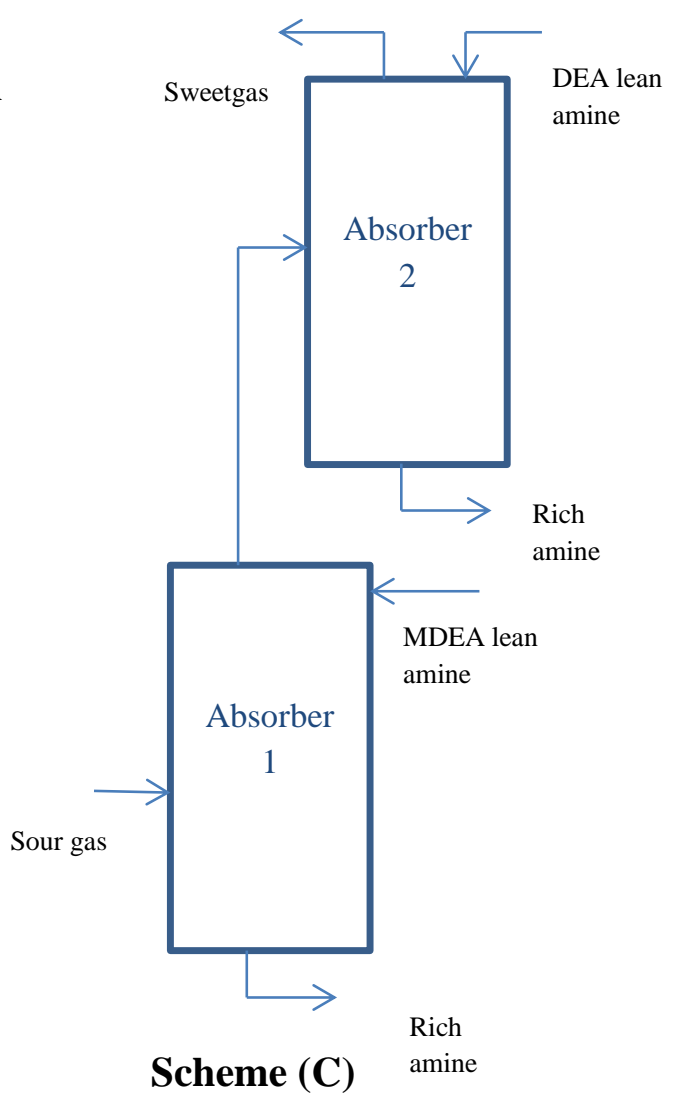

Figure 7.3 Three operating schemes for acid gas removal unit. 
Table 7.2 Metrics for comparing scheme B and C for acid gas removal unit.

\begin{tabular}{|lcccc|}
$\begin{array}{l}\text { Amine } \\
\text { system }\end{array}$ & Unit & $\begin{array}{c}\text { Scheme A } \\
\text { Per pound of sweetgas }\end{array}$ & $\begin{array}{c}\text { Scheme B } \\
\text { Per pound of sweetgas }\end{array}$ & $\begin{array}{c}\text { Scheme C } \\
\text { Per pound of sweetgas }\end{array}$ \\
\hline Energy & $\mathrm{lb}$ & 0.038 & 0.110 & 0.305 \\
\hline Water & $\mathrm{lb}$ & $1.23 \mathrm{E}-04$ & 0.001 & 0.005 \\
\hline $\mathbf{C O}_{\mathbf{2 e q}}$ & $\mathrm{lb}$ & $-1.31 \mathrm{E}-03$ & 0.875 & 2.512 \\
\hline
\end{tabular}

Again, material intensity index, energy intensity index, water consumption, and pollution emissions metrics are used to benchmark and evaluate the three schemes. Table 7.2 gives the metrics values for scheme A, scheme B, and scheme C. It seems that scheme A is the superior in terms of sustainability metrics, however, since it does not meet the $\mathrm{H}_{2} \mathrm{~S}$ specification level, we need to exclude it from the comparison. Now the comparison is between scheme B and scheme C. For material intensity metrics, scheme B has $0.110 \mathrm{lb}$ per pound of sweetgas product index. For energy intensity metrics, the input energy for absorber and stripper processing units obtained from the ASPEN Plus simulation are considered. It was found 0.001, 0.005, 0.11053 MMBtu per pound of product for scheme B and scheme C, respectively. Scheme B has a lower water consumption index. Similarly, it has a lower $\mathrm{CO}_{2 \mathrm{eq}}$ index. To conclude, scheme $\mathrm{B}$ is the best configuration in terms of sustainability and sustainability evaluation results are on agreement with the mathematical model results. 


\subsubsection{Case study 3}

Two distinctive classifications of FT reactor designated as low temperature Fischer Tropsch (LTFT) and high temp Fisher Tropsch (HTFT) are used in industry. The uses of the metrics as indicators of sustainability will help to evaluate the relative performance of each process in terms of impact per unit output. Table 7.3 shows the sustainability metrics od each process.

Table 7.3 Metrics for comparing LTFT and HTFT production processes.

\begin{tabular}{|lccc|}
\hline $\begin{array}{l}\text { Product } \\
\text { (Production Process) }\end{array}$ & Unit & $\begin{array}{c}\text { LTFT } \\
\text { Per pound of product }\end{array}$ & $\begin{array}{c}\text { HTFT } \\
\text { Per pound of product }\end{array}$ \\
\hline Material & $\mathrm{lb}$ & 0.175 & 0.304 \\
\hline Energy & MMBtu & 0.0003 & $6.0838 \mathrm{E}-05$ \\
\hline Water & gal & 0.000 & 0.000 \\
\hline CO $_{\text {2eq }}$ & $\mathrm{lb}$ & 0.047 & 0.257 \\
\hline
\end{tabular}

For material intensity metrics, LTFT has $0.175 \mathrm{lb}$ per pound of products index, whereas, HTFT has $0.304 \mathrm{lb}$ per pound of products index. For energy intensity metrics, the input energy for both LTFT and HTFT reactors are obtained from the ASPEN Plus simulation. It was found 0.0003, and 6.0838E-05 MMBtu per pound of product for LTFT and HTFT, respectively. Now, HTFT has a lower energy index. Both have a zero water consumption index, since water is not used and consumed for production. Finally, LTFT has a lower $\mathrm{CO}_{2 \mathrm{eq}}$ index of 0.047. This example presents a different case when not all metrics are lower for one process and other judgement criteria are needed to get a fair evaluation. 


\subsection{Conclusions}

For each production process alternative, the four 3D metrics previously identified and discussed were calculated. All intensity metrics were estimated directly from the results obtained from the simulation for the process alternatives. The energy intensity, which is the consumption of energy in MMBtu per pound of product produced, was determined to be $0.05783,0.0933,0.11053$ for LNG, GTL, and methanol processes respectively. For material intensity index, LNG process was shown to be better in terms of material consumption with $0.228856 \mathrm{lb}$ per pound of product produced. GTL and methanol processes have 1.163492 and 0.814444 as material intensity index, respectively. All the processes have zero water consumption indexes, because fresh water is not used as input feed to produce products. The $\mathrm{CO}_{2 \mathrm{eq}}$ is calculated and found to be $0.0000,36.7978$, $25.524 \mathrm{lb}$ per pound of product for LNG, GTL, and methanol processes, respectively. Clearly, the strategic planning of the natural gas production network directs us of the consideration of $\mathrm{CO}_{2}$ emissions targets and polices which implies that both the economic and environmental criteria will provide better information and understanding for decision-making processes. Also, the consideration of water management will help improve significantly the performance of the network. To conclude, the sustainability metrics can be applied on overall network to benchmark the performance as was shown in example 1 or can be applied on processing units as was shown in examples 2 and 3. The insights obtained from sustainability evaluation and formulated mathematical models showed to be in agreement. 


\section{CHAPTER EIGHT: \\ CONCLUSIONS AND FUTURE WORK}

In this chapter we provide the key findings of this dissertation and mention some recommendations for future work.

\subsection{Conclusions}

Global concerns and stringent environmental regulations, all motivate looking for alternative fuels and even prioritizing among available ones. Hence, natural gas with its abundance and relatively cheap prices has a clear advantage and will definitely maintain its $23 \%$ contribution of global energy demand. A framework for the design, synthesis, analysis, and planning of a natural gas processing and production network has been developed. Simulation and optimization techniques were applied sequentially to a network of gas processing and production plants, consisting of LNG, GTL, and methanol facilities. Furthermore, the developed framework has a general sense that can be applied also into different processing and production networks such as paper and pulp, oil refinery, or petrochemical industries. A novel natural gas processing and production network has been synthesized for analysis and optimization. A well know process simulation package, ASPEN Plus, is used to rigorously simulate and evaluate the initial design of the key processing units of selected production facilities namely, LNG, GTL, and Methanol. A steady state simulation helped to determine accurately mass and energy balances, operating conditions, and equipment specification. The simulations' flowsheet beneficially provides important aspects of decision making process, for example, determining accurate product yields and natural gas feedstock requirements, capital and operating cost estimates (using Aspen's 
Economic Analyzer) linked to plant capacities, environmental impacts in terms of quantified emissions, etc. The yields and costs obtained from the simulations are then used as inputs for the optimization step. An operational LP model showed to be helpful to optimize the processing and production network and to address the variation and changes. It also evaluates the processing and production network over a wide range of forecasted economic changes such as in gas market prices, product prices, and so on with the objective function set to maximize profitability. The initial network is expanded further into a superstructure that consists of multiple technologies, process operating conditions, and so on. A mixed-integer linear optimization model is formulated to select optimally the sustainable processing and production routes among different available utilization pathways, multiple technologies, and process operating conditions that maximize the annual profit. Trade-offs between material consumption, energy usage, and environmental impact are assessed by the sustainability metrics. Sustainability metrics showed to be helpful to benchmark the performance of production network and highlight the opportunities for process improvement. 


\subsection{Future work}

Although this research addresses the natural gas processing and production network in a comprehensively integrated manner, still some related work seem promising for further investigation, these include:

- Address other components of the supply chain, for example different transportation and storage modes of natural gas supply chain not just the processing and production network of selected utilization options, in particular, the transportation component. Different transportation modes are available and transportation plays a very important role in selecting the appropriate processing and production mode.

- Optimal percentage from the feedstock for power generation (i.e., electricity demand) and as fuel for running the processing facilities in the network. Polygeneration energy systems are considered to be superior to conventional stand-alone processing plants. This will result in improvements in three aspects (Liu et al., 2009) (1) Energy efficiency: the overall energy utilization of a polygeneration plant is expected to be higher than the overall efficiency of stand-alone plants, producing the same products, (2) Alternative fuels and energy carriers: chemical products produced by a typical polygeneration system can be used as substitutions for traditional liquid fuels; for example, methanol for gasoline, DME for diesel oil. Hydrogen can also be a product and (3) Cost-effective emissions reduction: the large-scale of polygeneration energy systems is expected to result in cost-effective solutions for the implementation of $\mathrm{CO}_{2}$ capture due to economy of scale. 
- As the sustainability assessment showed and suggested, more studies are needed to address the environmental aspect such as $\mathrm{CO}_{2}$ and water management, and this represents the significant losses stream from the production processes. Also, energy losses in the case of LNG. Thus, sustainability index should be considered in the optimization model. Multi-objective optimization has the potential to further refine the optimization model.

- Expand the network by considering either more promising utilization options such as gas to solid (hydrate) and gas to chemical, gas to petrochemical or further process current network's products to more valuable or demanding end product for example, gasoline from methanol (MTG), DME as diesel oil alternative, and so on.

- Address the variation in natural gas composition by stochastic modeling techniques to show its effect on the network performance and the optimal current configuration.

- Strategic planning of the network by considering the multi-period optimization technique to address the variation of demand and supply with time. 


\section{APPENDIX A}

\section{APPENDIX A1}

The out file for LINGO can be expressed as follows,

The following are the results of the optimal solution.

\begin{tabular}{|c|c|c|c|}
\hline \multicolumn{2}{|l|}{ Objective value: } & 219037.5 & \\
\hline \multicolumn{2}{|l|}{ Infeasibilities: } & 0.000000 & \\
\hline \multicolumn{2}{|l|}{ Total solver iterations: } & 2 & \\
\hline \multicolumn{2}{|l|}{ Elapsed runtime seconds: } & 0.05 & \\
\hline \multicolumn{2}{|l|}{ Model Class: } & LP & \\
\hline Total variables: & \multicolumn{3}{|c|}{25} \\
\hline Nonlinear variables: & \multicolumn{3}{|c|}{0} \\
\hline Integer variables: & \multicolumn{3}{|c|}{0} \\
\hline Total constraints: & \multicolumn{3}{|c|}{81} \\
\hline Nonlinear constraints: & \multicolumn{3}{|c|}{0} \\
\hline Total nonzeros: & \multicolumn{3}{|c|}{128} \\
\hline \multirow[t]{27}{*}{ Nonlinear nonzeros: } & \multicolumn{3}{|c|}{0} \\
\hline & Variable & Value & Reduced Cost \\
\hline & SULFUR3 & 30000.00 & 0.000000 \\
\hline & ETHANE3 & 70000.00 & 0.000000 \\
\hline & LPG3 & 80000.00 & 0.000000 \\
\hline & METHANOL & 900000.0 & 0.000000 \\
\hline & FIELD_COND3 & 70000.00 & 0.000000 \\
\hline & $-\quad$ NG3 & 1550000 & 0.000000 \\
\hline & SULFUR2 & 21150.00 & 0.000000 \\
\hline & ETHANE2 & 70000.00 & 0.000000 \\
\hline & LPG2 & 120000.0 & 0.000000 \\
\hline & GASOLINE2 & 230000.0 & 0.000000 \\
\hline & DIESEL2 & 180000.0 & 0.000000 \\
\hline & WAX2 & 100000.0 & 0.000000 \\
\hline & PLANT_COND2 & 15000.00 & 0.000000 \\
\hline & FIELD_COND2 & 70000.00 & 0.000000 \\
\hline & NG2 & 1550000 & 0.000000 \\
\hline & SULFUR1 & 20000.00 & 0.000000 \\
\hline & LNG1 & 1090000 & 0.000000 \\
\hline & ETHANE1 & 60000.00 & 0.000000 \\
\hline & LPG1 & 80000.00 & 0.000000 \\
\hline & PLANT_COND1 & 10000.00 & 0.000000 \\
\hline & EIELD_COND1 & 60000.00 & 0.000000 \\
\hline & NG1 & 1550000 & 0.000000 \\
\hline & LOSSES 1 & 230000.0 & 0.000000 \\
\hline & LOSSES 2 & 733000.0 & 0.000000 \\
\hline & LOSSES 3 & 400000.0 & 0.000000 \\
\hline
\end{tabular}

Figure A1.1 LINGO output for base case. 
If we decrease the availability of natural gas from field per day from 4,650,000 to 4,600,000 we found the following results,

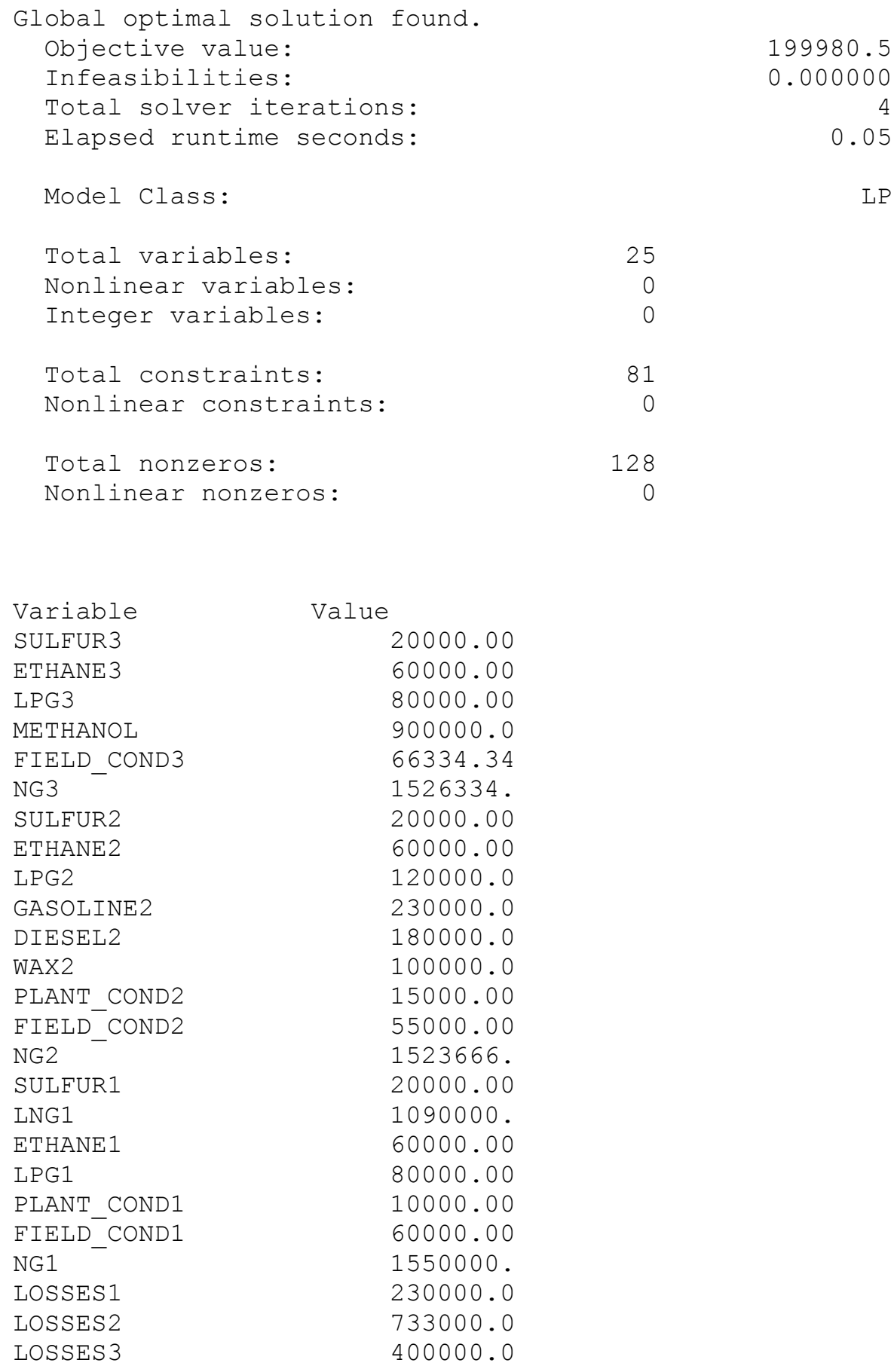

Figure A1.2 LINGO output for base case with 4,600,000 kg per day flowrate. 


\section{APPENDIX A2}

In this scenario, we consider the increase in natural gas feedstock flowrate by running the simulation for higher flowrate from 1500 to 1800 MMSCFD fed to the stabilization unit. After 1800 MMSCFD, we started to get some converge issues. So, 1800 MMSCFD is the maximum flowrate to be fed to each processing facility. With the new higher flow rate and updated operating and utility cost,

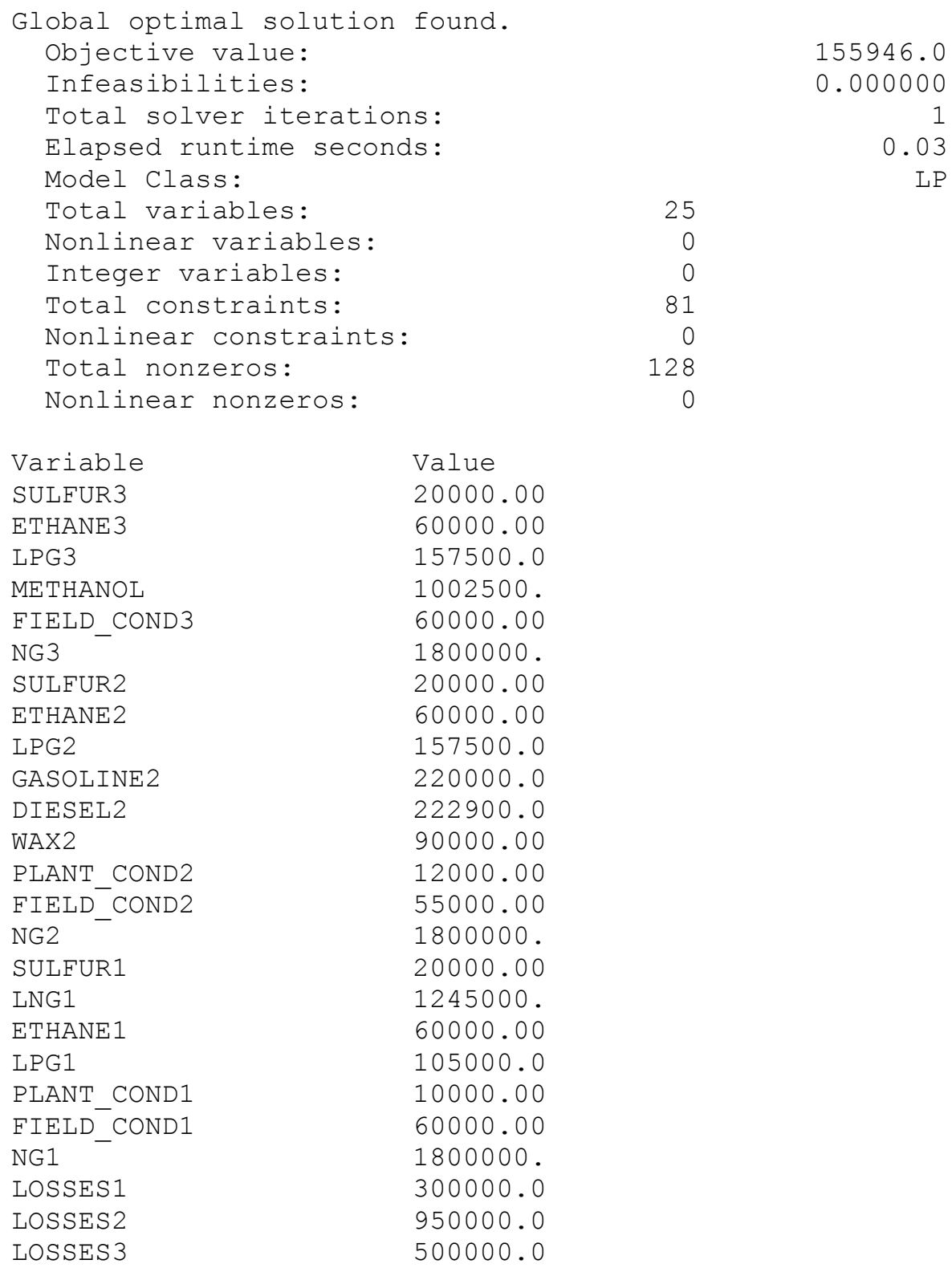

$\begin{array}{ll}\text { Variable } & \text { Value } \\ \text { SULFUR3 } & 20000.00 \\ \text { ETHANE3 } & 60000.00 \\ \text { LPG3 } & 157500.0 \\ \text { METHANOL } & 1002500 . \\ \text { FIELD_COND3 } & 60000.00 \\ \text { NG3 } & 1800000 . \\ \text { SULFUR2 } & 20000.00 \\ \text { ETHANE2 } & 60000.00 \\ \text { LPG2 } & 157500.0 \\ \text { GASOLINE2 } & 220000.0 \\ \text { DIESEL2 } & 222900.0 \\ \text { WAX2 } & 90000.00 \\ \text { PLANT_COND2 } & 12000.00 \\ \text { FIELD_COND2 } & 55000.00 \\ \text { NG2 } & 1800000 . \\ \text { SULFUR1 } & 20000.00 \\ \text { LNG1 } & 1245000 . \\ \text { ETHANE1 } & 60000.00 \\ \text { LPG1 } & 105000.0 \\ \text { PLANT_COND1 } & 10000.00 \\ \text { FIELD_COND1 } & 60000.00 \\ \text { NG1 } & 1800000 . \\ \text { LOSSES1 } & 300000.0 \\ \text { LOSSES2 } & 950000.0 \\ \text { LOSSES3 } & 500000.0\end{array}$

Figure A2.1 LINGO output for for 5,400,000 kg per day flowrate. 
If we lower the availability of natural gas feedstock from 5,400,000 kg per day to 5,200,000 and $5,100,000$ we find that the hourly net profit is $\$ 41,000$ and $\$-41,500$ respectively.

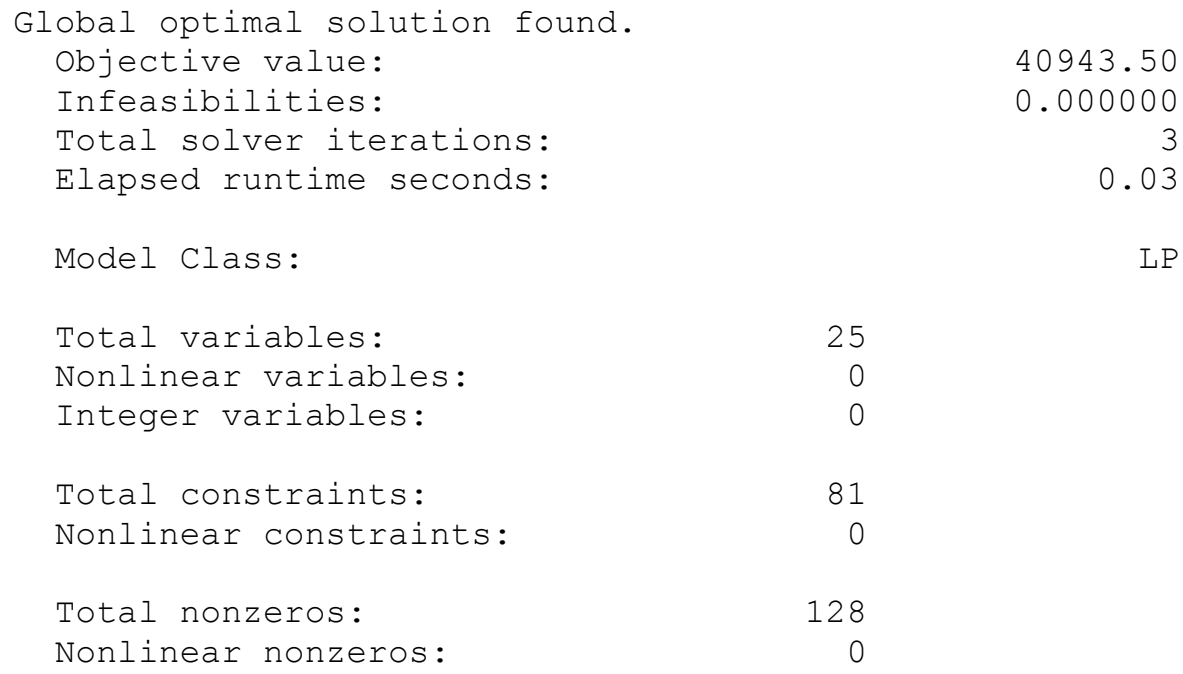

0

$\begin{array}{ll}\text { Variable } & \text { Value } \\ \text { SULFUR3 } & 20000.00 \\ \text { ETHANE3 } & 60000.00 \\ \text { LPG3 } & 157500.0 \\ \text { METHANOL } & 850000.0 \\ \text { FIELD_COND3 } & 60000.00 \\ \text { NG3 } & 1647500 . \\ \text { SULFUR2 } & 20000.00 \\ \text { ETHANE2 } & 60000.00 \\ \text { LPG2 } & 157500.0 \\ \text { GASOLINE2 } & 220000.0 \\ \text { DIESEL2 } & 222900.0 \\ \text { WAX2 } & 90000.00 \\ \text { PLANT_COND2 } & 12000.00 \\ \text { FIELD_COND2 } & 55000.00 \\ \text { NG2 } & 1800000 . \\ \text { SULFUR1 } & 20000.00 \\ \text { LNG1 } & 1197500 . \\ \text { ETHANE1 } & 60000.00 \\ \text { LPG1 } & 105000.0 \\ \text { PLANT_COND1 } & 10000.00 \\ \text { FIELD_COND1 } & 60000.00 \\ \text { NG1 } & 1752500 . \\ \text { LOSSES1 } & 300000.0 \\ \text { LOSSES2 } & 950000.0 \\ \text { LOSSES3 } & 500000.0\end{array}$

Figure A2.2 LINGO output for for 5,200,000 kg per day flowrate. 


\begin{tabular}{|c|c|c|c|}
\hline \multicolumn{3}{|l|}{ Objective value: } & $\begin{array}{r}-41491.50 \\
0.000000\end{array}$ \\
\hline \multicolumn{3}{|c|}{ Total solver iterations: } & 3 \\
\hline \multicolumn{3}{|c|}{ Elapsed runtime seconds: } & 0.03 \\
\hline \multicolumn{3}{|l|}{ Model Class: } & LP \\
\hline \multirow{2}{*}{\multicolumn{2}{|c|}{$\begin{array}{l}\text { Total variables: } \\
\text { Nonlinear variables: }\end{array}$}} & 25 & \\
\hline & & 0 & \\
\hline \multicolumn{2}{|l|}{ Integer variables: } & 0 & \\
\hline \multicolumn{2}{|l|}{ Total constraints: } & 81 & \\
\hline \multicolumn{2}{|l|}{ Nonlinear constraints: } & 0 & \\
\hline \multicolumn{2}{|l|}{ Total nonzeros: } & 128 & \\
\hline \multicolumn{2}{|l|}{ Nonlinear nonzeros: } & 0 & \\
\hline Variable & Value & & \\
\hline SULFUR3 & 20000.00 & & \\
\hline ETHANE3 & 60000.00 & & \\
\hline LPG3 & 157500.0 & & \\
\hline METHANOL & 850000.0 & & \\
\hline FIELD_COND3 & 60000.00 & & \\
\hline NG3 & 1647500 & & \\
\hline SULFUR2 & 20000.00 & & \\
\hline ETHANE2 & 60000.00 & & \\
\hline LPG2 & 157500.0 & & \\
\hline GASOLINE2 & 220000.0 & & \\
\hline DIESEL2 & 222900.0 & & \\
\hline WAX2 & 90000.00 & & \\
\hline PLANT COND2 & 12000.00 & & \\
\hline FIELD_COND2 & 55000.00 & & \\
\hline NG2 & 1800000 & & \\
\hline SULFUR1 & 20000.00 & & \\
\hline LNG1 & 1097500 & & \\
\hline ETHANE1 & 60000.00 & & \\
\hline LPGI & 105000.0 & & \\
\hline PLANT_COND1 & 10000.00 & & \\
\hline FIELD COND1 & 60000.00 & & \\
\hline NG1 & 1652500 & & \\
\hline LOSSES1 & 300000.0 & & \\
\hline LOSSES 2 & 950000.0 & & \\
\hline LOSSES 3 & 500000.0 & & \\
\hline
\end{tabular}

Figure A2.3 LINGO output for for 5,100,000 kg per day flowrate. 


\section{APPENDIX A3}

Scenario 3: natural gas feedstock and product prices incremental

The output file for LINGO can be expressed as follows,

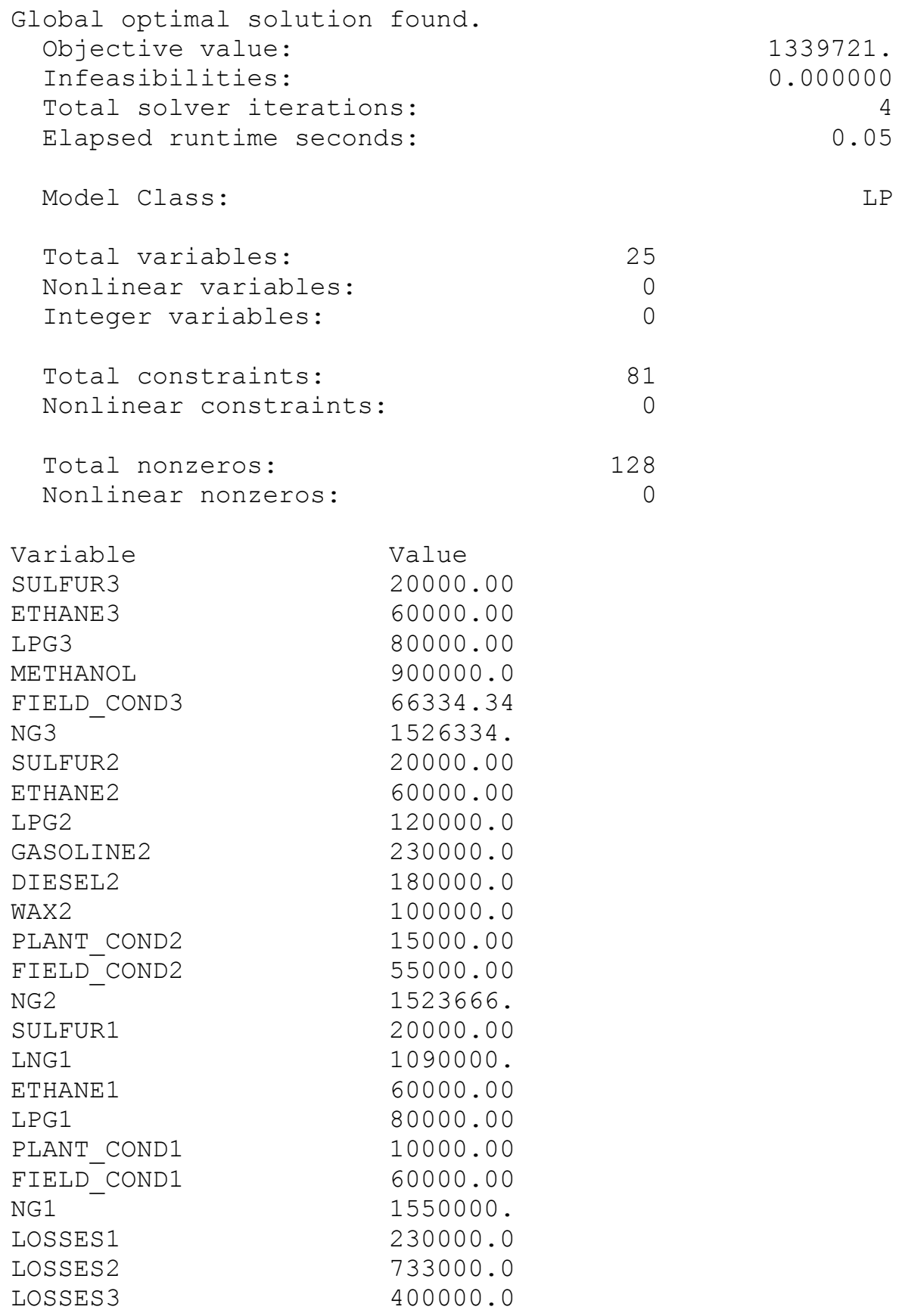

Figure A3.1 LINGO output for for 5,400,000 kg per day flowrate. 


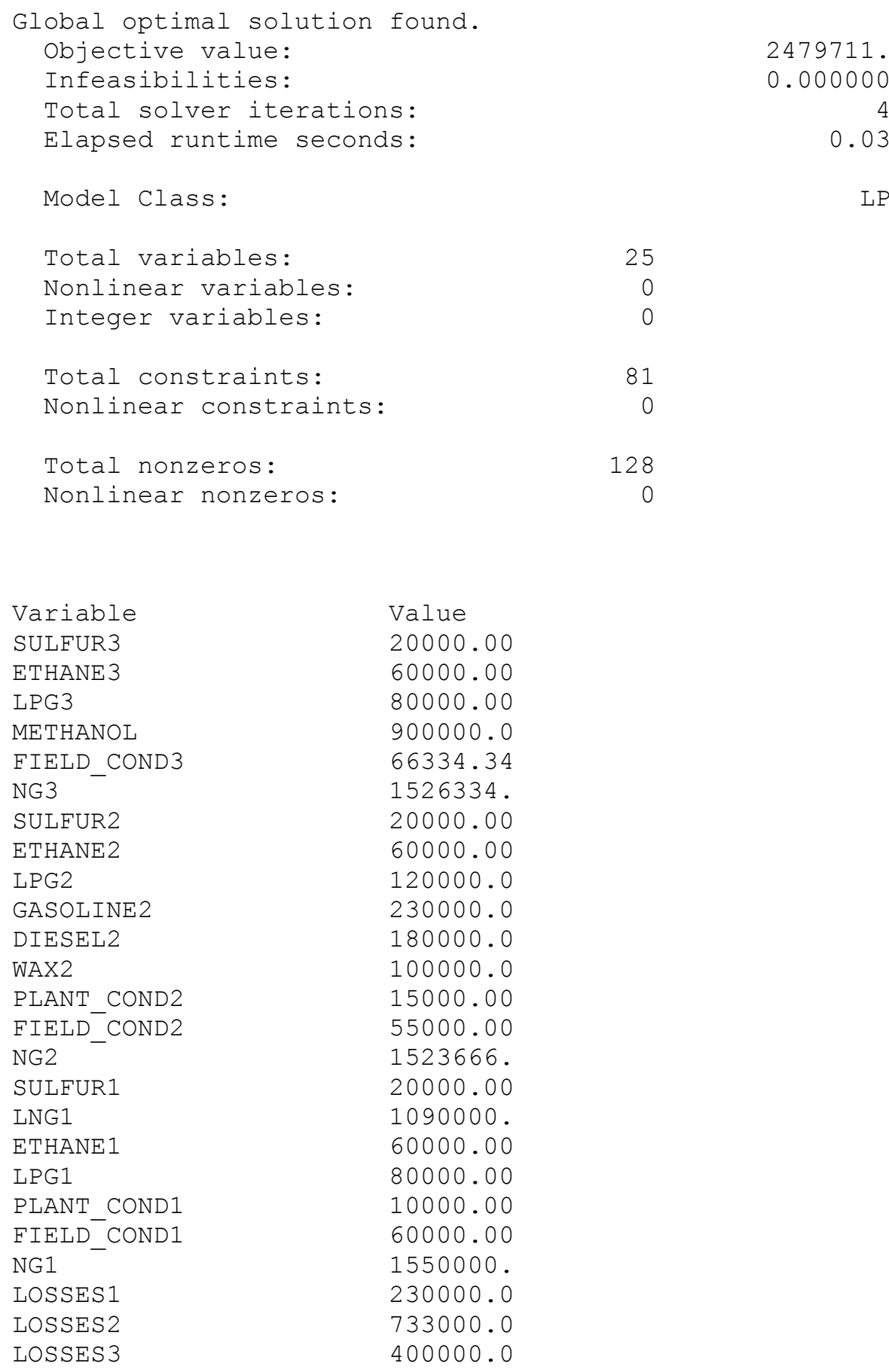

Figure A3.2 LINGO output for for $100 \%$ price increment. 


\section{APPENDIX B}

\section{APPENDIX B1}

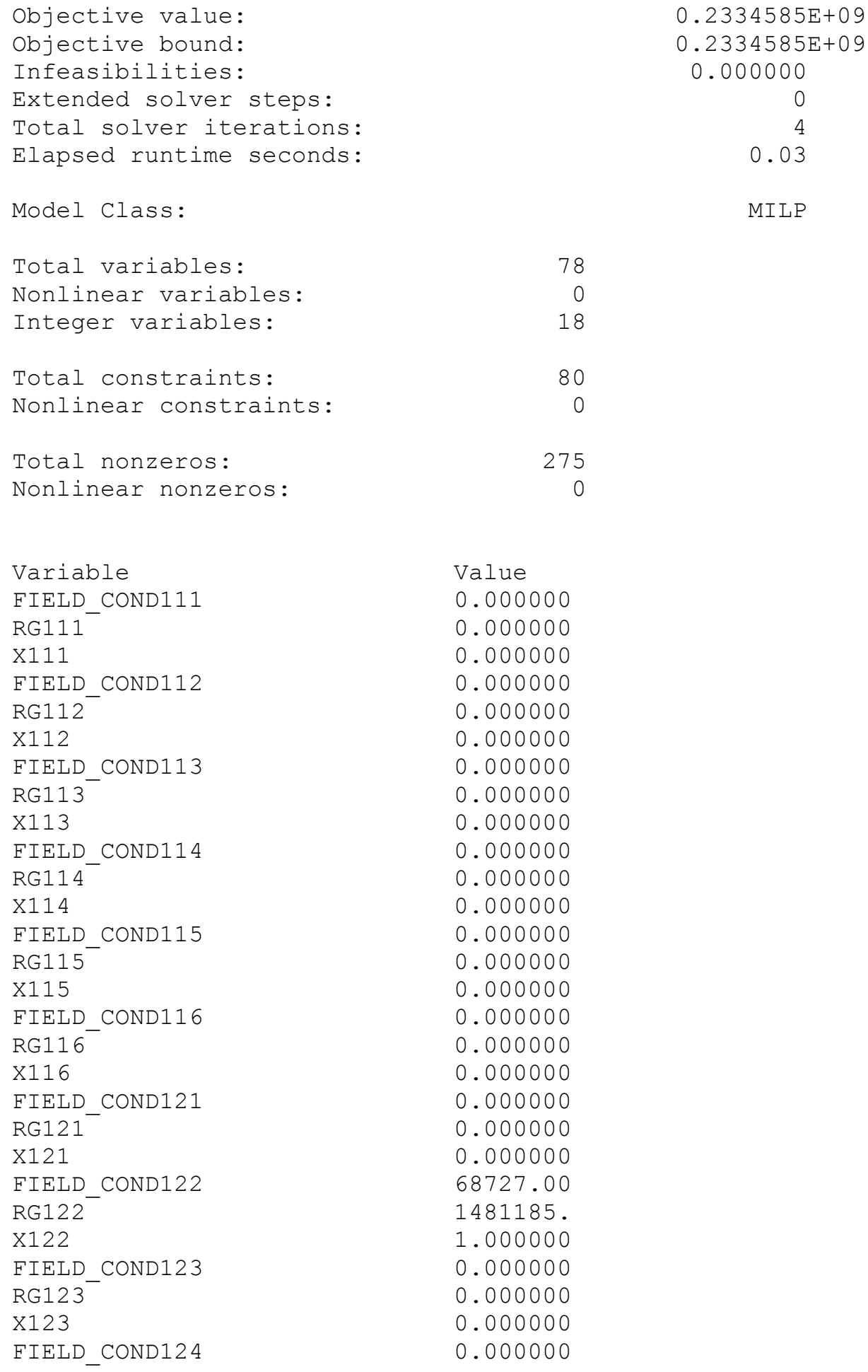

0.000000

0.000000

0.000000

0.000000

0.000000

0.000000

0.000000

0.000000

0.000000

0.000000

0.000000

0.000000

0.000000

0.000000

0.000000

0.000000

0.000000

0.000000

0.000000

0.000000

0.000000

68727.00

1481185 .

1.000000

0.000000

0.000000

0.000000

0.000000 


\begin{tabular}{|c|c|}
\hline RG124 & 0.000000 \\
\hline $\mathrm{X} 124$ & 0.000000 \\
\hline FIELD_COND125 & 0.000000 \\
\hline RG125 & 0.000000 \\
\hline $\mathrm{X} 125$ & 0.000000 \\
\hline FIELD_COND126 & 0.000000 \\
\hline RG126 & 0.000000 \\
\hline X126 & 0.000000 \\
\hline FIELD_COND131 & 0.000000 \\
\hline RG131 & 0.000000 \\
\hline X131 & 0.000000 \\
\hline FIELD_COND132 & 0.000000 \\
\hline RG132 & 0.000000 \\
\hline X132 & 0.000000 \\
\hline EIELD_COND133 & 0.000000 \\
\hline RG133 & 0.000000 \\
\hline X133 & 0.000000 \\
\hline FIELD_COND134 & 0.000000 \\
\hline RG134 & 0.000000 \\
\hline X134 & 0.000000 \\
\hline FIELD_COND135 & 0.000000 \\
\hline RG135 & 0.000000 \\
\hline X135 & 0.000000 \\
\hline FIELD_COND136 & 0.000000 \\
\hline RG136 & 0.000000 \\
\hline X136 & 0.000000 \\
\hline NG & 1550000 . \\
\hline FIELD_COND & 68727.00 \\
\hline NG11 & 0.000000 \\
\hline NG12 & 0.000000 \\
\hline NG13 & 0.000000 \\
\hline NG1 4 & 0.000000 \\
\hline NG1 5 & 0.000000 \\
\hline NG1 6 & 0.000000 \\
\hline NG21 & 0.000000 \\
\hline NG2 2 & 1550000 . \\
\hline NG2 3 & 0.000000 \\
\hline NG2 4 & 0.000000 \\
\hline NG2 5 & 0.000000 \\
\hline NG2 6 & 0.000000 \\
\hline NG31 & 0.000000 \\
\hline NG32 & 0.000000 \\
\hline NG33 & 0.000000 \\
\hline NG34 & 0.000000 \\
\hline NG3 5 & 0.000000 \\
\hline NG3 6 & 0.000000 \\
\hline NG 43 & 0.000000 \\
\hline NG53 & 0.000000 \\
\hline NG 63 & 0.000000 \\
\hline RG & 1481185 \\
\hline
\end{tabular}




\section{APPENDIX B2}

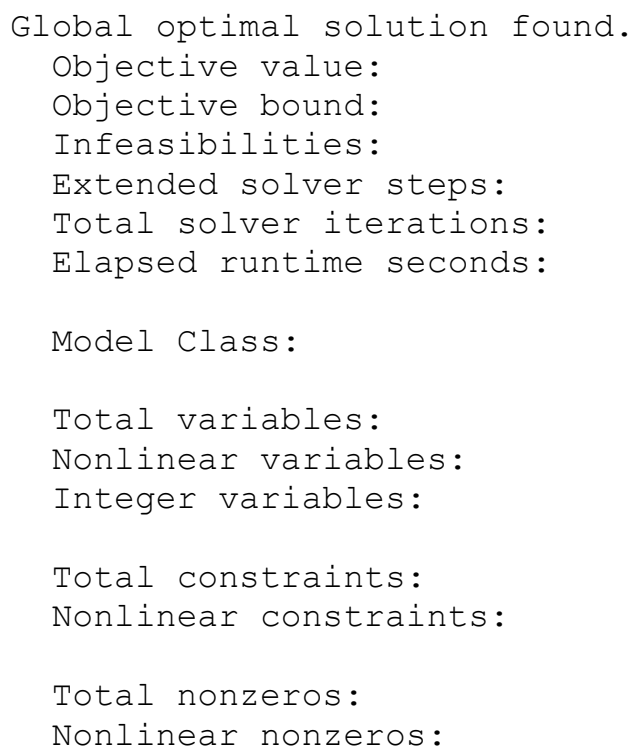

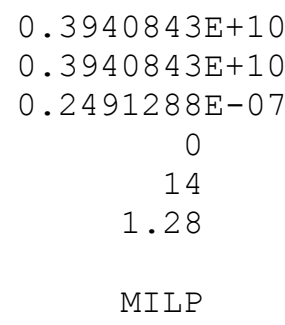

66

14

89

0

221

$\begin{array}{ll}\text { Variable } & \text { Value } \\ \text { FIELD_COND121 } & 0.000000 \\ \text { FIELD_COND122 } & 68727.00 \\ \text { FIELD_COND123 } & 0.000000 \\ \text { SWEETGAS211 } & 0.000000 \\ \text { SWEETGAS212 } & 1279591 . \\ \text { SWEETGAS213 } & 0.000000 \\ \text { ACIDGAS211 } & 0.000000 \\ \text { ACIDGAS212 } & 201593.7 \\ \text { ACIDGAS213 } & 0.000000 \\ \text { SULFUR311 } & 30587.81 \\ \text { SULFUR312 } & 0.000000 \\ \text { SULFUR313 } & 0.000000 \\ \text { SULFUR321 } & 0.000000 \\ \text { SULFUR322 } & 0.000000 \\ \text { SULFUR323 } & 0.000000 \\ \text { DRYGAS411 } & 1220190 . \\ \text { METHANE511 } & 1102851 . \\ \text { ETHANE611 } & 48547.56 \\ \text { LPG611 } & 56962.25 \\ \text { PLANT_COND611 } & 11828.52 \\ \text { ETHANE621 } & 0.000000 \\ \text { LPG621 } & 0.000000 \\ \text { PLANT_COND621 } & 0.000000 \\ \text { X121 } & 0.000000 \\ \text { X122 } & 1.000000 \\ \text { X123 } & 0.000000 \\ \text { X211 } & 0.000000 \\ \text { X212 } & 1.000000 \\ \text { X213 } & 0.000000 \\ \text { X311 } & 1.000000 \\ & \end{array}$




\begin{tabular}{|c|c|}
\hline X312 & 0.000000 \\
\hline$\times 313$ & 0.000000 \\
\hline X321 & 0.000000 \\
\hline X322 & 0.000000 \\
\hline X323 & 0.000000 \\
\hline $\mathrm{X} 411$ & 1.000000 \\
\hline X511 & 1.000000 \\
\hline X611 & 1.000000 \\
\hline X621 & 0.000000 \\
\hline NG & 1550000. \\
\hline FIELD_COND & 68727.00 \\
\hline SULFUR & 30587.81 \\
\hline ETHANE & 48547.56 \\
\hline LPG & 56962.25 \\
\hline PLANT_COND & 11828.52 \\
\hline METHAN̄ $E$ & 1000000 . \\
\hline RG121 & 0.000000 \\
\hline NG21 & 0.000000 \\
\hline RG122 & 1481185. \\
\hline $\mathrm{NG} 22$ & 1550000 . \\
\hline RG123 & 0.000000 \\
\hline NG23 & 0.000000 \\
\hline RG & 1481185 \\
\hline ACIDGAS & 201593.7 \\
\hline SWEETGAS & 1279591. \\
\hline RG22 & 1481185 . \\
\hline RG21 & 0.000000 \\
\hline RG23 & 0.000000 \\
\hline AG21 & 201593.7 \\
\hline AG22 & 0.000000 \\
\hline AG23 & 0.000000 \\
\hline $\mathrm{AG} 24$ & 0.000000 \\
\hline AG25 & 0.000000 \\
\hline AG26 & 0.000000 \\
\hline TAILGAS & 171005.9 \\
\hline NGL & 117338.3 \\
\hline NGL 61 & 117338.3 \\
\hline NGL 62 & 0.000000 \\
\hline
\end{tabular}




\section{APPENDIX C}

\section{APPENDIX C1}

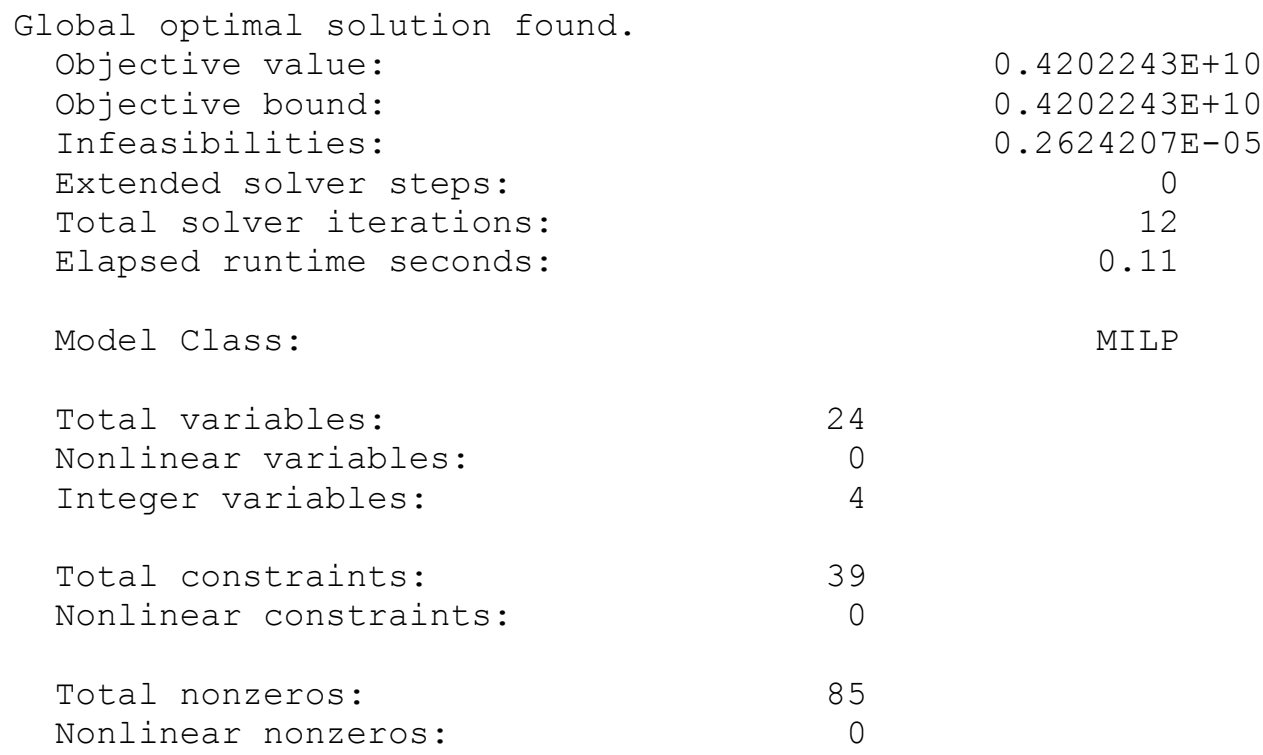

$\mathrm{CH} 4$

LPG 811

GASOLINE 811

DIESEL 811

WAX 811

LPG 821

GASOLINE 821

DIESEL 821

WAX 821

$\mathrm{CH} 4 \mathrm{~L}$

$\mathrm{CH} 4 \mathrm{M}$

$\mathrm{CH} 4 \mathrm{Gl}$

$\mathrm{CH} 4 \mathrm{G} 2$

$\mathrm{CH} 4 \mathrm{G}$

$0.5521215 \mathrm{E}-07$

$0.3594774 \mathrm{E}-06$

$0.6999656 \mathrm{E}-06$

$0.2624207 \mathrm{E}-05$

66094.39

299854.1

200000.0

200784.2

0.000000

196079.2

$0.4431187 \mathrm{E}-05$

1003921 .

1200000 . 


\section{APPENDIX C2}

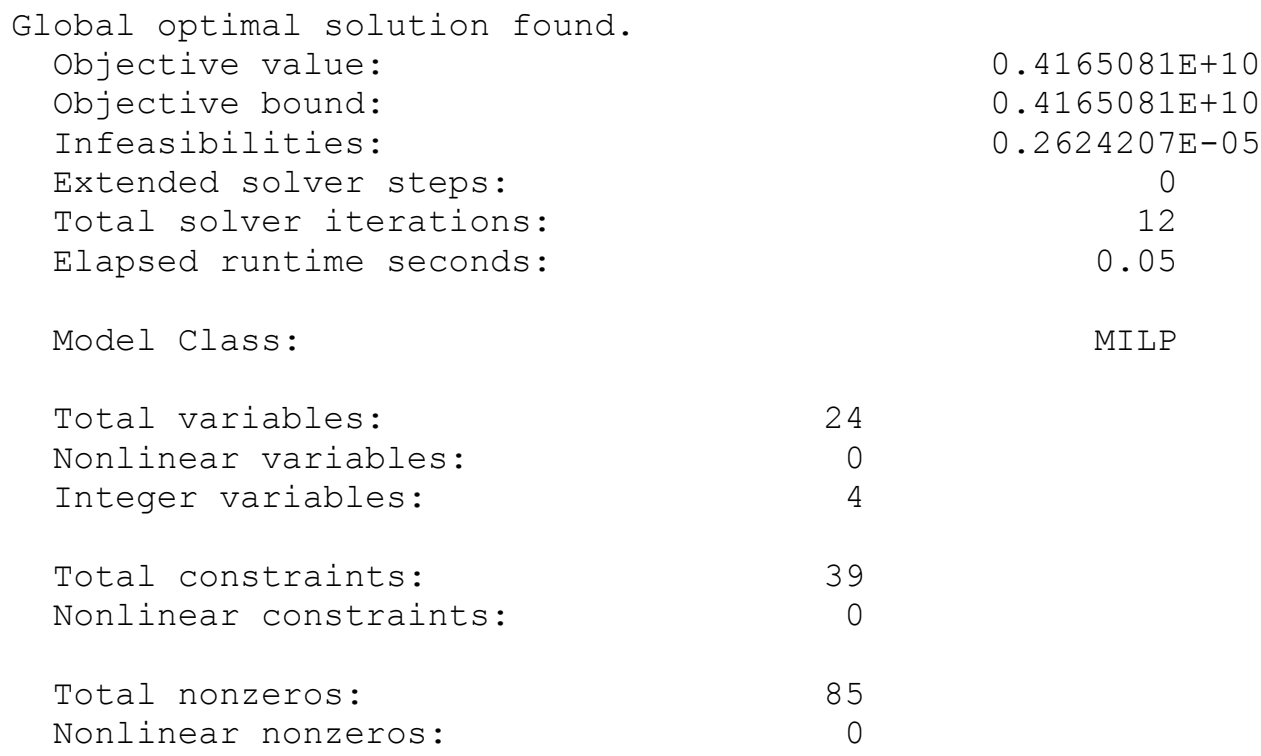

$\begin{array}{lc}\text { Variable } & \text { Value } \\ \text { METHANOL911 } & 130816.9 \\ \text { X911 } & 1.000000 \\ \text { LPG } & 66094.39 \\ \text { GASOLINE } & 299854.1 \\ \text { DIESEL } & 200000.0 \\ \text { WAX } & 200784.2 \\ \text { X811 } & 0.000000 \\ \text { X821 } & 1.000000 \\ \text { LNG711 } & 0.000000 \\ \text { X711 } & 0.000000 \\ \text { CH4 } & 1200000 . \\ \text { LPG811 } & 0.5521215 \mathrm{E}-07 \\ \text { GASOLINE811 } & 0.3594774 \mathrm{E}-06 \\ \text { DIESEL811 } & 0.6999656 \mathrm{E}-06 \\ \text { WAX811 } & 0.2624207 \mathrm{E}-05 \\ \text { LPG821 } & 66094.39 \\ \text { GASOLINE821 } & 299854.1 \\ \text { DIESEL821 } & 200000.0 \\ \text { WAX821 } & 200784.2 \\ \text { CH4L } & 0.000000 \\ \text { CH4M } & 196079.2 \\ \text { CH4G1 } & 0.4431187 \mathrm{E}-05 \\ \text { CH4G2 } & 1003921 . \\ \text { CH4G } & 1200000 . \\ & \end{array}$




\section{REFERENCES}

Aasberg-Petersen, K., Bak Hansen, J. H., Christensen, T. S., Dybkjaer, I., Christensen, P. S., Stub Nielsen, C., Rostrup-Nielsen, J. R. (2001). Technologies for large-scale gas conversion. Applied Catalysis A: General, 221(1-2), 379-387.

Aasberg-petersen, K., Christensen, T. S., Nielsen, C. S., \& Dybkjær, I. (2003). Recent developments in autothermal reforming and pre-reforming for synthesis gas production in GTL applications, Fuel Processing Technology, 83(1-3), 253-261.

Al-Saadoon, F. T. (2005). Economics of GTL Plants, Presented at SPE, 94380, Dallas, Tesax,USA.

Al-Sharrah, G. K., Alatiqi, I., Elkamel, A., \& Alper, E. (2001). Planning an Integrated Petrochemical Industry with an Environmental Objective. Industrial and Engineering Chemistry Research, 40(9), 2103-2111.

Al-Sobhi, S. A., \& Elkamel, A. (2015). Simulation and optimization of natural gas processing and production network consisting of LNG, GTL, and methanol facilities. Journal of Natural Gas Science and Engineering, 23, 500-508.

Al-Sobhi, S., Alfadala, H., \& El-Halwagi, M. M. (2009). Simulation and Energy Integration of a liquefied Natural gas (LNG) Plant. In H. Alfadala, G. Reklaitis, \& M. M. El-halwagi (Eds.), Advances in Gas Processing:Proceedings of the 1st International Gas processing Symposium, 131-135, Elsevier.

ASPEN Plus V7.3. (2011). MA, USA: Aspen Technology, Inc.

Azapagic, A., \& Perdan, S. (2000). Indicators of sustainable development for industry: a general framework. Process Safety and Environmental Protection, 78(4), 243-261.

Bakkerud, P. K. (2005). Update on synthesis gas production for GTL. Catalysis Today, 106(1-4), $30-33$.

Bakshi, B. R., \& Fiksel, J. (2003). The quest for sustainability: Challenges for process systems engineering. AIChE Journal, 49(6), 1350-1358.

Bao, B., El-halwagi, M. M., \& Elbashir, N. O. (2010). Simulation , integration , and economic analysis of gas-to-liquid processes. Fuel Processing Technology, 91(7), 703-713.

Batterham, R. J. (2003). Ten years of sustainability: Where do we go from here. Chemical Engineering Science, 58(11), 2167-2179.

Batterham, R. J. (2006). Sustainability-The next chapter. Chemical Engineering Science, 61(13), $4188-4193$. 
BC Ministry of Energy and Mines. (2012). BRITISH COLUMBIA'S Natural Gas Strategy Fuelling B.C.'s Economy for the Next Decade and Beyond.

BC Ministry of Energy, M. and N. G. (2013). British Columbia's Liquefied Natural Gas Strategy: One year update, $1-16$.

Biegler, L. T., \& Grossmann, I. E. (2004). Retrospective on optimization. Computers and Chemical Engineering, 28(8), 1169-1192.

Camm, J. D., Chorman, T. E., Dill, F. A., Evans, J. R., Sweeney, D. J., \& Wegryn, G. W. (1997). Blending OR/MS, judgment, and GIS: Restructuring P\&G's supply chain. Interfaces 27(1), $128-142$.

Campbell, J. (2000). Gas Conditioning and Processing (8th ed.). Norman, Oklahoma, USA: Campbell Petroleum Series.

Carvalho, A., Gani, R., \& Matos, H. (2008). Design of sustainable chemical processes: Systematic retrofit analysis generation and evaluation of alternatives. Process Safety and Environmental Protection, 86(5), 328-346.

De Klerk, A. (2011). Fischer-Tropsch refining. WILEY-VCH Verlag GmbH \& Co.

Dry, M. E. (2002). The Fischer-Tropsch process: 1950-2000. Catalysis Today, 71(3-4), 227-241.

Economides, M. J., \& Wood, D. A. (2009). The state of natural gas. Journal of Natural Gas Science and Engineering, 1(1-2), 1-13.

Edgar, T. F., Himmelblau, D. M., \& Lasdon, L. S. (2001). Optimization of chemical processes (2nd ed.). New York: McGraw-Hill Companies, Inc.

Ehlinger, V. M., Gabriel, K. J., Noureldin, M. M. B., \& El-Halwagi, M. M. (2014). Process design and integration of shale gas to methanol. ACS Sustainable Chemistry and Engineering, 2(1), 30-37.

EIA. (2011). Annual Energy Outlook 2011. Outlook (Vol. 0383).

El-Halwagi, M. M. (2012). Sustainable Design Through Process Integration. Elsevier Inc.

Espinoza, R. L., Steynberg, a. P., Jager, B., \& Vosloo, a. C. (1999). Low temperature FischerTropsch synthesis from a Sasol perspective. Applied Catalysis A: General, 186(1-2), 13-26.

Fissore, D., \& Sokeipirim, D. (2011). Simulation and energy consumption analysis of a propane plus recovery plant from natural gas. Fuel Processing Technology, 92(3), 656-662.

Gabriel, K. J., Linke, P., Jiménez-Gutiérrez, A., Martínez, D. Y., Noureldin, M., \& El-Halwagi, M. M. (2014). Targeting of the water-energy nexus in gas-to-liquid processes: A 
comparison of syngas technologies. Industrial and Engineering Chemistry Research, 53(17), 7087-7102.

GPSA (2004). Engineering Data Book (12th ed.). Tulsa, Oklahoma, USA.

Gupta, V., \& Grossmann, I. E. (2012). An Efficient Multiperiod MINLP Model for Optimal Planning of $\mathrm{O}$ ff shore Oil and Gas Field Infrastructure, Industrial and Engineering Chemistry Research, 51 (19), 6823-6840 .

Haid, J., \& Koss, U. (2001). Lurgi's Mega-Methanol technology opens the door for a new era in down-stream applications. Studies in Surface Science and Catalysis, 399-404.

Hao, X., Djatmiko, M. E., Xu, Y., Wang, Y., Chang, J., \& Li, Y. (2008). Simulation analysis of a gas-to-liquid process using aspen plus. Chemical Engineering and Technology, 31(2), 188196.

Iyer, R., \& Grossmann, I. (1998). Optimal planning and scheduling of offshore oil field infrastructure investment and operations. Industrial and Engineering Chemistry Research, 5885(97), 1380-1397.

Jager, B., \& Espinoza, R. (1995). Advances in Low-Temperature Fischer-Tropsch Synthesis. Catalysis Today, 23(1), 17-28.

Johansen, G. (2011). Optimization of offshore natural gas field development. Retrieved from http://www.diva-portal.org/smash/record.

Julia, L. M., Ortiz-espinoza, A. P., El-halwagi, M. M., \& Jime, A. (2014). Techno-Economic Assessment and Environmental Impact of Shale Gas Alternatives to Methanol, ACS Sustainable Chem. Eng., 2 (10), 2338-2344.

Kallrath, J. (2000). Mixed Integer Optimization in the Chemical Process Industry. Chemical Engineering Research and Design, 78(6), 809-822.

Khalilpour, R., \& Karimi, I. A. (2012). Evaluation of utilization alternatives for stranded natural gas. Energy, 40(1), 317-328.

Kidnay, A. J., \& Parrish, W. R. (2006). Fundamentals of natural gas processing. Boca Raton, FL, USA: taylor \& Francis group.

Kim, Y. H., Jun, K. W., Joo, H., Han, C., \& Song, I. K. (2009). A simulation study on gas-toliquid (natural gas to Fischer-Tropsch synthetic fuel) process optimization. Chemical Engineering Journal, 155(1-2), 427-432.

Klinkenbijl, A. J., Grootjans, H., Rajani, J., (2005). Best practice for deep treating sour natural gases ( to LNG and GTL), Paper presented at GasTech. 
Kohl, A., \& Nielsen, R. (1997). Gas Purification, 5th edition. Houston, Texas: Gulf Publishing Company.

LINGO. (2013). Chicago, IL: LINDO System Inc.

Liu, P., Pistikopoulos, E. N., \& Li, Z. (2009). A mixed-integer optimization approach for polygeneration energy systems design. Computers \& Chemical Engineering, 33(3), 759768.

Luyben, W. L. (2014). Design and Control of the Dry Methane Reforming Process. Industrial and Engineering Chemistry Research, 53 (37), pp 14423-14439.

Martins, A. a., Mata, T. M., Costa, C. a V, \& Sikdar, S. K. (2007). Framework for sustainability metrics. Industrial and Engineering Chemistry Research, 46(10), 2962-2973.

Mokhatab, S. and, \& Economides, M. J. (2006). Onshore LNG Production Process Selection. Presented at SPE Annual Technical Conference and Exhibition, San Antonio, Texas 2427September 2006, 1, 1-11.

Mokhatab, S., \& Poe, W. A. (2012). Handbook of Natural Gas Transmission and Processing. Waltham, MA, USA: Gulf Professional Publishing.

Noureldin, M. M. B., Elbashir, N. O., \& El-Halwagi, M. M. (2014). Optimization and selection of reforming approaches for syngas generation from natural/shale gas. Industrial and Engineering Chemistry Research, 53(5), 1841-1855.

Olah, G. A., Goeppert, A., \& Prakash, G. K. S. (2006). Beyond Oil and Gas: The Methanol Economy. WILEY-VCH Verlag GmbH \& Co. KGaA, Weinheim.

ExxonMobil (2014). The Outlook for Energy: A View to 2040F.

Peters, Max, S., Timmerhaus, Klaus, D., \& West, Ronald, E. (2004). Plant Design and Economics for Chemical Engineers (5th ed.). McGraw-Hill Companies, Inc.

Quaglia, A., Sarup, B., Sin, G., \& Gani, R. (2012). Integrated business and engineering framework for synthesis and design of enterprise-wide processing networks. Computers \& Chemical Engineering, 38, 213-223.

Review, B. P. S., \& June, W. E. (2011). BP Statistical Review What's inside ?, (June).

Robert, M., \& John, M. (1998). Gas conditioning and processing, volume 4:Gas Treating and Liquid Sweeting. Campbell Petroleum Series, Norman, Oklahoma, USA.

Rostrup-Nielsen, J. R. (2000). New aspects of syngas production and use. Catalysis Today, 63(24), 159-164. 
Rostrup-Nielsen, J. R. (2002). Syngas in perspective. Catalysis Today, 71(3-4), 243-247.

Schulz, E. P., Diaz, M. S., \& Bandoni, J. a. (2005). Supply chain optimization of large-scale continuous processes. Computers and Chemical Engineering, 29(6), 1305-1316.

Schwarz, J., Beloff, B., \& Beaver, E. (2002). Use sustainability metrics to guide decisionmaking. Chemical Engineering Progress, 98(7), 58-63.

Seider, Warren, D., Seader, J, D., \& Lewin, Daniel, R. (2004). Product \& Process Design Principles Synthesis, Analysis, and Evaluation. John Wiley \& Sons, Inc.

Selot, A., Kuok, L., Robinson, M., Mason, Thomas, L., \& Barton, Paul, I. (2008). A Short-Term Operational Planning Model for Natural Gas Production Systems. AIChE, 54(2), 495-515.

Shah, N. (2005). Process industry supply chains: Advances and challenges. Computers and Chemical Engineering, 29(April), 1225-1235.

Sikdar, S. K. (2003). Sustainable Development and Sustainability Metrics. AIChE Journal, 49(8), 1928-1932.

Steynberg, a. P., Espinoza, R. L., Jager, B., \& Vosloo, a. C. (1999). High temperature FischerTropsch synthesis in commercial practice. Applied Catalysis A: General, 186(1-2), 41-54.

Steynberg, A., \& Dry, M. (2004). FISCHER-TROPSCH TECHNOLOGY. Elsevier B.V.

Sudiro, M., \& Bertucco, A. (2009). Production of synthetic gasoline and diesel fuel by alternative processes using natural gas and coal: Process simulation and optimization. Energy, 34(12), 2206-2214.

Thomas, S. (2003). Review of ways to transport natural gas energy from countries which do not need the gas for domestic use. Energy, 28(14), 1461-1477.

Tugnoli, a., Santarelli, F., \& Cozzani, V. (2008). An approach to quantitative sustainability assessment in the early stages of process design. Environmental Science \& Technology, $42(12), 4555-4562$.

Tugnoli, A., Santarelli, F., \& Cozzani, V. (2011). Implementation of Sustainability Drivers in the Design of Industrial Chemical Processes. AIChE, 57(11), 3063-3084.

Tusiani, M., \& Shearer, G. (2007). LNG, A nontechnical Guide. Tulsa, Oklahoma, USA: PennWell Corporation.

EIA. (1999). Natural Gas 1998 Issues and Trends, Office of oil and gas, U.S. Department of Energy, Washington, DC, USA. 
Wilhelm, D. J., Simbeck, D. R., Karp, a. D., \& Dickenson, R. L. (2001). Syngas production for gas-to-liquids applications: Technologies, issues and outlook. Fuel Processing Technology, 71(1-3), 139-148.

Wood, D. A., Nwaoha, C., \& Towler, B. F. (2012a). Gas-to-liquids (GTL): A review of an industry offering several routes for monetizing natural gas. Journal of Natural Gas Science and Engineering, 9, 196-208.

Wood, D. a., Nwaoha, C., \& Towler, B. F. (2012b). Gas-to-liquids (GTL): A review of an industry offering several routes for monetizing natural gas. Journal of Natural Gas Science and Engineering, 9, 196-208.

Zhang, N., \& Zhu, X. X. (2000). Computers \& Chemical Engineering A novel modelling and decomposition strategy for overall refinery optimisation. Chemical Engineering, 24, 15431548 .

Zheng, K., Lou, H. H., Gangadharan, P., \& Kanchi, K. (2012). Incorporating sustainability into the conceptual design of chemical process-reaction routes selection. Industrial and Engineering Chemistry Research, 51(27), 9300-9309.

Zheng, L., \& Furimsky, E. (2003). ASPEN simulation of cogeneration plants. Energy Conversion and Management, 44(11), 1845-1851. 